ANDREI ZNAMENSKY

\title{
HEURÍSTICAS PARA O PROBLEMA DE DISTRIBUIÇÃO COM ESTOQUES GERIDOS PELO FORNECEDOR
}

Tese apresentada à Escola Politécnica da Universidade de São Paulo para obtenção do título de Doutor em Engenharia.

São Paulo 


\section{HEURÍSTICAS PARA O PROBLEMA DE DISTRIBUIÇÃO COM ESTOQUES GERIDOS PELO FORNECEDOR}

Tese apresentada à Escola Politécnica da Universidade de São Paulo para obtenção do título de Doutor em Engenharia.

Área de Concentração:

Engenharia de Transportes

Orientador:

Professor Associado

Claudio Barbieri da Cunha

São Paulo 
Este exemplar foi revisado e alterado em relação à versão original, sob responsabilidade única do autor e com a anuência de seu orientador.

São Paulo, 03 de novembro de 2006.

Autor: Andrei Znamensky

Orientador: Prof. Dr. Claudio Barbieri da Cunha

FICHA CATALOGRÁFICA

Znamensky, Andrei

Heurísticas para o problema de distribuição com estoques geridos pelo fornecedor / A. Znamensky. -- São Paulo, 2006. $215 \mathrm{p}$.

Tese (Doutorado) - Escola Politécnica da Universidade de São Paulo. Departamento de Engenharia de Transportes.

1.Logística (Administração de materiais) 2.Cadeia de suprimento 3.Roteirização 4.Heurísticas I.Universidade de São Paulo. Escola Politécnica. Departamento de Engenharia de Transportes II.t. 
A Patrícia e Gabriela 


\section{AGRADECIMENTOS}

A minha esposa Patrícia e minha filha Gabriela, pela paciência, apoio e compreensão durante o desenvolvimento deste trabalho, que nos privou de preciosas horas de lazer e convivência familiar.

Aos meus pais, Dimitry e Venus, pelo exemplo de perseverança e constante apoio ao meu desenvolvimento educacional e profissional.

Ao Prof. Claudio Barbieri da Cunha, pela orientação e constante incentivo recebidos durante o desenvolvimento desta tese, e pelas valiosas sugestões e críticas, que muito auxiliaram a conclusão deste trabalho.

Ao Prof. Luca Bertazzi, pela gentileza em fornecer as versões preliminares de algumas de suas publicações, bem como pela boa vontade em esclarecer as dúvidas surgidas da leitura desses trabalhos.

Finalmente, minha gratidão a todos que, direta ou indiretamente, contribuíram para que este projeto se realizasse. 


\section{RESUMO}

O presente trabalho aborda o sistema logístico usualmente denominado "Vendor Managed Inventory" (VMI), no qual o fornecedor controla e coordena as decisões de reabastecimento, sendo responsável por manter os estoques de seus clientes dentro de limites fixados de antemão. $\mathrm{O}$ modelo proposto incorpora ainda as decisões relativas à produção e manutenção de estoque por parte do fornecedor, além da utilização de frota heterogênea na distribuição, e busca a minimização dos custos totais do sistema. Quatro heurísticas de duas etapas são propostas para a resolução do problema abordado. A primeira etapa, comum a todas as heurísticas, baseia-se em uma heurística recentemente publicada na literatura e fornece uma solução inicial viável, utilizada como ponto de partida para a etapa de melhoria subsequente, na qual é utilizada a metaheurística busca tabu ou busca em vizinhança variável. As heurísticas propostas foram avaliadas em um conjunto de teste, sendo obtidos resultados melhores que os reportados na literatura em todas as instâncias testadas. Dentre as estratégias de solução avaliadas, destaca-se a heurística baseada em busca tabu com diversificação, que demonstrou ser superior às demais heurísticas propostas. Os resultados obtidos indicam ainda que, no caso da frota disponível ser heterogênea, é vantajosa a utilização de uma adaptação do procedimento de obtenção da solução inicial, como forma de privilegiar a utilização de veículos de maior eficiência. 


\begin{abstract}
This thesis deals with the logistic system usually called Vendor Managed Inventory (VMI). In this system the supplier controls and coordinates the supply decisions and is responsible for keeping the inventory of each of his clients within predetermined minimum and maximum levels. Heterogeneous fleet and production/stocking decisions at the supplier are considered as well, and the proposed model seeks to minimize the total system cost. Four two-stage heuristics are proposed for this problem. The first stage consists in an adaptation of a heuristic found in the bibliography, which provides an initial viable solution that will be improved in the second stage by means of the metaheuristics tabu search or variable neighborhood search. The proposed heuristics were tested on a set of benchmark instances with improvements found on the best known results in all of the tested instances. The obtained results indicate that the tabu search based heuristic with diversification strategy is clearly superior to the other proposed heuristics and that a better fleet utilization can be obtained in the case of heterogeneous fleet by a simple improvement in the first stage, that favors the selection of more efficient vehicles.
\end{abstract}




\section{SUMÁRIO}

Lista de tabelas

Lista de quadros

Lista de figuras

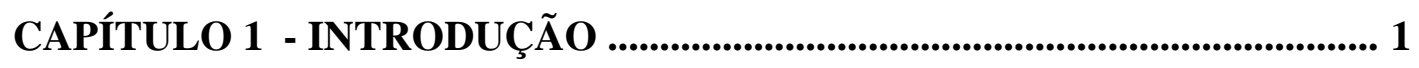

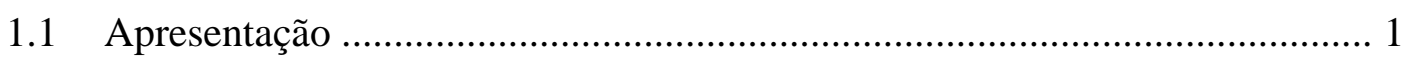

1.2 Caracterização do Problema ….................................................................... 1

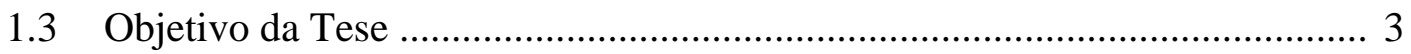

1.4 Delineamento do Trabalho ........................................................................ 3

CAPÍTULO 2 - REVISÃO BIBLIOGRÁFICA ................................................. 5

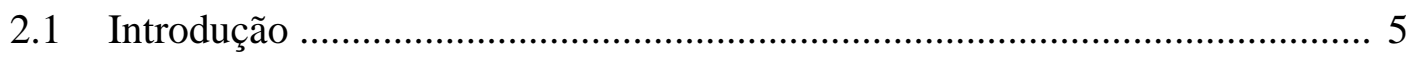

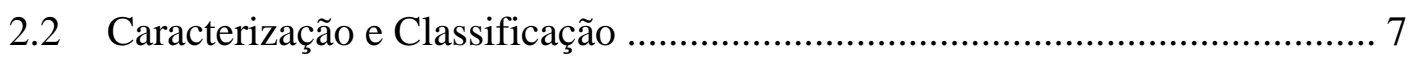

2.2.1 O Trabalho de BALL (1988) ............................................................... 7

2.2.2 O Trabalho de BAITA et al. (1998) ........................................................... 9

2.2.3 O Trabalho de SARMIENTO;NAGI (1999) ......................................... 14

2.2.4 O Trabalho de CHEN (2004) ............................................................... 18

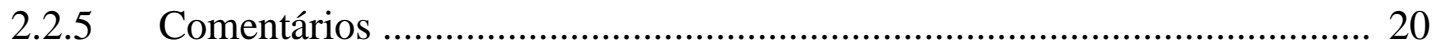

2.3 Modelos de Freqüência de Atendimento ..................................................... 24

2.3.1 Modelos Agregados .............................................................................. 24

2.3.2 Modelos de Política de Partição Fixa ......................................................... 26

2.3.2 Modelos de Freqüência Discreta de Atendimento .................................... 30

2.4 Modelos de Instante de Atendimento ......................................................... 33

2.4.1 Modelos de Fluxo Dinâmico com Demanda Desconhecida ..................... 34

2.4.2 Modelos com Demanda Conhecida ........................................................ 35

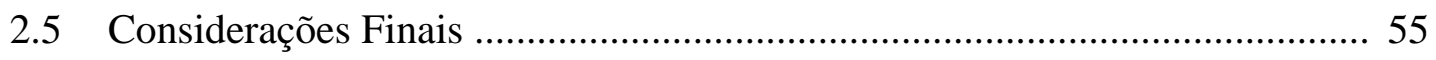

CAPÍTULO 3 - FORMULAÇÃO MATEMÁTICA .................................... 60

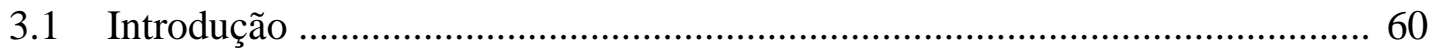




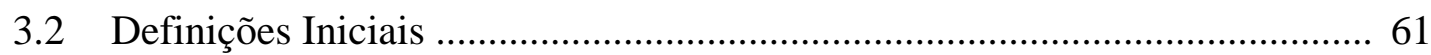

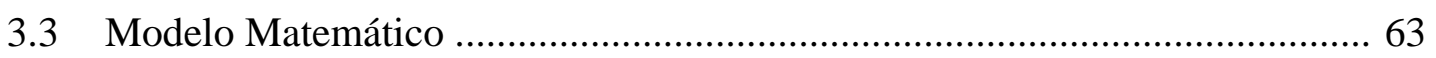

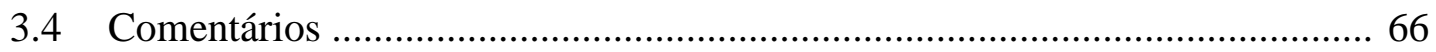

CAPÍTULO 4 - ESTRATÉGIAS DE SOLUÇÃO .................................................. 71

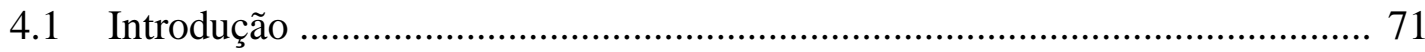

4.2 Esquema Geral das Heurísticas Propostas ....................................................... 71

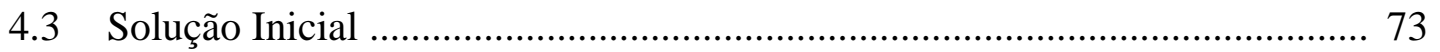

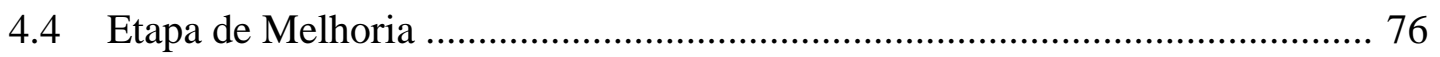

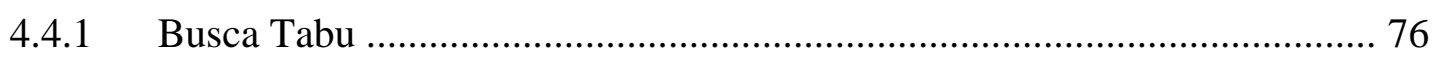

4.4.2 Busca em Vizinhança Variável ................................................................ 79

CAPÍTULO 5 - SOLUÇÃO INICIAL ……………………................................ 82

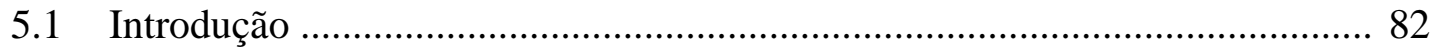

5.2 Decomposição do Problema Original ....................................................... 82

5.2.1 Subproblema de Planejamento da Distribuição ...................................... 83

5.2.2 Subproblema de Planejamento da Produção ............................................. 84

5.3 Resolução do Subproblema de Planejamento da Distribuição ....................... 86

5.4 Resolução do Subproblema de Planejamento da Produção ............................ 94

5.5 Seleção de Clientes para Programação ........................................................... 97

CAPÍTULO 6 - HEURÍSTICAS DE MELHORIA …............................................... 101

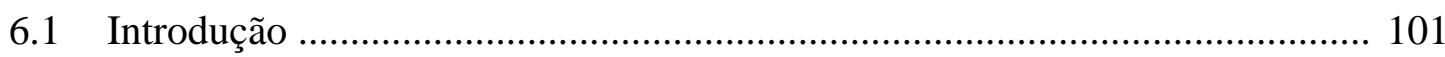

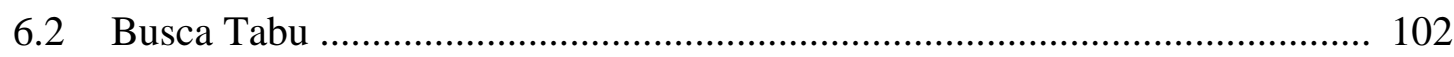

6.2.1 Movimentos e Vizinhança ................................................................... 103

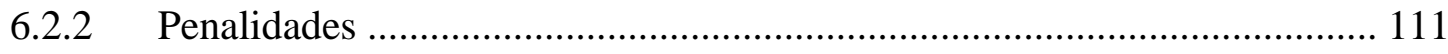

6.2.3 Memória de Curta Duração ........................................................................ 115

6.2.4 Estratégia de Diversificação e Intensificação .......................................... 119

6.2.5 Avaliação dos Movimentos Candidatos ................................................... 125

6.2.6 Gerenciamento da Lista de Movimentos Candidatos .............................. 127

6.2.7 Critério de Parada .................................................................................. 129

6.3 Busca em Vizinhança Variável .................................................................... 130

6.3.1 Movimentos e Estrutura de Vizinhança ................................................... 130 
6.3.2 Seleção e Avaliação dos Movimentos ................................................... 135

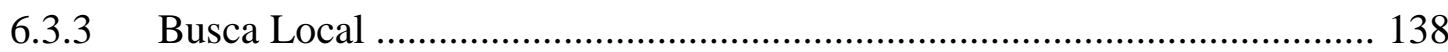

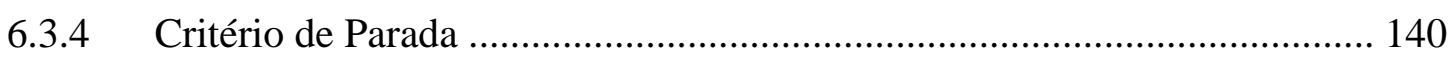

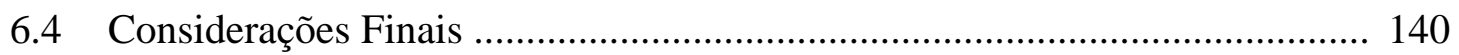

CAPÍTULO 7 - AVALIAÇÃO COMPUTACIONAL .......................................... 144

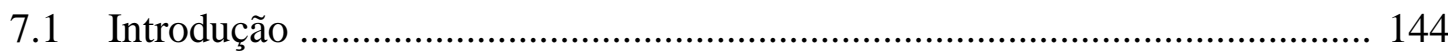

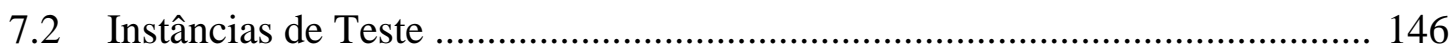

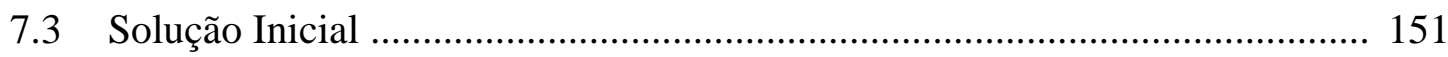

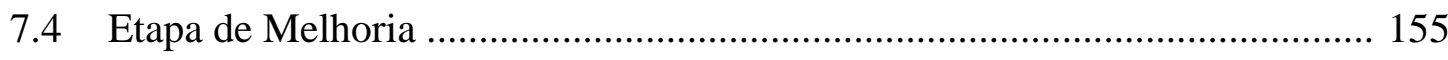

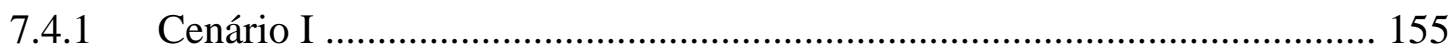

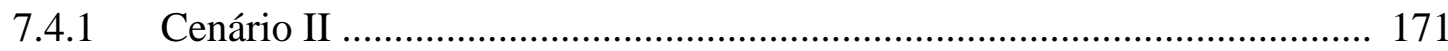

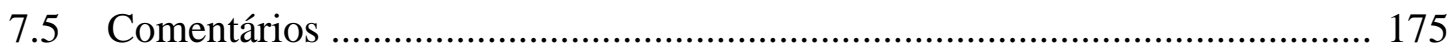

CAPÍTULO 8 - CONCLUSÕES E RECOMENDAÇÕES .................................. 177

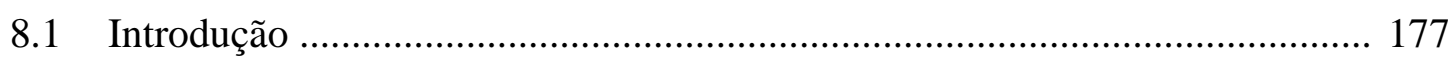

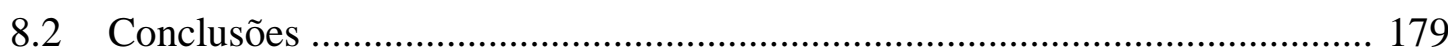

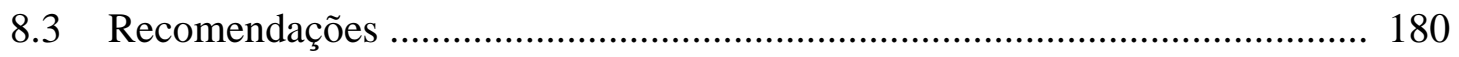

ANEXO A - PARÂMETROS UTILIZADOS NO CENÁRIO I .......................... 183

ANEXO B - CUSTO TOTAL MÉDIO POR INSTÂNCIA CENÁRIO I ......... 187

ANEXO C - PARÂMETROS UTILIZADOS NO CENÁRIO II ....................... 203

ANEXO D - CUSTO TOTAL MÉDIO POR INSTÂNCIA CENÁRIO II ....... 205

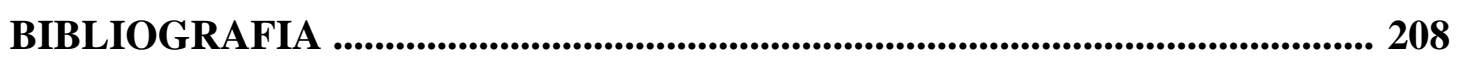

Apêndice 


\section{LISTA DE TABELAS}

TABELA 7.1 - Tempo médio de processamento da solução inicial 154

TABELA 7.2 - Custo médio por instância e variação percentual em relação à heurística DP

TABELA 7.3 - Erro médio percentual por grupo do conjunto de teste em relação aos melhores valores obtidos (cenário I)

TABELA 7.4 - Análise de variância aplicada aos resultados do cenário I 166

TABELA 7.5 - Variação percentual do custo médio por instância em relação às instâncias correspondentes (grupo 1) do cenário I 173

TABELA 7.6 - Número médio de veículos utilizados por instância 174

TABELA 7.7 - Custo médio por instância associado à frota utilizada 175 


\section{LISTA DE QUADROS}

QUADRO 2.1 - Elementos de classificação para problemas dinâmicos de roteirização e estoque

QUADRO 2.2 - Classificação dos modelos integrados de produção e distribuição

QUADRO 2.3 - Comparativo dos elementos de classificação utilizados por BAITA et al. (1998) e SARMIENTO; NAGI (1999)

QUADRO 2.4 - Resumo dos principais modelos de freqüência de atendimento ... 58

QUADRO 2.5 - Resumo dos principais modelos de instante de atendimento 59

QUADRO 6.1 - Estrutura de vizinhanças utilizada na BVV 134

QUADRO 7.1 - Parâmetros utilizados na geração das instâncias do conjunto base 148

QUADRO 7.2 - Características da frota utilizada no cenário II 150

QUADRO 7.3 - Resumo das características das instâncias de teste 150

QUADRO 7.4 - Tempo médio de processamento por instância reportado por BERTAZZI et al. (2005)

QUADRO 7.5 - Teste de Friedman 160

QUADRO 7.6 - Diferença absoluta entre as estatísticas de ordem $R_{i}$ e $R_{j}$ e sua comparação com valor crítico 160

QUADRO A.1 - Parâmetros utilizados na Heurística EGF-BT 183

QUADRO A.2 - Parâmetros utilizados na Heurística EGF-BT-D 184

QUADRO A.3 - Parâmetros utilizados na Heurística EGF-BT-DI 185 
QUADRO A.4 - Parâmetros utilizados na Heurística EGF-BVV

QUADRO B.1 - Custo total médio por instância para a Heurística EGF-BT 187

QUADRO B.2 - Custo total médio por instância para a Heurística EGF-BT-D .... 191

QUADRO B.3 - Custo total médio por instância para a Heurística EGF-BT-DI ... 195

QUADRO B.4 - Custo total médio por instância para a Heurística EGF-BVV ..... 199

QUADRO C.1 - Parâmetros utilizados na Heurística EGF-BT-D(t) 203

QUADRO C.2 - Parâmetros utilizados na Heurística EGF-BT-D(p) 204

QUADRO D.1 - Custo total médio por instância para as Heurísticas EGF-BT-D(t) e EGF-BT-D(p) 205 


\section{LISTA DE FIGURAS}

FIGURA 2.1 - Classificação utilizada por BAITA et al. (1998) para os modelos relativos a problemas dinâmicos de roteirização e estoque

FIGURA 2.2 - Classificação proposta por SARMIENTO; NAGI (1999) para os modelos de distribuição-estoque

FIGURA 2.3 - Classificação proposta por SARMIENTO; NAGI (1999) para os modelos de estoque-distribuição-estoque

FIGURA 2.4 - Classificação proposta por SARMIENTO; NAGI (1999) para os modelos de produção-estoque-distribuição-estoque

FIGURA 4.1 - Estruturação das heurísticas propostas

FIGURA 4.2 - Funcionamento do procedimento de obtenção da solução inicial

FIGURA 4.3 - Funcionamento da metaheurística BT

FIGURA 4.4 - Funcionamento da metaheurística BVV 80

FIGURA 5.1 - Exemplo de grafo G utilizado na resolução do SPD 87

FIGURA 5.2 - Procedimento de cálculo da parcela $\tilde{D}^{j}$ relativa ao custo de transporte

FIGURA 5.3 - Exemplo de decomposição do estoque de um cliente 91

FIGURA 5.4 - Exemplo de SPP representado como problema de caminho mínimo em grafo orientado. Fonte: EVANS (1985)

FIGURA 5.5 - Iteração do procedimento de obtenção da solução inicial com seleção aleatória de clientes em lista reduzida 
FIGURA 6.1 - Alteração da quantidade associada à entrega posterior em função da inserção ou remoção de um atendimento

FIGURA 6.2 - Exemplo de movimento do tipo I

FIGURA 6.3 - Exemplo de movimento do tipo R

FIGURA 6.4 - Exemplo de movimento do tipo A 108

FIGURA 6.5 - Exemplo de movimento do tipo P 108

FIGURA 6.6 - Exemplo de movimento do tipo TV1 109

FIGURA 6.7 - Exemplo de movimento do tipo TV2 110

FIGURA 6.8 - Exemplo da variação da penalidade por falta de estoque nos clientes ao longo da busca

FIGURA 6.9 - Comportamento de variação do custo da solução final em função da duração tabu

FIGURA 6.10 - Fragmento de pseudocódigo correspondente ao mecanismo de ativação da estratégia de diversificação inserido no cálculo da função de avaliação $F(s)$

FIGURA 6.11 - Exemplo do comportamento decorrente da ativação do mecanismo de diversificação

FIGURA 6.12 - Funcionamento da estratégia de intensificação baseada em reinício com soluções de elite

FIGURA 6.13 - Exemplo de movimento do tipo TC

FIGURA 6.14 - Exemplo de movimento do tipo RA

FIGURA 6.15 - Exemplo de movimento do tipo RP

FIGURA 6.16 - Funcionamento do processo de seleção de movimento da BVV 
FIGURA 6.17 - Heurística proposta por SILVER; MEAL (1973) apud

FIGURA 6.18 - Procedimento de busca local da BVV

FIGURA 7.1 - Variação do custo total médio da solução inicial em função do tamanho da lista reduzida

FIGURA 7.2 - Variação do custo total médio da solução inicial em função do número de iterações

FIGURA 7.3 - Erro médio percentual por instância em relação aos melhores valores obtidos.

FIGURA 7.4 - Redução média de custo em relação à solução inicial 163

FIGURA 7.5 - Erro médio por heurística em função da capacidade dos veículos

FIGURA 7.6 - Erro médio por heurística em função custo fixo dos veículos 169

FIGURA 7.7 - Erro médio por heurística em função do custo unitário diário de manutenção de estoque no depósito 169

FIGURA 7.8 - Erro médio por heurística em função do custo unitário diário de manutenção de estoque nos clientes 


\section{LISTA DE ABREVIATURAS E SIGLAS}

VMI

EGF

PDEGF

EDI

BT

BVV

GRASP

EGF-BT

EGF-BT-D

EGF-BT-DI

EGF-BVV

SPD

SPP

EGC

EGF-BT-D(t) Variação da Heurística EGF-BT-D em que o custo fixo dos veículos é considerado em sua totalidade na construção do grafo utilizado na etapa de obtenção da solução inicial

EGF-BT-D(p) Variação da Heurística EGF-BT-D em que o custo fixo dos veículos é considerado proporcional à utilização da capacidade dos veículos na construção do grafo utilizado na etapa de obtenção da solução inicial

ECR

Vendor Managed Inventory

Estoque Gerido pelo Fornecedor

Problema de Distribuição com Estoque Gerido pelo Fornecedor

Electronic Data Exchange

Busca Tabu

Busca em Vizinhança Variável

Greedy Randomized Adaptive Search Procedure

Heurística para o Problema de Distribuição com Estoques Geridos pelo Fornecedor baseada em Busca Tabu

Heurística para o Problema de Distribuição com Estoques Geridos pelo Fornecedor baseada em Busca Tabu com Diversificação

pelo Fornecedor baseada em Busca Tabu com Diversificação e Intensificação

Heurística para o Problema de Distribuição com Estoques Geridos pelo Fornecedor baseada em Busca em Vizinhança Variável

Subproblema de Planejamento da Distribuição

Subproblema de Planejamento da Produção

Estoque Gerido pelo Cliente

Efficient Consumer Response

Continuous Replenishment Program 
$\mathrm{CF}$

$\mathrm{CP}$

CPFR

VICS
Collaborative Forecasting

Collaborative Planning

Collaborative Planning, Forecasting and Replenishment

Voluntary Inter-industry Commerce Standards 


\section{INTRODUÇÃO}

\subsection{Apresentação}

O presente trabalho trata do planejamento da produção e distribuição de um produto a um conjunto de clientes dispersos geograficamente, sujeito a restrições operacionais diversas. A principal característica do problema abordado reside no fato de que o fornecedor é o responsável pela gestão dos estoques dos clientes, devendo ser respeitadas restrições de estoque mínimo e máximo dos mesmos. Esse tipo de sistema logístico é usualmente conhecido como "Vendor Managed Inventory" VMI, e por esse motivo, serão adotadas ao longo deste trabalho as denominações estoque gerido pelo fornecedor (EGF) e problema de distribuição com estoques geridos pelo fornecedor (PDEGF) para o tipo de sistema logístico e o problema em estudo, respectivamente.

\subsection{Caracterização do Problema}

Segundo CAMPBELL et al. (1998), a utilização de sistemas logísticos do tipo EGF é uma das recentes tendências da logística. Nesse sistema de gerenciamento, a gestão de estoques nos clientes ou pontos de consumo é de responsabilidade da indústria que abastece esses pontos. Em outras palavras, ao invés de os clientes encaminharem seus pedidos de reabastecimento, o fornecedor é quem define as datas de entrega e as respectivas quantidades a ser entregues. Dessa forma, o fornecedor pode auferir vantagens, na medida em que o controle dos processos de produção e de distribuição permite a coordenação das entregas e um melhor planejamento da produção, reduzindo os custos de produção e distribuição, bem como evitando o ônus do desabastecimento ou de vendas perdidas pela não disponibilidade do produto. Ganha também o cliente, que não necessita despender recursos para a administração de estoques nem corre risco do custo de falta do produto. Busca-se assegurar, dessa 
forma, a minimização do custo total do sistema, dado pela soma dos custos incorridos pelo fornecedor e pelos clientes.

Esse sistema de gerenciamento de estoques e entregas pelo fornecedor é uma consequiência natural quando os pontos de demanda pertencem à mesma empresa ou grupo que produz os produtos. Em outros casos, é fruto de negociação entre produtores e consumidores, como forma a responder de forma mais eficiente às variações de demanda e diminuir o risco de falta do produto e de outras flutuações indesejáveis ao longo da cadeia de suprimentos. BRAMEL; SIMCHI-LEVI (1997) apontam que, no caso de demanda estocástica, o gerenciamento de estoques pelo fornecedor pode trazer benefícios adicionais, devido ao compartilhamento de um estoque de segurança agregado, o qual é menor que a soma dos estoques de segurança requeridos por cada consumidor, fenômeno esse conhecido como "risk pooling". Em particular, o EGF elimina uma das causas do "efeito chicote" (“bullwhip effect”) identificadas por LEE et al. (1997), que consiste em variações ou flutuações cada vez maiores quanto mais a montante da cadeia de suprimentos, em resposta a pequenas variações na ponta de consumo, ocasionadas por incertezas e "lead times" elevados, entre outros fatores. Ao possuir a liberdade e a responsabilidade de decidir quando repor os estoques, o fornecedor é também levado a acompanhar de maneira próxima a situação dos estoques de seus clientes, reduzindo assim a distorção de informações na cadeia de suprimentos e, por conseqüência, o efeito chicote.

Segundo BALLOU (1998), a utilização de sistemas de distribuição do tipo EGF ganhou impulso com a disseminação da tecnologia de troca de dados por via eletrônica ("Electronic Data Interchange" - EDI), que facilita ao fornecedor manter-se informado dos níveis de estoques nos clientes pelos quais é responsável. CAMPBELL et al. (1998) afirmam ainda que, embora atualmente a tecnologia necessária para a implantação do controle de estoques pelo fornecedor seja relativamente barata, uma das razões que impede a sua utilização em larga escala é a dificuldade de se determinar uma estratégia de distribuição que otimize os custos e reduza as ocorrências de falta de estoque nos clientes, o que vem a ser, efetivamente, a questão central do PDEGF. 
A aplicação prática de modelos do tipo EGF tem sido observada desde a distribuição de gases industriais e derivados de petróleo até o abastecimento de lojas de departamentos e distribuição de refrigerantes. STALK et al. (1992) consideram que um eficiente planejamento integrado de reposição de estoques foi a peça central da estratégia competitiva adotada com sucesso pelo Wal-Mart, e principal responsável pelo seu notável crescimento no final dos anos 80. Observa-se ainda que redes de supermercados vêm sistematicamente transferindo a responsabilidade de reposição de determinados produtos a seus fornecedores, o que amplia o leque de situações em que a aplicação de modelos do tipo EGF pode ser essencial para a maior eficiência da cadeia de suprimentos.

\subsection{Objetivo da Tese}

A resolução do PDEGF consiste em determinar a programação da produção, dos atendimentos e os roteiros de entrega para cada dia do período de planejamento, minimizando o custo total da distribuição e respeitando as restrições operacionais existentes.

O objetivo da presente tese é desenvolver um modelo flexível, que permita representar distintas configurações de custo, e heurísticas capazes gerar, de forma automatizada, soluções econômicas para o PDEGF.

\subsection{Delineamento do Trabalho}

Este item tem por objetivo fornecer uma descrição da organização e estrutura do presente trabalho.

No Capítulo 2 é apresentada a revisão bibliográfica da literatura que aborda problemas decorrentes da integração de decisões de transporte, estocagem, e eventualmente planejamento da produção, no contexto da distribuição física de produtos, assim como trabalhos que tratam de problemas similares, cuja estratégia de solução seja de interesse para a abordagem estudada no presente trabalho. 
O Capítulo 3 apresenta a formulação matemática para o PDEGF com frota heterogênea e sujeito a restrições operacionais. O Capítulo 4 apresenta uma descrição geral do funcionamento das heurísticas propostas, que serão detalhadas nos Capítulos 5 e 6. O Capítulo 5 trata da primeira etapa das heurísticas propostas, que consiste na obtenção de uma solução inicial viável para o PDEGF. A segunda etapa das heurísticas é apresentada no Capítulo 6, e consiste em utilizar a solução obtida na etapa anterior como ponto de partida para um processo de melhoria, baseado na metaheurística busca tabu (BT) ou busca em vizinhança variável (BVV).

Uma avaliação computacional das estratégias de solução propostas é apresentada no Capítulo 7, com base em um conjunto de instâncias de teste encontradas na literatura. As conclusões e recomendações do presente trabalho são apresentadas no Capítulo 8.

O Anexo A contém os parâmetros utilizados para o processamento das instâncias do primeiro cenário de teste, sendo os resultados obtidos apresentados de forma detalhada no Anexo B. De forma análoga, o Anexo C apresenta os parâmetros utilizados no processamento do segundo cenário de teste, e o Anexo D apresenta de forma detalhada os resultados obtidos nesse cenário. 


\section{REVISÃO BIBLIOGRÁFICA}

\subsection{Introdução}

Neste capítulo será examinada a literatura que aborda, no contexto da distribuição física de produtos, problemas decorrentes da integração de decisões de transporte, estocagem e, eventualmente, planejamento da produção. Em particular, serão analisados trabalhos que tratam de sistemas de distribuição usualmente conhecidos pela denominação "Vendor Managed Inventory" - VMI, e da classe de problemas associados a esse tipo de sistema de logístico, denominada problema de distribuição com estoques geridos pelo fornecedor, ou simplesmente PDEGF.

Em sua forma mais geral, esse tipo de problema trata da distribuição repetida de um ou mais produtos, a partir de um ou mais depósitos, para um conjunto de clientes geograficamente dispersos, sujeitos a restrições de estoque, dentro de um horizonte de planejamento, finito ou não. A característica principal do PDEGF é a integração das decisões de transporte e estocagem em um único tomador de decisões, responsável pela gestão do sistema, e que busca a otimização do sistema de distribuição como um todo. Pode-se dizer que a resolução do problema envolve três decisões simultâneas e inter-relacionadas:

- quando atender cada cliente;

- quanto fornecer do(s) produto(s) quando o cliente é atendido;

- que rotas utilizar no atendimento.

As duas primeiras decisões envolvem a gestão dos estoques nos clientes, devendo ser respeitadas as restrições de capacidade de armazenagem e não ocorrência de falta de estoque nos clientes. Definidos os dias de atendimento e as quantidades a ser entregues, a definição das rotas de entrega corresponde à resolução de um problema de roteirização de veículos para cada dia do período de planejamento. Entretanto, 
esses subproblemas não podem ser resolvidos de forma independente e seqüe ncial, como poderia parecer à primeira vista. A definição dos dias dos atendimentos depende dos custos de distribuição, os quais, por sua vez, dependem da programação dos reabastecimentos, ficando patente a necessidade da definição conjunta dos atendimentos e da roteirização.

É interessante notar aqui as diferenças entre o PDEGF e o problema clássico de roteirização de veículos. Nesse último, as demandas são conhecidas e a roteirização corresponde a um único período, compatível com a jornada de trabalho dos veículos, não fazendo sentido se falar em horizonte de planejamento. Em outras palavras, o problema de roteirização de veículos não considera as questões de quando atender os clientes, nem quanto fornecer ao cliente quando esse é atendido, concentrando-se apenas nas rotas de atendimento.

Por sua vez, os modelos de estoque que tratam do problema de reabastecimento conjunto de clientes ("joint replenishment problem") consideram estruturas de custo de distribuição simplificadas, em que se supõe a separabilidade ou independência de custos em relação a pontos de entregua distintos, como se fosse feita uma viagem redonda, de ida e volta, para cada ponto atendido. ANILY; FEDERGRUEN (1990) apontam ainda que esses custos são tratados em geral como a soma de um termo fixo e um termo proporcional à quantidade entregue, e que, embora estruturas de custo mais sofisticadas tenham sido encontradas na literatura, as hipóteses adotadas não condizem com o contexto de distribuição com roteirização de veículos, em que ocorre o fracionamento da capacidade de cada veículo, e conseqüentemente dos custos, entre os diferentes clientes que compõem uma rota.

Usualmente a função objetivo utilizada no PDEGF busca a minimização do custo variável de distribuição, associado à distância total percorrida pela frota disponível. Entretanto, como será visto em detalhe mais adiante, há variações que incluem outras parcelas de custo, em especial os custos referentes à manutenção de estoques, seja nos clientes, seja nos depósitos, e em alguns casos o custo de produção dos itens distribuídos. 


\subsection{Caracterização e Classificação}

Nesta seção serão apresentados alguns trabalhos que tratam da caracterização de problemas que envolvem simultaneamente decisões de estoque, distribuição e, eventualmente, planejamento da produção, assim como da classificação dos modelos adotados para sua resolução. Pretende-se relacionar, de forma sucinta, as principais contribuições desses trabalhos, quer fornecendo elementos para a estruturação da revisão bibliográfica, quer analisando a inserção desse tipo de problema em um contexto logístico mais amplo.

\subsubsection{O Trabalho de BALL (1988)}

BALL (1988) apresenta uma análise dos principais modelos e estratégias de resolução de problemas que envolvem simultaneamente decisões de alocação e roteirização. Segundo o autor, essa categoria trata de problemas de roteirização de veículos ao longo de um horizonte de planejamento de vários dias, juntamente com a determinação do(s) dia(s) de atendimento a cada cliente, o que vem a ser justamente o componente de alocação desse tipo de problema.

Inicialmente, são identificadas as principais situações reais em que essa categoria de problema se apresenta:

- coleta de lixo;

- distribuição de combustíveis e gases industriais;

- venda/distribuição do tipo "driver sell".

O caso de coleta de lixo é sem dúvida o mais comum, tratando da coleta de resíduos domésticos e/ou industriais de clientes dispersos geograficamente e seu transporte a instalações de processamento ou aterros sanitários. Esse caso é usualmente tratado como um problema de roteirização periódica, mas, mesmo sob esse enfoque, observa-se que as restrições de freqüência de atendimento são decorrentes de restrições de gestão de estoque, que nesse caso corresponde à quantidade de lixo que os clientes podem armazenar entre atendimentos sucessivos. 
O caso da distribuição de combustíveis e gases industriais trata tipicamente do reabastecimento repetido de um produto a clientes dispersos geograficamente, de forma a evitar ou minimizar a ocorrência de falta de estoque. Segundo o autor, esse é um exemplo de um sistema de gestão de estoques do tipo "push", em que o distribuidor reabastece seus clientes sem que estes tenham que fazer pedidos, como ocorre no caso de sistemas de estoque do tipo "pull".

A venda/distribuição do tipo "driver sell" ocorre tipicamente na distribuição de bebidas e consiste em um ou mais motoristas que visitam clientes dispersos geograficamente, procurando realizar o maior número de vendas possível. Observa-se que, nesse caso, o motorista faz simultaneamente o papel de vendedor e distribuidor, e não sabe a priori a quantidade que cada cliente irá comprar. Usualmente há restrições de natureza espacial, na forma de regiões de atendimento, e a roteirização é feita de forma periódica, similar ao caso da coleta de lixo.

São identificados três tipos de formulação para os problemas de alocação e roteirização:

- modelos dinâmicos com tamanho de entrega fixa;

- modelos dinâmicos com tamanho de entrega variável;

- modelos periódicos.

Os modelos dinâmicos com tamanho de entrega fixa tratam do caso em que as entregas a um determinado cliente não obedecem a uma periodicidade e, uma vez determinados os dias de atendimento, a quantidade entregue é fixa e calculada em função do cliente e do dia de atendimento. Já nos modelos dinâmicos com tamanho de entrega variável, a quantidade entregue é uma variável de decisão que deve ser definida juntamente com o dia de atendimento. Por sua vez, os modelos periódicos tratam do caso em que as entregas são realizadas obedecendo-se uma periodicidade fixa.

Segundo o autor, as três formulações possuem um componente comum, relativo à roteirização dos veículos, e que envolve a resolução de um problema de roteirização 
e programação de veículos para cada dia do horizonte de planejamento. A diferença entre as formulações residiria na forma em que são determinadas as quantidades e os dias de atendimento, ou seja, no componente de alocação do problema. Observa-se que, embora não enfatizado pelo autor, as restrições quanto aos dias de entrega ou frequiências de atendimento são quase sempre decorrentes de restrições relativas à gestão de estoques.

A presença de variáveis de alocação de clientes/demanda a veículos, dias ou freqüências de atendimento acaba por sugerir heurísticas de duas etapas, do tipo agregação-roteirização (“cluster first, route second”). Essa estratégia de solução é usualmente encontrada em modelos periódicos e de tamanho de entrega fixo, e muitas vezes seguida de uma etapa de melhorias baseada em busca local. O autor aponta ainda como significativas duas estratégias de solução, baseadas na resolução de um problema modificado de caixeiro viajante coletor de prêmios ("prize collecting traveling salesman problem") para a determinação dos dias de atendimento e no método da Relaxação Lagrangiana para o caso de modelos dinâmicos com tamanho de entrega variável.

\subsubsection{O Trabalho de BAITA et al. (1998)}

BAITA et al. (1998) publicaram um levantamento da bibliografia referente a problemas que se caracterizam pela presença de três aspectos: roteirização, estoque e comportamento dinâmico. O primeiro aspecto decorre da dispersão geográfica dos clientes e depósitos, e envolve a movimentação física dos bens distribuídos. O segundo decorre da necessidade de armazenagem desses bens em diferentes pontos do sistema e por diferentes períodos. E finalmente, o terceiro aspecto dá-se pela estrutura dinâmica em que as decisões envolvidas são tomadas. Isto é, tais decisões devem ser tomadas repetidas vezes dentro de um determinado horizonte de planejamento, sendo que decisões anteriores influenciam decisões posteriores. Os autores denominam essa categoria problemas dinâmicos de roteirização e estoque (“dynamic routing-and-inventory problems"). Cerca de 40 modelos são comentados e classificados segundo sete dimensões do problema, identificadas pelos autores. Esta classificação é reproduzida no Quadro 2.1, apresentado a seguir. 


\section{QUADRO 2.1 - Elementos de classificação para problemas dinâmicos de} roteirização e estoque

\begin{tabular}{|c|c|c|c|c|}
\hline Elemento & Atributo & \multicolumn{3}{|c|}{ Alternativas } \\
\hline $\begin{array}{l}\text { Topologia da rede } \\
\text { de atendimento }\end{array}$ & $\begin{array}{c}\text { Pontos de } \\
\text { abastecimento } \\
\text { ou distribuição }\end{array}$ & Um-para-u m & Um-para-muitos & $\begin{array}{l}\text { Muitos-para- } \\
\text { muitos }\end{array}$ \\
\hline Itens a ser entregues & Número & $\mathrm{Um}$ & Muitos & \\
\hline \multirow{3}{*}{ Demanda } & Tipo & Conhecida & Desconhecida & \\
\hline & Comportamento & Constante & Variável & \\
\hline & $\begin{array}{l}\text { Distribuição } \\
\text { entre clientes }\end{array}$ & Uniforme & Não uniforme & \\
\hline Decisões & Domínio & $\begin{array}{l}\text { Freqüência de } \\
\text { atendimento }\end{array}$ & $\begin{array}{l}\text { Instante de } \\
\text { atendimento }\end{array}$ & \\
\hline \multirow{4}{*}{ Restrições } & $\begin{array}{c}\text { Capacidade dos } \\
\text { veículos }\end{array}$ & Igual & Diferente & \\
\hline & $\begin{array}{l}\text { Capacidade de } \\
\text { estocagem }\end{array}$ & & & \\
\hline & $\begin{array}{l}\text { Capacidade de } \\
\text { abastecimento }\end{array}$ & & & \\
\hline & $\begin{array}{l}\text { Número de } \\
\text { veículos }\end{array}$ & Fornecido & $\begin{array}{l}\text { Variável de } \\
\text { decisão }\end{array}$ & Não restritivo \\
\hline \multirow{2}{*}{ Custos } & Estoque & Manutenção & Falta & Pedido \\
\hline & Distribuição & Fixo & $\begin{array}{l}\text { Proporcional à } \\
\text { distância }\end{array}$ & $\begin{array}{l}\text { Proporcional ao } \\
\text { número de clientes }\end{array}$ \\
\hline \multirow{4}{*}{$\begin{array}{l}\text { Estratégia de } \\
\text { solução }\end{array}$} & Decomposição & Tempo & Agrupa-Roteiriza & \\
\hline & Agregação & Tempo & Frequência & Distância \\
\hline & Algoritmo & Exato & Aproximado & \\
\hline & $\begin{array}{l}\text { Programação } \\
\text { matemática }\end{array}$ & Linear & Inteira & Não-linear \\
\hline
\end{tabular}

Fonte: BAITA et al. (1998)

Observa-se que, embora detalhada, essa classificação não abrange alguns aspectos comuns em modelos de roteirização e que podem efetivamente ocorrer na categoria de problemas de roteirização e estoque. Como exemplo, pode-se citar o caso de 
janelas de atendimento, restrições de precedência ou restrições de alocação de cliente a veículo, no caso de frota heterogênea.

É fácil constatar que o elevado número de combinações dos diversos elementos de classificação torna a enumeração das diversas variantes do problema virtualmente impossível. Entretanto, alguns elementos se destacam dentre a classificação proposta, em função da importância e influência de suas características. É o caso da categoria relativa à forma em que as decisões são modeladas, a qual, segundo os autores, identifica as duas principais abordagens do problema:

- modelos de frequiência de atendimento;

- modelos de instante de atendimento.

Os modelos classificados como modelos de freqüência de atendimento são aqueles em que, como o próprio nome indica, as variáveis de decisão são as freqüências com que os clientes devem ser atendidos, ou, expresso de outra forma, os intervalos entre entregas sucessivas para esses mesmos clientes. Esses modelos, por sua própria natureza periódica, são aplicáveis apenas a situações estáveis de distribuição, em que tanto a demanda como a oferta não são afetadas por sazonalidades ou outros efeitos aleatórios. Assim sendo, a maioria dos modelos dessa categoria assume demandas constantes, embora não necessariamente iguais, por parte dos clientes atendidos.

Os modelos classificados como modelos de instante de atendimento são aqueles que tratam os instantes de entrega como variáveis de decisão. Se nos modelos de freqüência de atendimento procura-se minimizar os custos de distribuição periódica em um horizonte infinito de planejamento, nestes o horizonte de planejamento é necessariamente finito e as entregas podem ser realizadas sem obedecer a uma periodicidade fixa. Apesar da maior flexibilidade, essa abordagem implica a introdução de um novo problema: a conciliação da minimização de custos em um modelo de curto prazo (horizonte finito) com a minimização de custos de longo prazo (horizonte infinito).

Segundo os autores, uma recente linha de pesquisa dentre os modelos de instante de atendimento vem a ser os modelos de fluxo dinâmico com demanda desconhecida, 
em que o problema é tratado como um sistema dinâmico, sujeito a perturbações que, embora desconhecidas, respeitam limites conhecidos a priori. Nessa abordagem, o problema passa a ser determinar uma estratégia de controle com realimentação que mantenha, ao longo do horizonte de planejamento, o estado do sistema dentro de certos limites preestabelecidos.

Dentre os modelos de freqüiência de atendimento, é proposta ainda uma subdivisão em três subcategorias:

- modelos agregados;

- modelos de política de partição fixa;

- modelos de freqüência discreta de atendimento.

Os modelos agregados de freqüência de atendimento são modelos analíticos baseados em premissas simplificadoras relativamente agregadas. São modelos de grande apelo intuitivo, que representam os custos de forma detalhada, mas que muitas vezes chegam a resultados mais qualitativos que quantitativos. Um resultado típico desse tipo de modelo é a análise de conflitos ("trade-offs") entre os custos envolvidos em função das diferentes decisões logísticas possíveis.

Os modelos de freqüência de atendimento com política de partição fixa são aqueles que adotam uma política de partição dos clientes, ou seja, definem a priori conjuntos fixos de clientes que serão tratados como regiões de atendimento. Embora a determinação de uma política ótima de partição que minimize os custos de estoque e transporte seja computacionalmente difícil ("NP-hard"), uma vez definidas tais regiões, a determinação da freqüência de atendimento de cada região e dos custos associados é simples e se assemelha à conhecida fórmula de lote ótimo de pedido, usualmente permitindo a dedução de limites inferiores e superiores para os custos dessa classe de política de abastecimento.

Essa simplicidade na determinação das freqüências de atendimento, tem entretanto sua contrapartida. Via de regra, os resultados assim obtidos são fracionários, o que torna sua aplicação prática questionável. HALL (1985) reconhece esse resultado 
como inviável, e sugere o arredondamento para o valor inteiro mais próximo. Esse procedimento, conquanto aparentemente natural, pode elevar desnecessariamente os custos da distribuição, o que fomentou o desenvolvimento dos modelos de freqüência discreta de atendimento. Nesses modelos, como o próprio nome indica, apenas um conjunto discreto de freqüências de atendimento são possíveis, evitando-se assim os inconvenientes apontados anteriormente.

Um resumo da classificação utilizada pelos autores para a descrição dos modelos analisados é apresentada na Figura 2.1.

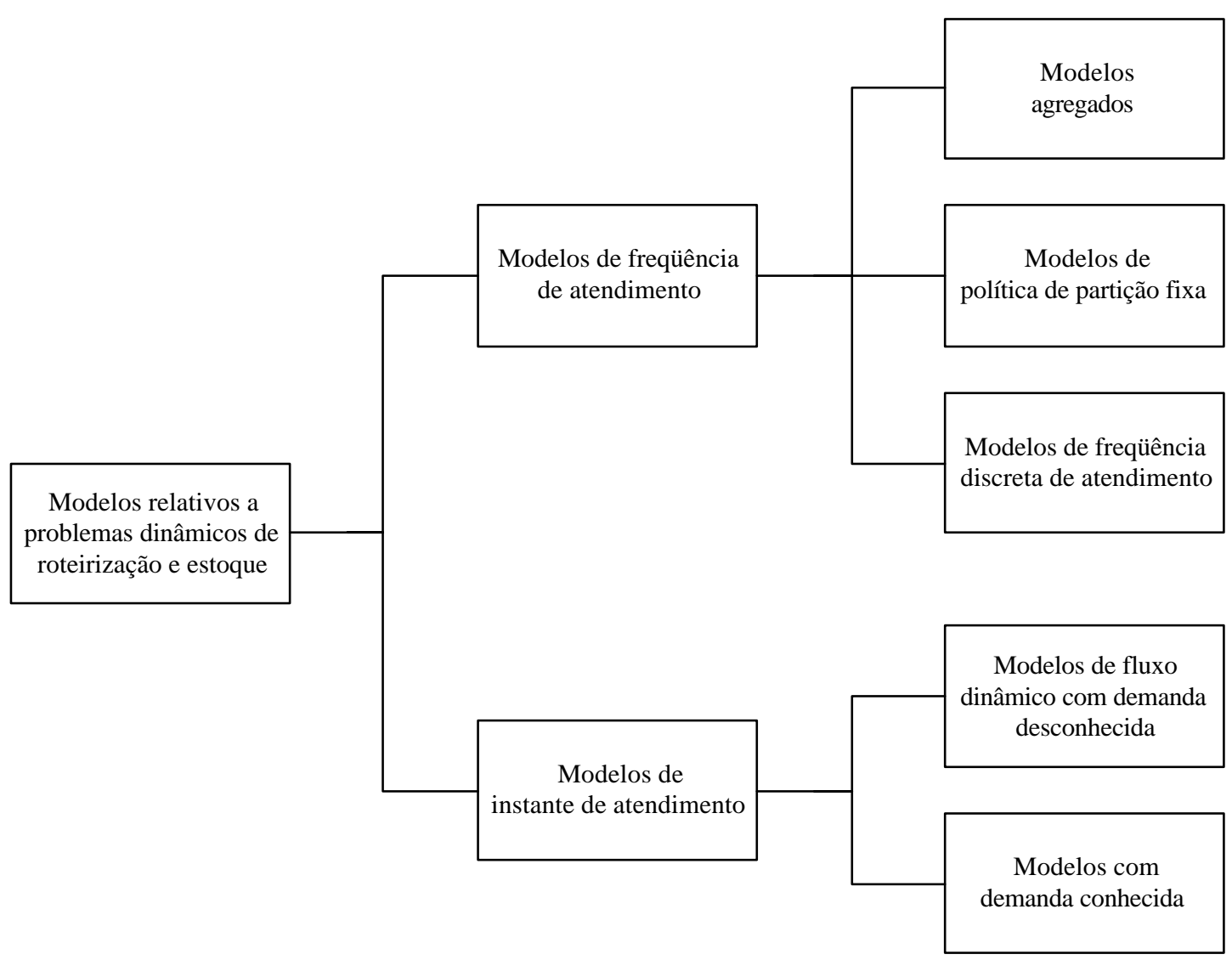

Figura 2.1 - Classificação utilizada por BAITA et al. (1998) para os modelos relativos a problemas dinâmicos de roteirização e estoque. 


\subsubsection{O Trabalho de SARMIENTO; NAGI (1999)}

SARMIENTO; NAGI (1999) publicaram uma revisão da bibliografia referente à análise e planejamento integrados de sistemas de produção e distribuição. Inicialmente, são diferenciadas duas formas de integração encontradas nas empresas: integração de uma mesma função entre diversos níveis gerenciais, e integração de funções distintas dentro da empresa. Essa última categoria vem a ser o foco do trabalho dos autores, que abordam especificamente a integração das funções de produção e distribuição.

Em seguida, é proposta uma classificação baseada nas funções envolvidas na tomada de decisão e na topologia ou configuração do problema. Essa classificação faz uma clara distinção entre modelos que integram funções tradicionalmente consideradas de forma isolada e seqüencial, e aqueles que, mesmo considerando restrições relativas a outras funções, não incorporam o custo correspondente a essas funções na função objetivo considerada.

É citado como exemplo o caso do problema de estoque-roteirização, que não corresponderia a um modelo integrado, pois busca a otimização apenas da operação do depósito a partir do qual se realiza a distribuição, sem levar em conta o custo incorrido pelos clientes atendidos. Por sua vez, os modelos integrados buscariam a coordenação e otimização simultânea de decisões tomadas tradicionalmente de maneira independente por diversos participantes da cadeia de distribuição. Em outras palavras, o que diferencia um caso do outro são os limites e a função de desempenho do sistema representado no modelo. Se o problema modelado se restringir à operação do depósito e buscar minimizar apenas os custos associados, é denominado pelos autores problema de estoque-roteirização, já no caso de abranger os custos dos clientes e/ou da produção, passa a ser um modelo integrado.

A classificação proposta para os modelos integrados de produção, distribuição e estoque é então subdividida em:

- modelos de distribuição-estoque; 
- modelos de estoque-distribuição-estoque;

- modelos de produção-estoque-distribuição-estoque.

Fica evidente a preocupação dos autores com a definição dos limites dos sistemas representados nos modelos e a inclusão ou não das funções envolvidas na tomada de decisão, como o próprio nome das categorias indica. Os modelos de distribuiçãoestoque envolvem a otimização simultânea da distribuição a partir de um depósito e da gestão dos estoques dos clientes. Por sua vez, os modelos de estoque-distribuiçãoestoque incorporam à categoria anterior decisões de gestão do estoque no depósito, e por fim, os modelos de produção-estoque-distribuição-estoque agregam as decisões de planejamento da produção aos modelos de estoque-distribuição-estoque.

Posteriormente, essas categorias são subdivididas segundo a topologia do sistema de distribuição (um-para-um, um-para-muitos ou muitos-para-muitos), a existência ou não de entregas emergenciais para clientes com falta de estoque, a utilização ou não de roteirização na distribuição, e o comportamento da demanda (estocástico ou determinístico).

Vale ressaltar que não é proposta uma classificação nos moldes acima para o caso do problema de estoque-roteirização, o qual representa uma categoria de problema distinta das anteriores, segundo os critérios adotados. As Figuras 2.2, 2.3 e 2.4 reproduzem a classificação proposta pelos autores. 


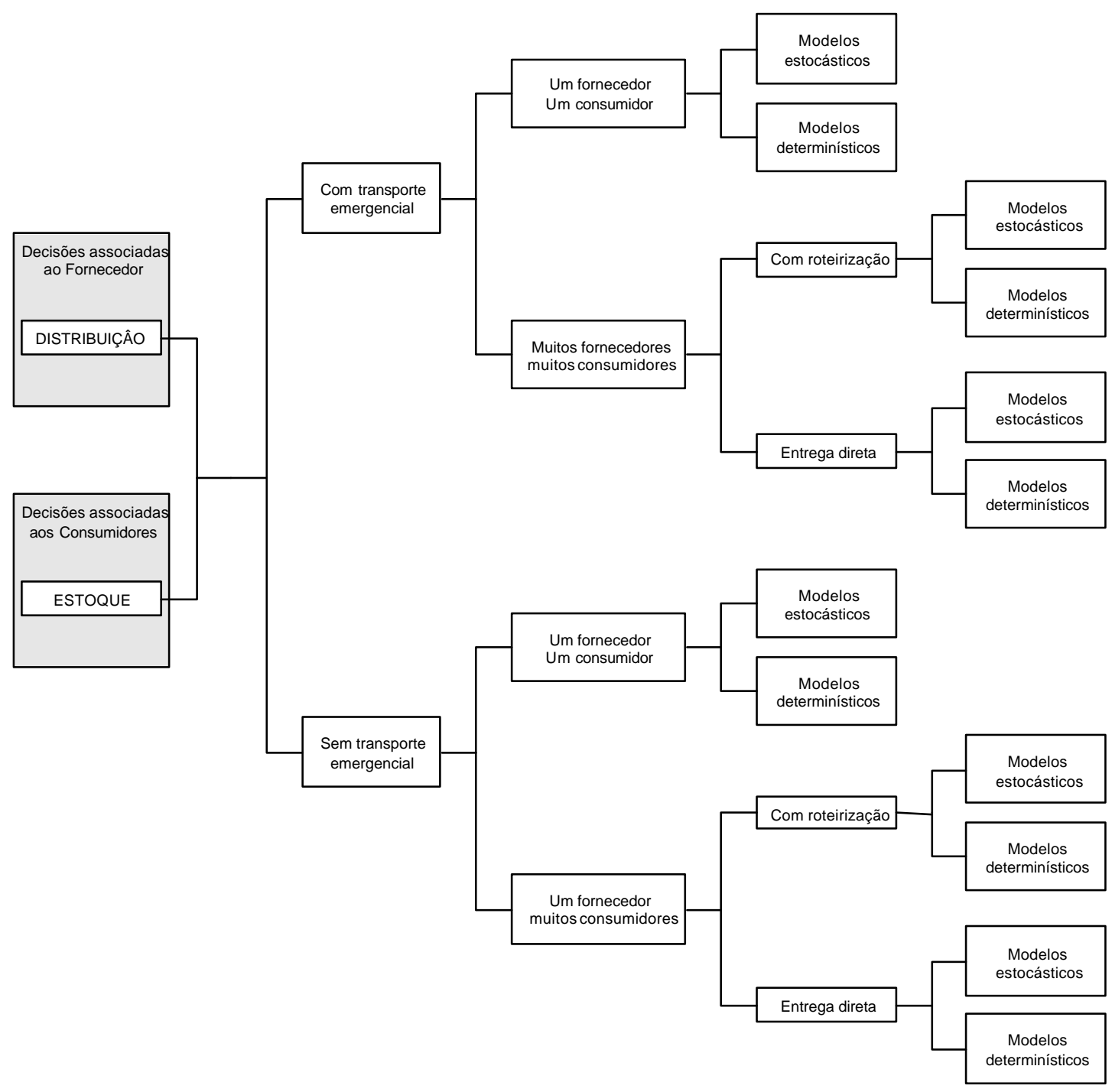

Figura 2.2 - Classificação proposta por SARMIENTO; NAGI (1999) para os modelos de distribuição-estoque. 


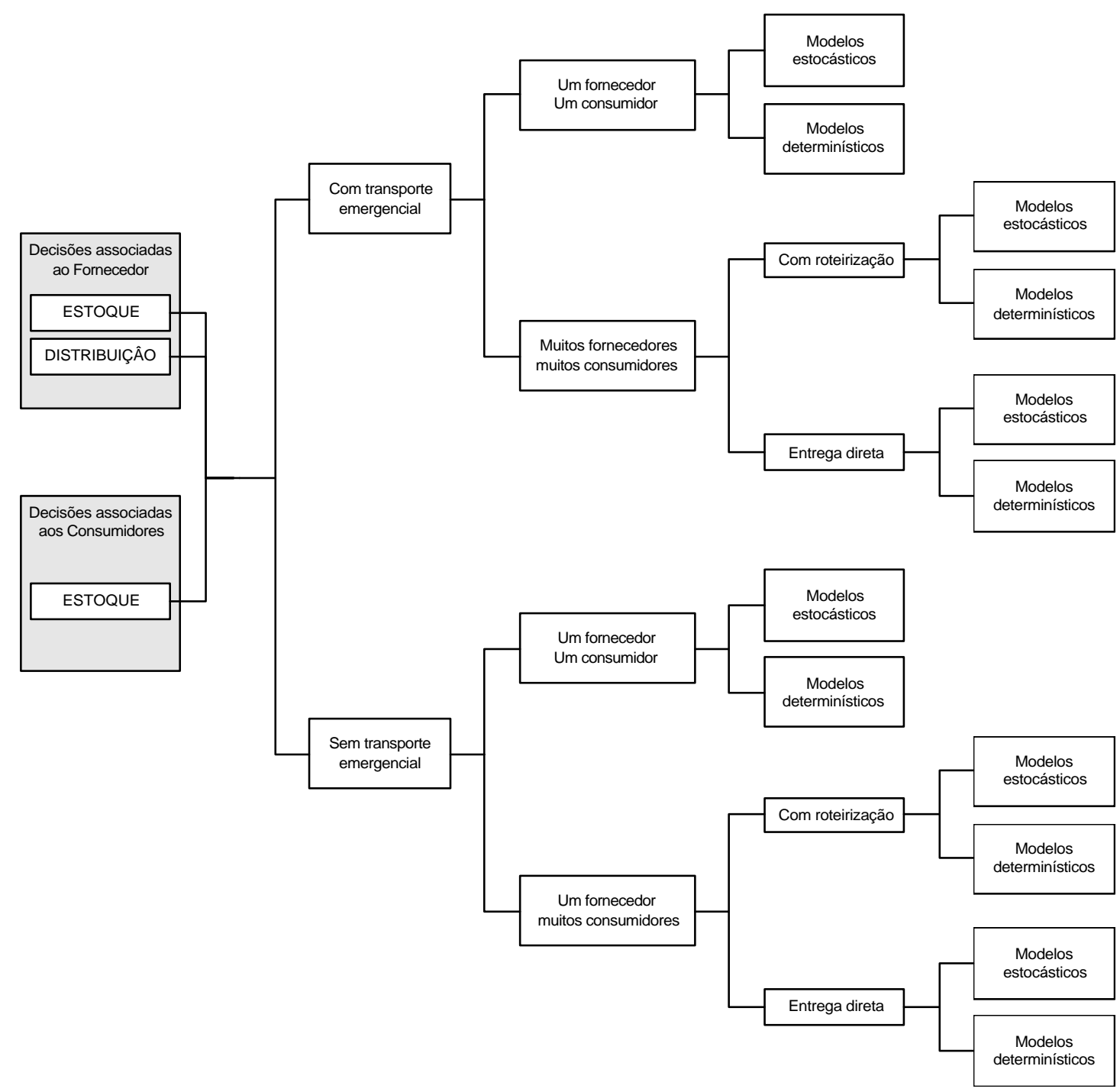

Figura 2.3 - Classificação proposta por SARMIENTO; NAGI (1999) para os modelos de estoque-distribuição-estoque. 


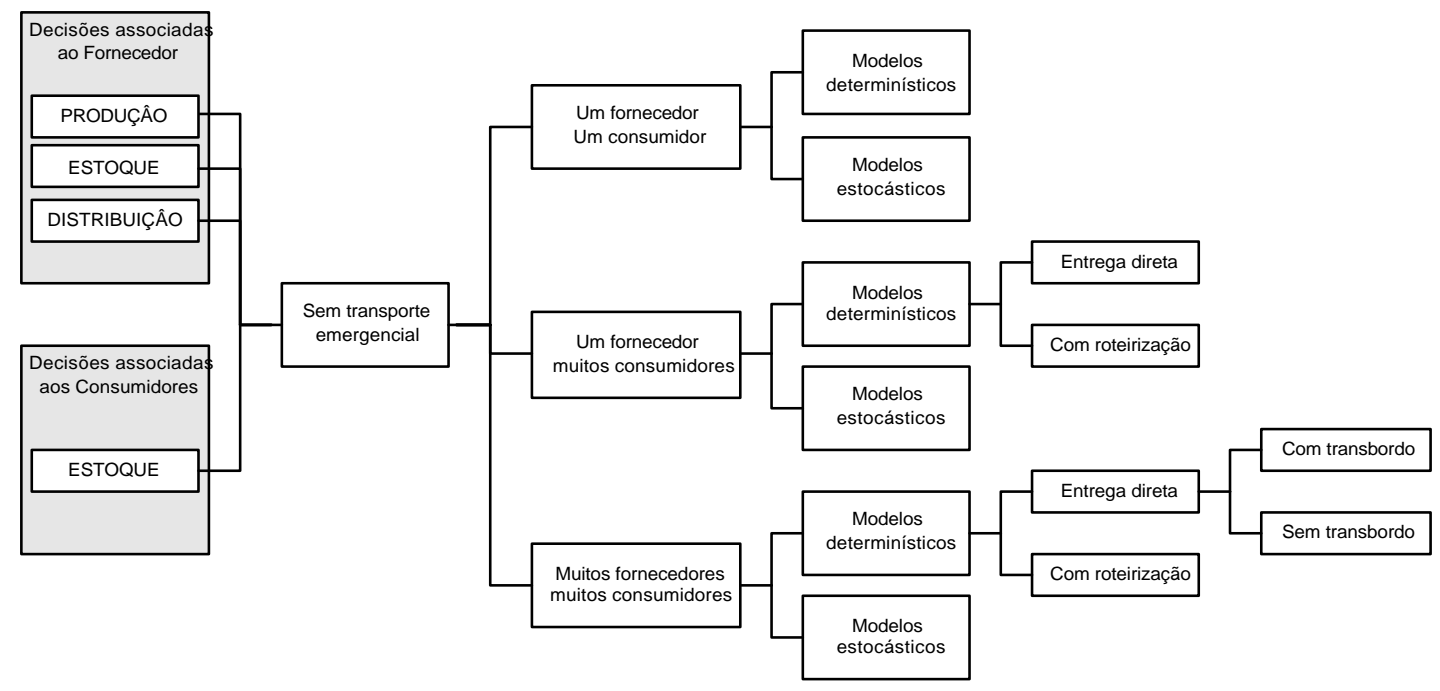

Figura 2.4 - Classificação proposta por SARMIENTO; NAGI (1999) para os modelos de produção-estoque-distribuição-estoque.

\subsubsection{O Trabalho de CHEN (2004)}

CHEN (2004) apresenta uma revisão da bibliografia referente aos modelos em que, além da gestão da distribuição, são incluídas explicitamente as decisões de produção. Inicialmente, o autor identifica três dimensões principais de classificação dos modelos encontrados:

- nível de decisão;

- estrutura de integração;

- parâmetros do problema.

Em termos de nível de decisão, os modelos podem ser classificados como táticos ou operacionais. Modelos táticos envolvem decisões agregadas, tais como quanto produzir ou distribuir em cada período. Já por sua vez, os modelos operacionais envolvem decisões mais detalhadas, tais como a programação das máquinas utilizadas na produção ou programação das rotas de distribuição. Note-se que o autor deliberadamente exclui da revisão os modelos que envolvem decisões de nível estratégico, tais como localização de terminais ou desenho da rede de distribuição. 
Em termos de estrutura de integração, os modelos são classificados segundo as etapas da cadeia de abastecimento representadas, sendo considerados três tipos de estrutura:

- integração da produção e da distribuição (“outbound transportation”);

- integração do abastecimento ("inbound transportation”) e da produção;

- integração do abastecimento (“inbound transportation”), da produção e da distribuição ("outbound transportation");

A primeira categoria consiste em cadeias de abastecimento de dois estágios, e tipicamente envolve a integração entre o produtor e seus clientes. De forma análoga, o segundo grupo envolve a integração entre os fornecedores de matéria prima ou produtos semi-acabados e o produtor. Já o terceiro grupo consiste em cadeias de abastecimento de três estágios que envolvem os fornecedores de matéria prima, o produtor e os clientes.

Por fim, a dimensão parâmetros do problema corresponde às características da demanda e do horizonte de planejamento, podendo tomar os seguintes valores:

- um único período;

- horizonte infinito com demanda constante;

- horizonte finito com demanda dinâmica.

Baseado nas dimensões descritas e na ocorrência dos problemas na prática e/ou bibliografia, o autor propõe um classificação dos modelos integrados de produção e distribuição em cinco categorias, apresentadas no Quadro 2.2 a seguir. 
QUADRO 2.2 - Classificação dos modelos integrados de produção e distribuição.

\begin{tabular}{|c|c|c|c|c|c|c|}
\hline \multirow{2}{*}{ Dimensão } & \multirow{2}{*}{ Valor } & \multicolumn{5}{|c|}{ Categoria } \\
\hline & & $\mathrm{C} 1$ & $\mathrm{C} 2$ & $\mathrm{C} 3$ & $\mathrm{C} 4$ & $\mathrm{C} 5$ \\
\hline Nível de decisão & $\begin{array}{c}\text { Tático } \\
\text { Operacional }\end{array}$ & $X$ & $\mathrm{X}$ & $X$ & $\mathrm{X}$ & $X$ \\
\hline $\begin{array}{l}\text { Estrutura de } \\
\text { integração }\end{array}$ & $\begin{array}{c}\text { Produção + Distribuição } \\
\text { Abastecimento + Produção } \\
\text { Abastecimento + Produção + Distribuição }\end{array}$ & $\mathrm{X}$ & $\mathrm{X}$ & $X$ & $\begin{array}{l}\mathrm{X} \\
\mathrm{X}\end{array}$ & $\mathrm{X}$ \\
\hline $\begin{array}{l}\text { Parâmetros do } \\
\text { problema }\end{array}$ & $\begin{array}{l}\text { Um único período } \\
\text { Horizonte infinito com demanda constante } \\
\text { Horizonte finito com demanda dinâmica }\end{array}$ & $X$ & $\mathrm{X}$ & $X$ & $\begin{array}{l}\mathrm{X} \\
\mathrm{X}\end{array}$ & $X$ \\
\hline
\end{tabular}

Fonte: Adaptado de CHEN (2004)

Nota-se que, mesmo com a utilização de um número reduzido de dimensões, a classificação proposta não abrange todas as possíveis combinações dos valores das dimensões consideradas. Vale enfatizar que o trabalho de CHEN (2004) considera apenas modelos que representem explicitamente a etapa de produção. Segundo o autor, há uma extensa bibliografia de modelos que fazem referência a problemas de produção e distribuição, porém, afirma-se que a maior parte desses trabalhos simplesmente ignora ou representa de forma extremamente simplificada a etapa de produção, não sendo incluídos na revisão realizada.

\subsubsection{Comentários}

Uma avaliação dos trabalhos de classificação apresentados permite afirmar que há em realidade uma família de problemas que envolvem simultaneamente gestão de estoques e roteirização, similar ao que se observa no caso da roteirização e programação de veículos. Se neste caso, a combinação das diversas características e restrições torna inviável a classificação por enumeração das possíveis combinações desses elementos, a inclusão de novas restrições, relativas aos estoques dos clientes, 
adiciona complexidade ao problema original e torna a tarefa de classificação ainda mais difícil.

Embora relativamente antigo, e não voltado especificamente para a classificação de problemas de gestão de estoques e roteirização, o trabalho de BALL (1988) aponta com clareza uma das características fundamentais dessa categoria de problema: a alocação de atendimentos ao longo do horizonte de planejamento. A resolução dessa questão implica a determinação dos dias de atendimento e das quantidades entregues, sendo essa a principal diferença entre os modelos, segundo o autor.

Por sua vez, os trabalhos de BAITA et al. (1998) e de SARMIENTO; NAGI (1999) abordam a questão da classificação dos problemas e modelos utilizados. Como seria de se esperar, dada a multiplicidade de elementos classificatórios, diferentes conjuntos de elementos são utilizados nas classificações propostas. Uma comparação desses elementos é apresentada no Quadro 2.3.

Pode-se notar que a classificação proposta por BAITA et al. (1998) não diferencia entre aspectos do problema em si e estratégias de solução, utilizando ambas como elementos de classificação para os modelos. Embora seja considerado em termos gerais o tipo de método de resolução (exato ou aproximado), chama a atenção a ausência de referências a modelos baseados em metaheurísticas, uma vez que essa categoria tem apresentado sucesso na resolução de problemas de natureza combinatória, tais como os problemas de roteirização de veículos e programação de produção.

Embora a contribuição de SARMIENTO; NAGI (1999) no sentido de explicitar as decisões envolvidas nas diversas categorias de problemas que envolvem estocagem e distribuição seja importante e pertinente, a sua subsequente aplicação na classificação dos trabalhos encontrados na bibliografia nem sempre é clara. Um exemplo disso é a utilização do horizonte de planejamento (finito ou infinito) como elemento classificador na descrição dos modelos analisados, muito embora esse não seja um critério incorporado formalmente à sua classificação. Vale destacar ainda a semelhança desse critério com a classificação utilizada por BAITA et al. (1998), uma vez que os modelos de freqüência de atendimento estão associados a um horizonte 
infinito de planejamento, e os modelos de instante de atendimento a um horizonte finito de planejamento.

QUADRO 2.3 - Comparativo dos elementos de classificação utilizados por BAITA et al. (1998) e SARMIENTO; NAGI (1999).

\begin{tabular}{|c|c|c|c|}
\hline Elemento & Atributo & $\begin{array}{l}\text { BAITA et al. } \\
\quad(1998)\end{array}$ & $\begin{array}{l}\text { SARMIENTO; } \\
\text { NAGI (1999) }\end{array}$ \\
\hline $\begin{array}{l}\text { Topologia da rede de } \\
\text { atendimento }\end{array}$ & $\begin{array}{l}\text { Pontos de abastecimento ou } \\
\text { distribuição }\end{array}$ & $\mathrm{X}$ & $\mathrm{X}$ \\
\hline Itens a ser entregues & Número & $\mathrm{X}$ & \\
\hline Demanda & $\begin{array}{c}\text { Tipo } \\
\text { Comportamento } \\
\text { Distribuição entre clientes }\end{array}$ & $\begin{array}{l}\mathrm{X} \\
\mathrm{X} \\
\mathrm{X}\end{array}$ & $\mathrm{X}$ \\
\hline Decisões & Domínio & $\mathrm{X}$ & \\
\hline Roteirização & $\begin{array}{l}\text { Entregas diretas ou roteirizadas } \\
\text { Entregas regulares ou emergenciais }\end{array}$ & & $\begin{array}{l}X \\
X\end{array}$ \\
\hline Restrições & $\begin{array}{l}\text { Capacidade dos veículos } \\
\text { Capacidade de estocagem } \\
\text { Capacidade de abastecimento } \\
\text { Nú mero de veículos }\end{array}$ & $\begin{array}{l}X \\
X \\
X\end{array}$ & \\
\hline Função/Custos(*) & $\begin{array}{c}\text { Produção } \\
\text { Estoque } \\
\text { Distribuição }\end{array}$ & $\begin{array}{l}X \\
X\end{array}$ & $\begin{array}{l}X \\
X \\
X\end{array}$ \\
\hline Estratégia de solução & $\begin{array}{c}\text { Decomposição } \\
\text { Agregação } \\
\text { Algoritmo } \\
\text { Programação matemática }\end{array}$ & $\begin{array}{l}X \\
X \\
X\end{array}$ & \\
\hline
\end{tabular}

(*) Considera-se a adoção de determinadas parcelas de custo equivalente à incorporação ao modelo das funções correspondentes. 
Além de características do problema relacionadas à duração do período de planejamento e ao comportamento da demanda, o trabalho de CHEN (2004) considera como critérios de classificação o nível de tomada de decisão e a estrutura da cadeia de abastecimento considerada. Esses critérios, não encontrados nos demais trabalhos citados nesta seção, estão diretamente relacionados à decisão do autor de restringir sua análise a problemas que consideram explicitamente a etapa de produção. Nesse sentido, pode-se afirmar que a classificação proposta por CHEN (2004) é restrita a modelos com essa característica, não podendo ser generalizada para modelos que não abranjam a etapa de produção.

Pode-se concluir, pelo apresentado, que não há uma classificação consolidada para essa categoria de problemas, em que se inclui o PDEGF. Classificações usuais, como as propostas para problemas de roteirização ou correlatos (BODIN et al., 1983; LAPORTE, 1992; MIN et al., 1998) também não se aplicam diretamente ou não são relevantes no contexto do PDEGF. Um exemplo disso é a subdivisão de estratégias de solução em algoritmos exatos, heurísticas e metaheurísticas. Observa-se que tal classificação não seria eficaz no caso do PDEGF, uma vez que algoritmos exatos foram encontrados apenas para casos específicos que tratam de entrega direta fornecedor-consumidor, e estratégias de solução que utilizam metaheurísticas são escassas, o que indica a necessidade de se levar em conta aspectos específicos do problema e dos modelos na classificação e estruturação da revisão bibliográfica.

À luz das considerações acima, propõe-se organizar a revisão da bibliografia segundo a estrutura proposta por BAITA et al. (1998), já apresentada na Figura 2.1. Essa escolha, conquanto arbitrária, se justifica por ser essa uma estrutura mais concisa que a proposta por SARMIENTO; NAGI (1999), e por destacar características dos modelos utilizados mais apropriadas para uma revisão das estratégias de resolução encontradas na bibliografia. Referências a outros aspectos classificatórios serão inseridas ao longo do texto, sempre que venham a contribuir para a compreensão dos modelos e enriquecimento de sua análise.

Seguindo a classificação adotada, a seção 2.3 apresenta uma revisão dos modelos de freqüência de atendimento, subdividida nas subseções modelos agregados, modelos de partição fixa e modelos de freqüência discreta de atendimento. 
Por sua vez, a seção 2.4 apresenta uma revisão dos modelos de instante de atendimento, subdivididos em modelos de fluxo dinâmico com demanda desconhecida e modelos com demanda conhecida. E finalmente, a seção 2.5 apresenta alguns comentários a respeito da bibliografia analisada.

Cabe aqui informar que a revisão bibliográfica apresentada nas seções a seguir não se restringe a modelos com as mesmas características do modelo proposto no presente trabalho. Nesse sentido, pode-se afirmar que a revisão realizada busca apresentar uma visão geral dos problemas e modelos que envolvem simultaneamente decisões de transporte, estocagem e, eventualmente, planejamento da produção. Ao leitor interessado exclusivamente na classe de modelos dentre os quais se insere o presente trabalho, sugere-se passar diretamente à seção 2.4.2, que trata dos modelos de instante de atendimento com demanda conhecida.

\subsection{Modelos de Freqüiência de Atendimento}

Nessa categoria enquadram-se os modelos em que as decisões de atendimento são modeladas na forma de freqüências de atendimento ou, de forma equivalente, como intervalos entre reabastecimentos consecutivos. Como regra, os modelos aqui analisados refletem situações estáveis de abastecimento, em que a demanda é considerada constante e o horizonte de planejamento infinito.

\subsubsection{Modelos Agregados}

Segundo BAITA et al. (1998), os modelos agregados de freqüência de atendimento são modelos analíticos que identificam propriedades qualitativas, permitindo chegar a soluções práticas. A principal hipótese utilizada por esses modelos é que, tanto a demanda como a distribuição geográfica dos clientes varia muito lentamente, podendo ser considerada constante para efeitos de análise. Apesar da detalhada representação dos custos, esses modelos não se preocupam com a sua alocação a diferentes participantes da cadeia de distribuição, considerando que, de uma forma ou de outra, os excessos decorrentes de uma configuração de distribuição que não a ótima acabam sendo repartidos entre todos os envolvidos. 
Fruto de uma pesquisa realizada em conjunto pela General Motors Corporation e Universidade da Califórnia na década de 80, o trabalho de BLUMENFELD et al. (1985) estudou redes de distribuição com entregas diretas fornecedor-consumidor. Partindo do caso mais simples, com apenas um fornecedor e um consumidor, são progressivamente analisados casos mais complexos, com múltiplos consumidores e, finalmente, múltiplos fornecedores, com ou sem a utilização de terminal de consolidação. Os resultados obtidos permitem a análise de trocas cruzadas entre diferentes redes de distribuição e, em particular, a identificação das configurações de custo que tornam vantajosa a utilização de um terminal de consolidação. Observe-se que, embora as análises tenham sido feitas para um único produto, o caso com múltiplos produtos também pode ser resolvido com o artifício da definição de um produto "composto", correspondente ao conjunto dos produtos que utilizam a mesma ligação fornecedor-consumidor. Uma extensão desse modelo é proposta por BURNS et al. (1985), que consideram também a possibilidade de roteirização na distribuição. É interessante notar que, nesse caso, a localização dos consumidores é tratada de maneira agregada, através de um parâmetro de densidade, e não de maneira individualizada, como é usual nos modelos de roteirização.

Complementando os trabalhos anteriores, BLUMENFELD et al. (1987) apresentam uma aplicação real que descreve a sua utilização na distribuição de componentes eletrônicos da General Motors Corporation. É descrita a implantação de um sistema de apoio à tomada de decisão baseado nos modelos analíticos anteriormente desenvolvidos, o que permitiu identificar um potencial de redução de custos logísticos da ordem de $26 \%$, correspondentes a cerca de US\$ 2,9 milhões/ano à época.

Um método baseado na heurística das economias de CLARKE; WRIGHT (1964) foi proposto por LARSON (1988), e aplicado com sucesso ao problema de coleta e transporte de resíduos gerados em estações de tratamento de água da cidade de Nova York. O método proposto considera rotas fixas de coleta e consolidação em estações de transbordo, sendo interessante ressaltar que as demandas, isto é, as quantidades de resíduos a ser coletados, não são determinísticas, mas seguem uma distribuição normal, sendo tratadas, no entanto, como determinísticas a partir da especificação 
prévia de um nível de serviço. A utilização de rotas fixas acarreta, entretanto, o inconveniente de clientes serem visitados com uma frequiência muito maior que a necessária, o que levou WEBB; LARSON (1995) a proporem uma extensão do modelo, em que os clientes são atendidos apenas quando realmente necessário, o que possibilita um melhor aproveitamento da frota e conseqüente redução de custos, especialmente quando as demandas dos pontos de atendimento são muito distintas. Vale notar que ambos modelos buscam a redução da frota total necessária ao atendimento da demanda, sendo denominados por seus autores modelos estratégicos de estoque-roteirização, em oposição a modelos táticos de estoque-roteirização, que considerariam apenas a otimização da utilização de uma frota existente.

BENJAMIN (1989) estudou o problema de distribuição de vários fornecedores para vários clientes, considerando custos de estoque nos fornecedores, nos clientes e o custo de transporte. Partindo da resolução independente das etapas de planejamento da produção, problema de transporte e determinação do lote econômico de pedido, o autor apresenta uma heurística para a resolução simultânea dos três subproblemas de uma maneira conjunta. Essa heurística baseia-se na aplicação da decomposição de Benders para a resolução de instâncias relaxadas (linearizadas) do problema e iterativamente convergir para a solução do problema original. Vale ressaltar que o modelo apresentado trata a etapa de transporte de uma maneira simplificada, não considerando a roteirização no atendimento aos clientes. Essa situação, embora ocorra na prática em casos de entrega direta, não corresponde ao caso mais geral do PDEGF.

\subsubsection{Modelos de Política de Partição Fixa}

Segundo CHAN et al. (1998), dada a complexidade do PDEGF, a identificação de uma estratégia ótima de reabastecimento é extremamente improvável, ainda que com a adoção de estruturas de custo mais simples. Os autores afirmam ainda que, mesmo que uma estratégia ótima de atendimento possa ser encontrada, sua estrutura seria tão complexa que tornaria sua implantação inviável, o que significa, do ponto de vista prático, que a abordagem do problema acaba sendo restrita a algumas classes de políticas de reabastecimento, em particular políticas de pedido com estoque zero e 
políticas de partição fixa. No primeiro caso, um cliente é atendido se, e somente se, está na iminência de ficar sem estoque, podendo-se demonstrar que, na ausência de restrições de capacidade dos veículos ou de freqüências de atendimento dos clientes, essa classe de política é ótima, muito embora ela também seja demasiado complexa para permitir uma implementação prática.

Já os modelos de partição fixa se caracterizam por determinar uma partição dos clientes em regiões independentes, de forma que cada região seja atendida sem interferência ou coordenação com o atendimento das demais regiões. Uma vez realizada a partição dos clientes, o problema original se reduz à determinação do lote ótimo de pedido e à resolução de um problema de caixeiro viajante para os clientes de cada região, sendo usualmente possível a dedução de limitantes que permitem a avaliação do comportamento assintótico da política de reabastecimento adotada. Embora de grande apelo prático, BAITA et al. (1998) apontam que essa abordagem freqüentemente gera soluções de baixa qualidade para instâncias de porte modesto, sugerindo a necessidade de uma investigação sobre as dimensões mínimas recomendadas para a aplicação prática dessa abordagem.

ANILY; FEDERGRUEN (1990) estudaram o problema da distribuição de um único produto a um conjunto de clientes geograficamente dispersos, cada qual possuindo uma demanda constante conhecida, e atendidos por uma frota homogênea, baseada em um único depósito. São considerados estoques apenas nos clientes, sem restrição quanto à capacidade de armazenamento, e o modelo busca a minimização conjunta dos custos de transporte e estoque no sistema. É proposta uma heurística que particiona os clientes em grupos fixos, de forma que todos os clientes de um mesmo grupo sejam atendidos por um único veículo, a intervalos regulares e segundo rotas fixas. Uma importante característica do modelo proposto é o fracionamento da demanda dos clientes em múltiplos de uma demanda base, que passam a ser denominados pontos de demanda e podem ser atendidos independentemente por rotas distintas.

O problema original fica então reduzido à determinação de uma partição ótima do conjunto de pontos de demanda, utilizando-se uma função de custo que depende apenas da extensão e do número de clientes atendidos em cada rota, o que é feito 
agrupando-se os pontos de demanda em setores circulares contíguos, com centro no depósito, posteriormente subdivididos em seções correspondentes a cada veículo a ser utilizado. São deduzidos limitantes inferiores e superiores para os custos de longo prazo da classe de política de reabastecimento utilizada, sendo demonstrado que a heurística proposta é assintoticamente ótima dentro dessa classe de políticas de reabastecimento. Isto é, ao se aumentar o número de clientes, o custo de longo prazo e o seu limitante superior tendem para o limitante inferior deduzido para a política de reabastecimento.

É importante destacar que a heurística proposta foi criticada por HALL (1991), que mostrou que o modelo superestima os custos de distribuição quando do fracionamento da demanda dos clientes, uma vez que não se considera a possibilidade de coordenação entre as entregas ou compartilhamento dos estoques. Em resposta às críticas recebidas, ANILY; FEDERGRUEN (1991) argumentam que tais deficiências são inerentes à política de reabastecimento adotada, em que cada região da partição é tratada independentemente das demais, mesmo que alguns pontos de entrega pertencentes a várias rotas (regiões) correspondam a um mesmo cliente físico. Os autores argumentam ainda que a heurística não deve ser avaliada exclusivamente pelo desempenho do pior caso ou por sua comparação com o mínimo custo possível, devendo ser considerados também aspectos positivos, tais como a facilidade de implementação e administração do sistema de distribuição.

Generalizando o proble ma analisado por ANILY; FEDERGRUEN (1990), ANILY (1994) estudou o caso da distribuição de um único produto a um conjunto de clientes geograficamente dispersos, que podem possuir diferentes custos unitários de manutenção de estoque. Da mesma forma que no problema original, a distribuição é realizada por frota homogênea, sem restrição de número de veículos, baseada em um único depósito, e são considerados estoques apenas nos clientes, sem restrição quanto à capacidade de armazenamento.

Um estudo sobre a eficiência de uma política de entregas diretas para o PDEGF com frota homogênea foi apresentada por GALLEGO; SIMCHI-LEVI (1990). Entende-se aqui por política de entregas diretas o abastecimento independente e individual de cada cliente, isto é, cada rota de entrega possui um único cliente. Inicialmente é 
deduzida uma formulação para o limitante inferior de todas as políticas de abastecimento para o problema, que posteriormente é utilizado para a avaliação da política de entregas diretas. Os resultados obtidos indicam que, quando o abastecimento é realizado segundo a fórmula do lote econômico de reposição e o menor lote assim determinado corresponde a no mínimo $71 \%$ da capacidade dos veículos de distribuição, o custo da política de entregas diretas não é maior que $6,38 \%$ do limitante inferior deduzido anteriormente.

BRAMEL; SIMCHI-LEVI (1995) apresentaram uma heurística que pode ser utilizada na resolução tanto de problemas de roteirização de veículos quanto do PDEGF com demanda determinística. Nesse caso, adota-se a hipótese de que os clientes não possuem restrições de capacidade de armazenagem e o modelo busca a minimização conjunta dos custos de transporte, manutenção de estoques e custos fixos por pedido de reabastecimento.

A heurística proposta tem como idéia central determinar a partição do conjunto de clientes por meio da resolução de um problema de localização de concentrador capacitado ("capacitated concentrator location problem"), que consiste em escolher um conjunto de localizações que atuam como concentradores e determinar a ligação de cada terminal a um dos concentradores escolhidos, de forma a minimizar o custo total das ligações terminalconcentrador e concentrador-base, respeitando-se as restrições de capacidade em cada concentrador. No caso do PDEGF, a base corresponde ao depósito a partir do qual é feita a distribuição, o concentrador a um conjunto de clientes e cada terminal a um único cliente. Um concentrador e os terminais a ele ligados definem uma região de atendimento e cada concentrador possui capacidade igual à de um veículo da frota (homogênea) utilizada. Embora o problema de localização de concentrador capacitado seja também um problema computacionalmente difícil ("NP-hard"), sua resolução é mais simples que o problema original e, com a aplicação do método da Relaxação Lagrangiana, equivale à resolução de um conjunto de problemas de mochila binária.

Do ponto de vista prático, a abordagem proposta possui alguns pontos positivos que vale a pena destacar. Como os atendimentos são realizados a intervalos fixos, tanto os clientes quanto os motoristas dos veículos sabem de antemão a programação das 
entregas, que não necessita ser refeita diariamente, como ocorre em especial nos modelos de horizonte deslocável, além de que a utilização de rotas fixas facilita o aprendizado dos motoristas. Entretanto, é importante notar que a hipótese adotada de capacidade de estoque ilimitada nos clientes pode não ser aceitável em alguns casos, resultando em programações de atendimento que não são factíveis.

Mais recentemente, SINDHUCHAO et al. (2005) estudaram o problema de coleta de múltiplos itens, produzidos por um conjunto de fornecedores dispersos geograficamente, por uma frota homogênea de capacidade limitada. São considerados os custos fixos e variáveis de transporte, bem como os custos de manutenção dos estoques nos fornecedores, e busca-se a determinação de uma partição ótima dos itens em rotas de coleta periódica, de forma a minimizar os custos totais decorrentes. Duas estratégias de solução são propostas pelos autores: um algoritmo exato, baseado no método "branch-and-price", e um conjunto de heurísticas de duas etapas, baseadas na aplicação do método "very large-scale neighborhood search" - VLNS.

\subsubsection{Modelos de Freqüiência Discreta de Atendimento}

Tanto nos modelos agregados quanto nos de partição fixa, a determinação das freqüências de atendimento decorre da aplicação de alguma adaptação da fórmula de lote ótimo de pedido, o que leva, via de regra, a valores não inteiros para os intervalos de reabastecimento. $\mathrm{O}$ questionamento desses resultados fomentou a pesquisa de políticas de distribuição que permitam apenas valores discretos para as freqüências de atendimento, em particular, valores que correspondam a intervalos múltiplos de um período base, tipicamente de um dia.

ANILY; FEDERGRUEN (1993) estudaram o problema da distribuição de um único produto a um conjunto de clientes geograficamente dispersos, cada qual possuindo uma demanda constante conhecida, e atendidos por frota homogênea, localizada em um único depósito. São considerados estoques tanto nos clientes quanto no depósito, sendo esse uma extensão do trabalho de ANILY; FEDERGRUEN (1990), que não considera estoques no depósito. Não há restrição quanto à capacidade de 
armazenamento, e o modelo busca a minimização conjunta dos custos de distribuição e de estoque no sistema.

A heurística proposta é basicamente a mesma proposta pelos autores em seu trabalho anterior para o caso sem estoque no depósito (ANILY; FEDERGRUEN, 1990), entretanto com a diferença de que, em sua etapa final, os intervalos de atendimento calculados são retificados para valores correspondentes a potências de dois de um período base de planejamento. Verifica-se que, embora essa seja uma heurística que adota uma política de partição fixa, sua característica distintiva é a adoção de freqüências discretas de atendimento, sendo, pois, classificada com tal.

SPERANZA; UKOVICH (1994) estudaram a distribuição de múltiplos produtos no caso de entregas diretas fornecedor-consumidor. O problema consiste em determinar as frequiências das entregas de cada produto, dentre um conjunto discreto de possíveis freqüências de atendimento, com o objetivo de minimizar conjuntamente os custos de transporte, de estoque no fornecedor e de estoque no consumidor. Não há restrições quanto ao número de veículos disponíveis, nem quanto à capacidade de armazenamento dos produtos. Duas alternativas para determinação das freqüências de atendimento são consideradas: freqüência simples ou múltipla, conforme sejam utilizadas uma ou mais freqüências de atendimento por produto, respectivamente. A consolidação das entregas nos veículos também pode ser feita de duas formas distintas: agregação por freqüência ou por instante de atendimento. No primeiro caso, apenas produtos com mesma freqüência de atendimento podem compartilhar um veículo. Já no segundo caso, podem compartilhar o veículo quaisquer entregas simultâneas, independentemente da frequiência de atendimento dos respectivos produtos.

Uma extensão do modelo de SPERANZA; UKOVICH (1994) foi proposta por BERTAZZI et al. (1997), com a introdução da possibilidade de roteirização dos veículos. Assim como o modelo original, busca-se a minimização dos custos de transporte e estoque, e não há restrições de capacidade de estocagem, seja nos clientes ou no depósito. A heurística proposta possui três etapas, podendo ser resumida da seguinte forma: inicialmente, cada cliente é tratado isoladamente, segundo o modelo de SPERANZA; UKOVICH (1994). Com base nos resultados 
obtidos, são separados na segunda etapa subconjuntos de consumidores atendidos com a mesma freqüência e identificadas agregações de consumidores e/ou modificações de frequiência que gerem redução de custo. Finalmente, a última etapa consolida as rotas geradas na segunda etapa por meio da heurística de economias de CLARKE; WRIGHT (1964).

Em uma extensão do problema abordado por ANILY; FEDERGRUEN (1990), VISWANATHAN; MATHUR (1997) estudaram o caso da distribuição conjunta de múltiplos produtos em que são considerados estoques apenas nos clientes, sem restrições quanto à capacidade de armazenamento ou número de veículos. Duas heurísticas são propostas, sendo as freqüências de reabastecimento restritas a potências de dois de um período base, tipicamente de um dia. Esse tipo de política de atendimento é dita aninhada, pois se um item apresenta um intervalo de reabastecimento maior que o de outro item, o primeiro é necessariamente múltiplo do segundo.

As heurísticas foram testadas com um conjunto de instâncias geradas por computador, restringindo-se ao caso com apenas um produto, de forma a permitir comparações com a heurística proposta por ANILY; FEDERGRUEN (1990). Os resultados obtidos indicam a superioridade da heurística de VISWANATHAN; MATHUR (1997) na maioria das instâncias, em particular nos casos em que a demanda dos clientes é distinta. Entretanto, os casos em que a capacidade dos veículos é completamente utilizada tendem a favorecer a heurística de ANILY; FEDERGRUEN (1990).

BERTAZZI et al. (2000) estudaram a distribuição de múltiplos produtos no caso de entregas diretas fornecedor-consumidor, em que se busca determinar as freqüências de atendimento e correspondentes quantidades entregues, minimizando, de forma conjunta, os custos de transporte e de estoque. Não há restrições quanto ao número de veículos disponíveis, nem quanto à capacidade de armazenamento dos produtos.

Os autores demonstram, a partir da dedução de limitantes inferiores e superiores para esse tipo de problema, que algumas soluções são dominadas, isto é, sempre apresentam custos superiores em relação a outras soluções disponíveis para o 
problema. Esse resultado é utilizado no desenvolvimento de uma nova versão do algoritmo exato proposto por SPERANZA; UKOVICH (1996), baseado no método "branch-and-bound". Segundo os autores, a análise dos resultados obtidos com o método exato mostrou que a solução ótima do problema em geral utiliza apenas duas frequiências de atendimento, sendo que os veículos designados à freqüência de atendimento mais alta têm sua capacidade totalmente utilizada. Essa particularidade inspirou o desenvolvimento de uma heurística que gerasse soluções com essa mesma característica.

Uma comparação de modelos que tratam do problema com entrega direta fornecedor-consumidor foi realizada por BERTAZZI; SPERANZA (2002). São analisados os casos em que a freqüência de atendimento pode tomar qualquer valor real ou apenas valores discretos. O primeiro caso corresponde ao modelo apresentado por BLUMENFELD et al. (1985), já o segundo corresponde à situação em que os reabastecimentos são realizados a freqüências e volumes constantes de entrega, analisado em SPERANZA; UKOVICH (1994). Um terceiro caso analisado considera que as freqüências possíveis estão uniformemente distribuídas ao longo de um horizonte de planejamento, sendo que as quantidades entregues, com uma certa freqüência, não são necessariamente constantes. Os autores demonstram que existe uma relação de dominância entre as soluções ótimas dos modelos analisados, sendo que a solução ótima obtida pelo primeiro modelo nunca será pior que as soluções ótimas obtidas pelos demais modelos e, de forma similar, que a solução ótima do terceiro modelo nunca será pior que a do segundo. Demonstra-se ainda que as diferenças de custo das soluções ótimas dos modelos analisados não são limitadas em seu pior caso.

\subsection{Modelos de Instante de Atendimento}

Nessa categoria enquadram-se os modelos em que as decisões de atendimento são modeladas na forma de instantes de atendimento. Diferentemente dos modelos de frequiência de atendimento, os trabalhos aqui analisados utilizam um horizonte de planejamento finito e em geral permitem considerar variações da demanda ao longo 
desse período, o que possibilita a incorporação de sazonalidades ou outros comportamentos dinâmicos da demanda dos clientes.

\subsubsection{Modelos de Fluxo Dinâmico com Demanda Desconhecida}

Segundo BAITA et al. (1998), a categoria de modelos de fluxo dinâmico com demanda desconhecida constitui uma nova e promissora linha de pesquisa para o PDEGF. Sua principal característica é tratar o problema como um sistema dinâmico, sujeito a perturbações desconhecidas, mas que respeitam limites definidos a priori. A resolução do problema envolve a determinação de uma estratégia de controle com realimentação que mantenha o estado do sistema dentro de limites preestabelecidos, ao longo do horizonte de planejamento. Embora promissora, os autores apontam como desvantagem o elevado custo computacional dos modelos desenvolvidos, o que compromete sua aplicabilidade prática.

BLANCHINI et al. (1996a) modelaram o PDEGF como um problema de fluxo dinâmico em rede de um único produto com tempo discreto, em que as demandas e produções são periódicas e conhecidas de antemão. Cada nó da rede corresponde a um ponto de consumo ou armazenamento e os arcos da rede representam os possíveis fluxos do produto na rede, podendo ser classificados em dois tipos: fluxos controlados e fluxos não controlados. O primeiro conjunto corresponde às variáveis de decisão, já o segundo corresponde às demandas e produções, determinadas exogenamente. É adotada ainda a hipótese de que o sistema esteja isolado.

Para cada nó da rede são conhecidos os limites mínimo e máximo de armazenamento do produto e dos fluxos controlados. Esses limites podem variar ao longo do tempo, mas são periódicos por hipótese. Assim definido, o problema consiste em determinar uma estratégia de controle que mantenha o sistema dentro dos limites preestabelecidos. Observe-se que o modelo apresentado não busca diretamente a minimização dos custos de distribuição, mas apenas o controle do sistema, respeitando-se as restrições existentes.

Segundo os autores, a resolução desse tipo de problema já foi realizada por ORLIN (1984) apud BLANCHINI et al. (1996a) e ARONSON (1989) apud BLANCHINI 
et al. (1996a), mas na forma de estratégia de controle aberta ("open loop control"), em que a seqüência de fluxos de controle é determinada a priori. Entretanto, afirmase que, na prática, é preferível a utilização de estratégias de controle com realimentação, isto é, estratégias em que os fluxos de controle que possam ser calculados a partir do estado do sistema em um determinado instante.

Esse modelo foi posteriormente estendido por BLANCHINI et al. (1996b) para o caso em que as demandas são conhecidas apenas de forma agregada. Isto é, conhece-se o total da demanda e o limite superior da demanda de cada nó, mas não sua distribuição entre os diversos nós da rede. Embora testes computacionais extensos não tenham sido apresentados, pode-se suspeitar que o método proposto apresenta um custo computacional excessivamente elevado para lidar com instâncias de porte real, uma vez que os autores afirmam que somente foi possível a resolução de instâncias com até 10 nós.

Observa-se que, conquanto interessante e inovadora, a abordagem proposta não busca a minimização dos custos de distribuição, não sendo portanto um modelo otimizante, como geralmente encontrado na literatura. Nota-se ainda que a distribuição é representada no modelo apenas através dos fluxos de controle, sem qualquer consideração a respeito dos veículos envolvidos na distribuição, seus custos ou a existência ou não de roteirização.

\subsubsection{Modelos com Demanda Conhecida}

Se no caso dos modelos de fluxo dinâmico não há informação precisa sobre o comportamento da demanda, nessa categoria são abordados os modelos em que essa informação existe, seja ela determinística ou na forma de distribuição probabilística. Em geral, os modelos aqui analisados apresentam grande flexibilidade, podendo ser alimentados por modelos de previsão de demanda e assim incorporar efeitos dinâmicos tais como sazonalidades. Por considerar um período de planejamento limitado, estão geralmente inseridos em uma estrutura de replanejamento contínuo, em que o horizonte de planejamento é constantemente deslocado e um novo planejamento realizado ("rolling horizon"). 
Uma das primeiras aplicações práticas descritas na bibliografia sobre o PDEGF é o trabalho de BELL et al. (1983), que abordaram o caso da distribuição de gases industriais e desenvolveram um sistema computadorizado para a programação das rotas e apoio à tomada de decisão. Embora o caso apresentado seja de uma empresa com cerca de 23 depósitos, a alocação dos clientes aos depósitos é feita a priori, podendo-se considerar que a formulação apresentada corresponde ao problema com um único depósito e múltiplos veículos.

A estratégia de solução proposta pelos autores é uma decomposição do problema em duas etapas. Na primeira etapa são geradas rotas candidatas, sem especificar horários de atendimento ou quantidades distribuídas, que são determinados numa segunda etapa. Argumenta-se que a quantidade de rotas candidatas enumeradas nessa primeira etapa não chega a tornar inviável a abordagem descrita, pois o número de clientes por rota atendidos diariamente é reduzido (tipicamente 2, e raramente maior que 4), além do fato de que várias rotas podem ser descartadas a priori, com base em critérios de custo, capacidade do veículo ou outras restrições adotadas. Por sua vez, a segunda etapa consiste na seleção das rotas a partir do conjunto de candidatas geradas na primeira etapa, juntamente com a determinação dos horários das entregas e quantidades distribuídas, o que é feito pela resolução de um problema de programação inteira mista por meio de um algoritmo baseado no método da Relaxação Lagrangiana. Os autores afirmam que essa estratégia de solução, incorporada ao sistema de apoio à decisão desenvolvido, resultou na redução de $6 \%$ a $10 \%$ dos custos operacionais de distribuição.

FEDERGRUEN; ZIPKIN (1984) estudaram o problema da distribuição de uma quantidade finita de um produto a partir de um único depósito para um conjunto de clientes com demanda estocástica, sendo considerados os custos associados à manutenção e à falta de estoque nos clientes, assim como os custos de transporte. O horizonte de planejamento considerado é de apenas um período, sendo conhecidos os estoques de cada cliente ao início do mesmo. São propostas duas estratégias de solução: um algoritmo exato e uma heurística baseada em busca local. Ambas abordagens são adaptações de métodos desenvolvidos para o problema de roteirização de veículos, e valem-se da constatação de que, fixada uma alocação de 
clientes a rotas, o problema inicial se divide em dois subproblemas independentes: a alocação do estoque do depósito aos diversos clientes, e um conjunto de problemas de caixeiro viajante.

O algoritmo exato baseia-se na decomposição de Benders generalizada, e a heurística proposta consiste em uma adaptação de métodos de busca local baseados em trocas ou intercâmbios de atendimentos. Isto é, partindo-se de uma solução inicial viável, são realizadas trocas intra-rotas e inter-rotas de atendimentos, até que não seja mais possível melhorar a solução obtida. É importante enfatizar que o modelo proposto pelos autores permite o eventual não atendimento a clientes, seja em função de avaliações de custo, ou restrição do estoque disponível no depósito. Testes realizados com instâncias de até 75 clientes indicam que, no caso da restrição de estoque no depósito não ser atuante, o não atendimento de alguns clientes, a despeito dos custos decorrentes de falta de estoque, pode proporcionar uma redução do custo total da ordem de 6 a 7\% quando comparados com o caso em que todos clientes devem ser atendidos.

Uma adaptação do modelo de FEDERGRUEN; ZIPKIN (1984) foi proposta por FEDERGRUEN et al. (1986) para o caso da distribuição de um produto perecível. A distribuição é feita a partir de um único depósito para um conjunto de clientes sujeitos a demandas estocásticas, sendo considerados os custos de descarte e falta de estoque nos clientes, além dos custos de transporte. Assim como no modelo original, o horizonte de planejamento considerado é de apenas um período, e a validade do produto distribuído é definida em termos de múltiplos desse período base. Isso permite classificar os estoques segundo sua validade: estoques "velhos", cujo prazo de validade termina ao final do período de planejamento, e estoques "novos", cuja validade se estende além do período de planejamento. Evidentemente, deve-se priorizar a distribuição dos estoques "velhos", o que implica adaptar o modelo original de forma a representar as duas categorias de produto de forma separada.

Duas estratégias de entrega são avaliadas: entregas diretas a cada cliente e roteirização de entregas. No primeiro caso, a abordagem proposta consiste em aplicar o método da Relaxação Lagrangiana, reduzindo o problema original ao problema de alocação de um único recurso, que pode ser facilmente resolvido com métodos 
encontrados na literatura (FEDERGRUEN; ZIPKIN, 1983). Já para o segundo caso, propõe-se uma adaptação da heurística de busca local desenvolvida por FEDERGRUEN; ZIPKIN (1984).

Um dos primeiros esforços em tratar explicitamente a relação dos custos de longo prazo com os de curto prazo nos problemas de distribuição com decisões simultâneas de estocagem e roteirização foi o trabalho de DROR; BALL (1987). Segundo os autores, aos quais se atribui a introdução da denominação problema de estoqueroteirização, o objetivo da resolução dessa classe de problema deve ser a minimização dos custos de longo prazo (tipicamente um ano). No entanto, a variabilidade dos parâmetros envolvidos em um horizonte de planejamento dessa extensão, aliado ao proibitivo custo computacional, fazem com que, na prática, sejam utilizados apenas modelos de curto prazo (tipicamente uma ou duas semanas). Argumenta-se ainda que, devido ao seu limitado horizonte de planejamento, os modelos de curto prazo apresentam a tendência de postergar entregas sempre que possível, o que pode acarretar um desnecessário aumento no custo de longo prazo.

A estratégia de solução proposta tem como idéia central introduzir no modelo de curto prazo componentes de custo que reflitam as conseqüências a longo prazo das decisões tomadas. Duas componentes são consideradas, sendo que a primeira aplica-se aos clientes que devem necessariamente ser atendidos no horizonte de planejamento de curto prazo, e corresponde ao aumento de custo decorrente da antecipação de uma entrega em relação ao seu instante ótimo de atendimento. Já a segunda componente aplica-se aos clientes que possuem estoque suficiente para não ser atendidos no horizonte de curto prazo, e corresponde ao decréscimo de custo nos períodos subsequentes decorrente da antecipação do seu atendimento no período de planejamento considerado.

Observe-se que não são considerados os custos de estoque nos clientes, e a política de reabastecimento adotada é a reposição integral dos estoques, isto é, somente são permitidos reabastecimentos que restaurem o nível máximo de estoque nos clientes. Outra interessante característica do modelo proposto é a forma com que a variabilidade da demanda é tratada. Considera-se conhecida a distribuição de demanda para cada cliente, sendo então calculado um estoque de segurança, com 
base nos custos esperados de falta de estoque e custos de distribuição. Definido o estoque de segurança, utiliza-se a demanda média de cada cliente como uma demanda determinística.

Para a resolução do modelo, os autores propõem uma estratégia de solução baseada na conhecida heurística de FISHER; JAIKUMAR (1981) para o problema de roteirização de veículos, que consiste na determinação dos dias de atendimento dos clientes pela resolução de um problema de designação generalizada ("generalized assignment problem"), seguido da determinação dos roteiros de cada dia de atendimento por meio de uma versão modificada da heurística das economias de CLARKE; WRIGHT (1964). Por fim, as rotas obtidas passam por uma etapa de melhorias baseada em busca local. A heurística proposta foi aplicada com sucesso a um caso real de distribuição de gás combustível, sendo reportada uma redução de custos da ordem de $50 \%$ em relação ao planejamento manual efetuado anteriormente pela empresa.

Em uma extensão do estudo de DROR; BALL (1987), duas heurísticas de busca local foram analisadas por DROR; LEVY (1986) como etapa de melhoria de uma solução viável obtida anteriormente. Assim como no trabalho anterior, as heurísticas estudadas incorporam componentes de custo de forma a corrigir as distorções de custo de longo prazo decorrentes da aplicação repetida de um modelo de curto prazo, e baseiam-se em trocas de atendimentos entre rotas e/ou dias. Sete tipos de trocas são consideradas, abrangendo todas as possibilidades de inserção, remoção ou troca de 1 ou 2 atendimentos entre rotas.

Na primeira heurística, a cada iteração é realizada a troca que resulte na maior redução de custo. Em outras palavras, essa é uma heurística míope do tipo guloso ("greedy"), que realiza apenas um movimento por iteração, até que não seja mais possível a ealização de trocas que acarretem redução de custo. Por sua vez, a segunda heurística busca realizar a cada iteração o conjunto de trocas que resulte na maior redução de custo. Para tanto, as trocas realizadas devem ser independentes, isto é, a realização de uma troca não afeta as rotas envolvidas nas demais trocas, e a determinação dessas trocas é feita por meio da resolução de um problema de emparelhamento ("maximum weight matching problem"). 
O desempenho das heurísticas foi testado no mesmo conjunto de nstâncias reais utilizado por DROR; BALL (1987), sendo reportada melhoria da ordem de 52\% em relação às soluções obtidas pelo modelo original. Os autores afirmam ainda que, embora conceitualmente mais atrativa, a segunda heurística não apresentou resultados significativamente melhores que a heurística do tipo "guloso", não havendo indicação de uma superioridade de uma em relação à outra.

CHIEN et al. (1989) estudaram um problema de distribuição de um estoque limitado de um produto a clientes geograficamente dispersos. Em decorrência da limitada disponibilidade do produto a ser distribuído, é admitida a possibilidade de atendimentos parciais, ou mesmo o não atendimento da demanda de todos clientes, casos em que incorre-se em uma penalidade proporcional à demanda não atendida. Cada unidade de demanda atendida proporciona uma receita, e são considerados componentes de custo proporcionais à distância e proporcionais à quantidade transportada. A distribuição é feita a partir de um único depósito por meio de frota heterogênea, e a função objetivo adotada busca maximizar o lucro, isto é, a diferença entre as receitas obtidas e a soma das penalidades incorridas e dos custos associados à distribuição.

Observe-se que o modelo proposto é de curto prazo, abrangendo um horizonte de planejamento de apenas um dia. Sendo concebido para utilização diária, considera-se que as penalidades, receitas e estoques iniciais sejam atualizados e corrigidos diariamente, de forma a minimizar as distorções no custo de longo prazo da distribuição decorrentes da utilização de um modelo de curto prazo.

A estratégia de solução proposta consiste em aplicar o método da Relaxação Lagrangiana ao problema original, que pode então ser decomposto em um subproblema de alocação de estoques e um subproblema de designação de clientes e utilização dos veículos. Fixado um conjunto de multiplicadores, ambos subproblemas podem ser reduzidos a instâncias do problema de mochila contínua e resolvidos facilmente. Os multiplicadores são então recalculados segundo um método de busca por subgradiente e o processo se repete até a que seja alcançado um critério de parada preestabelecido. A cada iteração o resultado do problema relaxado fornece um limitante superior da função objetivo do problema original, além das soluções 
dos subproblemas, que podem ser utilizadas em uma heurística de duas etapas. Essa heurística inicialmente constrói as rotas de distribuição diretamente a partir dos resultados dos subproblemas, posteriormente corrigindo as violações de capacidade decorrentes da relaxação do problema original e otimizando as quantidades entregues por meio de um processo de busca local. O resultado assim obtido pela aplicação da heurística pode ser entendido como um limitante inferior do problema original, e comparado com o limitante superior obtido pela resolução do problema relaxado, o que funciona como um indicador da qualidade da solução a cada iteração do processo. A heurística proposta foi testada em instâncias artificiais com até 30 clientes, geradas por computador, e os resultados obtidos confirmam a convergência do processo iterativo.

Um problema integrado de produção e distribuição de múltiplos itens para um conjunto geograficamente disperso de clientes foi estudado por CHANDRA (1993). São consideradas demandas variáveis e conhecidas, sendo a distribuição realizada por uma frota homogênea de veículos, sem restrição de disponibilidade de veículos. Busca-se a minimização conjunta dos custos fixos de produção, custos de estoque no fornecedor e nos clientes, assim como custos fixos e variáveis associados à distribuição dos produtos. Não há restrições de capacidade de estocagem nos clientes ou na unidade produtora.

A estratégia de solução apresentada consiste em uma heurística de duas etapas. $\mathrm{Na}$ primeira etapa é obtida uma solução inicial viável pela resolução independente do subproblema de planejamento da produção dos múltiplos itens e da resolução do subproblema de distribuição. Esse último se traduz na resolução de um conjunto de problemas de roteirização de veículos, seguida da consolidação das rotas obtidas de forma compatível com a programação da produção obtida anteriormente.

A segunda etapa da heurística consiste em modificar a programação dos atendimentos obtida na primeira etapa, permitindo uma reavaliação dos custos de planejamento da produção. Cada modificação (movimento) testa a consolidação temporal de entregas de dois dias distintos a um mesmo cliente. Cabe ressaltar que o modelo proposto permite mais de um atendimento por dia a um mesmo cliente, e a utilização de viagens dedicadas ("full truck load") a clientes cuja demanda seja 
superior à capacidade dos veículos. Essa característica favorece a obtenção de ganhos de escala e é fundamental para o processo de consolidação da segunda etapa da heurística.

Para reduzir o esforço computacional do processo, a cada iteração apenas um número preestabelecido de modificações que resultem nas maiores reduções de custo de distribuição é selecionado, e o subproblema de planejamento da produção é resolvido apenas para esse subconjunto de movimentos. $\mathrm{O}$ movimento que resulte na maior redução global de custo é então executado e o processo se repete enquanto houver movimentos que resultem em redução de custos.

A heurística proposta foi testada em instâncias geradas segundo diferentes características de capacidade dos veículos, horizonte de planejamento e relação entre custos fixos e variáveis de distribuição. Foram comparados os resultados obtidos pela aplicação da heurística em relação à solução obtida na primeira etapa, o que corresponde a comparar os modelos com e sem coordenação entre os subproblemas de planejamento de produção e distribuição. Os resultados indicam uma redução de até $11 \%$ decorrente da coordenação dos subproblemas.

O modelo de CHANDRA (1993) foi posteriormente estendido por CHANDRA; FISHER (1994), com a inclusão de restrições de capacidade de produção na unidade produtora, o que torna o subproblema de planejamento de produção um problema de lote de produção com restrições de capacidade (“capacitated lot size problem"). Adicionalmente, dois processos de consolidação foram testados na segunda etapa da heurística: o primeiro mantém fixo o resultado do subproblema de planejamento da produção, já o segundo permite alterações nas decisões de produção. Observa-se que, no primeiro caso os subproblemas de produção e distribuição são resolvidos de maneira independente, ao passo que no segundo caso a interação entre os resultados dos subproblemas de produção e distribuição permite uma melhor coordenação das funções e, por consequiência, menores custos globais.

A heurística proposta foi igualmente testada em instâncias geradas segundo diferentes características de capacidade de produção, capacidade dos veículos e relação entre custos fixos e variáveis de distribuição. Os resultados indicam que a 
redução de custos obtida pela coordenação dos subproblemas de produção e distribuição varia de $3 \%$ a $20 \%$, sendo que os maiores ganhos correspondem aos casos com restrições de capacidade de produção mais brandas e maior número de clientes e produtos.

Em uma extensão dos trabalhos de DROR; BALL (1987) e DROR; LEVY (1986), HERER; LEVY (1997) estudaram um PDEGF com uma estrutura de custos mais complexa, que inclui custos de manutenção de estoques, custos de pedido, custos de falta do produto e custos fixos de transporte, não considerados no modelo original. A heurística proposta tem como idéia central a definição de uma "distância temporal" entre dois atendimentos, calculada a partir da diferença dos custos de manutenção de estoques, pedido e falta de estoque entre as situações de realização dos atendimentos em dias distintos ou em um mesmo dia. As "distâncias temporais" assim calculadas, juntamente com as distâncias geográficas entre os cliente, são utilizadas para formar as rotas de distribuição, por meio do conhecido método de economias de CLARKE; WRIGHT (1964).

A heurística proposta foi testada em um conjunto de instâncias geradas por computador e os resultados comparados com a aplicação de uma heurística de duas etapas, do tipo proposto por DROR; BALL (1987), em que os dias de atendimento e as rotas de distribuição são determinados seqüencialmente e de maneira independente. Os resultados indicam a superioridade da heurística proposta, especialmente nos cenários com maior consumo diário, o que pode ser atribuído ao fato de que a coordenação temporal das entregas adquire maior importância nos casos em que a freqüência de atendimento é maior.

Uma interessante variante do PDEGF é estudada por BARD et al. (1998), que tratam do caso em que os veículos de distribuição, conquanto partindo de um depósito principal e devendo retornar ao mesmo, podem ser reabastecidos em depósitos satélites ao longo das rotas. Considera-se que a demanda dos clientes é aleatória e obedece a uma distribuição de probabilidade conhecida, não havendo restrições de capacidade nos depósitos. A frota de distribuição é homogênea e a estratégia de solução proposta consiste em uma heurística de cinco etapas, inserida em uma 
estrutura de replanejamento contínuo, com a utilização de um horizonte de planejamento deslocável.

A primeira etapa da heurística consiste em determinar quais clientes incluir no planejamento, o que é realizado a partir do cálculo do intervalo ótimo de reabastecimento de cada cliente. São incluídos no planejamento apenas os clientes cujo intervalo ótimo de reabastecimento seja menor que o período de planejamento, além daqueles para os quais se espera a ocorrência de falta de estoque, caso não sejam reabastecidos.

A segunda etapa consiste em determinar qual o dia de atendimento de cada cliente, de forma a balancear a demanda ao longo do período de planejamento e minimizar o acréscimo de custo. Essa etapa corresponde à resolução de um problema de designação generalizado ("generalized assignment problem") com a inclusão de restrições que estipulam o mínimo e o máximo da demanda para cada dia de atendimento.

Definidos os atendimentos de cada dia do horizonte de planejamento, a terceira etapa consiste em determinar as rotas de distribuição, o que corresponde à resolução de um conjunto de problemas de roteirização de veículos com instalações satélites. Três heurísticas desenvolvidas para o problema de roteirização de veículos foram adaptadas e testadas para esse caso: a conhecida heurística de economias de CLARKE; WRIGHT (1964), a heurística GRASP ("greedy randomized adaptative search procedure") de KONTORAVDIS; BARD (1995) e a heurística de varredura de GILLETT; MILLER (1974). As etapas subsequentes correspondem a um processo de melhoria das rotas por meio de trocas de atendimentos intra-rotas e inter-rotas, e à aplicação de uma etapa de melhoria baseada na troca do dia de atendimento dos clientes.

A heurística proposta foi testada em instâncias geradas por computador, com até 500 clientes e 5 instalações satélites. Os resultados indicam que a heurística adaptada de CLARKE; WRIGHT (1964) é claramente superior às demais heurísticas testadas para a etapa de roteirização, embora seu tempo de processamento seja até três vezes maior. Os autores indicam ainda que as etapas de melhoria correspondem ao maior 
esforço computacional, sendo reportado o tempo total de processamento de quase 2 horas para a resolução de uma instância de 500 clientes em um computador SUN Sparcstation 10.

Um problema integrado de produção e distribuição de múltiplos itens foi estudado por FUMERO; VERCELLIS (1999), que consideram clientes geograficamente dispersos com demandas variáveis e conhecidas. A produção dos diversos itens é limitada pela disponibilidade de recursos no depósito, e não há restrições de capacidade de estocagem nos clientes ou na unidade produtora. A distribuição é realizada por meio de uma frota homogênea de veículos, sendo permitido o fracionamento dos atendimentos em mais de um veículo. Ou seja, em um dado dia, parte dos itens destinados a um dado cliente pode ser transportada por um determinado veículo, e os demais itens transportados em veículo(s) distinto(s).

Duas estratégias de solução são apresentadas pelos autores: a aplicação do método da Relaxação Lagrangiana e uma heurística baseada na decomposição do problema original. A primeira abordagem envolve a relaxação de um conjunto de restrições do modelo, o que permite a decomposição do problema original em um conjunto de subproblemas mais simples, sendo que a determinação dos multiplicadores se dá por um método de busca por subgradiente. A segunda abordagem considera a decomposição do problema original em um subproblema de planejamento da produção e um subproblema de distribuição. O subproblema de planejamento da produção é resolvido de forma exata, sendo esse resultado utilizado para a resolução do subproblema de distribuição. Note-se que, nesse caso, as decisões de produção e distribuição não são coordenadas, como ocorre na primeira abordagem proposta pelos autores.

LAU et al. (2000) estudaram uma cadeia de distribuição em que diversos fornecedores abastecem um depósito com um conjunto de produtos, que são posteriormente distribuídos por frota homogênea a um conjunto de clientes geograficamente dispersos e sujeitos a restrições temporais do tipo "janela de atendimento". O problema considera a minimização conjunta dos custos de estoque nos clientes e no depósito, assim como os custos decorrentes dos pedidos pendentes dos clientes ("backlogging") e os custos de transporte envolvidos. 
A estratégia de solução proposta consiste em decompor o problema em dois subproblemas que são resolvidos iterativamente. $\mathrm{O}$ primeiro subproblema corresponde a um problema de lote ótimo de produção dinâmico, e o segundo corresponde a um problema de roteirização de veículos com restrições de janelas de tempo. Os autores afirmam que a chave para o sucesso da estratégia proposta é a definição de uma adequada interface entre os subproblemas, de modo que sua iteração seja colaborativa e a convergência global do processo assegurada.

Para a resolução do primeiro subproblema é proposta a utilização de uma heurística baseada em busca tabu, não sendo informados detalhes sobre a implementação utilizada para o segundo subproblema. A estratégia proposta foi testada em um conjunto de instâncias adaptadas de casos de roteirização de veículos com restrições de janela de tempo e os resultados reportados confirmam a esperada convergência do processo, embora não sejam suficientemente detalhados para permitir uma avaliação mais objetiva da qualidade das soluções obtidas.

Uma estratégia de solução pouco usual foi utilizada por LAO; LEONG (2002) para a resolução do problema de distribuição de um produto a um conjunto de clientes geograficamente dispersos, sendo considerados os custos associados à manutenção de estoque nos clientes, assim como os custos de transporte. A abordagem proposta baseia-se em uma estrutura computacional multiagente, em que cada agente representa um elemento (rota, cliente ou atendimento) envolvido no problema. Cada agente possui um conjunto de operadores que lhe permite interagir com os demais agentes do problema, e busca maximizar uma função objetivo própria. Como as funções objetivo são eminentemente míopes, as operações realizadas por diferentes agentes são freqüentemente conflitantes, podendo inclusive resultar em violações de restrições. Essa característica conflituosa da interação dos diversos agentes é compensada por meio de um mecanismo de controle similar ao utilizado no método "simulated annealing", em que a probabilidade de aceitação de operações que violem restrições decresce ao decorrer do processo de busca. Segundo os autores, tal estrutura proporciona um híbrido de cooperação e competição entre os agentes, favorável à resolução de um problema de otimização global como o PDEGF. 
A heurística proposta foi testada em um conjunto de 80 instâncias geradas por computador e os resultados comparados com a aplicação da heurística de política de partição fixa originalmente proposta por CHAN et al. (1998), sendo obtida uma redução média de custo de cerca de $13 \%$. Segundo os autores, a heurística de CHAN et al. (1998) prioriza a alocação dos estoques, obtendo melhores resultados nas instâncias em que o custo de manutenção dos estoques é mais significativo, ao passo que a heurística proposta apresenta um comportamento mais robusto e consistente, considerando-se o conjunto de instâncias testadas.

CAMPBELL et al. (2002) apresentam uma estratégia de resolução do PDEGF, aplicada com sucesso à distribuição de gases industriais, que também se vale da decomposição do problema em duas etapas. A primeira etapa consiste na determinação das quantidades e dias das entregas aos clientes, e a segunda etapa trata da programação e roteirização das entregas determinadas na etapa anterior para cada dia do horizonte de planejamento. Dessa forma, o problema é decomposto em um problema de programação inteira mista (primeira etapa), cuja resolução será utilizada como dado de entrada para um conjunto de problemas de roteirização e programação de veículos com restrições de janela de tempo (segunda etapa).

Os autores propõem a utilização de "clusters" e de agregação temporal como forma de redução da complexidade do problema tratado na primeira etapa. A agregação de clientes em "clusters" busca considerar a proximidade espacial e compatibilidade de capacidade de estoque e taxa de consumo, de forma a reduzir o espaço de busca de clientes que possam ser atendidos num mesmo dia por um mesmo veículo. Já a agregação temporal busca reduzir o número de variáveis do problema de programação inteira mista considerando períodos de tempo mais agregados no final do horizonte de planejamento.

Um aspecto interessante da abordagem apresentada é que, na segunda etapa, as rotas de distribuição são construídas de forma a manter a soma das quantidades planejadas na primeira etapa para entrega nos dois primeiros dias do horizonte de planejamento, entretanto sem se ater às quantidades planejadas para cada dia em particular. Essa flexibilidade facilita a incorporação de pedidos adicionais e correções decorrentes de variações nas previsões de demanda, sem no entanto perder de vista os resultados 
obtidos na primeira etapa, que considera a distribuição ao longo de todo o horizonte de planejamento. A abordagem proposta foi aplicada pelos autores a casos reais de um distribuidor de gases industriais nos Estados Unidos, sendo reportado um incremento de até cerca de $11 \%$ nos indicadores de quantidade transportada por distância, em relação à prática comum de planejamento e roteirização da empresa.

BERTAZZI et al. (2002) estudaram o PDEGF com um único veículo, demanda constante e aplicação de uma política de reabastecimento com reposição integral do estoque a cada atendimento, ou seja, não são permitidos atendimentos parciais que não restaurem o nível máximo do estoque em um cliente. Essa abordagem simplifica o problema, uma vez que, ao se determinar quando o cliente será atendido, a quantidade a ser entregue fica definida automaticamente. A estratégia de solução proposta consiste em uma heurística de duas etapas: construção de uma solução inicial viável e uma etapa de melhoria.

A construção da solução inicial consiste em inserir seqüencialmente os clientes não programados na solução em construção. Nesse contexto, entende-se por inserção de um cliente a determinação do(s) melhor(es) dia(s) de atendimento desse cliente e respectiva(s) rota(s) de entrega. A ordem com que são realizadas as inserções está associada a um critério de urgência, baseado na relação entre a capacidade de estoque e na taxa de consumo de cada cliente. A determinação da inserção de menor custo de um cliente é realizada com o auxílio de um grafo orientado acíclico, construído de forma que a obtenção da combinação de atendimentos de menor custo corresponda à resolução de um problema de caminho mínimo no grafo. Esse processo é repetido, segundo a ordem de inserção determinada, até que todos os clientes tenham sido inseridos na solução em construção. A etapa de melhoria baseiase no mesmo procedimento de inserção utilizado na obtenção da solução inicial, e consiste em retirar e reinserir dois clientes da solução. Esse processo é repetido até que não seja possível obter redução do custo da solução.

A heurística foi aplicada a um conjunto de problemas gerados por computador, sendo comparado seu desempenho com o de duas estratégias práticas de reabastecimento. Os resultados mais interessantes, no entanto, advêm da comparação de diferentes componentes de custo na função objetivo considerada. A consideração ou não das 
componentes de estoque no fornecedor e no cliente refletem situações práticas de falta de comunicação e coordenação na cadeia de suprimentos e o modelo proposto permite avaliar os impactos decorrentes de tal situação com a utilização da política de reabastecimento adotada.

Mais recentemente, esse modelo foi estendido por BERTAZZI et al. (2005) com a inclusão dos aspectos de planejamento da produção e estoque no fornecedor, além da utilização de uma frota homogênea de veículos na distribuição. São considerados no modelo os custos de produção, estoque no fornecedor, distribuição e estoque nos clientes. Os custos de produção incluem uma parcela fixa por lote de produção e uma parcela proporcional à quantidade produzida. De forma similar, os custos de transporte incluem uma parcela fixa por veículo utilizado no período de planejamento e uma parcela proporcional à distância percorrida nas rotas de distribuição. Note-se que esse problema seria classificado por SARMIENTO; NAGI (1999) como um problema de produção-estoque-distribuição-estoque, uma vez que abrange decisões relativas à produção, além das decisões de estocagem e transporte.

Duas políticas de reabastecimento são exploradas: reposição integral do estoque a cada atendimento, e reabastecimentos do tipo "fill-fill-dump". No primeiro caso, cada reabastecimento repõe o estoque máximo do cliente atendido, ao passo que, no segundo caso, essa exigência é relaxada para o último cliente da rota. Nesse caso, a quantidade entregue ao último cliente depende da quantidade de produto disponível no veículo, que pode ser menor que a quantidade que restaura o nível máximo de estoque no último cliente.

Para a política de reposição integral dos estoques são propostas duas heurísticas, que valem-se da separação do problema original em dois subproblemas mais simples, que correspondem ao planejamento da produção e ao planejamento da distribuição propriamente dita. São analisadas ainda duas decomposições alternativas do problema original, que diferem pela incorporação dos custos variáveis da produção no primeiro ou segundo subproblema, conforme a decomposição adotada. A primeira heurística consiste em: 
a) Resolver o subproblema de planejamento da produção considerando-se entregas diárias a todos os clientes;

b) Resolver o subproblema de planejamento da distribuição, a partir do planejamento da produção obtido no item a);

c) Resolver novamente o subproblema de planejamento da produção, a partir do planejamento da distribuição obtido no item b).

E a segunda heurística consiste em:

a) Resolver o subproblema de planejamento da distribuição, considerando-se que a produção é suficiente para atender entregas diárias a todos os clientes;

b) Resolver o subproblema de planejamento da produção, a partir do planejamento da distribuição obtido no item b).

Demonstra-se que, com a obtenção da solução ótima dos subproblemas considerados, o custo da solução obtida com a aplicação da primeira heurística é igual ao obtido com a aplicação da segunda heurística, razão pela qual os autores descartam a primeira heurística e as análises subsequentes são realizadas apenas com a aplicação da segunda heurística. Entretanto, observe-se que apenas o primeiro subproblema é resolvido de maneira ótima, sendo a resolução do subproblema de planejamento da distribuição feita por meio de uma heurística de inserção. Uma segunda etapa da heurística consiste em um processo de melhoria, em que a programação de atendimentos de dois clientes é sistematicamente removida e reinserida no planejamento de atendimentos, segundo o processo proposto por BERTAZZI et al. (2002), sendo o processo repetido até que não seja mais possível obter redução do custo.

A heurística foi testada em um conjunto de instâncias geradas em computador, e os resultados indicam que a decomposição que considera os custos variáveis de produção no primeiro subproblema gera melhores resultados que a segunda decomposição. Um segundo teste foi realizado comparando-se a heurística com a estratégia de reabastecimento tradicional, do tipo "pull", em que os clientes solicitam 
atendimento na iminência da ocorrência de falta de estoque. Nesse caso, os resultados indicam que a heurística obtém uma redução de custo da ordem de 50\%, principalmente devido à diminuição dos custos de distribuição. E finalmente, a comparação entre a política de reabastecimento de reposição integral e a política do tipo "fill-fill-dump" indica uma redução de custos da ordem de $1 \%$ em favor da última.

COUSINEAU-OUMIET (2002) apresenta uma heurística para o PDEGF baseada na metaheurística busca tabu. A abordagem utilizada consiste em uma adaptação da heurística desenvolvida por CORDEAU et al. (1997) para os problemas de roteirização periódica de veículos, caixeiro viajante periódico e o problema de roteirização de veículos com múltiplos depósitos. A heurística apresentada está inserida em um contexto de horizonte de planejamento deslocável, em que o problema é resolvido para dois períodos de planejamento, mas apenas o primeiro período é efetivamente implementado. Ao término deste, o horizonte de planejamento é deslocado de um período, sendo novamente realizados o planejamento e a roteirização para os dois períodos seguintes, e assim sucessivamente. A heurística foi testada em uma adaptação das instâncias apresentadas por CHAO et al. (1995) para o problema de roteirização periódica de veículos, assim como em uma adaptação do conjunto de instâncias apresentadas por BERTAZZI et al. (2002) para o caso com um único veículo. Embora a autora tenha ressaltado que a comparação direta de tais resultados não seja rigorosa, os resultados obtidos foram em média apenas $1,58 \%$ discrepantes daqueles obtidos por BERTAZZI et al. (2002).

LEE et al. (2003) estudaram o problema de abastecimento de uma montadora do setor automotivo por um conjunto de fornecedores dispersos geograficamente. Cada fornecedor produz um determinado tipo de componente, e as coletas são realizadas por uma frota homogênea de veículos, baseados em um depósito, geograficamente distinto da planta de montagem. São considerados os custos fixos e variáveis de transporte, assim como os custos de manutenção dos estoques na planta de montagem, e busca-se a determinação do planejamento de abastecimento de forma a minimizar o custo total decorrente. É considerado um limite para a extensão das rotas 
e são permitidas coletas fracionadas, isto é, a coleta dos componentes de um fornecedor em um determinado dia pode ser realizada por mais de um veículo. Observe-se que o problema trata da coleta de um produto, e não de sua distribuição, como é o caso mais comum do PDEFG. Entretanto, do ponto de vista matemático, os dois problemas são equivalentes.

A estratégia de solução proposta consiste em um processo de duas etapas, em que inicialmente é construída uma programação viável de coleta, que serve de ponto de partida para a segunda etapa de melhoria, baseada na metaheurística "simulated annealing". A primeira etapa utiliza uma adaptação da conhecida heurística de varredura de GILLETT; MILLER (1974) para gerar uma solução inicial viável. A subsequente etapa de melhoria utiliza duas classes de movimentos para definir a vizinhança a ser explorada. A primeira classe de movimentos consiste em separar uma rota em duas ou adicionar um atendimento a uma rota, aumentando as combinações de atendimentos viáveis, e de forma inversa, a segunda classe de movimentos consiste na remoção de um atendimento de uma rota. Em ambos casos, determinado o conjunto de rotas, o subproblema de determinação da quantidade a ser coletada em cada fornecedor passa a ser um problema de programação linear, que pode ser resolvido com o auxílio de softwares comerciais de otimização. A seleção dos movimentos a ser executada é guiada por uma metaheurística do tipo "simulated annealing", em que a aceitação de movimentos que resultem em aumento de custo é probabilística, e essa probabilidade decresce ao decorrer do processo de busca.

Um exemplo numérico é apresentado para ilustrar o desempenho da heurística proposta, sendo os resultados obtidos comparados com a solução exata do modelo de programação inteira mista correspondente. Segundo os autores, só foi possível obter solução exata para instâncias de no máximo 6 fornecedores e 7 instantes de planejamento. Para essas instâncias, a heurística proposta apresentou um acréscimo de custo da ordem de 1,1\% em relação à solução ótima correspondente.

Um algoritmo para otimização da quantidade entregue por rota no contexto do PDEGF foi proposto por CAMPBELL; SAVELSBERGH (2004). O problema consiste em determinar os horários e quantidades de cada atendimento, dada uma roteirização das entregas preestabelecida, de forma a maximizar a quantidade de 
produto entregue aos clientes, respeitando-se as restrições de estoque dos clientes e capacidade dos veículos. Observe-se que, esse procedimento por si só não constitui uma estratégia de solução do problema, mas foi desenvolvido para ser utilizado como uma etapa de processamento em uma heurística mais abrangente.

Tipicamente, o modelo recebe como dados de entrada um conjunto de rotas viáveis, a janela de tempo em que cada cliente pode receber a entrega, a taxa de descarga e capacidade dos veículos utilizados, e eventualmente a duração máxima das rotas. Algumas variações do modelo principal são consideradas, com a inclusão de taxas de descarga distintas para cada cliente ou variáveis em função do horário da entrega. Observa-se que a quantidade possível de ser entregue a um cliente depende da combinação de restrições atuantes, em particular, da capacidade do veículo, capacidade de armazenamento do cliente e da programação do cliente subsequente. Os autores demonstram que a solução ótima do problema é obtida percorrendo-se a rota no sentido inverso da seqüência de atendimentos, redefinido-se, a cada cliente, o instante de atendimento de forma a maximizar a quantidade entregue e respeitar as restrições existentes.

Segundo os autores, o problema abordado é original, e não há na literatura métodos alternativos de resolução que possam ser utilizados na comparação com o algoritmo proposto, o que levou ao desenvolvimento de um conjunto de heurísticas simples para comparação, a saber:

- seguindo a seqüência de atendimento, entregar tão cedo quanto seja possível, respeitando-se as restrições decorrentes da programação dos clientes predecessores;

- seguindo a seqüência de atendimento, entregar tão tarde quanto seja possível, respeitando-se as restrições decorrentes da programação dos clientes predecessores;

- seguindo a seqüência de atendimento, entregar o máximo possível, respeitando-se as restrições decorrentes da programação dos clientes predecessores; 
- entregar o máximo possível segundo a ordem decrescente de taxas de consumo dos clientes, respeitando-se as restrições decorrentes da programação dos clientes anteriormente programados.

O algoritmo proposto, assim como as heurísticas acima apresentadas, foram testados em instâncias adaptadas de situações reais de distribuição de gases industriais. A comparação dos resultados indica que o método proposto domina as heurísticas testadas, apresentando resultados no mínimo 4\% melhores que os obtidos com as heurísticas.

SAVELSBERGH; SONG (2005) abordaram uma variação do problema de distribuição de um único produto em que se relaxa a restrição que obriga os veículos retornar ao depósito ao final de cada dia de trabalho. Dessa forma, são permitidas rotas abertas, em que a localização geográfica dos pontos inicial e final pode ser distinta, e é possível efetuar múltiplos reabastecimentos do veículo durante o dia. O reabastecimento pode ser realizado em qualquer uma das plantas de produção, sendo conhecidos para cada planta o estoque inicial e a respectiva taxa de produção. Segundo os autores, as características particulares do modelo refletem a situação encontrada na distribuição de alguns tipos de gases industriais em que a distribuição se dá em grandes áreas.

A estratégia de solução proposta consiste em uma heurística de duas etapas: na primeira etapa é determinada a programação e roteirização das entregas, e na segunda etapa há uma otimização dos volumes entregues, relaxando-se restrições de quantidades mínimas de entrega e preservando as rotas definidas na etapa anterior. Três heurísticas de inserção foram testadas para a primeira etapa e os melhores resultados foram obtidos com a utilização do método GRASP ("greedy randomized adaptive search procedure") em que, a cada iteração, o cliente a ser atendido é sorteado de uma lista de clientes com maior urgência em receber atendimento, isto é, clientes que incorrerão primeiro em falta de estoque. A idéia do método é flexibilizar a escolha dos atendimentos no processo de construção das rotas de atendimento, aumentando a chance de se encontrar uma melhor solução ao final do processo. $\mathrm{O}$ processo é repetido um número preestabelecido de vezes, e a melhor solução 
encontrada ao longo das iterações é adotada como dado de entrada para a segunda etapa da heurística.

A segunda etapa consiste na resolução de um problema de programação linear que busca maximizar a quantidade entregue, preservando a roteirização encontrada na primeira etapa. Esta etapa reflete a utilização de indicadores de produtividade que relacionam a quantidade entregue com a distância percorrida, encontrados na distribuição de gases industriais analisada pelos autores.

A heurística foi testada em instâncias adaptadas de situações reais de distribuição de gases industriais, provando ser efetiva na resolução do problema em questão. Um interessante resultado foi a constatação de que, a introdução da etapa de otimização das quantidades entregues, aplicada em um modelo de curto prazo com horizonte de planejamento deslocável, pode levar à redução de custos a longo prazo. Segundo os autores, esse comportamento se deve provavelmente ao fato de que a otimização das quantidades entregues no modelo de curto prazo aumenta a eficiência com que o atendimento dos clientes é realizado. Os resultados obtidos indicam ainda que a redução de custo a longo prazo com a introdução da etapa de otimização das quantidades entregues é de cerca de $2 \%$ em relação à alternativa sem otimização.

\subsection{Considerações Finais}

A análise dos trabalhos comentados na revisão bibliográfica, em especial dos trabalhos de classificação, permite constatar que a integração de decisões de estocagem, transporte e, eventualmente, planejamento da produção, gera não um único problema, mas sim toda uma família de problemas, similar ao que se observa em relação aos modelos de roteirização e programação de veículos. Observa-se que não há uma nomenclatura ou classificação amplamente aceita e reconhecida, como se pode inferir da comparação dos trabalhos de BAITA et al. (1998) e SARMIENTO; NAGI (1999). Embora a denominação problema de estoque-roteirização seja até certo ponto freqüentemente encontrada na bibliografia, nota-se que, via de regra, ela é aplicada a problemas distintos e em geral relacionados de alguma forma com o trabalho de DROR; BALL (1987), que cunharam o termo. 
Para enfatizar a principal característica do sistema logístico em estudo, que é justamente a centralização da gestão da distribuição nas mãos do fornecedor, optou-se por utilizar no presente trabalho o termo problema de distribuição com estoques geridos pelo fornecedor (PDEGF) para designar genericamente essa classe de problemas.

Adicionalmente, algumas observações podem ser realizadas a partir da revisão realizada:

- Em última instância, o PDEGF é um problema eminentemente estocástico, uma vez que o conhecimento preciso do consumo que gera a demanda a ser atendida em cada cliente é a exceção, e não a regra em casos reais de distribuição. Entretanto, modelos que consideram a demanda determinística não são irreais, visto que o comportamento estocástico pode ser absorvido, por exemplo, pela introdução de um estoque de segurança. Vale ainda lembrar que modelos estocásticos em geral requerem grande quantidade de dados históricos, nem sempre disponíveis, além do adequado tratamento estatístico. Sob essa ótica, modelos de demanda determinística apresentam grande aplicabilidade prática, como se pode verificar pelo sucesso de seu emprego em problemas reais encontrados na literatura.

- Dentre os modelos com demanda determinística, os modelos de instante de atendimento permitem ratar situações em que a demanda não é constante, diferentemente dos modelos de freqüência de atendimento. Dessa forma, podem ser utilizados conjuntamente com um modelo exógeno de previsão de demanda, e assim considerar variações da demanda tais como sazonalidade.

- A aplicação dos modelos de instante de atendimento dentro de um horizonte de planejamento de longo prazo (tipicamente 1 ano) não é viável do ponto de vista prático, devido ao grande número de variáveis envolvidas. Por esse motivo, tais modelos são aplicados apenas a horizontes de curto prazo (tipicamente dias ou semanas), e a forma mais comum de contornar as distorções decorrentes é considerar o horizonte de planejamento deslocável. 
- Mesmo dentro de um horizonte de curto prazo, os modelos de instante de atendimento freqüentemente fazem uso de alguma estratégia de decomposição do problema em etapas ou subproblemas, o que permite sua aplicação a instâncias de maior porte, porém ao preço de uma redução da qualidade do resultado obtido.

- Dada a complexidade do problema, é comum a adoção de alguma política de reabastecimento, como por exemplo a partição fixa dos clientes ou a reposição integral dos estoques a cada reabastecimento. Naturalmente, a adoção de tais simplificações tem seu custo em termos da qualidade da solução possível de ser obtida, desvantagem essa que é geralmente compensada pela praticidade e facilidade que se obtém no gerenciamento da distribuição.

- Pode-se afirmar que o PDEGF pertence à classe de problemas "NP-hard", uma vez que um de seus subproblemas, o problema de roteirização de veículos o é (LENSTRA; RINNOOY KAN, 1981), e portanto é improvável que existam algoritmos exatos que o resolvam em tempo polinomial. Por esse motivo, métodos exatos de resolução são encontrados apenas em poucos casos particulares, em geral nos modelos em que a demanda é estável e há apenas entregas diretas fornecedor-consumidor. Modelos que envolvem roteirização, via de regra, fazem uso de alguma heurística para tal.

Considerando-se a bibliografia analisada, verifica-se que os sistemas logísticos do tipo EGF buscam conciliar duas funções conflitantes, tradicionalmente tratadas de maneira separada pelas empresas, o que contribui para a integração e otimização da cadeia de distribuição como um todo. Nesse sentido, BALLOU (1998) afirma que a integração do controle de estoques e distribuição física impõe restrições cada vez mais rígidas às funções de produção e distribuição das empresas, e que pode-se esperar no futuro uma integração ainda maior de ambas. Isso sinaliza uma tendência de integração dos modelos ainda mais abrangente que a otimização conjunta do estoque e da roteirização, com a incorporação de aspectos da produção, não encontrados, salvo poucas exceções, nos modelos aqui analisados. 
Uma última consideração pode ainda ser feita em relação aos modelos encontrados na literatura. Embora tenham crescente utilização em problemas de natureza combinatória, tais como planejamento da produção ou roteirização de veículos, são raras as aplicações de metaheurísticas encontradas na bibliografia pesquisada.

A título de comparação, um resumo dos principais modelos de freqüência de atendimento e modelos de instante de atendimento é apresentado nos Quadros $2.4 \mathrm{e}$ 2.5, podendo-se notar que a consideração de parcelas de custos e de restrições de capacidade é significativamente distinta, mesmo entre modelos de uma mesma categoria.

QUADRO 2.4 - Resumo dos principais modelos de freqüência de atendimento

\begin{tabular}{|l|c|c|c|c|c|c|c|}
\hline \multicolumn{1}{|c|}{ Autor(es) } & Ano & Topologia & Itens & Demanda & Capacidade & $\begin{array}{c}\text { Custo } \\
\text { Estoque }\end{array}$ & $\begin{array}{c}\text { Custo } \\
\text { Distrib. }\end{array}$ \\
\hline Blu menfeld et al. & 1985 & M-M & M & CI & VC & MP & C \\
Burns et al. & 1985 & U-M & U & CD & V & M & FDC \\
Blumenfeld et al. & 1987 & M-M & U & CD & V & M & C \\
Larson & 1988 & U-M & U & CD & VC & & F \\
Benjamin & 1989 & M-M & U & CD & VD & MP & D \\
Anily; Federgruen & 1990 & U-M & U & CD & V & M & FD \\
Gallego; Simchi-Levi & 1990 & U-U & U & CD & V & MP & D \\
Anily; Federgruen & 1993 & U-M & U & CD & VD & MP & FD \\
Anily & 1994 & U-M & U & CD & V & M & FD \\
Speranza; Ukovich & 1994 & U-U & M & CD & V & M & C \\
Bramel; Simchi-Levi & 1995 & U-M & U & CD & V & MP & D \\
Webb; Larson & 1995 & U-M & U & CD & VC & & F \\
Bertazzi et al. & 1997 & U-M & M & CD & V & M & D \\
Bertazzi; Speranza & 2002 & U-U & M & CD & V & M & C \\
\hline
\end{tabular}


QUADRO 2.5 - Resumo dos principais modelos de instante de atendimento

\begin{tabular}{|l|c|c|c|c|c|c|c|}
\hline \multicolumn{1}{|c|}{ Autor(es) } & Ano & Topologia & Itens & Demanda & Capacidade & $\begin{array}{c}\text { Custo } \\
\text { Estoque }\end{array}$ & $\begin{array}{c}\text { Custo } \\
\text { Distrib. }\end{array}$ \\
\hline Bell et al. & 1983 & U-M & U & VD & VC & & FD \\
Dror; Levy & 1986 & U-M & U & VD & V & FP & D \\
Dror; Ball & 1987 & U-M & U & VD & VC & FP & D \\
Chien et al. & 1989 & U-M & U & CD & VD & F & DQ \\
Chandra & 1993 & U-M & M & VD & PV & MP & FD \\
Chandra; Fisher & 1994 & U-M & M & VD & V & MP & FD \\
Blanchini et al. & $1996 \mathrm{a}$ & M-M & U & VD & PDC & & \\
Herer; Levy & 1997 & U-M & U & VD & VC & MFP & FD \\
Bard et al. & 1998 & M-M & U & VD & VC & FP & D \\
Fumero; Vercellis & 1999 & U-M & M & VD & PV & MP & FDQ \\
Lau et al. & 2000 & U-M & M & VD & VDC & MF & D \\
Lao; Leong & 2002 & U-M & U & CD & VC & M & FD \\
Campbell et al. & 2002 & U-M & U & CD & VC & & D \\
Lee et al. & 2003 & M-U & U & VD & V & M & FD \\
Savelsbergh; Song & 2005 & M-M & U & CD & VC & & D \\
Bertazzi et al. & 2005 & U-M & U & VD & VC & MP & FD \\
\hline
\end{tabular}

onde:

$$
\begin{array}{ll}
\text { topologia/itens: } & \mathrm{U}=\text { um, } \\
& \mathrm{M}=\text { muitos; } \\
\text { demanda (tempo): } & \mathrm{C}=\text { constante, } \\
& \mathrm{V}=\text { variável; } \\
\text { demanda (distrib.): } & \mathrm{I}=\text { igual para todos clientes, } \\
& \mathrm{D}=\text { diferente para cada cliente; } \\
& \mathrm{P}=\text { produção, } \\
\text { capacidade: } & \mathrm{V}=\text { veículos, } \\
& \mathrm{D}=\text { depósito, } \\
& \mathrm{C}=\text { clientes; } \\
& \mathrm{M}=\text { manutenção ("holding"), } \\
\text { custos (estoque): } & \mathrm{F}=\text { falta, } \\
& \mathrm{P}=\text { pedido } / \text { "setup"; } \\
& \mathrm{F}=\text { fixo, } \\
\text { custos (distrib.): } & \mathrm{D}=\text { proporcional à distância, } \\
& \mathrm{C}=\text { proporcional ao número de clientes, } \\
\mathrm{Q}=\text { proporcional à quantidade transportada. }
\end{array}
$$




\section{FORMULAÇÃO MATEMÁTICA}

\subsection{Introdução}

Este capítulo tem por objetivo apresentar a formulação matemática do modelo proposto para o problema de distribuição com estoques geridos pelo fornecedor (PDEGF), envolvendo decisões de planejamento de produção, gestão de estoques e roteirização de veículos. Em outras palavras, a resolução do problema envolve as seguintes decisões inter-relacionadas:

- quando e quanto produzir;

- quando atender cada cliente;

- quanto fornecer do produto quando o cliente é atendido;

- que rotas seguir para o atendimento dos clientes.

As decisões de quando e quanto produzir caracterizam o planejamento da produção; já as de quando atender e quanto fornecer caracterizam a gestão dos estoques dos clientes; e, finalmente, as decisões associadas às rotas caracterizam a programação dos veículos para entrega. Assim, o PDEGF envolve simultaneamente três tipos de subproblemas: um subproblema de planejamento de produção, um subproblema de reposição de estoques e um subproblema de roteirização de veículos.

Considerados separadamente, cada um desses problemas apresenta extensa bibliografia e métodos de resolução consagrados. Entretanto, a sua resolução de forma seqüencial e isolada não é possível, pois os mesmos são inter-relacionados e as possíveis decisões interdependentes, o que requer uma abordagem integrada para a sua resolução de maneira ótima.

Como observado na revisão bibliográfica apresentada anteriormente, dada a complexidade desse tipo de problema, é usual a adoção de algum tipo de política de reabastecimento simplificadora. No presente trabalho será adotada uma política de reabastecimento de reposição integral dos estoques dos clientes; em outras palavras, 
cada entrega a um cliente repõe integralmente o estoque máximo permitido para o mesmo, e a decisão de quanto entregar a cada cliente passa a ser condicionada pela decisão de quando o cliente é atendido.

\subsection{Definições Iniciais}

Seja $N=\{1,2, \ldots,|N|\}$ o conjunto dos pontos de atendimento (clientes), e $S=N \bigcup\{0\}$ a união do conjunto $N$ com o ponto 0 , a partir do qual será feita a distribuição de um único produto. No presente problema, o ponto 0 , denominado depósito, corresponde ao local onde é fabricado o produto a ser distribuído, e de onde partem os veículos que realizam as entregas.

Seja $T=\{1,2, \ldots,|T|\}$ o período de planejamento, medido em dias. Para cada cliente $i \in N$ é conhecido o consumo diário $r_{i}^{t}$ do produto em cada dia $t \in T$. Note-se que, embora determinística, a demanda assim definida não é necessariamente constante ao longo do período de planejamento, podendo ser estimada a partir de um modelo de previsão de demanda que incorpore sazonalidades ou outras peculiaridades do consumo dos clientes em questão.

Estoques são permitidos em todos os clientes, sendo conhecidos para cada cliente $i \in N$ o estoque inicial $I_{i}^{0}$, o estoque mínimo admissível $L_{i}$, o estoque máximo admissível $U_{i}$ e o custo unitário diário de manutenção de estoque $h_{i}$.

A fabricação do produto acarreta um custo fixo de preparação ("setup") $K$, por dia em que ocorre produção, e um custo unitário $p$, por unidade produzida. Assume-se que as quantidades produzidas em um determinado dia possam ser entregues aos clientes no mesmo dia em que são produzidas. Cabe notar que, embora a terminologia adotada faça referência a um processo de fabricação, a mesma formulação se aplica ao caso em que o produto a ser distribuído é adquirido pelo distribuidor. Nesse caso, o custo de preparação corresponde ao custo de pedido, e o custo $p$ corresponde ao custo por unidade adquirida. De maneira similar aos clientes, é permitido estoque no depósito, muito embora não haja restrição de estoque máximo 
nesse caso. São conhecidos ainda o estoque inicial no depósito $B^{0}$, e o custo unitário diário de manutenção de estoque no depósito $h_{0}$.

Para o atendimento da demanda, o depósito dispõe de uma frota heterogênea de veículos, representada pelo conjunto $V=\{1,2, \ldots,|V|\}$; para cada veículo $v \in V$ são conhecidos o custo fixo para o período de planejamento $C_{f}^{v}$, o custo unitário variável com a distância $C_{d}^{v}$ e a capacidade de carga $Q^{v}$.

Note-se que o custo fixo dos veículos é incidente considerando-se a totalidade do horizonte de planejamento. Em outras palavras, incorre-se nesse custo caso o veículo seja utilizado em algum dia durante o período de planejamento. Ao deslocamento de um veículo de um ponto $i \in S$ até um ponto $j \in S, i \neq j$, associa-se a distância $d_{i j}$.

A formulação matemática do problema compreende as seguintes variáveis de decisão:

$Y^{t}= \begin{cases}1, & \text { se há produção no dia } t \in T \\ 0, & \text { caso contrário }\end{cases}$

$y^{t}=$ quantidade produzida no dia $t \in T$

$x_{i j}^{v t}= \begin{cases}1, & \text { se o ponto } j \in S \text { é visitado após o ponto } i \in S \text { pelo veículo } v \in V \text { no dia } t \in T \\ 0, & \text { caso contrário }\end{cases}$

$z_{i}^{v t}=$ quantidade fornecida ao cliente $i \in N$ no dia $t \in T$ pelo veículo $v \in V$

$F^{v}= \begin{cases}1, & \text { se veículo } v \in V \text { é utilizado em algum dia do período de planejamento } \\ 0, & \text { caso contrário }\end{cases}$

Definem-se ainda:

$B^{t}=$ estoque no depósito no dia $t \in T ;$

$I_{i}^{t}=\quad$ estoque no cliente $i \in N$ no dia $t \in T$;

$M=$ um número suficientemente grande (por exemplo, $M=\sum_{i \in N} \sum_{t \in T} r_{i}^{t}$ ). 
Adicionalmente, para conveniência da notação, são definidos o conjunto solução $s=\left\{x_{i j}^{v t}\right\} \cup\left\{z_{i}^{v t}\right\} \cup\left\{y^{t}\right\} \cup\left\{Y^{t}\right\} \cup\left\{F^{v}\right\}$, correspondente à união de todas as variáveis de decisão do problema, e $C(s)$ o custo dessa solução.

\subsection{Modelo Matemático}

Dadas as definições anteriores, pode-se formular o problema de distribuição com estoques geridos pelo fornecedor (PDEGF) com frota heterogênea de veículos, objeto do presente trabalho. Esse modelo corresponde a uma extensão que busca generalizar o modelo proposto por BERTAZZI et al. (2005), diferenciando-se deste por considerar a utilização de frota heterogênea, composta de veículos com diferentes características operacionais, tanto em termos de custo quanto de capacidade.

O modelo matemático pode ser escrito como:

\section{$[\mathrm{PDEGF}]$}

Minimizar $\quad C(s)=$

$$
K \sum_{t \in T} Y^{t}+p \sum_{t \in T} y^{t}+
$$

$$
\sum_{v \in V}\left(C_{f}^{v} \cdot F^{v}\right)+\sum_{t \in T} \sum_{v \in V} \sum_{i \in S} \sum_{j \in S}\left(C_{d}^{v} \cdot d_{i j} \cdot x_{i j}^{v t}\right)+
$$

$h_{0} \sum_{t \in T} B^{t}+\sum_{t \in T} \sum_{i \in N}\left(h_{i} \cdot I_{i}^{t}\right)$

sujeito a:

$$
\begin{array}{ll}
\sum_{i \in S} x_{i k}^{v t}-\sum_{j \in S} x_{k j}^{v t}=0 & , k \in N, \quad v \in V, \quad t \in T \\
\sum_{j \in N} x_{0 j}^{v t} \leq 1 & , v \in V, \quad t \in T
\end{array}
$$




$$
\begin{aligned}
& \sum_{v \in V} \sum_{j \in S} x_{i j}^{v t} \leq 1 \quad, i \in N, \quad t \in T \\
& \sum_{i \in N^{\prime}} \sum_{j \in N^{\prime}} x_{i j}^{v t} \leq\left|N^{\prime}\right|-1 \quad, v \in V, \quad t \in T, \quad N^{\prime} \subseteq N, \quad\left|N^{\prime}\right| \geq 2 \\
& F^{v} \geq \sum_{j \in N} x_{0 j}^{v t} \quad, v \in V, \quad t \in T \\
& \sum_{i \in N} z_{i}^{v t} \leq Q_{v} \quad, v \in V, \quad t \in T \\
& I_{i}^{t}=I_{i}^{t-1}+\sum_{v \in V} z_{i}^{v t}-r_{i}^{t} \quad, i \in N, \quad t \in T \\
& I_{i}^{t} \geq L_{i} \quad, i \in N, \quad t \in T \\
& I_{i}^{t} \leq U_{i} \quad, i \in N, \quad t \in T \\
& \sum_{v \in V} z_{i}^{v t} \geq\left(U_{i}+r_{i}^{t}\right) \sum_{j \in S} \sum_{v \in V} x_{i j}^{v t}-I_{i}^{t-1}, i \in N, \quad t \in T \\
& \sum_{v \in V} z_{i}^{v t} \leq\left(U_{i}+r_{i}^{t}\right) \sum_{j \in S} \sum_{v \in V} x_{i j}^{v t} \quad, i \in N, \quad t \in T \\
& B^{t}=B^{t-1}+y^{t}-\sum_{v \in V} \sum_{i \in N} z_{i}^{v t} \quad, t \in T \\
& y^{t} \leq Y^{t} \cdot M \quad, t \in T \\
& B^{t} \geq 0 \quad, t \in T \\
& y^{t} \geq 0 \quad, t \in T \\
& z_{i}^{v t} \geq 0 \quad, i \in N, \quad v \in V, \quad t \in T \\
& Y^{t} \in\{0,1\} \quad, t \in T \\
& x_{i j}^{v t} \in\{0,1\} \quad, i \in S, \quad j \in S, \quad v \in V, \quad t \in T
\end{aligned}
$$


$F^{v} \in\{0,1\}$

,$v \in V$

A função objetivo (1) requer que o custo total de distribuição seja minimizado. Esse custo é formado por seis parcelas: custo fixo de produção, custo variável de produção, custo de utilização da frota, custo de deslocamento dos veículos, custo de manutenção do estoque no depósito e custo de manutenção dos estoques nos clientes.

As restrições (2) e (3) asseguram, respectivamente, a continuidade das rotas, e que cada veículo não possa ser utilizado em mais que uma rota por dia. As restrições (4) impõem que um dado cliente não possa receber mais que um atendimento por dia, e as restrições (5) asseguram a não formação de sub-rotas, isto é, ciclos fechados desconectados do depósito. Essas restrições são análogas às restrições de eliminação de sub-rotas encontradas no tradicional problema de roteirização de veículos (CHRISTOFIDES; 1985), e garantem que as variáveis $x_{i j}^{v t}$ definam, para cada veículo $v$ e em cada dia $t$, um percurso contínuo que inicia e termina no depósito. As restrições (6) garantem a compatibilidade entre as variáveis de indicação de utilização dos veículos e as rotas, e as restrições (7) asseguram o respeito às restrições de capacidade dos veículos utilizados.

As restrições (8) impõem que, para cada cliente, o estoque em um dado dia do período de planejamento seja igual ao estoque do dia anterior, somado à quantidade entregue ao cliente no dia em questão, e subtraído da quantidade consumida nesse mesmo dia. Isto é, essa restrição garante a continuidade do estoque nos clientes ao longo do período de planejamento e assegura a compatibilidade entre as quantidades entregues e a demanda de cada cliente. As restrições (9) e (10) garantem o respeito aos limites inferior e superior dos estoques dos clientes.

Por sua vez, as restrições (11) e (12) asseguram a aplicação da política de reabastecimento adotada de reposição integral dos estoques dos clientes. Essas restrições podem ser melhor entendidas ao se notar que o atendimento a um cliente $i \in N$ em um determinado dia $t \in T$ corresponde a $\sum_{j \in S} \sum_{v \in V} x_{i j}^{v t}=1$. Nesse caso, as restrições (11) impõem que a quantidade a ser entregue deve ser maior ou igual a 
$U_{i}+r_{i}^{t}-I_{i}^{t-1}$, isto é, maior ou igual à diferença entre o estoque máximo e o estoque do dia anterior, somado à demanda do dia $t$ em questão. Essa desigualdade, entretanto, torna-se uma equação ao ser considerada em conjunto com as restrições (8) e (10), uma vez que a reposição de uma quantidade maior que $U_{i}+r_{i}^{t}-I_{i}^{t-1}$ acarretaria a violação do limite máximo de estoque para esse cliente.

No caso inverso, em que não há atendimento ao cliente $i \in N$ no dia $t \in T$, as restrições (12) asseguram que a quantidade entregue seja menor ou igual a zero, o que efetivamente força essa quantidade a zero, uma vez que não são permitidas entregas de quantidades negativas (restrição 17). Dessa maneira, mais que garantir a aplicação da política de reabastecimento adotada, as restrições (11) e (12) asseguram a compatibilidade entre as decisões de roteirização e reabastecimento dos clientes, representadas pelas variáveis $x_{i j}^{v t} \mathrm{e} z_{i}^{v t}$, respectivamente.

De forma similar às restrições (8), as restrições (13) impõem que, em um dado dia do período de planejamento, o estoque do depósito seja igual ao estoque do dia anterior, somado à quantidade produzida no dia em questão e subtraído da quantidade distribuída nesse mesmo dia, garantindo a continuidade do estoque no depósito ao longo do período de planejamento. Adicionalmente, a compatibilidade entre as variáveis de indicação de produção e as quantidades produzidas no depósito é assegurada pelas restrições (14).

A restrições (15) e (16) impõem, respectivamente, que o estoque no depósito não seja negativo e a não negatividade das quantidades produzidas. Por fim, as restrições (17) asseguram a não negatividade das quantidades distribuídas, e as restrições (18) a (20) garantem a integralidade da solução.

\subsection{Comentários}

O modelo apresentado foi desenvolvido como uma extensão do modelo proposto por BERTAZZI et al. (2005), diferenciando-se deste por considerar a utilização de frota heterogênea, composta de veículos com diferentes características operacionais, tanto em termos de custo quanto de capacidade. Cabe notar ainda que, no modelo apresentado originalmente por esses autores, algumas restrições estão representadas 
de forma não-linear. Tais restrições foram substituídas no presente trabalho por restrições lineares equivalentes, o que possibilitou a validação do modelo matemático e a resolução de instâncias de pequeno porte com o auxílio do software de programação matemática ILOG CPLEX 9.2.

Como visto anteriormente, modelos com características similares ao apresentado podem ser encontrados em CHANDRA (1993), CHANDRA; FISHER (1994) e FUMERO; VERCELLIS (1999), que tratam da distribuição de múltiplos produtos. Entretanto, nesses trabalhos não é considerada a possibilidade da frota de veículos ser heterogênea, como ocorre no modelo proposto. Vale ressaltar ainda que o presente modelo considera a distribuição de apenas um único produto, situação típica encontrada na distribuição de combustíveis ou gases industriais, em que a adoção da política de reabastecimento de reposição integral dos estoques dos clientes não é incomum.

Note-se que o modelo não permite a ocorrência de faltas, mesmo que limitadas em termos de quantidade ou período de tempo. Iniciativas de colaboração e integração de cadeias de suprimentos envolvem o desenvolvimento de relações de confiança entre seus participantes, o que pode ser comprometido pela ocorrência de faltas nos clientes. Vale recordar ainda que, no caso da distribuição de combustíveis, o desabastecimento pode acarretar prejuízos de grande monta, dependendo do processo produtivo envolvido. Um exemplo dessa situação é o caso das indústrias de vidro e cerâmica, em que o desligamento de um forno por falta de combustível acarretaria enormes prejuízos.

Segundo CRAINIC; LAPORTE (1997), os modelos de planejamento de transporte podem ser classificados em estratégicos, táticos ou operacionais. Modelos de localização de terminais e de desenho da rede de distribuição são exemplos de modelos estratégicos. Já os modelos táticos envolvem horizontes de planejamento de médio prazo e decisões de nível de serviço, alocação de recursos e política de atendimento, entre outras. Finalmente, os modelos operacionais consideram horizontes de planejamento de curto prazo e tipicamente tratam da determinação de roteiros e programação de equipes e atividades, em geral em um ambiente dinâmico em que o fator tempo tem papel fundamental. Uma classificação similar pode ser 
encontrada em HERER; LEVY (1997), que citam o dimensionamento e a determinação do "mix" da frota como exemplos de decisões de nível tático. Entretanto, ao analisar um problema integrado de estoque e roteirização, os autores afirmam que as decisões táticas e operacionais estão fortemente relacionadas, e em geral não devem ser tomadas de forma independente.

A inclusão de uma parcela de custo fixo da frota na função objetivo do modelo apresentado possibilita justamente essa interação entre as decisões operacionais de roteirização e programação de entregas e as decisões táticas de dimensionamento e composição da frota. Vale notar que, em alguns casos, a economia decorrente da redução de frota pode ser significativamente maior que a economia obtida com a redução de custos variáveis, fazendo com que essa última se torne um objetivo secundário da aplicação do modelo. No caso do modelo aqui proposto, a inclusão da parcela referente ao custo fixo da frota de distribuição também se justifica por estabelecer uma base de comparação compatível com os resultados obtidos por BERTAZZI et al. (2005), que será objeto do Capítulo 7.

Ao classificar os modelos integrados de produção e distribuição, CHEN (2004) denomina modelos táticos aqueles que envolvem decisões agregadas, tais como quantidade a ser produzida ou nível de estoque a ser mantido. Em contrapartida, modelos que envolvem decisões mais detalhadas, tais como programação das máquinas utilizadas na produção ou rotas de distribuição são denominados modelos operacionais. Nesse sentido, pode-se afirmar que o modelo apresentado possui características tanto táticas como operacionais. Pelo ponto de vista do planejamento da produção, o modelo pode ser classificado como tático, uma vez que as variáveis envolvidas representam decisões agregadas de produção. Já pela ótica do planejamento da distribuição, o modelo pode ser classificado como primordialmente operacional, por envolver decisões desagregadas de roteirização, muito embora também seja considerada a decisão tática de dimensionamento e composição da frota, como comentado anteriormente.

Observe-se que o modelo proposto apresenta considerável flexibilidade, permitindo a representação de distintos sistemas logísticos do tipo EGF por meio de uma adequada configuração dos custos considerados. Como exemplo, pode-se citar o caso 
em que a decisão tática de dimensionamento da frota já foi tomada a priori ou o caso em que o custo de produção não recai sobre o agente responsável pela distribuição. Em ambos casos, o modelo proposto pode ser utilizado, bastando zerar os coeficientes de custo fixo dos veículos ou os custos de produção no modelo, conforme o caso.

No que toca à complexidade do problema, é fácil perceber que, no caso extremo de horizonte de planejamento unitário $(|T|=1)$, o PDEGF reduz-se ao conhecido problema de roteirização de veículos, o que permite afirmar que o PDEGF também pertence à classe de problemas " $N P$-hard", sendo portanto improvável que existam algoritmos exatos que permitam a sua resolução em tempo polinomial.

Considerando-se ainda que instâncias reais do problema tipicamente envolvem horizontes de planejamento de dezenas de dias e o atendimento de dezenas de clientes, é razoável supor que pacotes comerciais sejam capazes de resolver de maneira exata apenas instâncias reduzidas do problema. Essa suposição foi corroborada por experimentos realizados com o software de programação matemática ILOG CPLEX 9.2, que se mostrou capaz de resolver instâncias com 5 clientes, 1 veículo e até 10 dias. Esse software, entretanto, não foi capaz de obter a solução exata para uma instância com 10 clientes, mesmo após cerca de 62 horas de processamento em um microcomputador Pentium IV de $2.66 \mathrm{GHz}$ com $1 \mathrm{~GB}$ de memória RAM.

Essa suposição é igualmente corroborada pelos resultados obtidos por ARCHETTI et al. (2004), que abordam uma versão do PDEGF sem programação de produção. Os autores reportam a resolução, com o software ILOG CPLEX 9.0, de instâncias com até 30 clientes, horizonte de planejamento de 6 dias e apenas um único veículo, para as quais foi registrado um tempo de processamento de cerca de 68 minutos em microcomputador Pentium IV de $2.8 \mathrm{GHz}$. No entanto, cabe ressaltar que, além da disponibilidade de um único veículo simplificar sobremaneira as decisões de roteirização, os autores valem-se nesse trabalho do artifício de incluir as restrições relativas à formação de sub-rotas de forma iterativa, à medida que estas sejam detectadas na solução. Isto é, inicialmente o modelo matemático é processado sem essas restrições. Verifica-se então a formação de sub-rotas na solução obtida, e as 
restrições correspondentes às violações observadas são adicionadas ao modelo. $\mathrm{O}$ modelo com as novas restrições é resolvido, e o processo se repete até que não haja mais violação de restrições de formação de sub-rotas, o que corresponde à solução ótima do modelo original.

Pelo considerável tempo de processamento e pela reduzida dimensão das instâncias para as quais é possível a obtenção de solução exata por meio de softwares de programação matemática, fica patente a necessidade da utilização de alguma heurística para a resolução de instâncias do PDEGF de maior dimensão, o que vem justamente a ser a motivação para o desenvolvimento das estratégias de solução apresentadas nos Capítulos 4, 5 e 6. 


\section{ESTRATÉGIAS DE SOLUÇÃO}

\subsection{Introdução}

Este capítulo tem por objetivo apresentar uma visão geral das estratégias de solução propostas para a solução do PDEGF com frota heterogênea, cuja formulação matemática foi apresentada no capítulo anterior. Essa visão geral objetiva descrever, de maneira sucinta, o funcionamento das heurísticas propostas e suas etapas constituintes, que serão posteriormente detalhadas nos Capítulos 5 e 6.

\subsection{Esquema Geral das Heurísticas Propostas}

São propostas quatro diferentes heurísticas de solução para o PDEGF. Cada uma delas pode ser classificada como uma heurística de duas etapas, em que inicialmente se obtém uma solução viável, que passa por um processo de melhoria na etapa subsequente. Essa abordagem de duas etapas é comum a diversas classes de heurísticas e está diretamente relacionada ao modo com que a etapa de melhoria funciona. Em geral, etapas de melhoria são baseadas em algum tipo de busca local através da exploração da vizinhança de uma solução corrente, e iterativamente transformam essa solução em outra, por meio de alterações em seus atributos. Em outras palavras, etapas de melhoria não criam soluções, mas sim transformam uma solução em outra, necessitando, portanto, de uma solução inicial para o início do processo.

No presente trabalho utiliza-se para a obtenção da solução inicial (etapa 1) uma adaptação da heurística proposta por BERTAZZI et al. (2005) para o PDEGF com frota homogênea, a qual se mostrou capaz de produzir soluções iniciais de boa qualidade em tempo de processamento reduzido.

Duas diferentes metaheurísticas foram testadas para a etapa 2, de melhoria: busca tabu e busca em vizinhança variável. Em conjunto, a combinação da heurística de 
obtenção da solução inicial com uma das etapas de melhoria consideradas resulta em duas heurísticas distintas. A primeira heurística, denominada EGF-BT, utiliza a metaheurística busca tabu na sua etapa de melhoria. De forma análoga, a segunda heurística, denominada EGF-BVV, utiliza a metaheurística busca em vizinhança variável na sua etapa de melhoria.

Duas variações da heurística EGF-BT também foram desenvolvidas. A primeira variação, denominada EGF-BT-D, utiliza um mecanismo de diversificação da busca, e a segunda variação, denominada EGF-BT-DI, incorpora mecanismos de diversificação e intensificação da busca.

Deve-se ressaltar que o mesmo procedimento de obtenção da solução inicial foi utilizado em todas as heurísticas testadas, o que permite afirmar que as diferenças dos resultados obtidos devem-se exclusivamente à etapa de melhoria de cada uma das heurísticas. A Figura 4.1 ilustra a estruturação das heurísticas propostas em termos de solução inicial e etapa de melhoria.

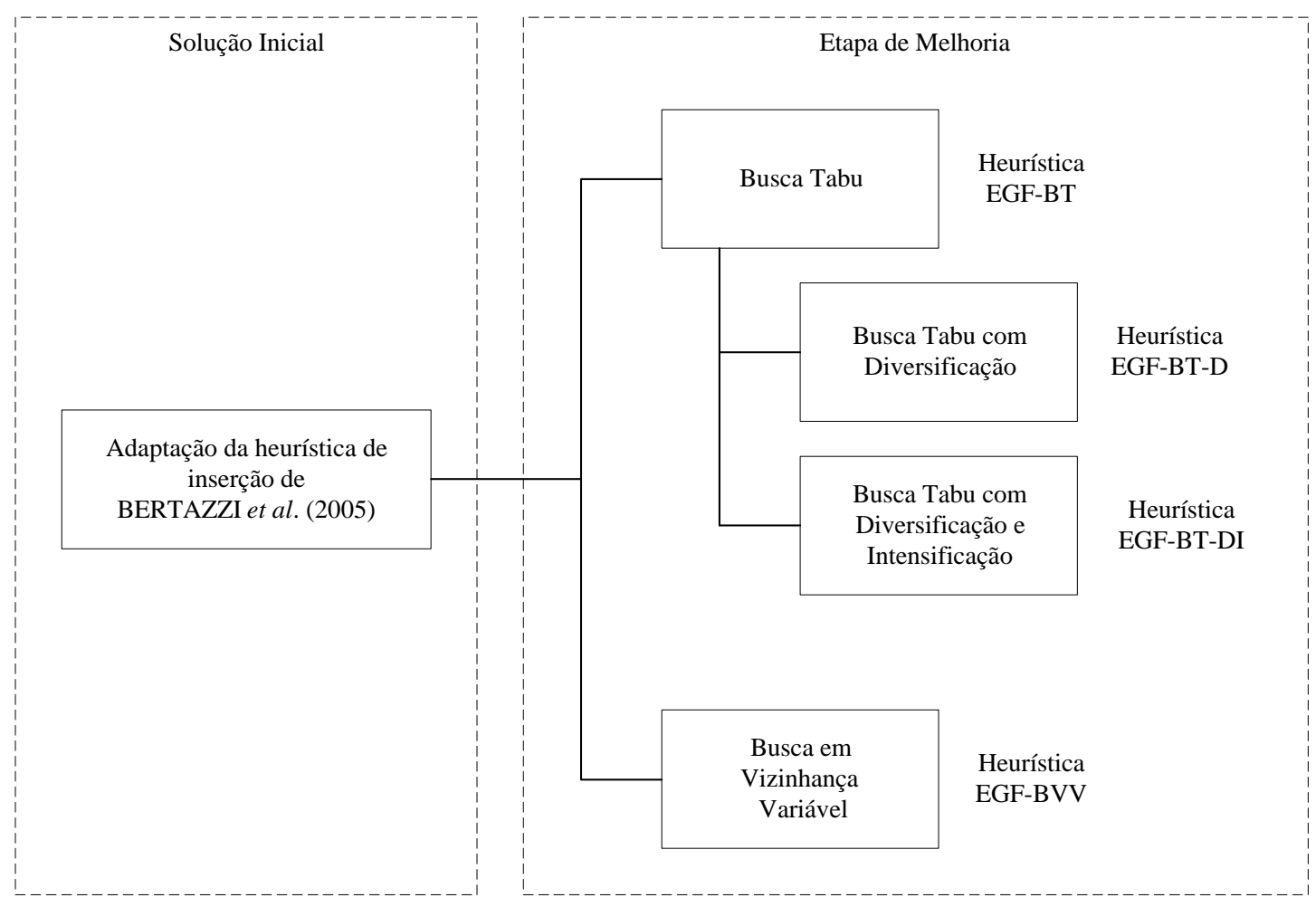

Figura 4.1 - Estruturação das heurísticas propostas 
A seção 4.3 tem por finalidade proporcionar uma visão geral do procedimento para a obtenção da solução inicial, enquanto que o funcionamento das metaheurísticas busca tabu e busca em vizinhança variável, utilizadas na etapa de melhoria, são descritos na seção 4.4 .

\subsection{Solução Inicial}

A etapa de obtenção da solução inicial corresponde a uma adaptação do procedimento proposto por BERTAZZI et al. (2005). Em linhas gerais, considera-se a decomposição do problema original em dois subproblemas: um de planejamento da distribuição (SPD) e um de planejamento da produção (SPP). Esses subproblemas são resolvidos de forma hierárquica e seqüencial: inicialmente resolve-se o subproblema de distribuição (SPD) e, com base nos resultados obtidos, resolve-se o subproblema de produção (SPP). A união das soluções obtidas para ambos subproblemas corresponde a uma solução do problema original.

Como o próprio nome sugere, o subproblema de planejamento da distribuição envolve a determinação dos dias de atendimento e das rotas de atendimento dos veículos. Devido à sua complexidade, a resolução do SPD requer uma heurística, que consiste na construção iterativa dos roteiros de distribuição por meio da inserção da programação dos clientes ainda não programados. Isto é, seleciona-se um cliente ainda não programado, determina-se a sua programação de atendimento de menor custo, e adiciona-se essa programação à programação em construção, sendo o processo repetido até que todos clientes tenham sido programados. Uma descrição pormenorizada do método adotado para a resolução do SPD será apresentada na seção 5.3 do Capítulo 5 .

A partir dos resultados obtidos pela resolução do SPD, pode-se proceder à resolução do SPP, que corresponde ao clássico problema de lote ótimo de produção dinâmico sem restrições de capacidade (“uncapacitated dynamic lot size problem”), formulado originalmente por WAGNER; WHITIN (1958). Esse subproblema envolve a determinação dos dias de produção e correspondentes quantidades a ser produzidas, podendo-se encontrar na literatura diversos algoritmos e heurísticas eficientes para a 
sua resolução. Uma descrição detalhada do método adotado para a resolução do SPP será apresentada na seção 5.4 do Capítulo 5.

Mesmo sem entrar em detalhes da resolução dos subproblemas, pode-se perceber que a ordem de seleção dos clientes para inserção, utilizada na resolução do SPD, é de central importância para a heurística descrita. Diferentes ordens de seleção dos clientes provavelmente corresponderão a diferentes soluções iniciais, uma vez que a determinação da programação de um cliente é realizada com base na programação parcial construída até o momento, constituída pelos atendimentos dos clientes previamente selecionados. Isso levanta a seguinte questão: qual a melhor ordem de seleção dos clientes para programação?

BERTAZZI et al. (2005) sugerem a utilização de um indicador que representa o número de dias que a demanda de cada cliente pode ser atendida exclusivamente com seu estoque inicial. Isto é, trata-se de um índice associado à urgência com que deve ser realizada a primeira entrega de cada cliente. Clientes com menor índice (maior urgência) devem ter prioridade sobre aqueles com maior índice (menor urgência), e a seleção é realizada segundo a ordem não decrescente dos índices calculados. Note-se, entretanto, que diversos clientes podem apresentar o mesmo valor para o índice proposto e, por conseguinte, pode ocorrer de diversas ordens de seleção dos clientes atenderem ao critério definido pelos autores.

Esse comportamento inspirou a introdução de uma adaptação no processo proposto por BERTAZZI et al. (2005), que consiste em selecionar aleatoriamente os clientes para inserção dentre uma lista reduzida de clientes candidatos, construída com base no índice de seleção originalmente proposto. Obtém-se assim uma nova seqüência de programação dos clientes, que são inseridos na solução em construção, correspondendo a uma (possivelmente) distinta resolução do SPD. Em seguida, resolve-se o SPP a partir da quantidade a ser entregue aos clientes, fornecida pela resolução do SPD. Esse processo é repetido um número predeterminado de vezes, e a melhor solução encontrada é utilizada como solução inicial para a etapa de melhoria subsequente. 
Em resumo, a principal diferença entre a etapa de obtenção da solução inicial aqui proposta e a adotada por BERTAZZI et al. (2005), reside no fato de que a estratégia proposta gera múltiplas soluções, ao passo que no trabalho de BERTAZZI et al. (2005) apenas uma solução inicial é gerada. A geração de múltiplas soluções baseia-se na seleção aleatória de clientes em uma lista reduzida, procedimento este inspirado nos conceitos do método GRASP ("greedy randomized adaptive search procedure"), sendo que a melhor solução obtida é adotada como solução inicial para a etapa subsequente de melhoria. $\mathrm{O}$ funcionamento do procedimento de obtenção da solução inicial é apresentado na Figura 4.2 em pseudo-linguagem estruturada.

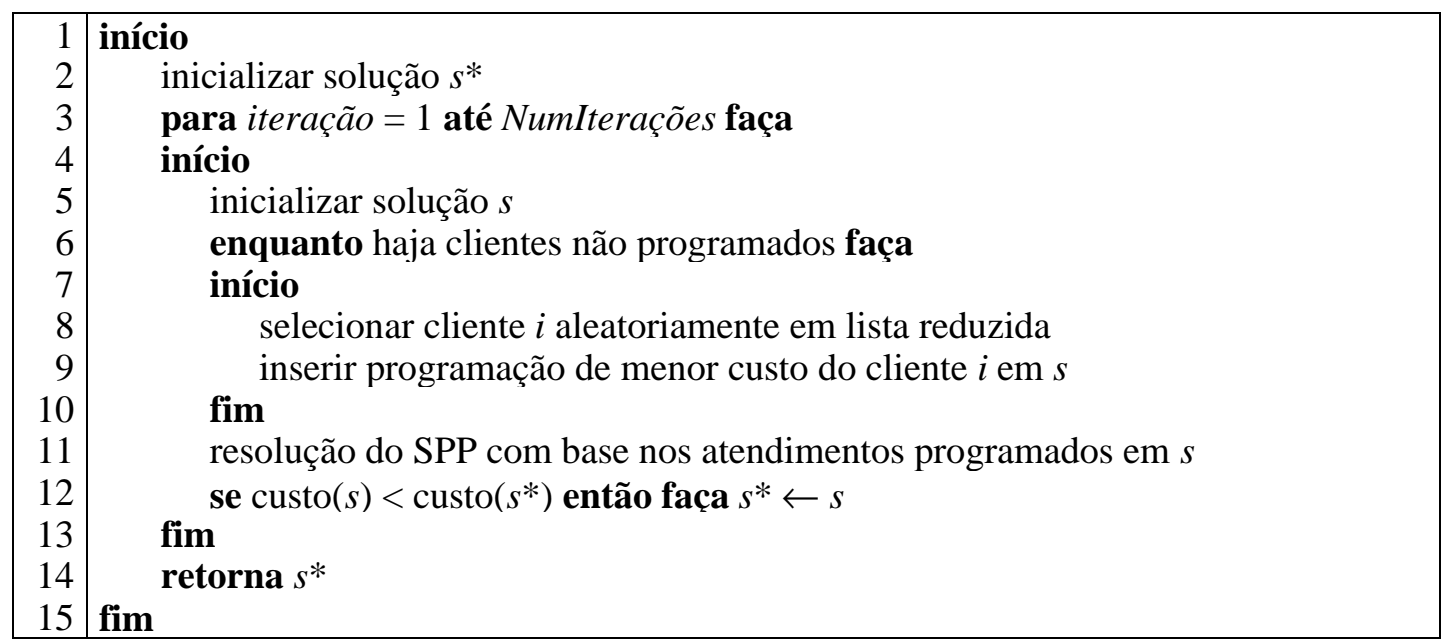

\section{Figura 4.2 - Funcionamento do procedimento de obtenção da solução inicial}

Pode-se notar que o procedimento é hierarquicamente constituído pela resolução do SPD (linhas 7 a 10), seguido pela resolução do SPP associado (linha 11), processo esse repetido um número predeterminado de vezes (linha 3). A cada iteração uma nova solução $s$ é obtida, que passa a ser a melhor solução $s^{*}$, caso seu custo seja menor que o custo da melhor solução encontrada até então (linha 12). Observe-se ainda que a inicialização da melhor solução (linha 2) pode ser realizada com a solução obtida pela resolução do SPD segundo a ordem de inserção originalmente proposta por BERTAZZI et al. (2005), seguida pela resolução do SPP correspondente. A solução inicial assim inicializada garante que a solução obtida ao final do processo seja, na pior das hipóteses, igual à solução obtida com a seqüência original de seleção de clientes. Uma descrição detalhada do processo de seleção de clientes será apresentada na seção 5.5 do Capítulo 5. 


\subsection{Etapa de Melhoria}

A partir da melhor solução inicial encontrada na primeira etapa, passa-se a uma etapa de melhoria. Conforme comentado anteriormente, as heurísticas propostas para a resolução do PDEGF utilizam a mesma solução inicial como ponto de partida para a etapa de melhoria, e diferenciam-se pelas características das metaheurísticas utilizadas nessa segunda etapa.

Duas metaheurísticas foram testadas na etapa de melhoria: busca tabu (BT) e busca em vizinhança variável (BVV). As seções a seguir apresentam uma descrição sucinta das suas características, assim como dos principais aspectos das implementações realizadas.

\subsubsection{Busca Tabu}

Originalmente desenvolvida por GLOVER (1986), busca tabu (BT) é uma metaheurística que tem como idéia central a utilização de estruturas adaptativas de memória para guiar uma heurística de busca local, direcionando a busca a regiões mais promissoras e evitando que o processo de busca fique preso a um mínimo local. Essa heurística de busca local baseia-se na exploração da vizinhança de uma solução, vizinhança essa definida por um conjunto de movimentos. Cada movimento transforma uma solução intermediária em outra, e a cada iteração um movimento da vizinhança é selecionado, sendo o processo repetido até se atingir um critério de parada. Ao alterar, a cada iteração, o conjunto de movimentos permitidos e suas respectivas avaliações, as estruturas de memória da BT atuam no ponto chave do processo, que vem a ser justamente a seleção dos movimentos ao longo da busca.

A principal característica da BT é a manutenção de uma lista de soluções (ou de atributos) que são consideradas proibidas (tabu) por um determinado número de iterações, denominada lista tabu. Isto é, após visitar uma solução, o processo de busca não pode retornar a essa mesma solução por um determinado número de iterações. Assim, evita-se que a busca fique presa a um mínimo local, já que essa solução, ao tornar-se tabu, força que outras soluções vizinhas sejam exploradas. Associado ao conceito de lista tabu, que nada mais é que uma memória de curta 
duração da busca realizada, está o conceito de critério de aspiração. Esse critério relaxa a aplicação da lista tabu, permitindo que movimentos proibidos possam ser executados, desde que atendam ao critério de aspiração. Em sua forma mais simples, esse critério permite a execução de um movimento tabu, desde que ele gere uma solução de menor custo que a melhor solução encontrada até então no processo de busca. Uma descrição em pseudo-linguagem estruturada do funcionamento da BT implementada no presente trabalho é apresentada na Figura 4.3. Note-se que $C(s)$ é a função de custo de uma solução $s$, definida pela expressão (1) do modelo matemático, e que $F(s)$ corresponde à função de avaliação de uma solução $s$, que será detalhada no Capítulo 6. Cabe comentar ainda que a implementação proposta considera um mecanismo de relaxação adaptativa, no qual soluções inviáveis são permitidas ao longo da busca, o que implica a utilização de penalidades por violação de restrições.

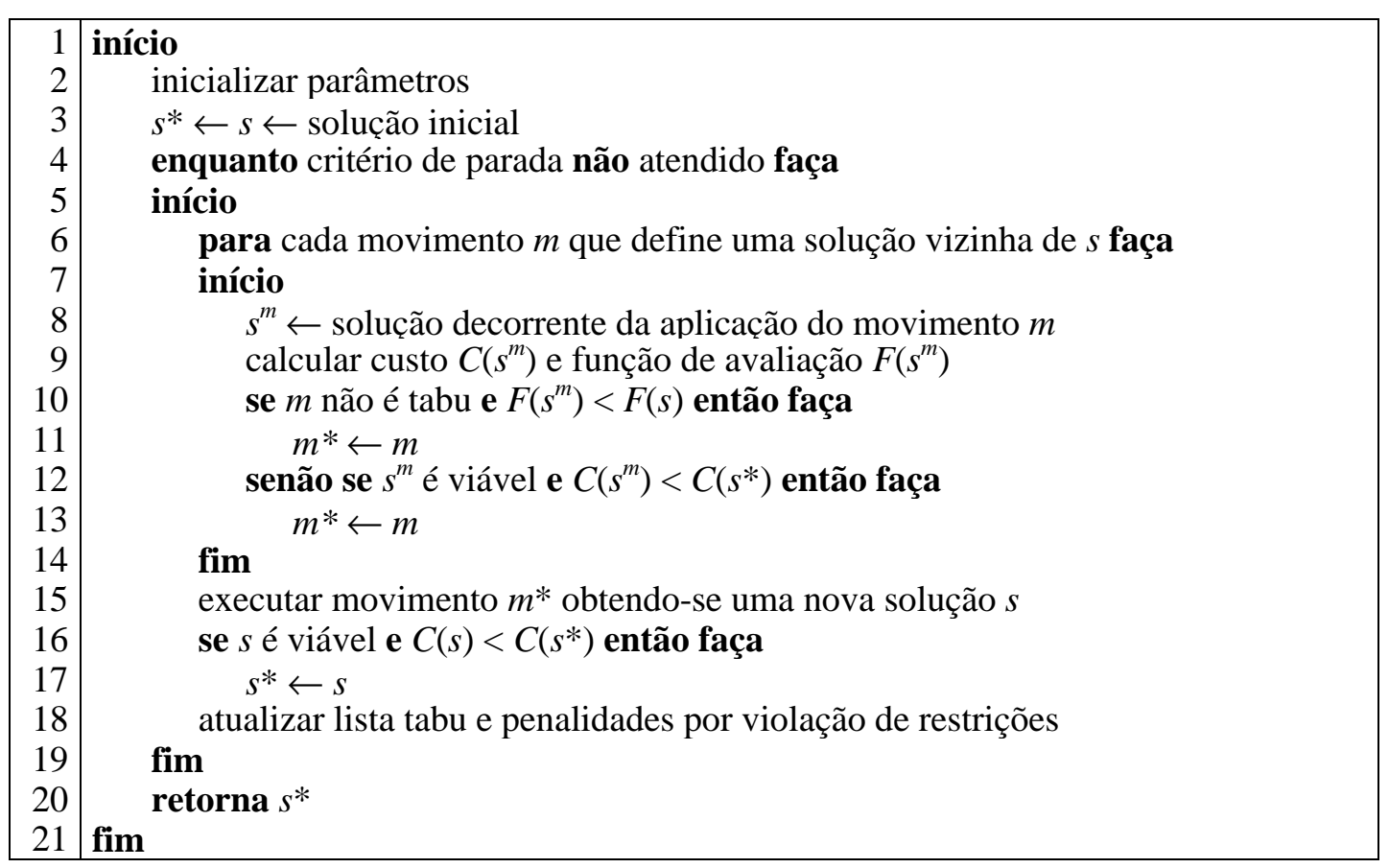

\section{Figura 4.3 - Funcionamento da metaheurística BT}

Observa-se que o procedimento baseia-se na exploração sistemática da vizinhança de uma solução intermediária $s$ (linha 6). Essa vizinhança é definida por um conjunto de movimentos, sendo alterada dinamicamente por meio da lista tabu. O movimento selecionado a cada iteração corresponde ao movimento não tabu de melhor avaliação (linhas 10 e 11), ou ao movimento tabu que atenda ao critério de aspiração (linhas 12 
e 13). O movimento selecionado é então executado (linha 15), obtendo-se uma nova solução $s$. A melhor solução é atualizada caso essa nova solução seja de menor custo (linhas 16 e 17), e são atualizadas a lista tabu e as penalidades por violação de restrições (linha 18), decorrentes do mecanismo de relaxação adaptativa adotado. Ao final do processo, é retornada a melhor solução $s^{*}$ (linha 20), que vem a ser justamente a solução final obtida pela etapa de melhoria.

Cabe ressaltar que a implementação proposta permite soluções não viáveis ao longo da trajetória de busca, e assim, para evitar que a busca permaneça presa a uma região inviável, as violações de restrições são penalizadas. Essas penalidades estão incorporadas à função de avaliação (linha 9), e ajustadas a cada iteração (linha 18), juntamente com a atualização da lista tabu. Essa característica propicia o desejável comportamento denominado oscilação estratégica, em que a região correspondente à fronteira de viabilidade do problema é explorada tanto a partir da região viável quanto inviável.

Conforme apresentado na seção 4.2, duas variações da metaheurística BT foram investigadas. A primeira envolve a utilização de um mecanismo de diversificação, incorporado à função de avaliação (linha 9), como forma de induzir o deslocamento para outra região do espaço de busca quando da estagnação do processo de busca normal. Na segunda variação, além do mecanismo de diversificação, ocorre o armazenamento de soluções de elite e o reinício da busca a partir dessas soluções armazenadas. Isto é, a etapa de melhoria é reiniciada sempre que a estagnação atingir um valor predeterminado, sendo a nova solução inicial (linha 3) escolhida dentre uma lista de soluções de elite, armazenadas ao longo da busca.

Outras características e mecanismos, além dos mencionados acima, podem ser encontrados em aplicações de BT, porém está além do escopo do presente trabalho uma discussão aprofundada desses aspectos. Ao leitor interessado, pode-se indicar os trabalhos de HERTZ et al. (1997), GLOVER; LAGUNA (1993), e GLOVER; LAGUNA (1997) que apresentam, além da descrição do funcionamento da metaheurística, uma ampla ilustração do seu potencial, ao comentar problemas aos quais a BT foi aplicada com sucesso. 
Uma descrição completa e detalhada da implementação da BT para o PDEGF será apresentada na seção 6.2 do Capítulo 6.

\subsubsection{Busca em Vizinhança Variável}

A busca em vizinhança variável (BVV) é uma metaheurística relativamente recente, originalmente proposta por MLADENOVIC; HANSEN (1997), e que explora a idéia de mudança de vizinhança como mecanismo de busca e escape de mínimos locais.

Como sua característica principal, a metaheurística BVV utiliza um conjunto ordenado e indexado de vizinhanças para a exploração do espaço de soluções. Em geral essas vizinhanças são indexadas e organizadas de maneira hierárquica, sendo as vizinhanças de maior índice construídas pelo progressivo acréscimo de novos movimentos à vizinhança de índice imediatamente inferior, o que pode ser visto como um processo de extensão das vizinhanças anteriores.

Segundo HANSEN; MLADENOVIC (2003), a BVV baseia-se em três princípios simples:

- Um mínimo local com relação a uma dada estrutura de vizinhança não corresponde necessariamente a um mínimo local com relação a uma outra estrutura de vizinhança;

- Um mínimo global corresponde a um mínimo local para todas estruturas de vizinhança possíveis;

- Para muitos problemas, mínimos locais com relação a uma ou mais estruturas de vizinhança são relativamente próximos.

Os autores afirmam que esse último princípio, de natureza empírica, indica que um mínimo local freqüentemente fornece algum tipo de informação sobre o mínimo global. Esse é o caso em que os mínimos local e global compartilham várias variáveis com o mesmo valor, o que sugere uma investigação sistemática da vizinhança de um mínimo local até a obtenção de uma nova solução de menor custo. 
Essa investigação da vizinhança de um mínimo local se dá pela seleção, geralmente aleatória, de uma solução da vizinhança ativa e sua subsequente avaliação. Caso essa solução seja de menor custo, a busca se desloca para esse novo mínimo local e o processo se repete; caso contrário, a vizinhança de índice imediatamente superior é selecionada, e todo o processo se repete até que seja atendido um critério de parada predeterminado. Obviamente, o número de vizinhanças considerado é limitado, assim, ao ser alcançada a vizinhança de maior índice, a busca retorna à primeira vizinhança e um novo ciclo de expansão da vizinhança ativa se inicia. Note-se que a expansão de uma vizinhança pode ser visto como um processo de intensificação da busca nas vizinhanças anteriores, uma vez que elas fazem parte da nova vizinhança.

Assim como ocorre na implementação da BT, aqui também são permitidas soluções intermediárias inviáveis, o que acarreta algumas alterações no funcionamento básico da BVV tal como é usualmente encontrado na literatura. Assim sendo, a solução base $\left(s_{\text {base }}\right)$ a partir da qual são definidas as vizinhanças pode se deslocar para a região inviável, o que é permitido quando não há soluções viáveis de menor custo na vizinhança. Nesse caso, a nova solução base passa a ser a solução de melhor função de avaliação $F(s)$, seja ela viável ou não. O funcionamento geral da BVV proposta para o PDEGF é apresentado a seguir na Figura 4.4.

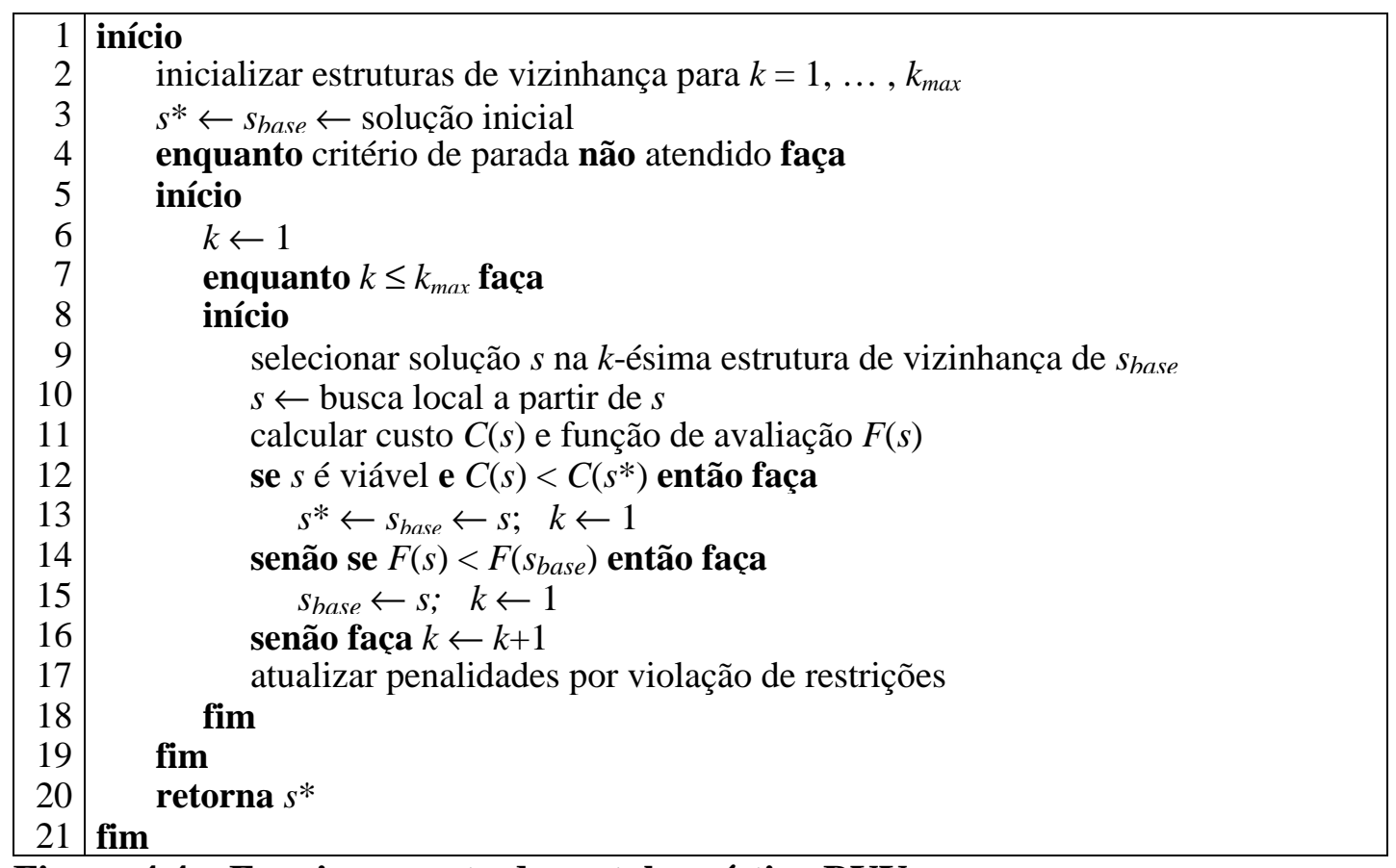

Figura 4.4 - Funcionamento da metaheurística BVV 
Como comentado anteriormente, a BVV baseia-se na definição das estruturas de vizinhança, indexadas de 1 a $k_{\max }$ (linha 2). A busca inicia-se com a vizinhança de índice 1 (linha 6), na qual uma solução é selecionada (linha 9), sendo em seguida melhorada por um processo de busca local (linha 10). Caso a solução obtida seja viável e de menor custo que a melhor solução já encontrada (linha 12), atualiza-se a melhor solução, que também passa a ser a solução base (linha 13). Caso contrário, se a solução obtida apresenta melhor avaliação que a solução base atual (linha 14), a solução base é atualizada (linha 15). Não ocorrendo modificação da solução base, a vizinhança correspondente ao índice seguinte é selecionada (linha 16) até que se atinja a vizinhança de índice $k_{\max }$ (linha 7). Nesse ponto, retorna-se à vizinhança de índice 1, e todo o processo é repetido até que um critério de parada seja alcançado (linha 4). Assim como ocorre na implementação da BT, para evitar que a busca permaneça presa a uma região inviável, as violações de restrições são penalizadas, estando essas penalidades incorporadas à função de avaliação (linha 11), e ajustadas a cada iteração (linha 17).

Uma interessante característica da BVV é o reduzido número de parâmetros utilizados, o que pode ser uma vantagem significativa em termos de implementação. Heurísticas mais populares, tais como BT, geralmente dependem de um considerável conjunto de parâmetros que requerem um grande esforço de calibração. Uma descrição completa e detalhada da implementação da BVV será apresentada na seção 6.3 do Capítulo 6. 


\section{SOLUÇÃO INICIAL}

\subsection{Introdução}

Este capítulo tem por objetivo detalhar a heurística que permite obter uma solução inicial viável para o PDEGF com frota heterogênea, cuja formulação matemática foi apresentada no Capítulo 3. Essa solução inicial viável será utilizada como ponto de partida para a posterior aplicação da etapa de melhoria, objeto do Capítulo 6.

Conforme apresentado anteriormente no Capítulo 4, a obtenção da solução inicial baseia-se na decomposição do problema original em um subproblema de planejamento da distribuição (SPD) e um subproblema de planejamento da produção (SPP). Essa decomposição é formalizada na seção 5.2, e os métodos de resolução dos subproblemas SPD e SPP são apresentados nas seções 5.3 e 5.4, respectivamente. Por fim, a seção 5.5 discute a questão da ordem de seleção dos clientes utilizada na resolução do SPD.

\subsection{Decomposição do Problema Original}

A decomposição do problema original considera sua separação em dois subproblemas: um subproblema de planejamento da distribuição (SPD) e um subproblema de planejamento da produção (SPP). O primeiro subproblema, como o próprio nome indica, corresponde às decisões de atendimento dos clientes e roteirização dos veículos, ou seja, quando realizar os atendimentos e que rotas utilizar na distribuição. Por sua vez, o segundo subproblema corresponde às decisões relativas ao planejamento da produção, isto é, quando e quanto produzir. Em termos matemáticos, a resolução do SPD define as variáveis de decisão $z_{i}^{v t}, x_{i j}^{v t}$ e $F^{v}$, e a resolução do SPP define as variáveis de decisão $y^{t}$ e $Y^{t}$, segundo a nomenclatura estabelecida no Capítulo 3. Ambos subproblemas são formalizados a seguir, obedecendo a notação definida anteriormente. 


\subsubsection{Subproblema de Planejamento da Distribuição}

O SPD corresponde à formulação matemática do PDEGF com as restrições (2) a (12), (17), (19) e (20), e função objetivo que considera apenas as parcelas de custo de utilização da frota, custo de deslocamento dos veículos e custo de manutenção dos estoques nos clientes. Essa formulação é apresentada a seguir:

[SPD]

\section{Minimizar}

$$
\sum_{v \in V}\left(C_{f}^{v} \cdot F^{v}\right)+\sum_{t \in T} \sum_{v \in V} \sum_{i \in S} \sum_{j \in S}\left(C_{d}^{v} \cdot d_{i j} \cdot x_{i j}^{v t}\right)+\sum_{t \in T} \sum_{i \in N}\left(h_{i} \cdot I_{i}^{t}\right)
$$

sujeito a:

$$
\begin{array}{ll}
\sum_{i \in S} x_{i k}^{v t}-\sum_{j \in S} x_{k j}^{v t}=0 & , k \in N, \quad v \in V, \quad t \in T \\
\sum_{j \in N} x_{0 j}^{v t} \leq 1 & , v \in V, \quad t \in T \\
\sum_{v \in V} \sum_{j \in S} x_{i j}^{v t} \leq 1 & , i \in N, \quad t \in T \\
\sum_{i \in N^{\prime}} \sum_{j \in N^{\prime}} x_{i j}^{v t} \leq\left|N^{\prime}\right|-1 & , v \in V, \quad t \in T, \quad N^{\prime} \subseteq N, \quad\left|N^{\prime}\right| \geq 2 \\
F^{v} \geq \sum_{j \in N} x_{0 j}^{v t} & , v \in V, \quad t \in T \\
\sum_{i \in N} z_{i}^{v t} \leq Q_{v} & \\
I_{i}^{t}=I_{i}^{t-1}+\sum_{v \in V} z_{i}^{v t}-r_{i}^{t} & , v \in V, \quad t \in T \\
I_{i}^{t} \geq L_{i} & \\
& , i \in N, \quad t \in T \\
&
\end{array}
$$




$$
\begin{array}{ll}
I_{i}^{t} \leq U_{i} & , i \in N, \quad t \in T \\
\sum_{v \in V} z_{i}^{v t} \geq\left(U_{i}+r_{i}^{t}\right) \sum_{j \in S} \sum_{v \in V} x_{i j}^{v t}-I_{i}^{t-1}, & , i \in N, \\
\sum_{v \in V} z_{i}^{v t} \leq\left(U_{i}+r_{i}^{t}\right) \sum_{j \in S} \sum_{v \in V} x_{i j}^{v t} & , i \in N, \quad t \in T \\
z_{i}^{v t} \geq 0 & , i \in N, \quad v \in V, \quad t \in T \\
x_{i j}^{v t} \in\{0,1\} & , i \in S, \quad j \in S, \quad v \in V, \quad t \in T \\
F^{v} \in\{0,1\} & , v \in V
\end{array}
$$

Não será fornecida aqui uma descrição das restrições presentes na formulação matemática do SPD, uma vez que todas essas restrições já foram comentadas quando da apresentação da formulação original. Sugere-se ao leitor interessado consultar o Capítulo 3 para uma descrição das restrições.

Pode-se, entretanto, notar que não há nesse subproblema qualquer referência a custos e estoques associados ao depósito, estando implícita a hipótese de que sempre haverá estoque suficiente no depósito para a distribuição em um dado dia.

\subsubsection{Subproblema de Planejamento da Produção}

O SPP corresponde à formulação matemática do PDEGF com as restrições (13) a (16), e (18), e função objetivo que considera apenas as parcelas de custo fixo de produção, custo variável de produção, e custo de manutenção do estoque no depósito. Essa formulação é apresentada a seguir: 


\section{Minimizar}

$$
K \sum_{t \in T} Y^{t}+p \sum_{t \in T} y^{t}+h_{0} \sum_{t \in T} B^{t}
$$

\section{sujeito a:}

$B^{t}=B^{t-1}+y^{t}-\sum_{v \in V} \sum_{i \in N} z_{i}^{v t} \quad, t \in T$

$y^{t} \leq Y^{t} \cdot M$

,$t \in T$

$B^{t} \geq 0$

,$t \in T$

$y^{t} \geq 0$

$t \in T$

$Y^{t} \in\{0,1\}$

$t \in T$

Igualmente, não será fornecida aqui uma descrição das restrições presentes na formulação matemática do SPP, uma vez que todas essas restrições já foram comentadas quando da apresentação da formulação original. Sugere-se ao leitor interessado consultar o Capítulo 3 para uma descrição das restrições.

Esse subproblema corresponde ao conhecido problema de lote ótimo de produção dinâmico sem restrições de capacidade ("uncapacitated dynamic lot size problem"), definido originalmente por WAGNER; WHITIN (1958). Pode-se observar, a partir da análise da formulação matemática, que a resolução do SPP depende da resolução prévia do SPD, uma vez que as variáveis $z_{i}^{v t}$, presentes na restrição (37) do SPP são definidas pela resolução do SPD.

Conforme comentado anteriormente, os subproblemas SPD e SPP são resolvidos de forma hierárquica para a obtenção da solução inicial. A própria dependência do SPP 
em relação ao SPD sugere a hierarquia com que os subproblemas devem ser resolvidos: inicialmente o SPD e em seguida o SPP.

\subsection{Resolução do Subproblema de Planejamento da Distribuição}

A heurística utilizada para a resolução do SPD tem como idéia central construir a programação dos atendimentos a partir da composição de programações realizadas individualmente para cada cliente. Isto é, seleciona-se um cliente ainda não programado e determinam-se os dias de atendimento e as rotas correspondentes à programação de menor custo para esse cliente. Essa programação é então adicionada à programação global em construção, sendo o processo repetido até que todos os clientes tenham sido programados.

Devido à sua característica construtiva, a determinação dos dias de atendimento do cliente a ser inserido e das respectivas rotas de distribuição é realizada com base em uma solução incompleta. Isso quer dizer que a inserção da programação de um cliente depende das restrições impostas pela solução parcial, e que o custo da inserção é função das programações dos clientes já inseridos.

Pode-se notar, portanto, que o ponto chave do processo de inserção consiste em, dada uma solução parcial do SPD, determinar a programação de menor custo para a inserção de um cliente ainda não programado. A determinação dessa programação é realizada com o auxílio de um grafo orientado, construído de forma que a obtenção da programação de menor custo corresponda à resolução de um problema de caminho de mínimo.

Seja $k$ o cliente a ser programado. Define-se o grafo orientado acíclico $G(J, A, P, W)$, em que cada elemento do conjunto de nós $J$ corresponde a um dia de 0 a $T+1$, e cada arco $a_{i j} \in A, 0 \leq i<j=1,2, \ldots, T+1$ corresponde ao atendimento consecutivo do cliente $k$ nos dias $i$ e $j$, caso isso seja possível. Dessa forma, o arco $a_{i j}$ corresponde ao atendimento do cliente em questão no dia $j$, dado que o último atendimento realizou-se no dia $i$, e somente são definidos arcos que correspondam a combinações viáveis de dias de atendimento, segundo as restrições de nível de 
estoque do cliente $k$ e da política de reabastecimento adotada. Em outras palavras, são enumeradas todas as combinações viáveis, isto é, que não impliquem desabastecimento do cliente, e criados os arcos respectivos. Um exemplo de grafo $G$ é apresentado na Figura 5.1, a seguir.

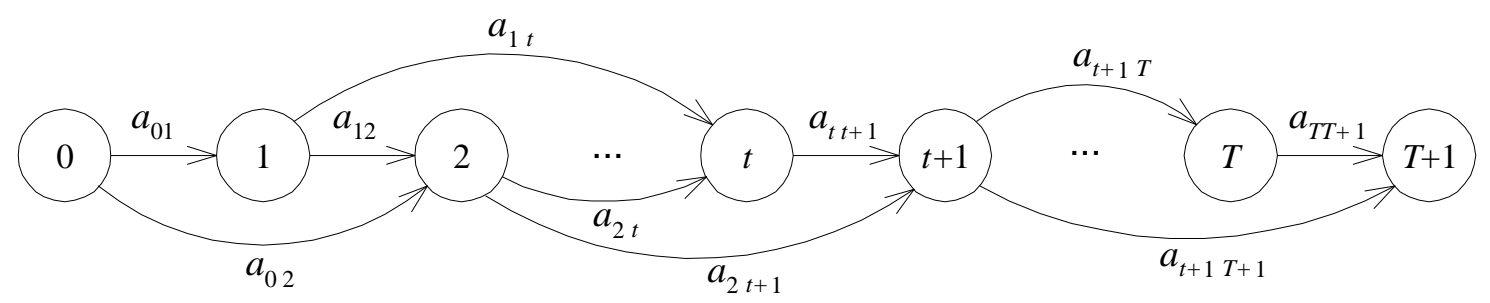

Figura 5.1 - Exemplo de grafo $G$ utilizado na resolução do SPD.

Tendo em vista que somente são definidos arcos para combinações viáveis de atendimento, observa-se, por exemplo, na Figura 5.1, que não existe um arco ligando o dia 1 ao dia $t+1$, o que significa que não é viável atender o referido cliente no dia $t+1$, dado que o último atendimento ocorreu no dia 1. Em outras palavras, essa não é uma seqüência de atendimentos possível, o que indica que o consumo do cliente $k$ entre os dias 1 e $t+1$ é maior que a capacidade de estocagem do cliente, determinada pela diferença entre seu estoque máximo e mínimo $\left(U_{k}-L_{k}\right)$.

A cada arco $a_{i j} \in A$ estão associadas a quantidade $P_{i j} \in P$ a ser entregue ao cliente $k$ no dia $j$ e a correspondente estimativa de incremento de custo $W_{i j} \in W$. Note-se que os arcos $a_{0 j}$ correspondem ao caso em que $j$ é o primeiro dia de atendimento no período de planejamento, o que implica que a demanda do respectivo cliente do dia 1 ao dia $j$ deve ser atendida pelo estoque inicial do mesmo. Nesse caso, a quantidade $P_{0 j}$ a ser entregue ao cliente $k$ no dia $j$ é dada por:

$$
P_{0 j}=U_{k}-I_{k}^{0}+\sum_{t=1}^{j} r_{k}^{t}
$$

A expressão (42) indica que a quantidade a ser entregue no dia $j$, dado que esse é o primeiro atendimento do cliente, é calculada como o consumo acumulado até o dia $j$, 
somado à diferença entre o estoque máximo e o estoque inicial. Isto é, repõe-se a quantidade consumida no período e complementa-se com a eventual diferença do estoque inicial em relação ao estoque máximo.

Nos demais arcos, em que $i \neq 0$, ou seja, correspondentes às entregas subseqüentes, a quantidade $P_{i j}$ a ser entregue corresponde à reposição da quantidade consumida desde o último atendimento, sendo definida por:

$P_{i j}=\sum_{t=i+1}^{j} r_{k}^{t}$

Finalmente, $W_{i j}$ corresponde a uma estimativa do incremento de custo decorrente do atendimento do cliente no dia $j$, dado que o último atendimento realizou-se no dia $i$. Essa estimativa pode ser decomposta em duas parcelas: $\tilde{D}^{j}$, relativa ao custo do transporte e $\tilde{I}^{i j}$, relativa ao custo de manutenção do estoque. Dessa forma, pode-se formalizar o cálculo do incremento de custo de atendimento do cliente no dia $j$ a partir de um atendimento anterior no dia $i$ como:

$W_{i j}=\tilde{D}^{j}+\tilde{I}^{i j}$

O cálculo da parcela $\tilde{D}^{j}$ consiste em estimar, para cada veículo disponível, o acréscimo de custo na respectiva rota resultante da inserção do atendimento do cliente $k$, sendo adotado como valor da parcela de transporte o menor acréscimo de custo encontrado. Note-se que, nesse cálculo, além da variação dos custos fixos e variáveis associados ao veículo, deve ser verificada a viabilidade da inserção do atendimento em função da capacidade disponível no veículo. Obviamente, veículos cuja capacidade disponível seja menor que a quantidade a ser entregue não são viáveis e devem ser descartados.

Uma variação do procedimento de cálculo da parcela $\tilde{D}^{j}$ consiste em substituir o custo fixo de um veículo $C_{f}^{v}$ pela expressão $P_{i j} \frac{C_{f}^{v}}{Q_{v}}$, que corresponde ao percentual 
do custo fixo proporcional à relação entre a quantidade programada para entrega no dia $j$ e a capacidade do veículo. Essa variação tem por finalidade favorecer a escolha de veículos com menor relação custo fixo/capacidade, o que, evidentemente, somente tem sentido no caso em que a frota disponível é heterogênea. A utilização ou não dessa variação é controlada pelo parâmetro UtilizaCustoProporcional, e seu efeito será analisado no Capítulo 7, quando da avaliação de um cenário de distribuição com frota heterogênea. O procedimento de cálculo da parcela relativa ao custo de transporte é apresentado na Figura 5.2, em pseudo-linguagem estruturada.

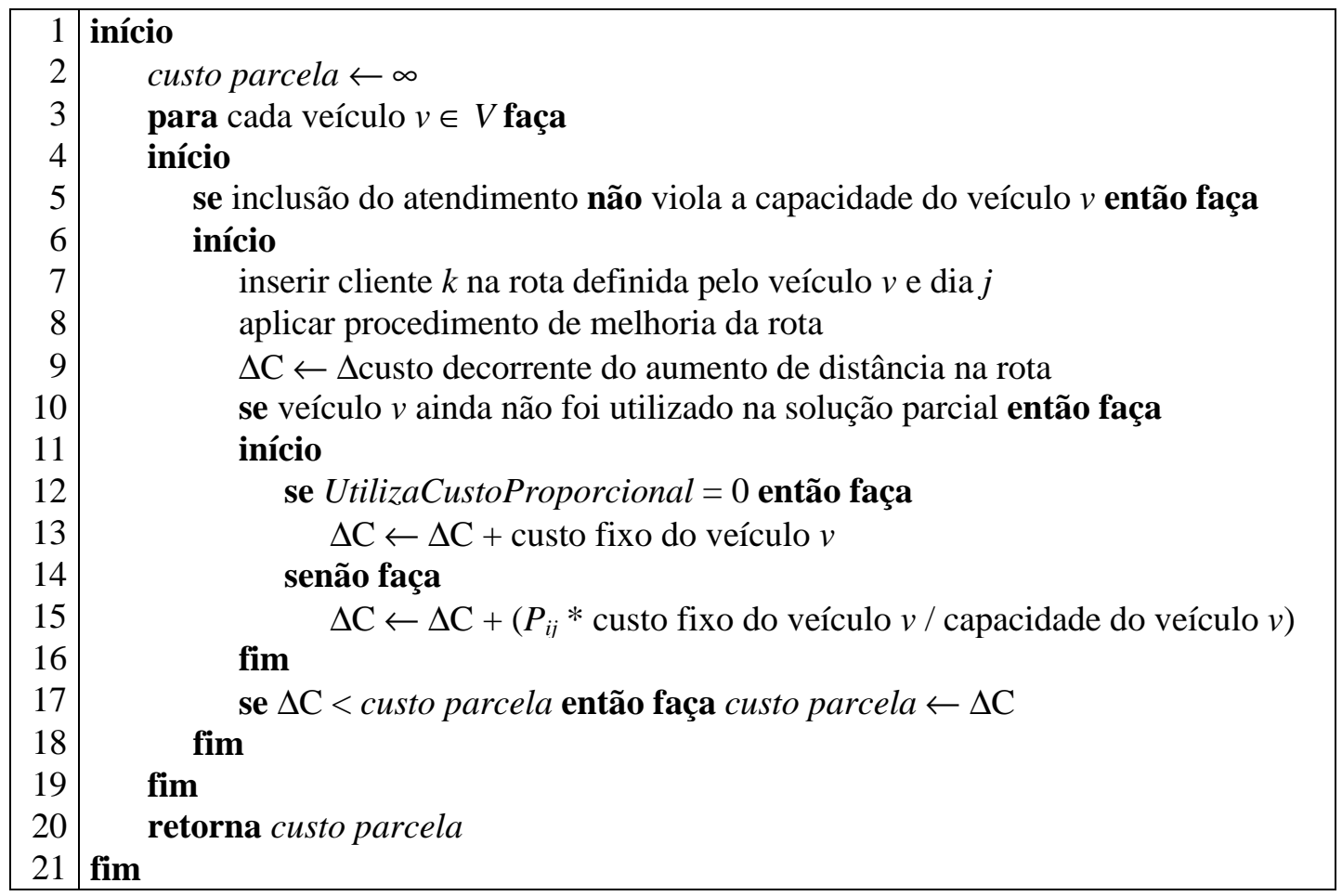

Figura 5.2 - Procedimento de cálculo da parcela $\tilde{D}^{j}$ relativa ao custo de transporte.

Vale destacar que, na presente implementação, a inserção do atendimento em uma rota envolve a melhoria da seqüência de atendimentos da rota, o que não é realizado na proposta original de BERTAZZI et al. (2005), que consideram apenas a inserção do atendimento na posição de menor acréscimo de custo. No presente trabalho, a inserção de um atendimento é inicialmente realizada na primeira posição da rota, ao que se seguem dois procedimentos de melhoria da seqüência de atendimentos: troca da posição de dois atendimentos, e trocas do tipo 2-intercâmbio (CROES, 1958; LIN; KERNIGHAN, 1973). Em ambos procedimentos, as trocas são realizadas 
segundo a estratégia "first improvement" até que não seja possível obter redução do custo da rota.

Por sua vez, a parcela $\tilde{I}^{i j}$, relativa ao incremento do custo de manutenção do estoque no cliente, é calculada como o produto da quantidade $P_{i j}$ pelo custo diário unitário de manutenção de estoque do cliente $k$, e pelo período do dia $j$ ao dia $T+1$, sendo formalizada como:

$\tilde{I}^{i j}=h_{k}(T+1-j) P_{i j}$

À primeira vista, o cálculo de $\tilde{I}^{i j}$ pode parecer superestimar o custo de manutenção do estoque, já que o efeito do atendimento do cliente no dia $j$ é considerado até o dia $T+1$, e não até o próximo reabastecimento do cliente. Entretanto, essa primeira impressão é equivocada, uma vez que é possível decompor o estoque de um dado cliente (e o correspondente custo de manutenção) segundo os efeitos da demanda e de cada um dos atendimentos realizados, o que está exemplificado na Figura 5.3.

No exemplo apresentado, a Figura 5.3(a) ilustra o efeito exclusivo da demanda sobre o estoque. Esse caso corresponde à situação hipotética em que não há reabastecimento, e o estoque ao longo do período depende apenas do estoque inicial $I_{i}^{0}$ e do consumo $r_{i}^{t}$ do cliente. Como pode-se observar, a ausência de atendimentos provoca o desabastecimento do cliente a partir do instante $t_{a}$, uma vez que o estoque inicial é insuficiente para suprir a demanda total do período. A falta de estoque está representada na Figura 5.3(a) por valores negativos de estoque, e indica o montante da demanda não atendida. Por sua vez, a Figura 5.3(b) apresenta o efeito exclusivo do atendimento do cliente no instante $t_{a}$ segundo a política de reabastecimento adotada. Uma representação análoga pode ser realizada para os demais reabastecimentos porventura existentes. Os efeitos da demanda e do reabastecimento são então combinados na Figura 5.3(c), que representa a soma dos efeitos apresentados isoladamente nas Figuras 5.3(a) e 5.3(b). 

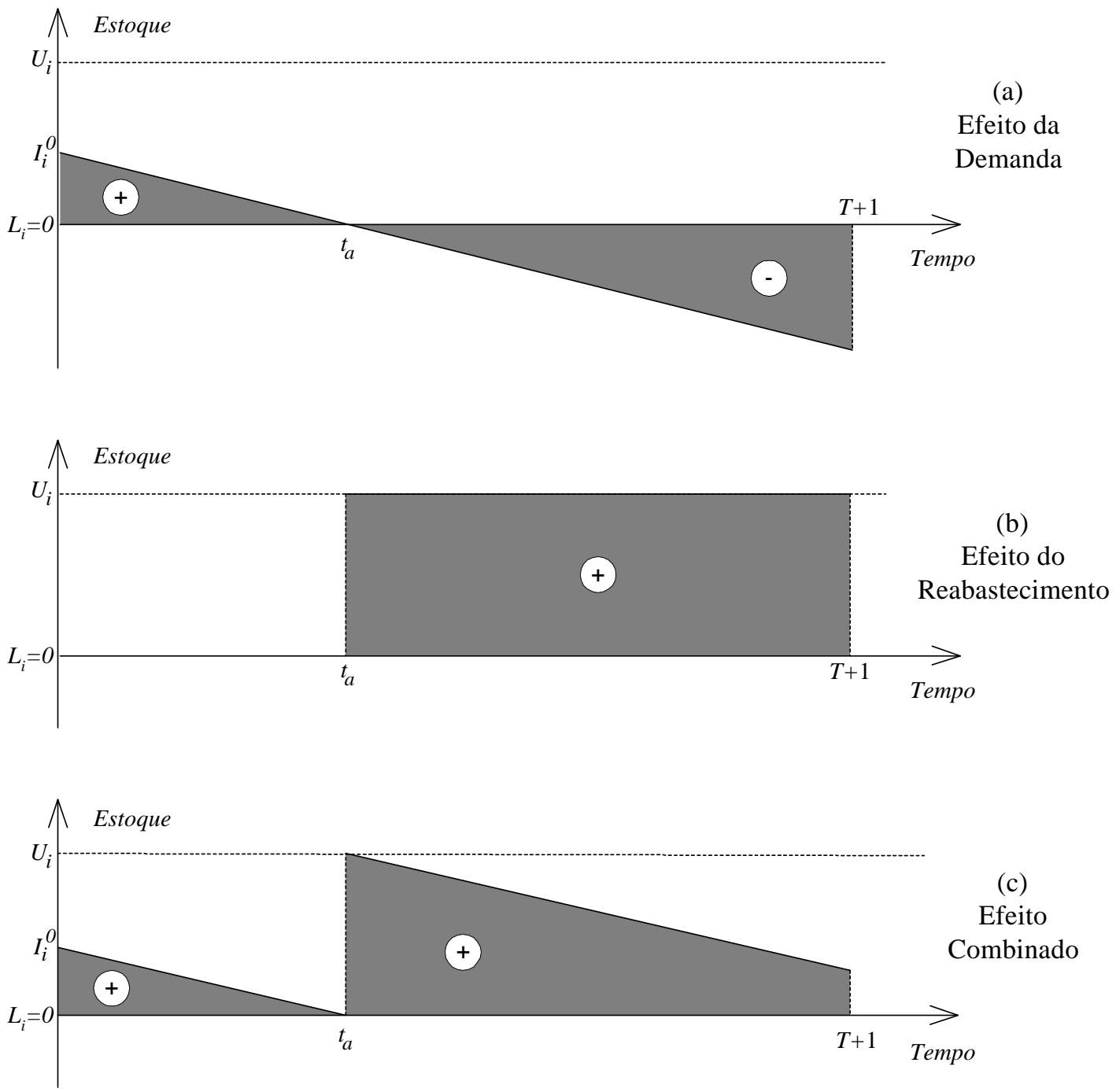

Figura 5.3 - Exemplo de decomposição do estoque de um cliente

Observe-se que a área hachurada da Figura 5.3(c) corresponde à soma (integral) do estoque ao longo do período de planejamento, sendo justamente esse valor que, multiplicado pelo custo unitário diário de manutenção de estoque, determina o custo de estoque do cliente. Note-se ainda que a área hachurada da Figura 5.3(c) pode ser entendida como a soma algébrica das áreas hachuradas das Figuras 5.3(a) e 5.3(b), o que permite decompor o custo de estoque segundo o efeito do estoque inicial e da demanda, e segundo o efeito dos atendimentos. Ora, a soma algébrica das áreas hachuradas da Figura 5.3(a) é constante para uma determinada instância do problema, pois depende apenas do estoque inicial e das demandas, dados conhecidos a priori. Por conseguinte, pode-se afirmar que a parcela de custo correspondente é constante, e pode ser omitida para efeito da determinação dos dias de 
reabastecimento de menor custo. Assim sendo, a estimativa de custo de estoque necessita considerar apenas as parcelas decorrentes dos reabastecimentos, cujo efeito se estende do instante do atendimento até o final do período de planejamento, como está corretamente representado na expressão (45).

Embora o exemplo apresentado ilustre o caso em que o tempo é considerado de forma contínua, o raciocínio continua válido para a situação em que apenas instantes discretos são considerados. Nesse sentido, vale notar que os efeitos de um reabastecimento são considerados até o instante $T+1$, como forma de representar o estoque residual ao final do período de planejamento $T$.

Uma vez definido o grafo $G$, a programação de atendimentos do cliente $k$ pode ser obtida encontrando-se o caminho mínimo entre os nós 0 e $T+1$. Os nós intermediários pertencentes ao caminho mínimo definem os dias de atendimento, e os valores $P_{i j}$ associados correspondem às quantidades a ser entregues em cada dia de atendimento $j$. Note-se que o grafo $G$ é acíclico e ordenado topologicamente, o que torna simples a determinação do caminho mínimo. Segundo AHUJA et al. (1993), a determinação do caminho mínimo em um grafo com essa característica apresenta ordem de complexidade $O(|A|)$, ou seja, proporcional ao número de arcos do grafo, não sendo possível encontrar algoritmo com grau de complexidade menor, uma vez que todos os arcos do grafo devem ser examinados.

O processo de inserção é repetido até que todos os clientes tenham sido programados, o que equivale à resolução do SPD. Obtida a solução do SPD, ou seja, a definição de quando entregar e como entregar, pode-se proceder à resolução do SPP, que vem a ser a definição de quando e quanto produzir.

Cabe aqui destacar uma importante diferença em relação ao procedimento proposto por BERTAZZI et al. (2005). No presente trabalho, não há qualquer restrição em termos da quantidade de produto disponível no depósito, estando implícita a hipótese de que, para a resolução do SPD, sempre haverá estoque suficiente no depósito para a distribuição em todos os dias do horizonte de planejamento. Entretanto, essa hipótese não é utilizada no trabalho de BERTAZZI et al. (2005), que consideram a resolução do SPD a partir de uma programação prévia da produção. Essa 
programação prévia pode ser vista como uma primeira aproximação do planejamento da produção, e consiste em considerar, a cada dia do período de planejamento, a produção da quantidade igual à soma do consumo de todos os clientes naquele dia. Essa regra tem como exceção o primeiro dia do período de planejamento, em que a quantidade produzida deve corresponder à quantidade necessária para o atendimento de todos os clientes segundo a política de reabastecimento adotada, ou seja, deve corresponder à quantidade necessária para a reposição integral dos estoques de todos os clientes.

A partir dessa programação prévia da produção, o estoque do depósito é corrigido durante a resolução do SPD, subtraindo-se, a cada atendimento inserido, a respectiva quantidade do estoque do depósito no dia correspondente. Em decorrência das restrições de não negatividade do estoque no depósito, a construção do grafo $G$ é alterada pela atribuição de custo infinito aos arcos que resultem na falta de estoque no depósito, o que virtualmente equivale a eliminar esses arcos do grafo. Em resumo, no trabalho de BERTAZZI et al. (2005), a resolução do SPD depende de uma programação prévia da produção, e a programação dos clientes segundo a heurística descrita anteriormente deve respeitar as restrições de estoque no depósito.

De forma distinta, a formulação adotada no presente trabalho não considera qualquer influência do custo ou dos estoques no depósito quando da resolução do SPD. Isto é, a resolução do SPD não depende de uma solução prévia do SPP, mas sim ocorre o contrário, conforme comentado na seção 5.2. Muito embora a formulação adotada possa ser entendida como uma hipótese simplificadora em relação ao procedimento original de BERTAZZI et al. (2005), acredita-se que, no contexto da estratégia de solução aqui proposta, a inclusão de restrições de estoque do depósito na formulação do SPD não traria benefícios significativos ao modelo apresentado.

Por fim, é importante salientar que a definição da frota a ser utilizada na solução inicial decorre do planejamento da distribuição, ou seja, ao determinar o atendimento de um cliente por um dado veículo, o próprio procedimento programação dos clientes acaba por determinar quais veículos serão utilizados, definindo assim a frota utilizada na solução inicial. Assim, toda vez que a inserção de um cliente faz uso de 
um veículo ainda não utilizado, esse veículo passa a fazer parte da frota empregada na solução inicial.

\subsection{Resolução do Subproblema de Planejamento da Produção}

Conforme comentado anteriormente no Capítulo 4, o subproblema SPP corresponde ao clássico problema de lote ótimo de produção dinâmico sem restrições de capacidade ("uncapacitated dynamic lot size problem"), definido originalmente por WAGNER; WHITIN (1958). Nesse trabalho, os autores apresentam o SPP como um problema de programação dinâmica, e propõem um algoritmo que corresponde à resolução de um problema de caminho mínimo em um grafo orientado acíclico. Essa abordagem foi posteriormente aprimorada por EVANS (1985), que propõe a construção desse grafo orientado de maneira recursiva, o que demonstra-se ser de maior eficiência, sendo esta a implementação adotada no presente trabalho.

WAGNER; WHITIN (1958) demonstram que a solução ótima do SPP apresenta a interessante característica de que o estoque no depósito é nulo nos dias que imediatamente antecedem os dias em que há produção (excetuando-se o primeiro dia de produção, que pode ser influenciado pelo estoque inicial do depósito). Exemplificando, se $t_{1}, t_{2}$ e $t_{3}$ são dias em que há produção, não há transferência de estoque do período definido pelos dias $t_{1}$ e $t_{2}$ para o período definido pelos dias $t_{2} \mathrm{e}$ $t_{3}$, uma vez que o estoque eventualmente transferido ficaria ocioso durante o período de $t_{1}$ a $t_{2}$, e poderia ser produzido em $t_{2}$ sem o ônus do custo de manutenção durante o período anterior.

Essa propriedade permite afirmar que o produto do estoque do dia anterior pela quantidade a ser produzida em um determinado dia é sempre nulo, conforme apresentado a seguir:

$$
B^{k-1} \cdot y^{k}=0 \quad, k \in T
$$

É fácil verificar a validade da expressão (46), uma vez que nos instantes $k$ em que há produção vale $B^{k-1}=0$ e nos demais instantes $y^{k}=0$. Como conseqüência, apenas 
necessitam ser considerados na resolução do SPP os valores de $y^{k}$ que apresentam a forma:

$$
y^{k}=\sum_{j=k}^{t} \sum_{i \in N} \sum_{v \in V} z_{i}^{v j} \quad, k \in T, \quad t \in T, \quad t \geq k
$$

Isto é, apenas devem ser consideradas soluções em que a quantidade programada para produção em um dado dia $k$ corresponda exatamente à quantidade de produto entregue aos clientes no período que vai do dia $k$ a um dia $t \geq k$, inclusive. Seja $\mu_{k t}$ o custo total associado à produção da quantidade $y^{k}$, o que corresponde à soma dos custos fixo e variável de produção no dia $k$, e do custo de manutenção de estoque no depósito do dia $k$ ao dia $t$. Esse custo total pode ser formalizado como:

$$
\mu_{k t}=K+p y^{k}+h_{0} \sum_{u=k}^{t-1} \sum_{j=u+1}^{t}\left(\sum_{i \in N} \sum_{v \in V} z_{i}^{v j}\right) \quad, k \in T, \quad t \in T, \quad t \geq k
$$

Seja $\Phi_{t}$ o custo total mínimo para o período que vai do dia 1 ao dia $t$, instante em que o estoque no depósito é nulo ( $B^{t}=0$ ), e seja ainda $\Phi_{0}=0$. Dada a propriedade definida em (46), a determinação dos valores de $\Phi_{t}$ corresponde a um problema de programação dinâmica, conforme indicado abaixo:

$$
\Phi_{t}=\min _{1 \leq k \leq t}\left[\Phi_{k-1}+\mu_{k t}\right] \quad, t \in T
$$

Observe-se que a resolução do SPP equivale à determinação de $\Phi_{T}$, ou seja, à determinação do planejamento da produção de menor custo para todo o período de planejamento. Pode-se verificar ainda que a resolução do problema de programação dinâmica acima corresponde à resolução de um problema de caminho mínimo em um grafo orientado acíclico, como exemplificado na Figura 5.4, reproduzida de EVANS (1985). 


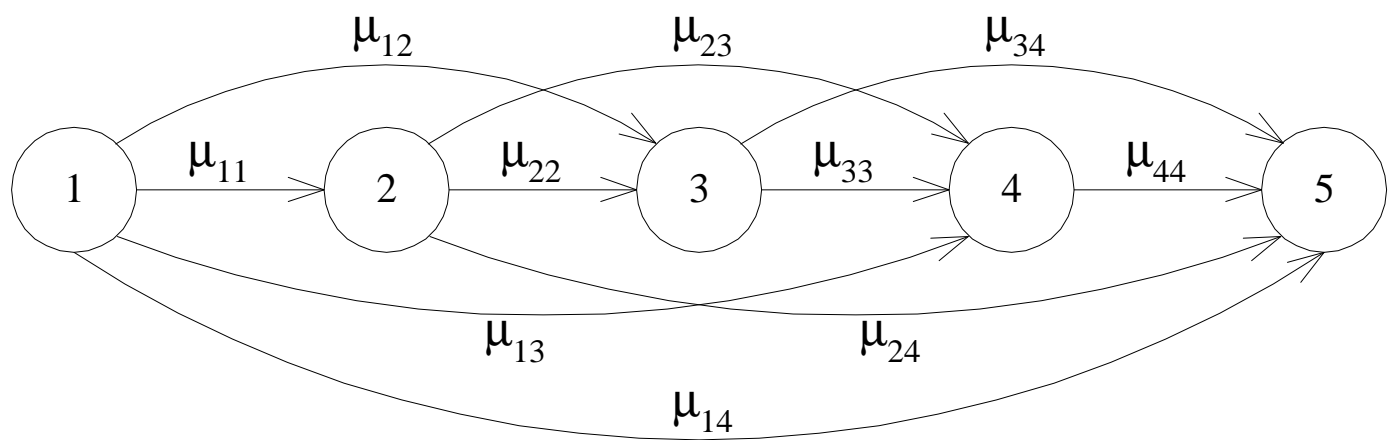

Figura 5.4 - Exemplo de SPP representado como problema de caminho mínimo em grafo orientado. Fonte: EVANS (1985).

O exemplo representa um problema com quatro instantes de produção ( 1 a 4). Cada arco do grafo, definido pelos nós $k$ e $t$, corresponde à produção no instante $k$ da quantidade necessária para atender às entregas do período de $k$ a $t$-1, sendo $\mu_{k, t-1} \mathrm{O}$ respectivo custo. Vale enfatizar que o custo do arco definido pelos nós $k$ e $t$ corresponde ao período que vai de $k$ a $t$-1, não incluindo o instante $t$, que faz parte do período de produção subsequente. Assim definido o grafo, o custo do caminho mínimo do nó 1 a qualquer nó $t$ corresponde ao cálculo de $\Phi_{t-1}$ e, em particular, o custo do caminho mínimo do nó 1 ao nó 5 corresponde ao custo da solução ótima do SPP associado. Note-se que o grafo utiliza um nó auxiliar (nó 5), correspondente ao instante de produção $T+1$. Esse nó se faz necessário, uma vez que o custo dos arcos definidos pelos nós $k$ e $t$ referem-se ao período de $k$ a $t$-1, e, por conseguinte, a determinação de $\Phi_{T}$ corresponde ao caminho mínimo do nó 1 ao nó $T+1$.

Definido o caminho mínimo entre os nós 1 e $T+1$, os instantes de produção e respectivas quantidades ficam automaticamente definidos pelos nós intermediários, o que corresponde à programação de produção de menor custo.

Embora a formulação e o exemplo apresentados correspondam ao caso particular em que o estoque inicial do depósito é nulo, o método é genérico, pois qualquer instância do problema pode ser facilmente transformada em uma equivalente com estoque inicial nulo. Verifica-se ainda que o grafo correspondente à resolução do SPP é acíclico e orientado topologicamente, o que simplifica a determinação do caminho mínimo, como já comentado anteriormente. Conquanto o valor do custo $\mu_{k t}$ de cada 
arco do grafo possa ser calculado de maneira separada e independente a partir da expressão (48), EVANS (1985) demonstra que o valor de $\mu_{k t+1}$ pode ser obtido em função de $\mu_{k t}$, e que essa forma recursiva de determinar o custo dos arcos do grafo é mais eficiente que a utilização da expressão (48).

A resolução do SPP segundo essa abordagem apresenta ordem de complexidade $O\left(|T|^{2}\right)$, como apontado por FLORIAN et al. (1980), sendo esse resultado teórico confirmado empiricamente pelos experimentos computacionais realizados por EVANS (1985). Mais recentemente, algoritmos com ordem de complexidade $O(|T| \log |T|)$ foram propostos por FEDERGRUEN; TZUR (1991), WAGELMANS et al. (1992), AGGARWAL; PARK (1993) e AHUJA; HOCHBAUM (2004). Em situações específicas, alguns desses algoritmos apresentam ordem de complexidade ainda menor, de $O(|T|)$, como é o caso do algoritmo proposto por FEDERGRUEN; TZUR (1991) nas situações em que os custos de preparação são não decrescentes, por exemplo.

A despeito da existência de algoritmos com menor ordem de complexidade, no presente trabalho foi adotada a abordagem proposta por EVANS (1985) para a resolução do SPP. Essa escolha se justifica pela sua simplicidade e eficiência, que permitiram uma rápida implementação computacional e resolução do SPP em um tempo de processamento compatível com as exigências da estratégia de solução desenvolvida para o PDEGF.

\subsection{Seleção de Clientes para Programação}

Uma importante questão ainda não totalmente examinada é a ordem de seleção dos clientes para programação na resolução do SPD. Em BERTAZZI et al. (2005), essa ordem é definida pelo índice $\alpha_{i}$, calculado para cada cliente $i$ como:

$$
\alpha_{i}=\max _{t \in T}\left\{t: \quad \sum_{j=1}^{t} r_{i}^{j} \leq I_{i}^{0}\right\}
$$


Esse índice corresponde ao número de dias que a demanda do cliente $i$ pode ser suprida por seu estoque inicial, e a seleção dos clientes para programação é realizada segundo a ordem não decrescente de $\alpha_{i}$. Assim, privilegia-se a programação dos clientes que sofrerão falta de estoque primeiro, o que se justifica por propiciar um maior número de combinações de inserção do primeiro atendimento desses clientes. É importante recordar que, em função da limitada capacidade dos veículos, os clientes já inseridos na programação restringem as possíveis inserções dos atendimentos de um cliente ainda não programado. Como conseqüência, a inserção de um cliente na programação pode eventualmente requerer a utilização de um veículo ainda não utilizado, incorrendo-se, nesse caso, no correspondente custo fixo do veículo. Ao priorizar os clientes com menor flexibilidade de programação do primeiro atendimento, diminui-se a probabilidade de ocorrer a indesejável situação em que alguns veículos são utilizados apenas para os primeiros atendimentos e ficam ociosos no restante do período de planejamento.

Embora os resultados reportados por BERTAZZI et al. (2005) indiquem que a solução inicial assim obtida é de boa qualidade, acredita-se ser possível se obter uma solução inicial de melhor qualidade com a modificação da ordem de inserção dos clientes na programação. Conforme descrito anteriormente no Capítulo 4, o que se propõe é um processo de seleção aleatória de clientes para programação dentre uma lista reduzida, cujo funcionamento será definido mais adiante. Esse processo é repetido um número predeterminado de vezes, e a melhor solução obtida é utilizada como solução inicial para a etapa de melhoria subsequente.

Em outras palavras, cada iteração consiste em criar uma solução inicial candidata por meio da heurística construtiva descrita nas seções 5.3 e 5.4, utilizando-se o procedimento proposto de seleção aleatória de clientes em lista reduzida. Assim, uma solução inicial provavelmente distinta é obtida a cada iteração, e a melhor solução encontrada ao longo do processo é utilizada como solução inicial para a etapa de melhoria subsequente. A construção de múltiplas soluções vem a ser justamente a principal diferença entre a adaptação proposta para obtenção da solução inicial e a heurística de BERTAZZI et al. (2005), em que apenas uma solução é construída. 
A organização da lista reduzida, elemento central para o processo de seleção aleatória dos clientes, é bastante simples e baseia-se no índice $\alpha_{i}$ definido anteriormente. Esse processo inicia-se com a ordenação do conjunto dos clientes segundo a ordem não decrescente do índice $\alpha_{i}$. Em seguida, são selecionados nesse conjunto ordenado os primeiros $n$ elementos, ou seja, os $n$ clientes de menor índice, o que justamente vem a ser a lista reduzida. Como pode-se notar, essa lista é nada mais que um subconjunto do conjunto ordenado de clientes ainda não programados, construído segundo os menores valores do índice $\alpha_{i}$. O número $n$ de clientes selecionados, doravante denominado TamanhoLista, é o único parâmetro utilizado na construção da lista reduzida, ficando subentendido que, quando o número de clientes ainda não programados for menor que TamanhoLista, aquele será utilizado como parâmetro para construção da lista reduzida.

Conforme apresentado anteriormente, a resolução do SPD seguida da resolução do SPP pode ser vista como uma iteração da heurística de obtenção da solução inicial, sendo esse procedimento apresentado na Figura 5.5.

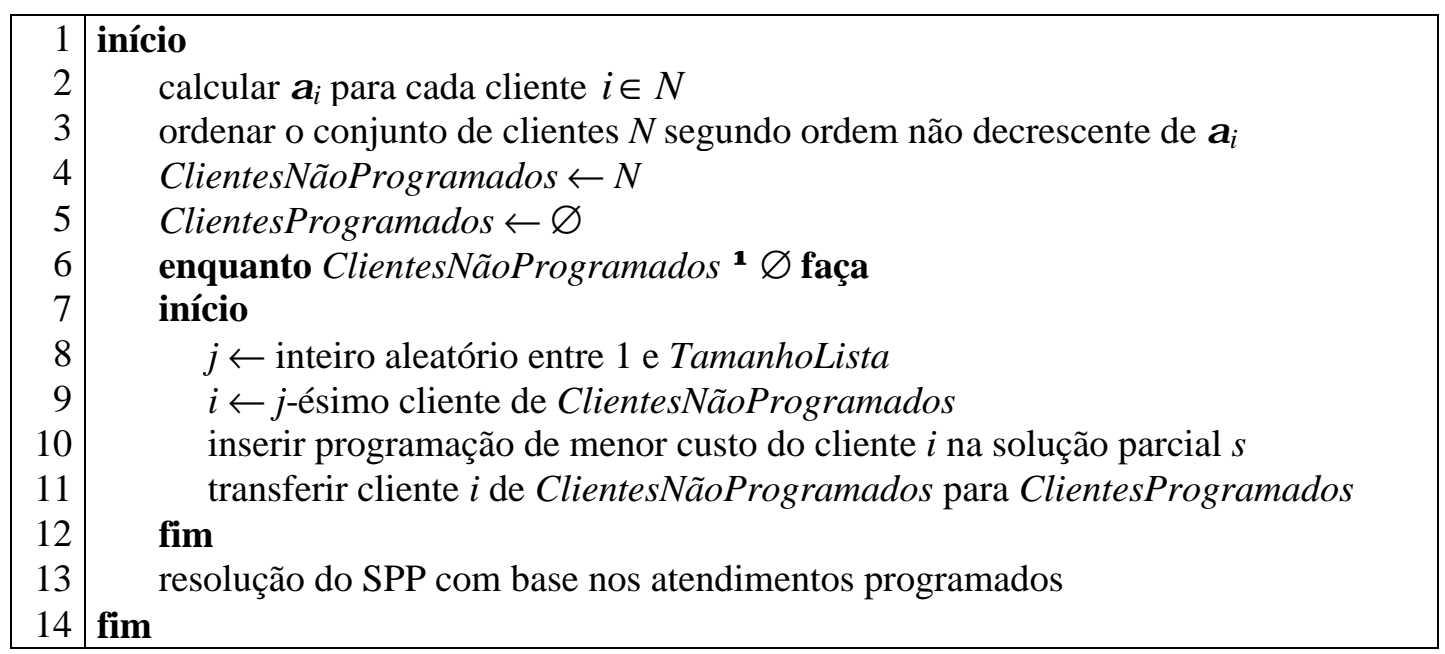

Figura 5.5 - Iteração do procedimento de obtenção da solução inicial com seleção aleatória de clientes em lista reduzida.

Como pode-se notar, cada iteração consiste na resolução do SPD (linha 2 a 12), seguido da resolução do SPP correspondente (linha 13), e o ponto central da adaptação proposta para a resolução do SPD consiste em selecionar aleatoriamente o próximo cliente a ser programado em uma lista reduzida (linhas 8 e 9). Observa-se ainda que a adaptação proposta pode ser entendida como uma generalização da 
heurística original de BERTAZZI et al. (2005), uma vez que esta corresponde ao caso particular em que o parâmetro TamanhoLista é igual a um e apenas uma iteração é realizada. 


\section{HEURÍSTICAS DE MELHORIA}

\subsection{Introdução}

Este capítulo tem por objetivo apresentar os detalhes de implementação das heurísticas correspondentes à etapa de melhoria da estratégia de solução proposta para o PDEGF. Conforme comentado anteriormente, duas diferentes metaheurísticas foram investigadas nessa fase: busca tabu (BT) e busca em vizinhança variável (BVV).

Antes de abordar os detalhes da implementação das heurísticas propostas, cabe recordar que uma etapa de melhoria também é proposta por BERTAZZI et al. (2005), a qual consiste em retirar dois clientes da programação e reinseri-los na solução por meio do processo de inserção utilizado na resolução do SPD. Isto é, retirados os dois clientes da solução, determina-se para o segundo cliente a programação de menor custo correspondente à sua reinserção na solução. Essa programação de menor custo é obtida por meio do procedimento descrito na seção 5.3, que pode ser resumido como a resolução de um problema de caminho mínimo em um grafo orientado acíclico, construído de forma a representar as possíveis combinações de atendimento de um dado cliente e respectivos custos. Essa programação de menor custo é executada e o mesmo procedimento é repetido para o primeiro cliente, resolvendo-se, em seguida, o SPP a partir da nova programação de atendimentos obtida. Todas as combinações de dois clientes são testadas e as reprogramações de atendimentos que resultem em redução de custo são executadas, segundo a estratégia "first improvement". O processo todo é repetido até que não seja possível obter redução de custo, quaisquer que sejam os dois clientes selecionados para reprogramação.

BERTAZZI et al. (2005) propõem ainda um aprimoramento dessa etapa de melhoria, que considera a alteração da programação da produção antes de cada iteração do processo de melhoria descrito acima. Essa variação da etapa de melhoria busca obter 
uma maior coordenação entre os subproblemas de produção e distribuição, e baseia-se no fato de que a heurística de resolução do SPD utilizada pelos autores incorpora restrições de estoque no depósito, conforme comentado no Capítulo 5. Os resultados apresentados indicam que essa versão aprimorada da etapa de melhoria é capaz de obter uma redução média de custo da ordem de $4 \%$ em relação à solução inicial.

A despeito dos expressivos resultados obtidos por BERTAZZI et al. (2005), acredita-se que a utilização de uma etapa de melhoria mais robusta, baseada nas metaheurísticas BT ou BVV, pode obter resultados significativamente melhores que a aplicação de um método de busca local, como o proposto pelos autores. Em realidade, o desenvolvimento de uma etapa de melhoria mais eficiente, capaz de obter resultados de melhor qualidade, vem a ser justamente a contribuição original do presente trabalho.

A seguir, as seções 6.2 e 6.3 apresentam os detalhes referentes à implementação da BT e da BVV, respectivamente, e a seção 6.4 algumas considerações finais a respeito da etapa de melhoria.

\subsection{Busca Tabu}

Nesta seção serão descritos os principais aspectos da implementação da metaheurística busca tabu (BT) buscando melhorar a solução inicial para o PDEGF. Esses aspectos abrangem os seguintes tópicos: movimentos e vizinhança, penalidades, memória de curta duração, estratégia de diversificação e intensificação, avaliação dos movimentos candidatos, gerenciamento da lista de movimentos candidatos e critério de parada.

Cada um dos itens acima relacionados será abordado em uma subseção específica, cabendo lembrar que não será reapresentado nesse capítulo o funcionamento geral da BT, uma vez que o mesmo já foi realizado no Capítulo 4. 


\subsubsection{Movimentos e Vizinhança}

Um dos elementos chave para a aplicação bem sucedida da BT é a escolha adequada dos movimentos que definem a vizinhança das soluções analisadas. Na presente implementação, os movimentos adotados baseiam-se no conceito de atendimento, que pode ser entendido como uma combinação de cliente, dia e veículo. Note-se que nessa abordagem não são especificadas diretamente variáveis de decisão, devendo a alteração destas ser calculada em função do movimento, quando da sua avaliação.

Essa abordagem permite que os movimentos sejam formulados em um nível de abstração mais elevado, além de preservar a compatibilidade entre as variáveis de decisão de reabastecimento $\left(z_{i}^{v t}\right)$, de roteirização $\left(x_{i j}^{v t}\right.$ e $F^{v}$ ), e de produção ( $y^{t}$ e $\left.Y^{t}\right)$. É fácil verificar que as variáveis de decisão do PDEGF são fortemente inter-dependentes, e que a sua alteração descoordenada certamente provoca a violação de restrições presentes na formulação matemática. Nesse sentido, o conceito de atendimento funciona como elemento de união entre as distintas dimensões do problema, assegurando que as alterações das variáveis de decisão, especialmente as relacionadas ao reabastecimento e roteirização, sejam sempre coerentes entre si.

Note-se ainda que as alterações dos atendimentos envolvem diretamente apenas as variáveis de decisão presentes no SPD, o que permite afirmar que os movimentos baseados em atendimentos podem ser entendidos como a obtenção de uma nova solução para esse subproblema (SPD). De forma similar ao procedimento utilizado para obtenção da solução inicial, a determinação das demais variáveis de decisão, correspondente à resolução do SPP, é realizada a partir dessa nova solução obtida para o SPD. Esse tópico será visto em maior detalhe na seção 6.2.5, quando será apresentado procedimento de avaliação dos movimentos candidatos.

Duas operações básicas são definidas em relação a um atendimento: inserção e remoção. A operação de inserção corresponde a determinar que seja realizado o atendimento a um dado cliente, em um dia específico, utilizando-se um determinado veículo. Naturalmente, não são permitidas inserções em combinações de cliente e dia que já possuam atendimento, e somente são considerados disponíveis nessa fase os veículos utilizados na solução inicial, como meio de reduzir o espaço de busca. De 
maneira inversa, a operação de remoção corresponde a determinar que não seja realizado o atendimento a um dado cliente em um dia específico. Observe-se que a operação de remoção fica definida apenas com a combinação de cliente e dia, sendo supérflua a especificação do veículo nesse tipo de operação, já que ele está implícito no atendimento que se quer remover.

É importante ressaltar que, dada a política de reabastecimento de reposição integral dos estoques dos clientes, a inserção ou remoção de um atendimento não afeta apenas o atendimento em questão, mas também altera a quantidade a ser entregue ao mesmo cliente no atendimento subseqüente, caso este exista. Esse comportamento é ilustrado na Figura 6.1, que apresenta dois gráficos estoque x tempo, representando as situações antes e após a inserção ou remoção de um atendimento $b$ entre os atendimentos $a$ e $c$

Pode-se verificar que a inserção do atendimento $b$ no instante $t_{b}$ implica a reposição do estoque máximo do cliente nesse instante e a redução da quantidade entregue no instante $t_{c}>t_{b}$, que passa a ser $z_{c}^{\prime}=z_{c}-z_{b}$. Já no caso da remoção, o efeito é inverso: a remoção do atendimento no atendimento $t_{b}$ implica o aumento da quantidade entregue no instante $t_{c}$, que passa a ser $z_{c}=z_{c}^{\prime}+z_{b}$.

Observe-se ainda que, por suas características, as operações de inserção e remoção não especificam diretamente a alteração da seqüência de atendimentos da rota afetada. No caso de uma operação de inserção, essa nova seqüência é determinada de forma idêntica à utilizada quando da obtenção da solução inicial. Inicialmente, o atendimento é inserido na primeira posição da rota, ao que se seguem dois procedimentos de melhoria da seqüência de atendimentos: troca da posição de dois atendimentos, e trocas do tipo 2-intercâmbio (CROES, 1958; LIN; KERNIGHAN, 1973). Em ambos procedimentos, as trocas são realizadas segundo a estratégia "first improvement" até que não seja possível obter redução do custo da rota.

No caso de uma operação de remoção o procedimento é similar: executa-se a remoção do atendimento, ao que se seguem os mesmos procedimentos de melhoria utilizados na operação de inserção. Aqui também as trocas são realizadas segundo a 
estratégia "first improvement", e os procedimentos de melhoria são repetidos até que não seja possível obter redução do custo da rota.
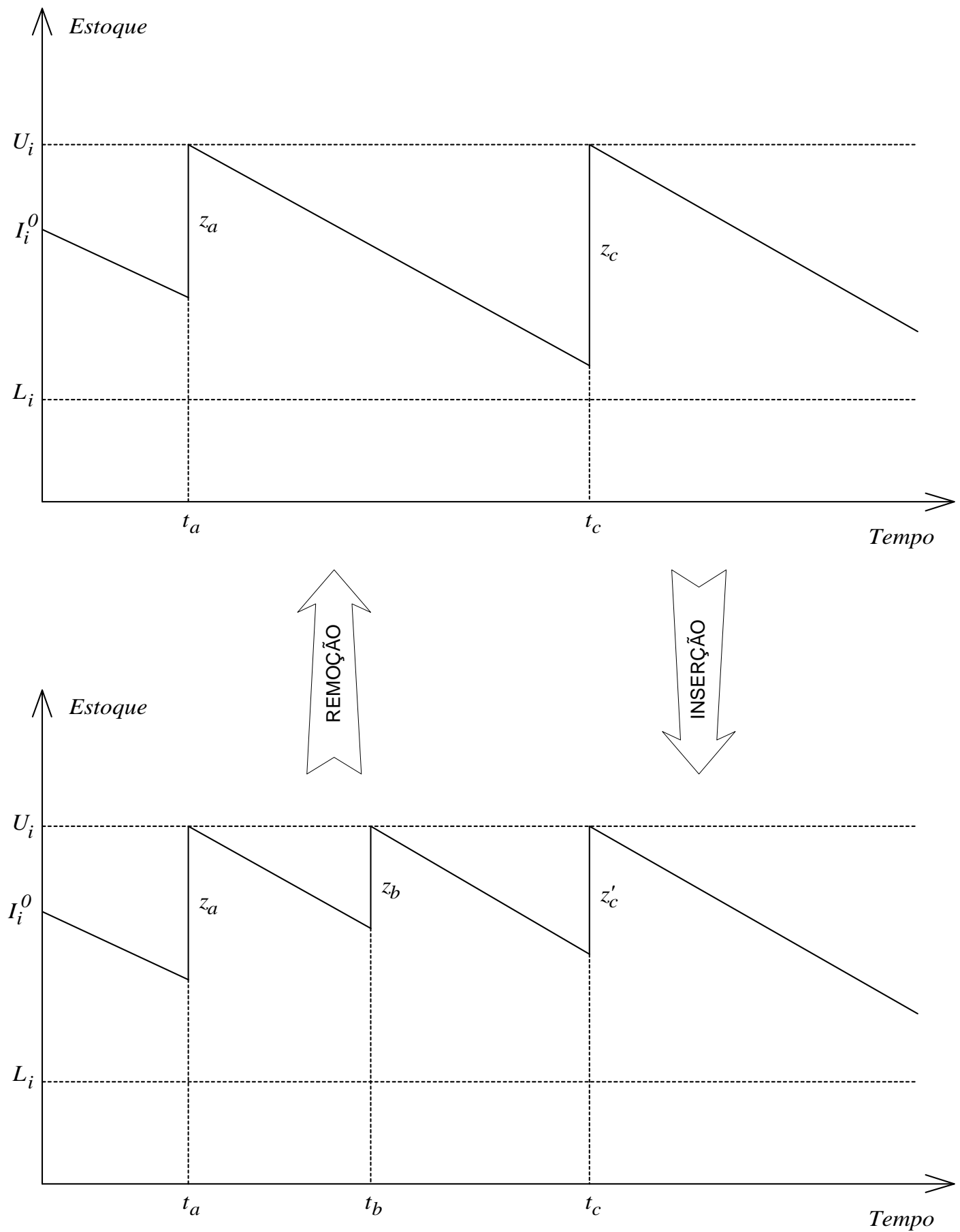

Figura 6.1 - Alteração da quantidade associada à entrega posterior em função da inserção ou remoção de um atendimento. 
A definição dos movimentos decorre de diferentes combinações das operações de inserção e remoção, que podem ser vistas como elementos construtivos dos movimentos, ou seja, um movimento corresponde a um conjunto de operações de inserção e remoção, estando implícita a alteração da quantidade entregue ao cliente no atendimento subsequente a uma operação, caso este exista.

Na presente implementação foram adotados os seguintes tipos de movimentos:

- Movimento I: Consiste em uma operação simples de inserção.

- Movimento R: Consiste em uma operação simples de remoção.

- Movimento A: Consiste em antecipar o atendimento a um cliente. Esse movimento pode ser visto como uma combinação de uma remoção, associada a uma inserção em um dia anterior ao dia do atendimento original.

- Movimento P: Consiste em postergar o atendimento a um cliente. Esse movimento pode ser visto como uma combinação de uma remoção, associada a uma inserção em um dia posterior ao dia do atendimento original.

- Movimento TV1: Consiste em trocar um atendimento de veículo. Esse movimento corresponde à remoção de um atendimento e sua inserção em um outro veículo no mesmo dia do atendimento original, sem alterar a quantidade entregue no cliente naquele dia.

- Movimento TV2: Consiste em trocar dois atendimentos de veículo. Esse movimento corresponde à remoção do primeiro atendimento e sua inserção na rota utilizada pelo segundo atendimento, associado à remoção do segundo atendimento e sua inserção na rota utilizada originalmente pelo primeiro atendimento. Naturalmente, somente são definidos movimentos desse tipo para atendimentos programados para um mesmo dia.

Para uma melhor compreensão dos movimentos adotados e suas características, as figuras a seguir ilustram cada um dos tipos de movimentos listados acima. As Figuras 6.2 e 6.3 apresentam, respectivamente, exemplos dos movimentos do tipo I e do tipo R. Em ambos casos as sequiências de atendimentos representadas 
correspondem a uma mesma rota (combinação de dia e veículo) nas situações antes (a) e após (b) a execução do movimento, e está implícita a alteração da seqüência de atendimentos decorrente da aplicação dos procedimentos de troca de posição e trocas do tipo 2-intercâmbio.

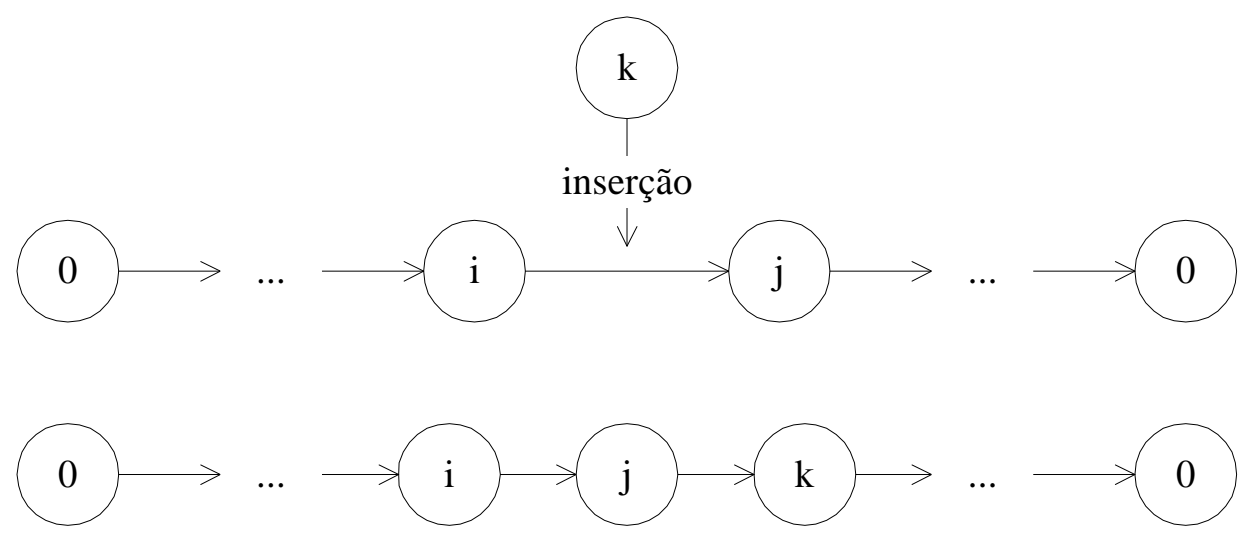

Figura 6.2 - Exemplo de movimento do tipo I

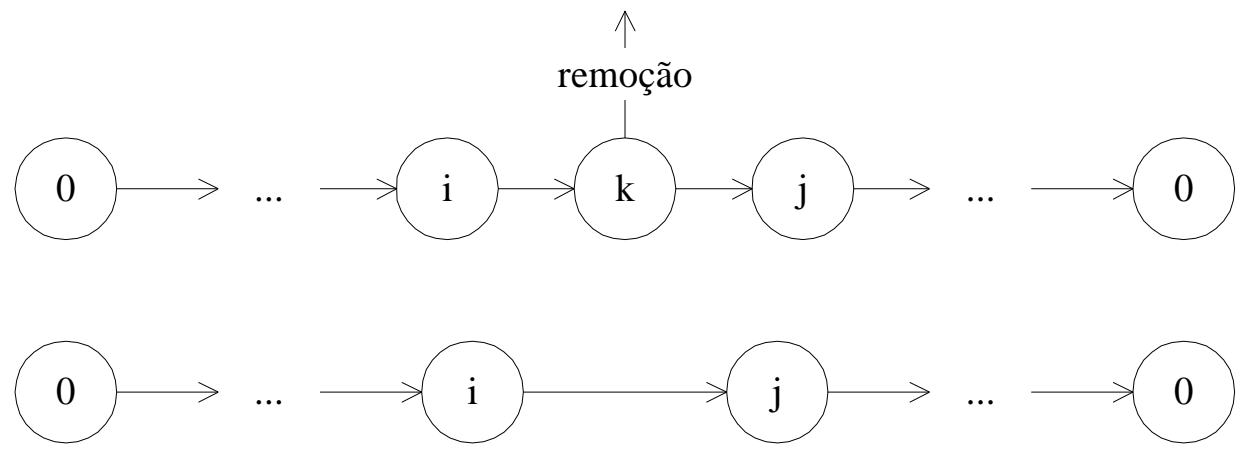

Figura 6.3 - Exemplo de movimento do tipo $R$

As Figuras 6.4 e 6.5 apresentam, respectivamente, exemplos dos movimentos de antecipação (tipo A) e de postergação (tipo P). Em ambos casos estão representadas duas rotas, correspondentes aos dias $d$ e $d^{\prime}>d$, entre as quais ocorre a antecipação ou postergação de um atendimento. Assim como nos exemplos anteriores, são apresentadas as situações antes (a) e após (b) a execução do movimento, e está implícita a alteração da seqüência de atendimentos aplicação dos procedimentos de troca de posição e trocas do tipo 2-intercâmbio. 
Rota dia d
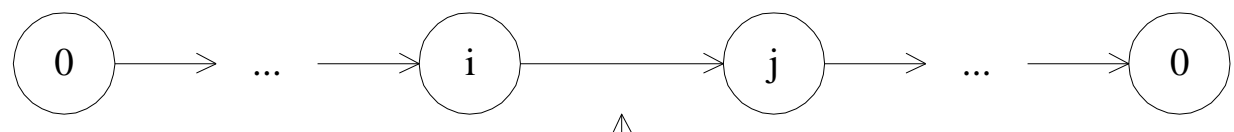

Rota dia d' > d

antecipação

(a)

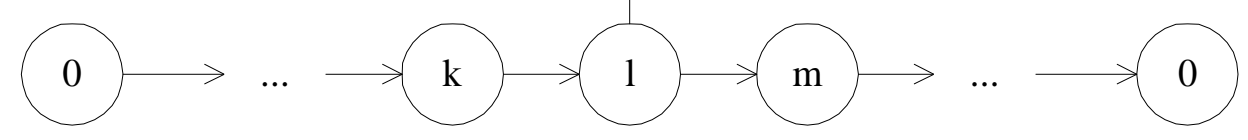

Rota dia d

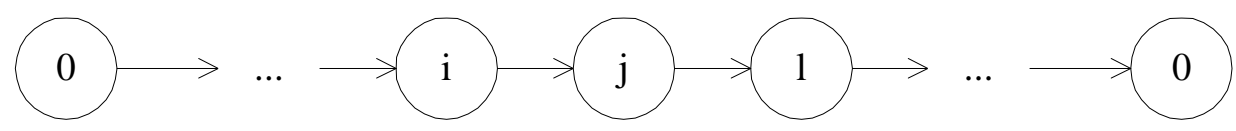

Rota dia d' > d

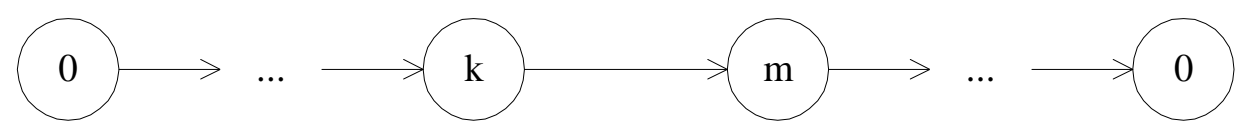

Figura 6.4 - Exemplo de movimento do tipo A

\section{Rota dia d}
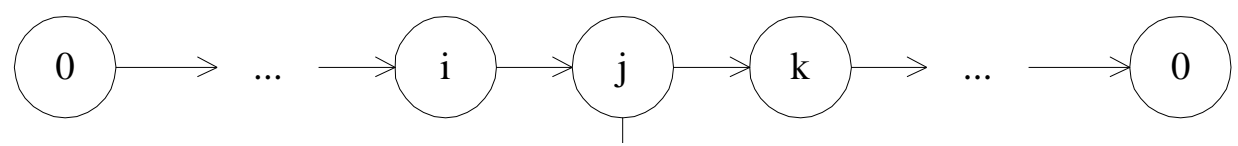

Rota dia d' > d

postergação

(a)
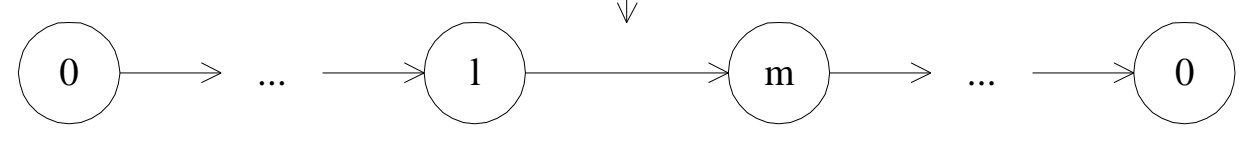

Rota dia d

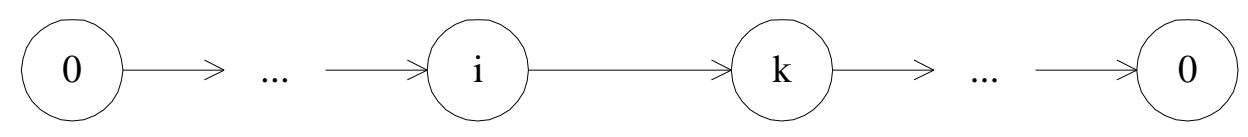

Rota dia d' > d

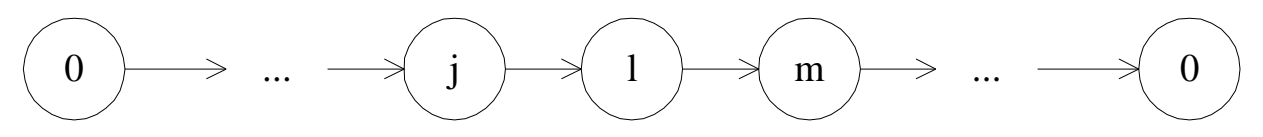

Figura 6.5 - Exemplo de movimento do tipo P 
As Figuras 6.6 e 6.7 apresentam exemplos dos movimentos do tipo TV1 e do tipo TV2, respectivamente. Esses tipos de movimentos envolvem duas rotas, representadas como referentes aos veículos $v$ e $v^{\prime} \neq v$, entre as quais ocorre a transferência do(s) atendimento(s). Note-se que ambas rotas referem-se a um mesmo dia do horizonte de planejamento. Assim como nos exemplos anteriores, são apresentadas as situações antes (a) e após (b) a execução do movimento, e está implícita a alteração da seqüência de atendimentos decorrente da aplicação dos procedimentos de troca de posição e trocas do tipo 2-intercâmbio.

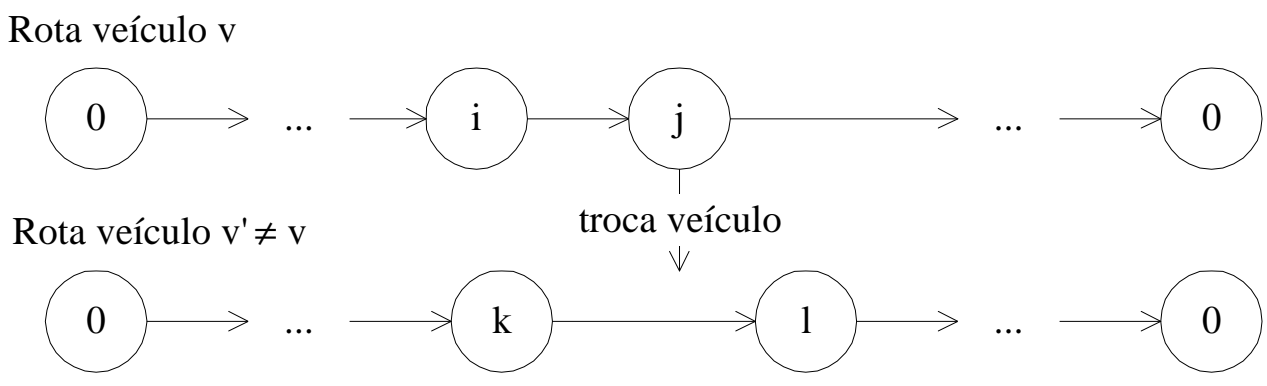

Rota veículo v

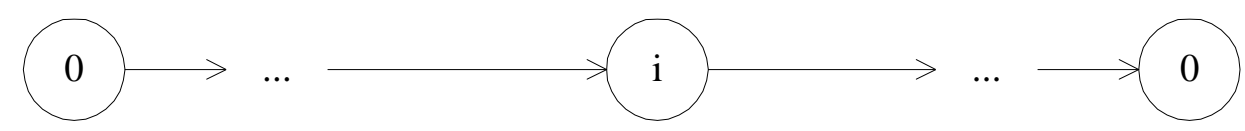

Rota veículo $v^{\prime} \neq \mathrm{v}$

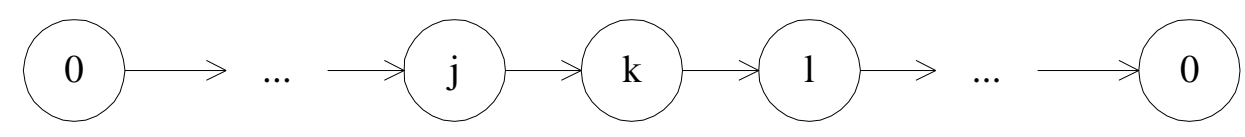

Figura 6.6 - Exemplo de movimento do tipo TV1 
Rota veículo $\mathrm{v}$

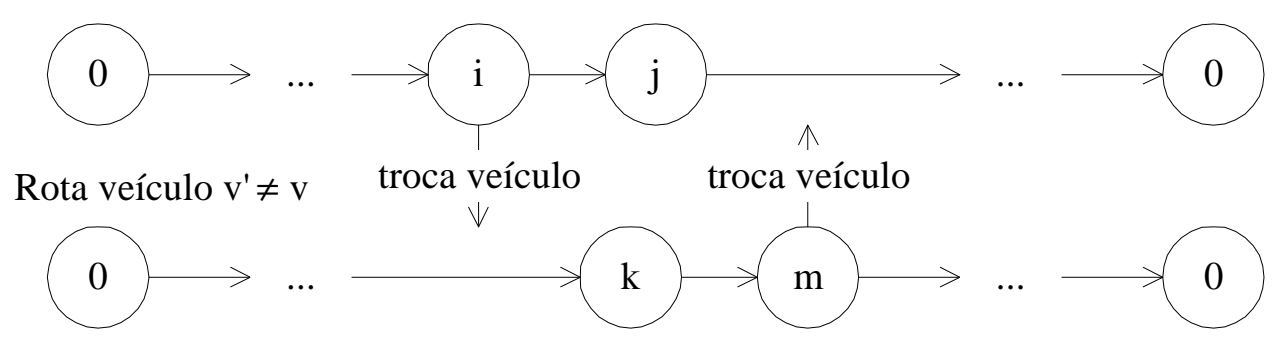

Rota veículo v

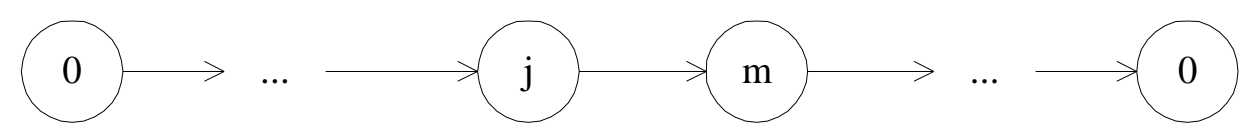

Rota veículo $\mathrm{v}^{\prime} \neq \mathrm{v}$

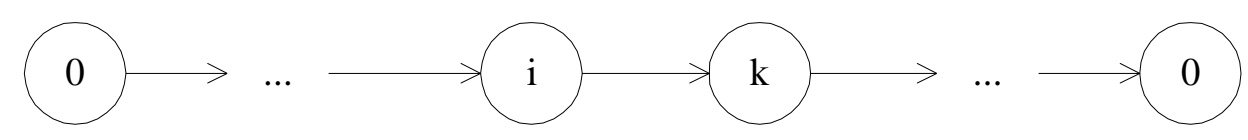

Figura 6.7 - Exemplo de movimento do tipo TV2

Ao longo do desenvolvimento do presente pesquisa, outros tipos de movimentos foram testados, optando-se pela atual seleção em função de um equilíbrio entre a eficiência do movimento e o esforço computacional requerido para a exploração da vizinhança correspondente. Experimentos realizados com movimentos mais complexos, compostos de maior número de operações de inserção e remoção, indicam que o incremento de eficiência obtido não compensa o aumento do esforço computacional requerido para a exploração da vizinhança correspondente, o que acaba por se refletir em piores resultados para um mesmo período de processamento. Um exemplo de movimento com essas características é a combinação de um movimento de remoção com um movimento de antecipação ou postergação. Experimentos realizados indicaram que o aumento explosivo do tamanho da vizinhança e do tempo necessário para sua exploração não é compensado por melhores resultados, podendo-se concluir que a inclusão desse movimento não é vantajoso para a implementação BT. 


\subsubsection{Penalidades}

Uma importante característica dos movimentos adotados é que a vizinhança resultante não se limita ao espaço de soluções viáveis. Ou seja, a execução de movimentos pode levar à violação da restrição de capacidade dos veículos ou à ocorrência de falta de estoque, sendo necessário algum mecanismo de correção que evite que a busca fique presa à região inviável. Isso é conseguido com a modificação da função de custo de uma solução, de modo a incorporar parcelas de penalidade decorrentes da violação de restrições. Essas parcelas de penalidade são recalculadas a cada iteração, aumentando-se o peso da violação se a restrição correspondente permanece violada. De forma inversa, diminui-se o peso da violação se a restrição correspondente passa a ser respeitada. Esse mecanismo é descrito a seguir, obedecendo à nomenclatura definida no Capítulo 3.

Seja $s$ uma solução qualquer (viável ou não) de uma instância do PDEGF, e $C(s)$ a função de custo associada, definida originalmente pela expressão (1) da formulação matemática, apresentada anteriormente no Capítulo 3. Com a incorporação das parcelas de penalidade referentes às violações de restrições, obtém-se:

$$
F(s)=C(s)+\alpha R^{V}(s)+\beta R^{E}(s)
$$

onde:

$$
\begin{aligned}
& R^{V}(s)=\sum_{t \in T} \sum_{v \in V} \max \left\{0, \sum_{i \in N} z_{i}^{v t}(s)-Q^{v}\right\} \\
& R^{E}(s)=\sum_{i \in N} \sum_{t \in T} \max \left\{0, L_{i}-I_{i}^{t}(s)\right\}
\end{aligned}
$$

A expressão (51) corresponde à função de avaliação $F(s)$, que agrega ao custo $C(s)$ da solução, dado pela expressão (1), uma parcela relativa à soma das violações de capacidade dos veículos, representada pela expressão (52), e uma parcela relativa à soma das violações do limite inferior do estoque dos clientes, representada pela expressão (53), ponderadas por seus respectivos pesos, $\alpha$ e $\beta$. Observe-se não ser 
necessária uma parcela de penalidade relativa à violação do limite superior do estoque dos clientes, uma vez que a política de reabastecimento adotada de reposição integral dos estoques assegura que essa restrição não seja violada. Note-se ainda que os multiplicadores $\alpha$ e $\beta$ possuem a dimensão [custo/quantidade], uma vez que as parcelas de penalidade devem ser expressas em termos de custo, e as violações das restrições consideradas correspondem a alguma medida de quantidade, seja esta em termos de peso ou de volume.

A cada iteração, verifica-se a violação das restrições de capacidade do veículo e de falta de estoque nos clientes, e os multiplicadores $\alpha$ e $\beta$ são atualizados de acordo com essa informação, segundo um parâmetro $\varphi$, e limites máximo e mínimo preestabelecidos. Esse procedimento de atualização dos multiplicadores pode ainda ser entendido como um mecanismo de auto-ajuste, que dirige a trajetória de busca de forma a induzir a alternância entre a exploração da região viável e da região inviável.

O processo de atualização dos pesos das penalidades é formalizado a seguir para uma solução $s$, correspondente a uma iteração $k$ do processo de BT:

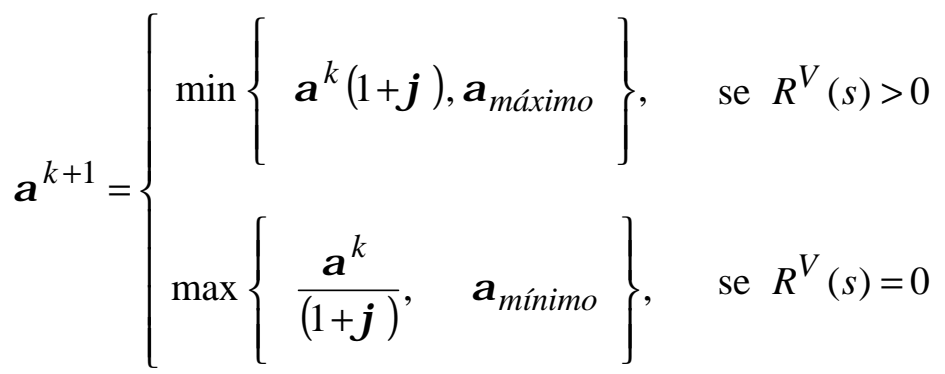

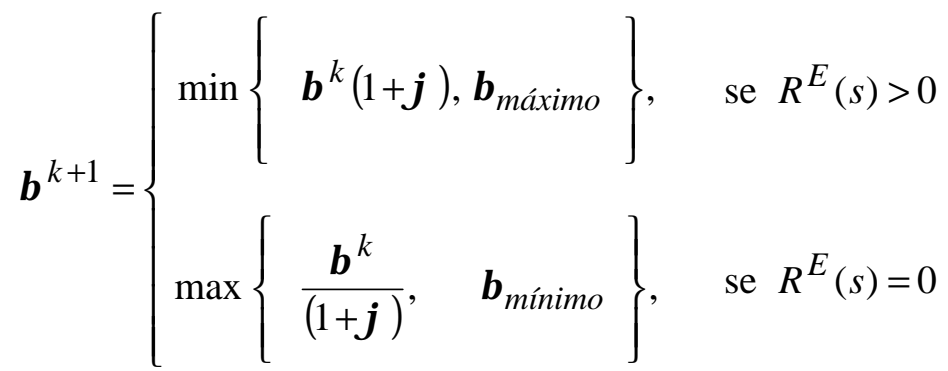

onde:

$$
\alpha^{k}=\text { valor de } \alpha \text { na iteração } k \text {; }
$$




$$
\begin{aligned}
& \beta^{k}=\text { valor de } \beta \text { na iteração } k \\
& \alpha_{\text {mínimo }}=\text { limite inferior para } \alpha ; \\
& \alpha_{\text {máximo }}=\text { limite superior para } \alpha ; \\
& \beta_{\text {mínimo }}=\text { limite inferior para } \beta ; \\
& \beta_{\text {máximo }}=\text { limite superior para } \beta ; \\
& \varphi=\text { parâmetro de atualização dos multiplicadores das penalidades. }
\end{aligned}
$$

Note-se que os limites inferior e superior dos pesos das penalidades são utilizados para manter as parcelas de custo referentes às violações de restrições dentro de uma faixa adequada de valores. Multiplicadores de valor muito baixo fazem com que a eventual violação das restrições seja virtualmente imperceptível em termos de custo. De forma inversa, multiplicadores de valor excessivamente alto fazem com que o custo de uma violação seja tão elevado que praticamente impede que a busca adentre a região de soluções não viáveis.

Observa-se que a exploração da região inviável, associada ao mecanismo de atualização dos multiplicadores das penalidades, induz um desejável comportamento de oscilação estratégica na trajetória de busca, o qual pode ser entendido como uma alternância entre períodos de diversificação e intensificação. Valores reduzidos dos multiplicadores de penalidade permitem a escolha de movimentos que implicam violação de restrições, levando à exploração da região inviável, o que, por sua vez, acarreta o aumento dos multiplicadores de penalidade, forçando a busca a retornar à região viável. Como resultado, obtém-se um comportamento pendular, em que a relaxação parcial das penalidades, resultado da diminuição do valor dos respectivos multiplicadores, produz um efeito de diversificação da busca, efeito este que é invertido com o aumento dos multiplicadores, o que leva a uma intensificação da busca na região viável. 
Um exemplo desse comportamento oscilatório é apresentado na Figura 6.8, que ilustra a variação da penalidade por falta de estoque nos clientes ao longo de um certo número de iterações.

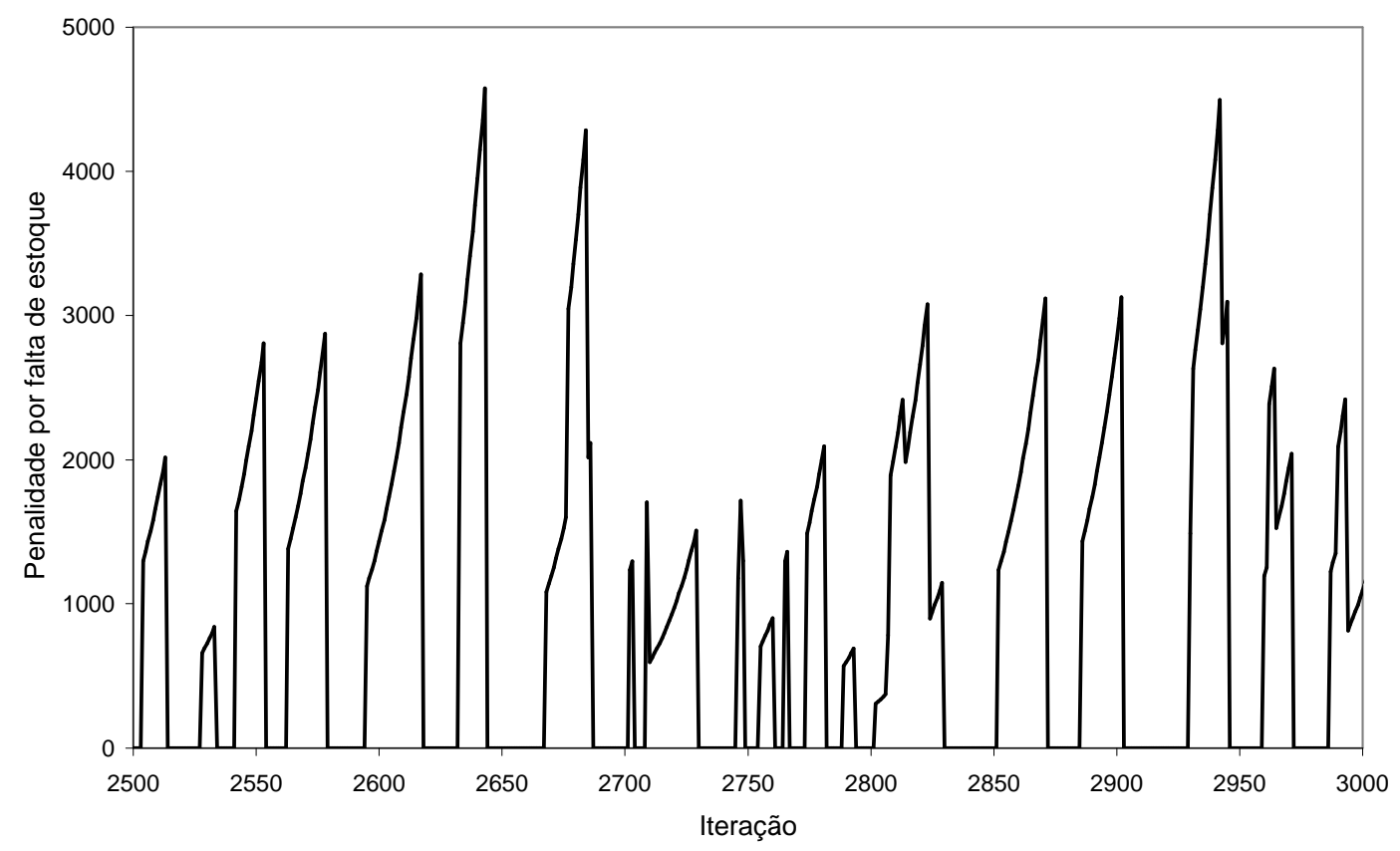

Figura 6.8 - Exemplo da variação da penalidade por falta de estoque nos clientes ao longo da busca.

Observe-se que as restrições de falta de estoque são respeitadas nas iterações em que a penalidade apresenta valor nulo, e violadas nas iterações em que a penalidade é maior que zero. Pode-se notar que há efetivamente uma alternância entre os períodos em que a busca explora soluções inviáveis (penalidade maior que zero) e soluções viáveis (penalidade nula), o que caracteriza o comportamento de oscilação estratégica.

É interessante ainda notar o efeito do aumento do valor da penalidade em função da atualização do respectivo multiplicador. Essa atualização é a responsável pela peculiar forma de "dente de serra" observada na Figura 6.8. Embora o exemplo ilustre apenas a variação da penalidade por falta de estoque, o comportamento da penalidade por violação da capacidade dos veículos é similar. 


\subsubsection{Memória de Curta Duração}

Conforme comentado anteriormente, a lista tabu é a estrutura de memória de curta duração utilizada pela BT a fim de evitar que a busca fique presa a um mínimo local. Na presente implementação, a lista tabu utilizada armazena informações relativas aos atendimentos afetados pelos movimentos realizados. Isto é, armazena-se a iteração em que cada atendimento, definido por uma combinação de cliente, dia e veículo, foi alterado pela última vez, e proíbe-se a realização de movimentos que afetem o mesmo atendimento por um certo número de iterações, usualmente denominado período ou duração tabu. Cabe ressaltar, entretanto, que são considerados tabu apenas os movimentos que incluam operações de inserção relativas a atendimentos com status tabu. Segundo GLOVER; LAGUNA (1997), esse cuidado se justifica, pois o número de atendimentos fora da solução é muito maior que o número de atendimentos pertencentes à solução, sendo razoável proibir o retorno à solução de um atendimento recém retirado, e não o contrário. Esse comportamento foi comprovado empiricamente em versões preliminares da presente implementação computacional, que indicaram que a extensão do status tabu para operações de remoção piora a qualidade das soluções obtidas.

GLOVER; LAGUNA (1997) apontam ainda que períodos tabu de menor duração geralmente induzem à exploração de soluções próximas a um mínimo local, ao passo que durações maiores permitem que a busca se desloque para uma região livre da influência de um mínimo local. Essa característica sugere a utilização de um período tabu variável que, segundo os autores, pode ser classificado como sistemático ou dinâmico. O primeiro caso consiste em utilizar, sistemática e seqüencialmente, valores de uma lista de períodos tabu previamente definida. Já o segundo caso consiste em selecionar aleatoriamente um valor para a duração tabu dentre uma faixa definida por limites máximo e mínimo preestabelecidos. Essa última abordagem é bastante comum, podendo-se citar aqui os trabalhos de TAILLARD (1993b) e GENDREAU et al. (1994), como exemplos bem sucedidos de aplicações de BT a problemas de roteirização de veículos que utilizam período tabu com essa característica. 
Versões preliminares da presente implementação utilizaram período tabu fixo, calculado como o número inteiro mais próximo de $7.5 \log _{10}(|N|)$, onde $|N|$ corresponde ao número de clientes da instância do problema, de acordo com o recomendado por CORDEAU et al. (1997) para o problema de roteirização periódica. Entretanto, uma investigação posterior demonstrou que essa forma de cálculo não é a mais adequada para o PDEGF. Experimentos realizados com instâncias de diferentes dimensões indicam que o valor mais adequado do período tabu é afetado não só pelo número de clientes da instância em questão, mas também pela extensão do horizonte de planejamento e pelo número de veículos utilizados.

Para uma adequada estimação do período tabu é necessário entender a influência desse parâmetro na qualidade da solução final. Nos experimentos realizados, verificou-se que o custo da solução final varia em função do período tabu segundo um padrão bem definido. Valores reduzidos de duração tabu não permitem que a busca escape de mínimos locais, e valores demasiado elevados impedem que a busca se aprofunde em regiões promissoras. Ambas situações se traduzem em soluções finais de maior custo, como apresentado na Figura 6.9, que ilustra, para uma instância de teste, o comportamento de variação do custo da solução final em função da variação da duração tabu.

Sob o ponto de vista prático, a construção experimental de uma curva de custo em função da duração tabu nem sempre é possível em um contexto operacional de tomada de decisão, uma vez que tal processo é consideravelmente demorado e muitas vezes não se dispõe de tempo suficiente para tal. Nesse caso, relações calibradas de antemão, tais como a função proposta por CORDEAU et al. (1997), podem ser de grande ajuda. Entretanto, uma vez mais, cabe enfatizar que a utilização de tais funções deve ser judiciosa e baseada em algum tipo de verificação prévia da sua validade para o tipo e as dimensões da instância do problema considerado. 


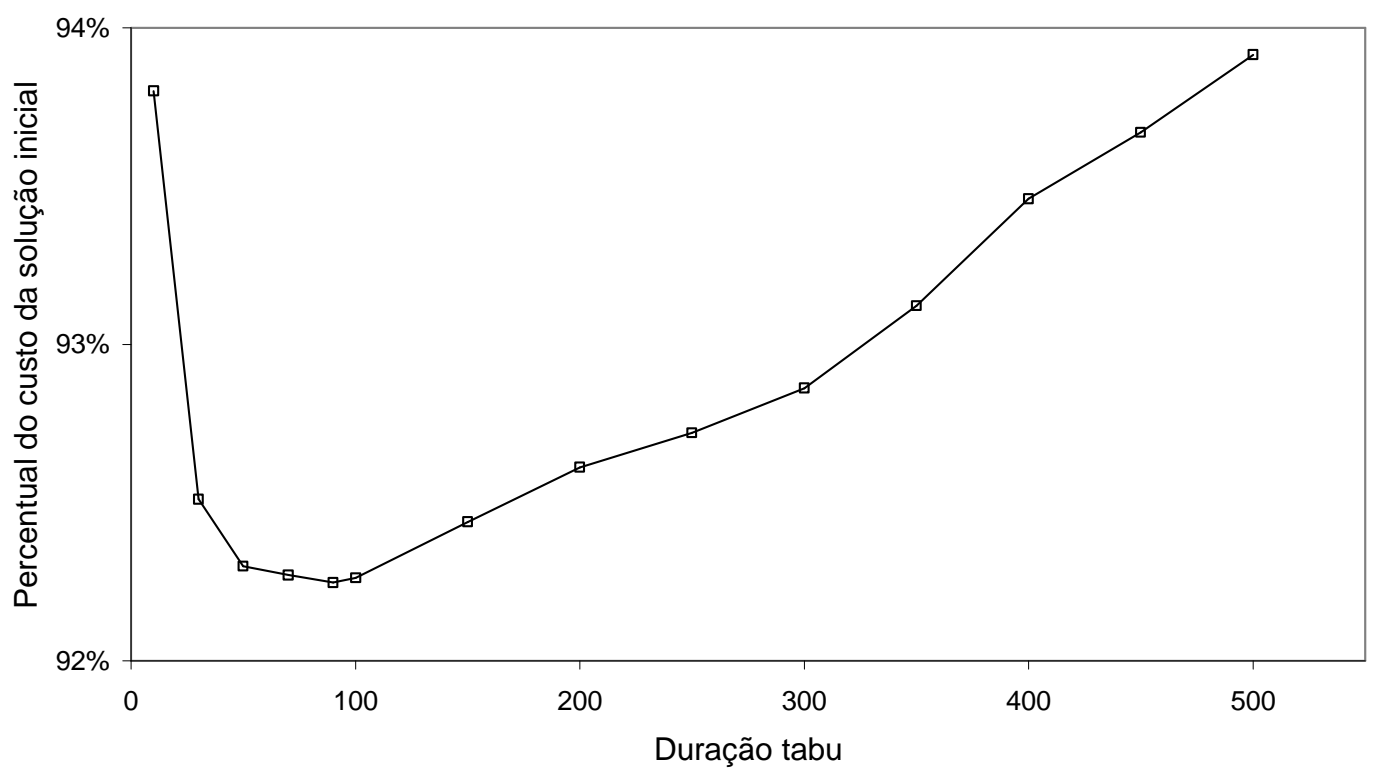

Figura 6.9 - Comportamento de variação do custo da solução final em função da duração tabu.

No presente trabalho, logrou-se ajustar, com razoável grau de sucesso $\left(\mathrm{R}^{2}=0,79\right)$, uma função que relaciona o parâmetro duração tabu com a dimensão do problema, entendida aqui como o produto do número de clientes, número de dias do horizonte de planejamento e número de veículos utilizados na solução inicial. Essa função foi obtida a partir de uma amostra de instâncias com 50 a 150 clientes e horizonte de planejamento de 6 ou 30 dias, podendo ser formalizada como:

$\theta=33.016 \times \ln (|N| \cdot|T| \cdot|V U|)-218.56$

onde

$\theta=$ duração tabu;

$|N|=$ número de clientes;

$|T|=$ número de dias do horizonte de planejamento;

$|V U|=$ número de veículos utilizados na solução inicial. 
Cabe sublinhar que a amostra utilizada para calibração da expressão (56) corresponde a instâncias com ordem de grandeza similares às instâncias de teste que serão utilizadas para a avaliação computacional das heurísticas propostas, e não deve ser aplicada indiscriminadamente a instâncias de qualquer dimensão. É fácil perceber que a função obtida pode tomar valores negativos para instâncias de dimensões reduzidas, o que, evidentemente, não tem qualquer sentido prático.

No presente trabalho, optou-se por utilizar um período tabu dinâmico e aleatório, sorteado em um intervalo definido em torno da duração tabu calculada segundo a expressão (56). Isto é, calculado o valor da duração tabu segundo a função calibrada, determina-se um intervalo cujos limites correspondem a uma dada variação percentual em torno desse valor, e a cada iteração um novo valor de período tabu é sorteado nesse intervalo. Esse procedimento busca incorporar um mecanismo adicional de escape de um mínimo local, representado pelo seleção aleatória dentro do intervalo predeterminado.

Como já comentado anteriormente, o funcionamento da lista tabu envolve também a utilização de mecanismos de flexibilização da proibição de movimentos, quando estes resultarem vantajosos. Esses mecanismos de flexibilização são denominados critérios de aspiração, e correspondem a condições a que um movimento deve obedecer para que seu status tabu seja revogado.

O critério utilizado no presente trabalho consiste em revogar a proibição de um movimento toda vez que sua aplicação levar a uma solução de menor custo que a melhor solução encontrada até então no processo de busca. GLOVER; LAGUNA (1993, 1997) apontam que esse tipo de critério é amplamente utilizado, embora outros critérios alternativos mereçam consideração, em particular aqueles que envolvem alguma medida da influência do movimento. No contexto da BT, a influência de um movimento é definida como o grau com que ele altera a estrutura (ou viabilidade) de uma solução. Movimentos de maior influência promovem alterações mais profundas na estrutura da solução e aumentam as chances da busca se deslocar para outra região, sendo importantes quando se procura escapar de um mínimo local. Nesse contexto, os autores afirmam que a alteração da estrutura da solução, decorrente da execução de um movimento de grande influência, pode 
justificar a revogação do status tabu de movimentos de pouca influência, o que também vem a ser uma forma de critério de aspiração.

\subsubsection{Estratégia de Diversificação e Intensificação}

Embora em muitos casos as estruturas de memória de curto prazo sejam suficientes para se obter uma solução de boa qualidade, geralmente considera-se que a incorporação de estratégias de diversificação e/ou intensificação complementa o funcionamento das estruturas de memória de curta duração e torna o processo de busca mais poderoso. Estratégias de diversificação procuram evitar que regiões do espaço de busca permaneçam completamente inexploradas, ao passo que as estratégias de intensificação procuram focar a busca nas regiões mais promissoras do espaço de busca.

Grande parte das estratégias de diversificação e/ou intensificação baseia-se na utilização de informação associada à freqüência da ocorrência de atributos das soluções ao longo do processo de busca. GLOVER; LAGUNA $(1993,1997)$ ensinam que essas medidas de freqüência são calculadas como razões, em que o numerador corresponde a uma medida de transição ("transition measure") ou medida de permanência ("residence measure"), e que os denominadores geralmente representam um valor tal como o total do número de ocorrências dos eventos representados nos numeradores, ou a média (ou soma, ou máximo) desse valores. Medidas de transição medem a freqüência com que atributos são alterados durante a busca, isto é, a freqüência com que são adicionados ou eliminados durante esse processo; já as medidas de permanência correspondem à frequiência com que atributos pertencem às soluções visitadas durante o processo de busca.

Entretanto, vale notar que estratégias de diversificação e/ou intensificação nem sempre necessitam estruturas de memória de longa duração para alcançar seus objetivos. Como exemplos, HERTZ et al. (1997) citam a modificação da vizinhança pela inclusão de movimentos mais complexos como uma forma de intensificação, e a utilização de reinícios aleatórios como uma forma de diversificação. No presente trabalho propõe-se a utilização de uma estratégia de diversificação baseada na 
modificação da função de avaliação dos movimentos. Esse mecanismo não faz uso de informação associada à freqüência, mas sim está relacionado ao comportamento de oscilação estratégica descrito na seção 6.2.2. Conforme observado naquela ocasião, a relaxação parcial das restrições induz a exploração da região inviável do espaço de busca, efeito esse que é invertido com a atualização dos multiplicadores das penalidades. Como resultado, obtém-se um efeito pendular, em que as regiões viáveis e inviáveis são exploradas de maneira alternada. Observa-se ainda que o deslocamento da busca para a região inviável acaba por gerar um efeito de diversificação, uma vez que, devido à atuação da memória de curta duração, a busca usualmente retorna ao espaço viável em uma região diferente da região de partida.

Esse comportamento é explorado de forma deliberada como um mecanismo simples de diversificação, que consiste em forçar um deslocamento expressivo em direção à região inviável toda vez que for observada uma estagnação da busca. Isto é, ao ser constatado que não foi obtida redução no custo da melhor solução por um determinado número de iterações, o peso da violação da restrição de capacidade dos veículos é alterado para o seu valor mínimo.

Verificou-se que a alteração do peso da penalidade de falta de estoque não é muito efetiva nesse mecanismo. Esse comportamento deve-se ao fato de que a relaxação das restrições de falta de estoque induz primordialmente operações de remoção de atendimentos. Essas remoções provocam o remanejamento dos demais atendimentos, o que geralmente dificulta a posterior reinserção dos atendimentos necessários para corrigir a falta de estoque, e resulta no retorno da busca a uma região viável de maior custo que a região de origem.

Já a relaxação das restrições de capacidade dos veículos induz primordialmente movimentos de inserção e transferência de atendimentos entre veículos e, nesse caso, o retorno à região viável envolve operações de remoção de atendimentos, que podem ser executadas com menor impacto no custo da solução viável resultante. Na presente implementação foi adotada a relaxação apenas das restrições de capacidade do veículo na estratégia de diversificação, sendo seu mecanismo de ativação ilustrado na Figura 6.10. 
Como pode-se notar, o mecanismo de ativação da diversificação está incorporado ao cálculo da função de avaliação $F(s)$, e consiste em alterar o valor de $\alpha$ para o seu limite inferior $\alpha_{\text {mínimo }}$ sempre que a estagnação da busca, entendida aqui como o número de iterações sem redução no custo da melhor solução, alcance um limite predeterminado (linha 2).

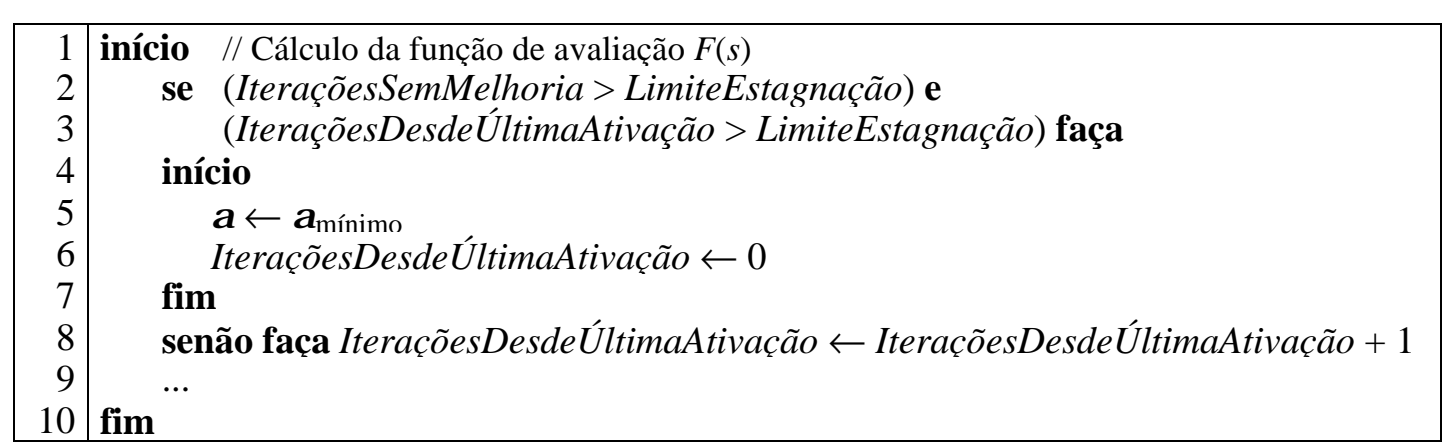

Figura 6.10 - Fragmento de pseudocódigo correspondente ao mecanismo de ativação da estratégia de diversificação inserido no cálculo da função de avaliação $F(s)$.

Naturalmente, é necessária uma verificação da última vez que a diversificação foi ativada (linha 3); caso contrário o mecanismo poderia ser ativado a cada iteração, mantendo a busca indefinidamente na região inviável. É importante notar que o mecanismo ocorre na forma de um pulso, de forma distinta dos casos em que a diversificação se baseia na penalização de atributos dos movimentos, casos estes em que usualmente são definidas condições para a ativação e desativação da diversificação.

Um exemplo do comportamento resultante do mecanismo de diversificação é apresentado na Figura 6.11, que ilustra a variação da penalidade por violação da capacidade dos veículos ao longo de um certo número de iterações. Pode-se observar que por volta da iteração 2250 o mecanismo de diversificação é ativado, deslocando a busca para a região inviável por cerca de 120 iterações (até iteração 2370 aproximadamente), quando a penalidade por violação de capacidade dos veículos volta a ser nula, indicando que as respectivas restrições passaram a ser respeitadas.

Note-se ainda que o valor da penalidade atinge seu pico em torno da iteração 2315, decrescendo a partir desse ponto. Esse comportamento indica que, numa primeira etapa, o multiplicador da penalidade ainda é pequeno o suficiente para permitir a 
reprogramação dos atendimentos incorrendo-se em eventuais aumentos da violação da capacidade dos veículos. Entretanto, a partir do pico, o multiplicador da penalidade atinge valor tal que força a escolha de movimentos que reduzam a violação das restrições, o que acaba por levar a trajetória de busca de volta à região viável.

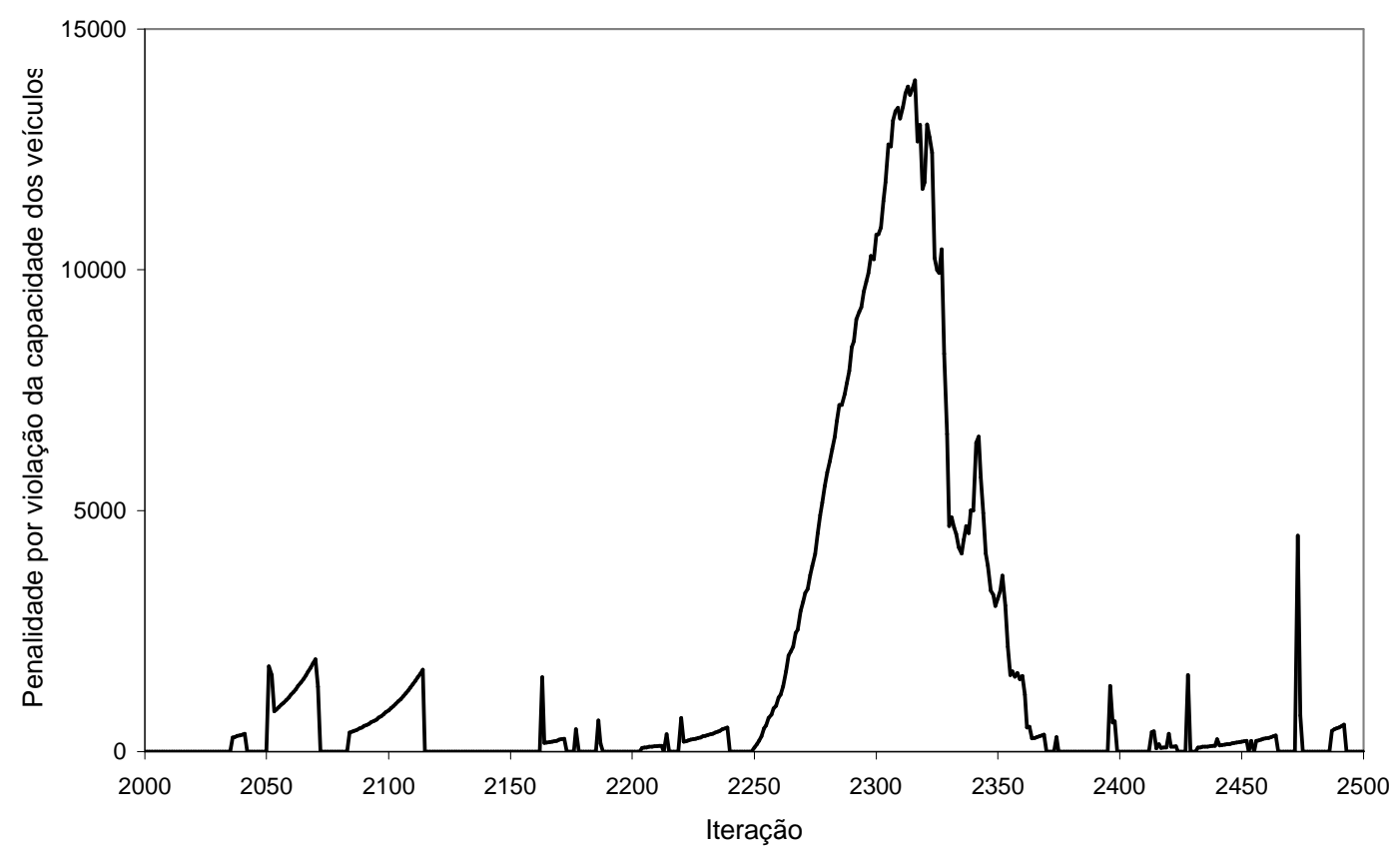

Figura 6.11 - Exemplo do comportamento decorrente da ativação do mecanismo de diversificação.

Exemplos da manipulação de pesos de penalidades como mecanismo de diversificação podem ser encontrados nos trabalhos de HERTZ; DE WERRA (1989) apud GLOVER et al. (1993) e COSTA (1994) para a resolução de problemas de programação de turnos e horários escolares. Nesse tipo de problema, o que se busca é a obtenção de uma solução viável, face a restrições de diversas categorias. A abordagem descrita, denominada "shifting penalty approach", baseia-se em funções de penalidade, definidas para cada restrição a partir da quantificação da correspondente violação. A função objetivo corresponde à soma das funções de penalidade, sendo que é dado maior peso às restrições mais importantes. Ao início da busca, as restrições com maiores pesos são atendidas em primeiro lugar, quando então o processo procura o atendimento das restrições associadas a menores pesos. Para diversificar a busca, o peso das restrições de maior importância é reduzido por 
um número predeterminado de iterações, ao fim do qual seu valor original é restaurado.

Observe-se que, embora compartilhando o mesmo princípio fundamental, a estratégia de diversificação proposta no presente trabalho e a apresentada no parágrafo anterior possuem características distintas. A estratégia proposta atua em conjunto com o mecanismo de auto-ajuste das penalidades, que se encarrega de dirigir a busca de volta à região viável, não havendo necessidade de uma regra para desligar o processo de diversificação.

Versões preliminares da presente implementação investigaram a utilização de um mecanismo de diversificação baseado na penalização de movimentos em função da freqüência de inserção de atendimentos ao longo da busca. Entretanto, esse tipo de diversificação mostrou-se menos eficaz que o mecanismo proposto, razão pela qual foi descartado.

Segundo GLOVER; LAGUNA (1997), as estratégias de intensificação usualmente baseiam-se na modificação da avaliação dos movimentos candidatos, ou no reinício da busca em regiões mais promissoras. A primeira abordagem consiste em alterar as regras de escolha ou avaliação dos movimentos candidatos, de maneira a incentivar movimentos com atributos desejáveis, como é o caso da estratégia de intensificação por decomposição, em que restrições são impostas a um subconjunto dos atributos de uma solução, e somente são considerados candidatos os movimentos que não afetem atributos pertencentes a esse subconjunto. Essa estratégia pode ser exemplificada no clássico problema do caixeiro viajante, em que a vizinhança de uma solução intermediária pode ser decomposta em função de um conjunto de soluções de elite previamente armazenadas. A interseção dessas soluções de elite define um conjunto de arcos, e apenas são avaliados os movimentos que não alterem esse conjunto de arcos. Ou seja, o problema é decomposto em duas partes: a primeira, correspondente à interseção dos arcos das soluções de elite, e a segunda, correspondente aos demais arcos. Ao limitar a busca apenas à segunda parte do problema, realiza-se, na verdade, uma intensificação da busca nessa região. 
A segunda categoria de estratégias de intensificação consiste em reiniciar a busca a partir soluções de elite armazenadas ao longo da busca. Nesse caso, GLOVER; LAGUNA (1997) apontam como variações aplicadas com sucesso a utilização de uma medida de diversidade mínima entre as soluções armazenadas no conjunto de elite, e o armazenamento adicional da memória de curta duração, como forma de evitar a repetição da trajetória de busca.

Na heurística EGF-BT-DI, a etapa de melhoria foi subdividida em duas fases. A primeira fase corresponde à aplicação da BT com o mecanismo de diversificação, armazenando-se, entretanto, as soluções de elite segundo critérios que serão descritos mais adiante. A segunda fase consiste em reinicializar a busca a partir de soluções de elite, armazenadas ao longo do processo de busca, e está diretamente relacionada à utilização de períodos tabu aleatórios, uma vez estes evitam que a trajetória de busca a partir de uma mesma solução seja repetida toda vez que é utilizada em um reinício. O funcionamento da estratégia de intensificação proposta é apresentado a seguir na Figura 6.12.

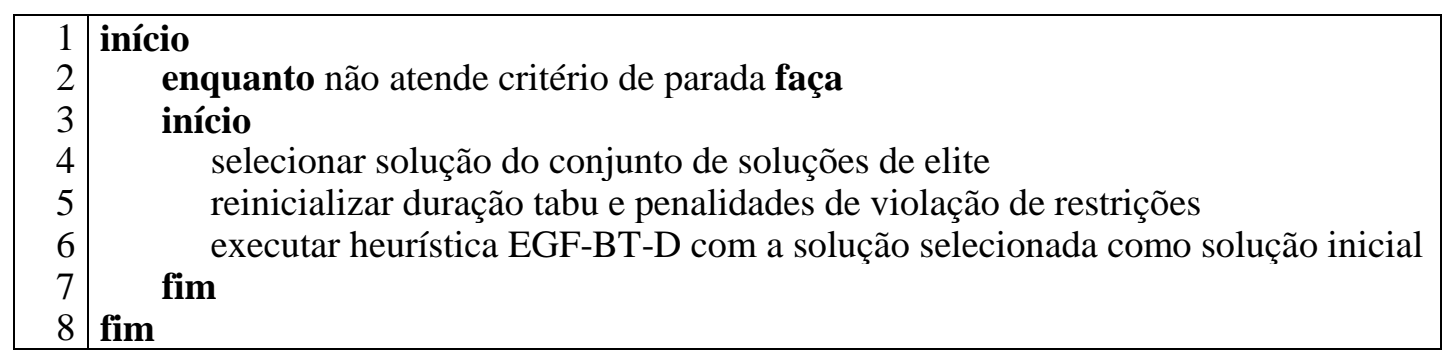

Figura 6.12 - Funcionamento da estratégia de intensificação baseada em reinício com soluções de elite.

O conjunto de soluções de elite é formado por uma seleção das melhores soluções encontradas ao longo da busca. Estipula-se que a inserção de uma solução nesse conjunto ocorra apenas se essa solução corresponder a uma redução de custo em relação à melhor solução encontrada até o momento, além de apresentar um nível mínimo de diversidade em relação às demais soluções já armazenadas. Após a inserção, verifica-se se o conjunto resultante possui mais elementos que um limite preestabelecido, caso em que o elemento de pior avaliação é descartado. No presente caso, a medida de diversidade é calculada como o número de atendimentos distintos entre duas soluções $s^{A}$ e $s^{B}$ quaisquer, podendo ser formalizada como: 
$\operatorname{diversidade}\left(s^{A}, s^{B}\right)=\sum_{j \in N} \sum_{v \in V} \sum_{t \in T}\left[\left|\sum_{i \in S} x_{i j}^{v t}\left(s^{A}\right)-\sum_{i \in S} x_{i j}^{v t}\left(s^{B}\right)\right|\right]$

Note-se que não são armazenadas informações relativas à duração tabu e peso das penalidades das soluções de elite, sendo essas estruturas reinicializadas para seus valores iniciais antes de cada reinício. Por fim, cabe notar que o armazenamento das soluções de elite permanece ativo durante a segunda fase da etapa de melhoria, isto é, uma melhor solução encontrada na fase de intensificação pode ser agregada ao conjunto de elite e utilizada como solução inicial para um reinício.

\subsubsection{Avaliação dos Movimentos Candidatos}

Seja $s$ uma solução qualquer de uma instância do PDEGF, e $C(s)$ a função de custo associada, definida originalmente pela expressão (1) da formulação matemática. Seja ainda $s^{m}$ uma solução da vizinhança de $s$, correspondente à execução de um movimento $m$.

A avaliação do movimento $m$ se dá pela avaliação da solução $s^{m}$ segundo a função $F\left(s^{m}\right)$ (expressão 52), que pode ser decomposta em duas partes, conforme apresentado na seção 6.2.2: custo da solução e penalidades relativas às violações de restrições. Tanto na primeira parcela quanto na segunda, os cálculos podem ser simplificados, levando-se em conta que a execução de um movimento altera apenas um conjunto limitado de rotas e clientes. Em outras palavras, não é necessário recalcular todas as parcelas de custo, mas apenas a diferença entre a solução corrente $s$ e a solução vizinha $s^{m}$.

A primeira parcela, relativa ao cálculo do custo da solução, corresponde à determinação das variáveis de decisão $z_{i}^{v t}, x_{i j}^{v t}, F^{v}, y^{t}$ e $Y^{t}$. Observa-se que as variáveis $z_{i}^{v t}$, correspondentes à quantidade de produto fornecida em cada atendimento, podem ser facilmente atualizadas, dada a política de reabastecimento adotada. Isto é, conhecido o instante do último atendimento, a quantidade a ser entregue a um cliente deve igualar o total consumido desde o último atendimento. No 
caso do primeiro atendimento a um cliente, o cálculo é feito em função do estoque inicial e do tempo decorrido desde o início do período de planejamento. É fácil perceber que não há necessidade de se recalcular todo o conjunto das variáveis $z_{i}^{v t}$ a cada movimento analisado, mas apenas as variáveis referentes aos clientes afetados pelo movimento.

De maneira similar, pode-se notar que a inserção ou a remoção de um atendimento afeta apenas as variáveis $x_{i j}^{v t}$ correspondentes ao mesmo dia $t$ e veículo $v$, ou seja, os atendimentos que utilizam a mesma rota. A determinação das alterações das variáveis $x_{i j}^{v t}$, utiliza um procedimento similar ao descrito no Capítulo 5 para a programação das rotas de distribuição da solução inicial, e que pode ser resumido como, após a inserção ou remoção de um atendimento, aplicar os procedimentos de melhoria por meio da troca de posição de dois atendimentos e trocas do tipo 2-intercâmbio (CROES, 1958; LIN; KERNIGHAN, 1973), até que não seja possível obter redução do custo da rota. A atualização das variáveis $F^{v}$ é ainda mais simples, bastando atualizar seu valor apenas para o(s) veículo(s) envolvido(s) no movimento.

Por sua vez, a atualização das variáveis $y^{t}$ e $Y^{t}$ depende da atualização prévia das variáveis $z_{i}^{v t}$, e corresponde à resolução do subproblema de planejamento da produção, para o qual é possível obter solução exata em tempo polinomial por meio do algoritmo descrito na seção 5.4. Atualizadas as variáveis de decisão correspondentes à solução $s^{m}$, o cálculo de $C\left(s^{m}\right)$ se dá pela aplicação direta da função de custo (1), definida na formulação matemática contida no Capítulo 3.

O cálculo da segunda parcela da função de avaliação, referente à violação das restrições, também pode ser acelerado ao se armazenar, a cada iteração, a soma das violações das restrições da solução executada. Isto é, os valores $R^{V}(s)$ e $R^{E}(s)$ são armazenados, e a obtenção de $R^{V}\left(s^{m}\right)$ e $R^{E}\left(s^{m}\right)$ passa a depender apenas das rotas e clientes afetados pelo movimento, o que demanda menor esforço computacional. 


\subsubsection{Gerenciamento da Lista de Movimentos Candidatos}

Estreitamente relacionada à avaliação dos movimentos, o gerenciamento da lista de movimentos candidatos é um dos fatores chave para uma eficiente implementação da busca tabu. Freqüentemente os movimentos adotados definem uma vizinhança demasiado ampla, cuja completa exploração pode ser muito custosa do ponto de vista computacional, como parece ser o caso da presente implementação.

Nesse sentido, GLOVER et al. (1993) afirmam que amiúde é recomendável aplicar a BT em conjunto com alguma estratégia que isole regiões da vizinhança que contenham movimentos com características desejáveis, inserindo-os na lista de movimentos candidatos. Diversas estratégias de gerenciamento da lista de movimentos que restringem o número de movimentos considerados são comentadas pelos autores, assim como por GLOVER; LAGUNA (1997), das quais pode-se destacar a estratégia de candidatos de elite ("elite candidate list") e a estratégia de filtros sucessivos (“successive filter strategy"), entre outras.

A primeira estratégia consiste em inicialmente construir a lista de candidatos de elite com todos os movimentos da vizinhança, que são então avaliados, mantendo-se apenas os melhores movimentos. A cada iteração subsequente, o melhor movimento da lista é selecionado, até que não seja possível alcançar um mínimo de qualidade preestabelecido, quando então a lista de candidatos é recriada, repetindo-se todo o processo. Essa estratégia fundamenta-se na hipótese de que a qualidade de um movimento não se deteriora em um número reduzido de iterações. Ou seja, um bom movimento continua sendo atrativo (de elite), mesmo após a realização de algumas iterações.

A segunda estratégia baseia-se no fato de que um movimento, em geral, pode ser decomposto em operações mais simples, e que o conjunto de movimentos candidatos pode ser reduzido pela eliminação dos movimentos cujas operações constituintes não alcancem um determinado limite de qualidade. Essa estratégia baseia-se na hipótese de que a avaliação aproximada dos movimentos por meio de suas operações mais simples, de menor esforço computacional, é suficiente para permitir a seleção dos melhores movimentos. 
Não se pode deixar de comentar ainda a interessante estratégia de redução da lista de movimentos candidatos denominada busca tabu granular, segundo proposta de TOTH; VIGO (2003). Os autores descrevem a aplicação dessa estratégia ao problema de roteirização de veículos, em que propõem a adoção de um limite de "granularidade" para a eliminação, a priori, dos arcos de maior custo do grafo associado ao problema, cuja probabilidade de pertencer a uma solução de boa qualidade é extremamente reduzida. Pode-se notar que essa abordagem incorpora elementos das estratégias comentadas anteriormente, pois reduz a lista de candidatos ao filtrar a vizinhança segundo características dos arcos formadores dos movimentos, e considera reconstruções periódicas da lista de candidatos, similar ao que ocorre na estratégia de candidatos de elite.

No contexto do presente trabalho, verifica-se que os movimentos considerados, por sua própria característica, não são apropriados para a adoção de uma estratégia de filtros sucessivos, como a exposta anteriormente. Embora os movimentos sejam passíveis de decomposição em operações mais simples de inserção e remoção, o custo dessas operações não é fixo e independente dos demais atendimentos, condição necessária para a aplicação da estratégia de filtros sucessivos. Por exemplo, a inserção de um atendimento aumenta o custo da rota em que é realizada a inserção, porém a quantificação desse aumento depende dos demais atendimentos da rota. O mesmo se aplica ao caso da remoção de um atendimento, não sendo possível falar de um custo absoluto para uma inserção ou remoção de um cliente em uma rota.

Essa mesma característica dificulta também a aplicação direta da estratégia de candidatos de elite, já que a execução de um movimento pode alterar significativamente a avaliação dos demais elementos da lista, exigindo a constante reconstrução da mesma, o que inviabilizaria a estratégia em questão. Um exemplo nesse sentido consiste em considerar uma solução intermediária não viável, em que se observa falta de estoque em um determinado cliente. É de se esperar que a lista de movimentos de elite contenha movimentos com operações de inserção para o cliente em questão, de forma a suprir a falta de estoque e anular a penalidade correspondente. Entretanto, a execução de um desses movimentos altera expressivamente a avaliação dos demais, quando não os elimina totalmente. É 
evidente que operações de inserção com a mesma combinação de cliente e dia perdem totalmente o sentido, e a eliminação da parcela relativa à penalidade por falta de estoque altera de forma significativa a avaliação de outros movimentos associados ao mesmo cliente.

Pelos motivos acima, fica patente a necessidade de alguma adaptação das estratégias apresentadas, moldando-as de acordo com as peculiaridades da presente implementação. Como resultado, optou-se por uma estratégia que consiste em gerar inicialmente a lista completa de movimentos possíveis e seletivamente atualizar, tanto a lista como a avaliação de seus elementos, em função do movimento executado na iteração anterior. Essa estratégia baseia-se na constatação de que a maior parte dos movimentos da lista de candidatos não é diretamente afetada pela execução de um movimento. Efetivamente, a inserção (ou remoção) de um atendimento afeta diretamente apenas movimentos referentes ao mesmo cliente da inserção (ou remoção) ou os demais atendimentos das rotas envolvidas, sendo realizada a atualização da avaliação somente dos movimentos relativos a esse conjunto.

Deve ficar claro que a estratégia adotada resulta em uma aproximação do custo real de um movimento, pois considera apenas parte da influência do movimento da iteração anterior nos demais da lista. Essa influência corresponde ao custo de manutenção do estoque do cliente afetado e aos custos fixo e variável da rota envolvida. Não são considerados possíveis efeitos indiretos, correspondentes à variação dos custos de manutenção do estoque no depósito e dos custos fixo e variável de produção.

\subsubsection{Critério de Parada}

O critério de parada adotado no presente trabalho consiste em um limite predeterminado do tempo de processamento, isto é, a etapa de melhoria é interrompida ao ser atingido um limite de tempo estipulado de antemão. Outros critérios de parada usualmente encontrados em aplicações da BT são o número de iterações e a estagnação da busca. Muito embora esses critérios sejam igualmente 
adequados para BT aqui apresentada, acredita-se que a adoção do tempo de processamento como critério de parada apresenta a vantagem de permitir uma comparação mais justa entre as distintas heurísticas desenvolvidas.

Vale recordar que essas heurísticas compartilham o mesmo procedimento de obtenção da solução inicial, o que permite afirmar que as diferenças de resultados devem-se exclusivamente às diferenças das respectivas etapas de melhoria. Nesse sentido, a utilização de um critério de parada comum a todas as distintas heurísticas permite uma avaliação mais precisa dos méritos de cada uma em relação às demais.

Cabe ressaltar que, no caso da heurística EGF-BT-DI, o critério de parada corresponde à soma do tempo de processamento das duas fases da etapa de melhoria. Isto é, a soma dos tempos de processamento da fase de BT com diversificação e da fase de intensificação não deve ultrapassar um limite predeterminado.

\subsection{Busca em Vizinhança Variável}

Nesta seção serão comentadas as principais características da implementação da metaheurística busca em vizinhança variável (BVV) como etapa de melhoria para a heurística proposta para a resolução do PDEGF. Essas características abrangem os seguintes tópicos: movimentos e estrutura de vizinhanças, busca local e critério de parada.

Cada um dos tópicos acima relacionados será abordado em uma subseção específica, cabendo lembrar que não será reapresentado nesse capítulo o funcionamento geral da BVV, uma vez que o mesmo já foi realizado no Capítulo 4.

\subsubsection{Movimentos e Estrutura de Vizinhanças}

A principal característica da metaheurística BVV consiste em utilizar um conjunto ordenado e indexado de vizinhanças para a exploração do espaço de soluções. Em geral essas vizinhanças são aninhadas, e a busca é realizada da menor vizinhança para a maior. Ou seja, as vizinhanças consideradas estão organizadas de maneira hierárquica, em que vizinhanças de maior índice são construídas pelo progressivo 
acréscimo de novos movimentos à vizinhança de índice imediatamente inferior, o que pode ser visto como um processo de extensão das vizinhanças anteriores.

Assim como ocorre na implementação da BT, os movimentos considerados baseiam-se no conceito de atendimento, entendido como uma combinação de cliente, dia e veículo, e as operações de inserção e remoção podem ser vistas como elementos construtivos dos movimentos, estando implícita a alteração da quantidade entregue ao cliente no atendimento subsequente a uma operação, caso este exista.

Na presente implementação foram considerados os seguintes movimentos:

- Movimento I: Consiste em uma operação simples de inserção.

- Movimento R: Consiste em uma operação simples de remoção.

- Movimento A: Consiste em antecipar o atendimento a um cliente. Esse movimento pode ser visto como uma combinação de um movimento de remoção associado a um movimento de inserção em um dia anterior ao dia do atendimento original.

- Movimento P: Consiste em postergar o atendimento a um cliente. Esse movimento pode ser visto como uma combinação de um movimento de remoção associado a um movimento de inserção em um dia posterior ao dia do atendimento original.

- Movimento TC: Consiste na remoção de um atendimento a um cliente, associado à inserção de um atendimento a outro cliente na mesma rota do atendimento removido. Ou seja, esse movimento pode ser visto como uma combinação de um movimento do tipo R com um movimento do tipo I, desde que as respectivas operações de remoção e inserção compartilhem a mesma rota (combinação de dia e veículo).

- Movimento RA: Consiste em combinar um movimento do tipo R com um movimento do tipo A, desde que as respectivas operações de remoção e inserção compartilhem uma mesma rota (combinação de dia e veículo), e que o movimento resultante não acarrete penalidade de falta de estoque. 
- Movimento RP: Consiste em combinar um movimento do tipo R com um movimento do tipo $\mathrm{P}$, desde que as respectivas operações de remoção e inserção compartilhem uma mesma rota (combinação de dia e veículo), e que o movimento resultante não acarrete penalidade de falta de estoque.

Pode-se notar que os movimentos I, R, A e P são idênticos aos utilizados na BT, e que os movimentos TC, RA e RP não são mais do que combinações de movimentos mais simples já conhecidos. Para uma melhor compreensão, os movimentos TC, RA e RP estão ilustrados nas Figuras 6.13 a 6.15, respectivamente. Na Figura 6.13, as seqüências de atendimentos representadas correspondem a uma mesma rota (combinação de dia e veículo) nas situações antes (a) e após (b) a execução do movimento; já nas Figuras 6.14 e 6.15, as situações antes (a) e após (b) a execução do movimento representam duas rotas, correspondentes aos dias $d$ e $d^{\prime}>d$, entre os quais ocorre a antecipação ou postergação de um atendimento. Assim como nos exemplos anteriormente considerados, está implícita a alteração da seqüência de atendimentos decorrente da aplicação dos procedimentos de troca de posição e trocas do tipo 2-intercâmbio.

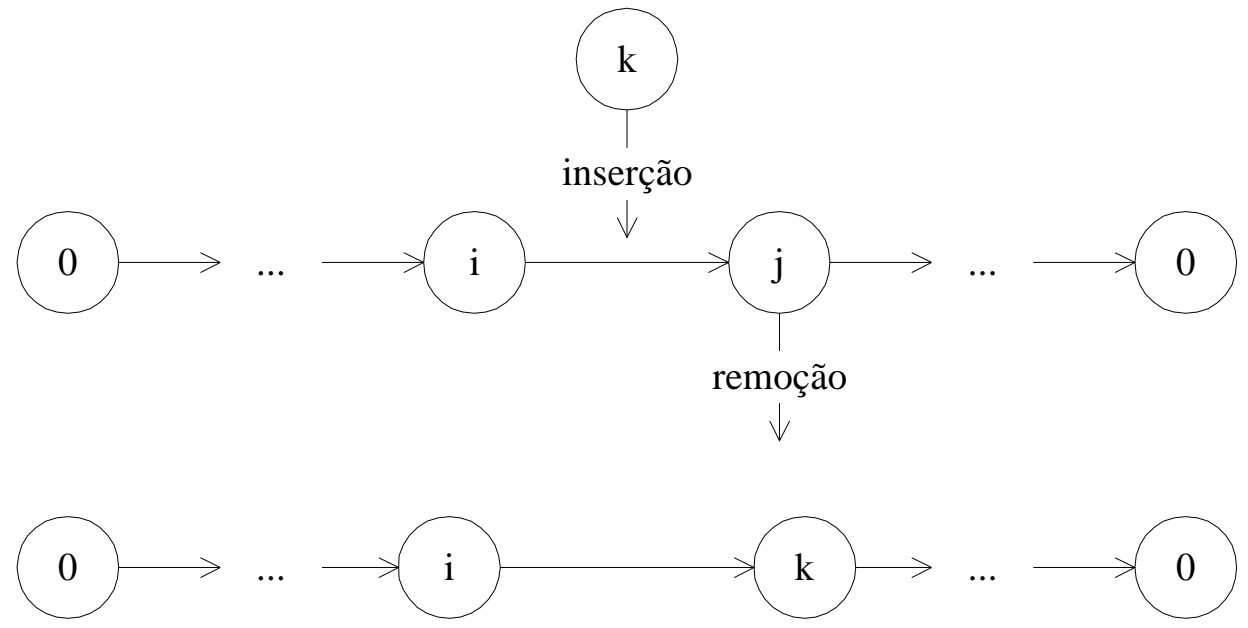

Figura 6.13 - Exemplo de movimento do tipo TC 


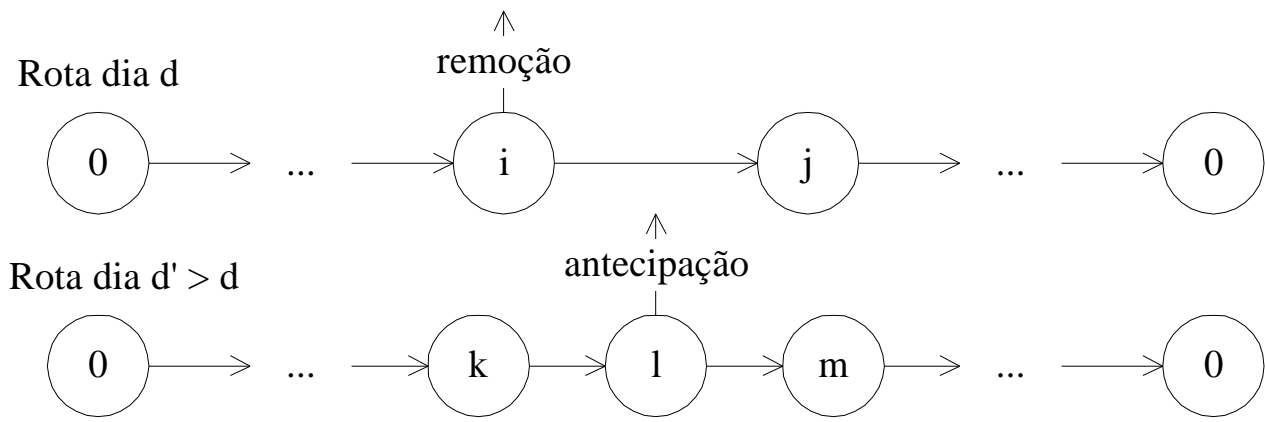

(a)

Rota dia d

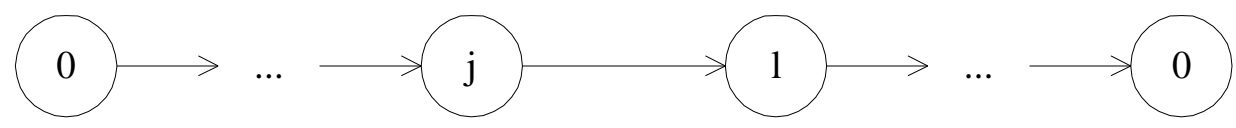

Rota dia d' > d

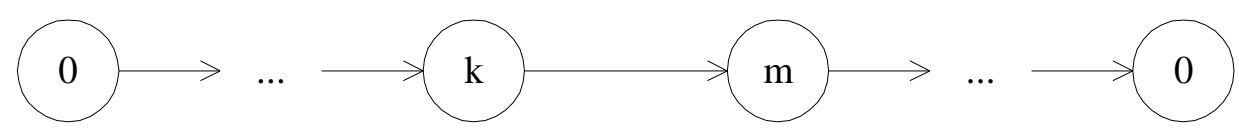

Figura 6.14 - Exemplo de movimento do tipo RA

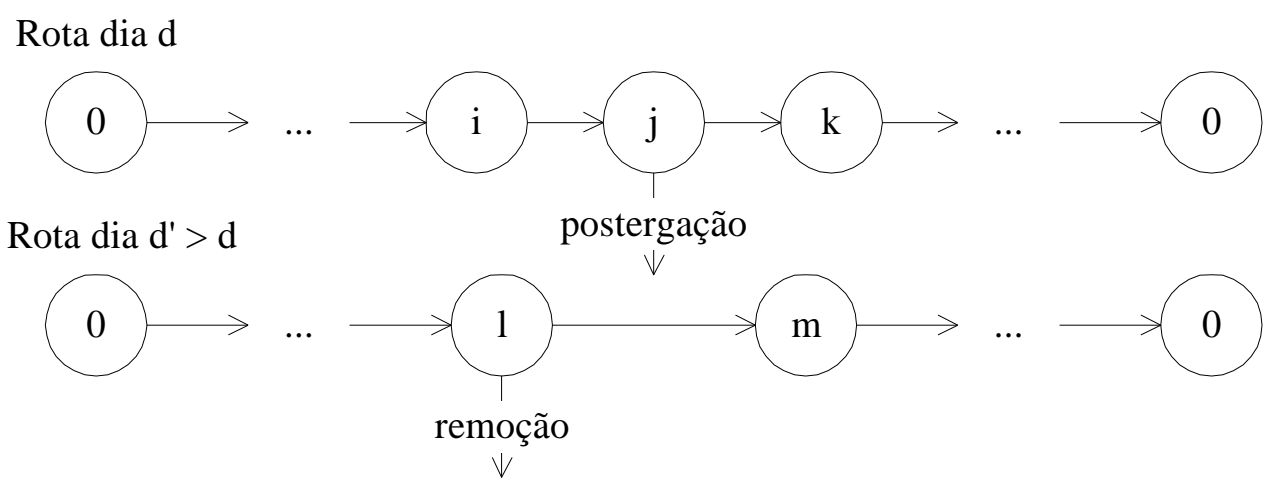

(a)

Rota dia d

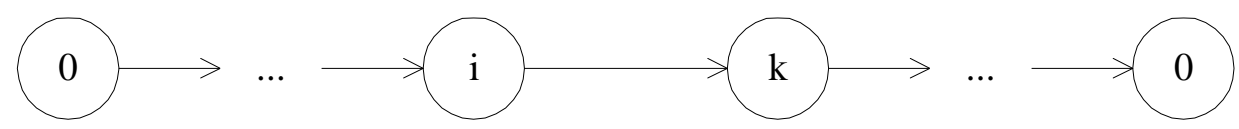

Rota dia d' > d

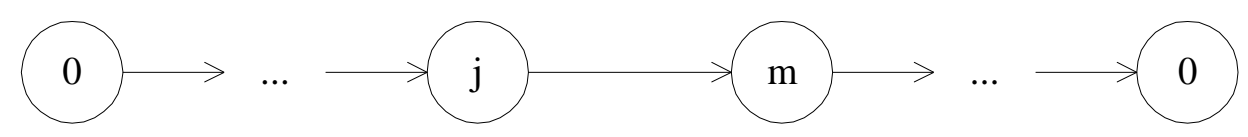

Figura 6.15 - Exemplo de movimento do tipo RP 
Apresentados os movimentos, pode-se passar à definição das vizinhanças adotadas. $\mathrm{Na}$ presente implementação, foram considerados quatro tipos de vizinhanças aninhadas $\left(k_{\text {máx }}=4\right)$, apresentadas no Quadro 6.1, segundo os movimentos utilizados.

QUADRO 6.1 - Estrutura de vizinhanças utilizada na BVV

\begin{tabular}{|c|c|}
\hline Vizinhança & Tipos de Movimentos \\
\hline 1 & I, R \\
2 & I, R, A, P \\
3 & I, R, A, P, TC \\
4 & I, R, A, P, TC, RA, RP \\
\hline
\end{tabular}

A primeira vizinhança utiliza apenas movimentos de inserção (tipo I) e remoção (tipo R); já a segunda vizinhança é definida com base na primeira, com o acréscimo de movimentos de antecipação de atendimento (tipo A) e postergação de atendimento (tipo P). Por sua vez, a terceira vizinhança consiste em uma extensão da segunda vizinhança, com o acréscimo de movimentos de troca de cliente (tipo TC). Por fim, a quarta e última vizinhança corresponde à terceira vizinhança, acrescida de movimentos combinados de remoção e antecipação de atendimento ou remoção e postergação de atendimento (tipos RA e RP).

Conforme comentado anteriormente, a busca não está restrita ao espaço de soluções viáveis, e a execução de um dado movimento pode implicar a violação de restrições. As violações de restrições são penalizadas de forma idêntica ao apresentado na implementação da BT (seção 6.2.2), sendo utilizada a mesma função $F(s)$ de avaliação dos movimentos apresentada naquela ocasião (expressão 52). A adoção de movimentos que permitem violação de restrições é pouco comum em aplicações da BVV, que usualmente deslocam o centro da busca de uma solução viável a outra solução viável de menor custo. Na presente implementação essa trajetória de busca não é composta necessariamente por soluções viáveis, podendo-se afirmar que a 
busca se desloca de uma solução a outra de melhor avaliação, não necessariamente viável.

\subsubsection{Seleção e Avaliação dos Movimentos}

A forma usual de seleção dos movimentos encontrada nas aplicações da BVV é a seleção aleatória, a cada iteração, de um dos movimentos da estrutura de vizinhança ativa. Embora essa seja a forma mais comum de exploração da vizinhança, formas alternativas de seleção de movimentos podem ser empregadas. Em particular, cabe destacar que a variação da BVV denominada descida em vizinhança variável ("variable neighborhood descent") vale-se de uma busca exaustiva de toda a vizinhança ativa, selecionando o movimento de melhor avaliação a cada iteração.

Na presente implementação, propõe-se uma estratégia de seleção de movimentos que pode ser vista como uma combinação da seleção puramente aleatória, usualmente utilizada na busca em vizinhança variável, e da busca exaustiva empregada na descida em vizinhança variável. A estratégia proposta consiste em sortear dois clientes distintos, sendo avaliados todos os possíveis movimentos segundo a estrutura de vizinhança ativa, e selecionando-se o movimento de melhor avaliação. Essa abordagem pode ser entendida como a seleção aleatória de um subconjunto da vizinhança ativa, seguido da exploração exaustiva desse subconjunto. $O$ funcionamento da estratégia proposta é apresentado na Figura 6.16.

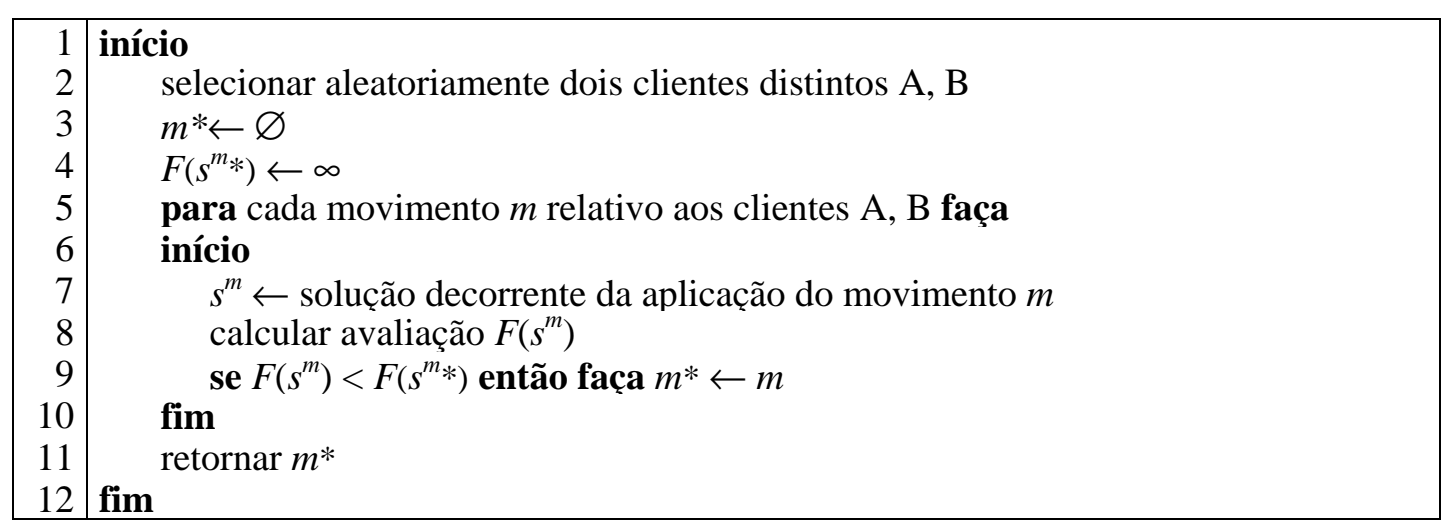

Figura 6.16 - Funcionamento do processo de seleção de movimento da BVV

Assim como no cálculo e atualização das penalidades, a avaliação dos movimentos candidatos segue o mesmo processo empregado na implementação da BT. Conforme 
descrito naquela ocasião, essa avaliação pode ser acelerada, considerando-se apenas os clientes e rotas afetadas pelo movimento em questão, o que permite a rápida atualização dos custos referentes à resolução do SPD, e a avaliação do custo do movimento é completada com a resolução do SPP correspondente. Nesse ponto, cabe destacar uma pequena diferença em relação às heurísticas baseadas em BT.

$\mathrm{Na}$ heurística EGF-BT e suas variações, a resolução do SPP, tanto para a avaliação dos movimentos candidatos quanto para a execução do melhor movimento selecionado, é realizada por meio do método exato descrito anteriormente na seção 5.4, que corresponde à implementação proposta por EVANS (1985) para a resolução do problema de lote ótimo de produção dinâmico sem restrições de capacidade. Embora o método exato seja perfeitamente adequado à heurística EGF-BVV, verificou-se que a utilização de um método aproximado para a resolução do SPP, quando da avaliação dos movimentos candidatos, pode ser vantajosa.

$\mathrm{Na}$ presente implementação, a resolução do SPP para avaliação dos movimentos candidatos utiliza a heurística proposta por SILVER; MEAL (1973) apud LEE; NAHMIAS (1993). Essa heurística permite a resolução do SPP em um tempo de processamento menor que o método exato, sem prejuízos significativos em termos de qualidade da solução obtida.

A razão para a utilização de um método aproximado no lugar de um método exato reside nas características da implementação da BVV, que permite soluções intermediárias inviáveis, juntamente com o sorteio dos clientes que serão considerados para a seleção dos movimentos a cada iteração. A primeira dessas características permite que a solução base, isto é, a solução a partir da qual será explorada a vizinhança, seja inviável. Como visto anteriormente, há dois tipos de restrições atuantes no presente problema: restrições de capacidade dos veículos e restrições de estoque mínimo nos clientes. Note-se que, ao executar um movimento que resulte na violação da restrição de estoque mínimo de um dado cliente, a busca só pode retornar à região viável com o sorteio desse mesmo cliente. Até que isso ocorra, o processo de seleção de movimentos não possui meios de restaurar a viabilidade da solução, fazendo com que a busca permaneça na região inviável por mais tempo que o necessário. 
Nesse sentido, a utilização de um método aproximado apresenta-se como um paliativo, que, embora não elimine essa característica desfavorável do processo de busca, permite que as iterações sejam mais rápidas, o que resulta em uma solução final de melhor qualidade para um mesmo tempo de processamento. Experimentos realizados com as duas alternativas indicam que, para um mesmo período de processamento, a utilização do método aproximado é vantajosa em cerca de $92 \%$ das instâncias testadas. Esse resultado foi corroborado pela aplicação do teste estatístico de Wilcoxon para observações emparelhadas (vide Apêndice I), que indicou que os resultados obtidos com a utilização dos métodos exato e aproximado para a resolução do SPP são estatisticamente distintos, a favor do método aproximado.

Cabe notar que o mesmo tipo de experimento foi aplicado às heurísticas baseadas em BT. Nesse caso, a aplicação do teste de Wilcoxon indicou que a utilização do método aproximado não leva a resultados estatisticamente distintos em relação aos resultados obtidos com o método exato, não justificando a sua utilização em tal situação.

Uma descrição da heurística de SILVER; MEAL (1973) apud LEE; NAHMIAS (1993) é apresentada na Figura 6.17.

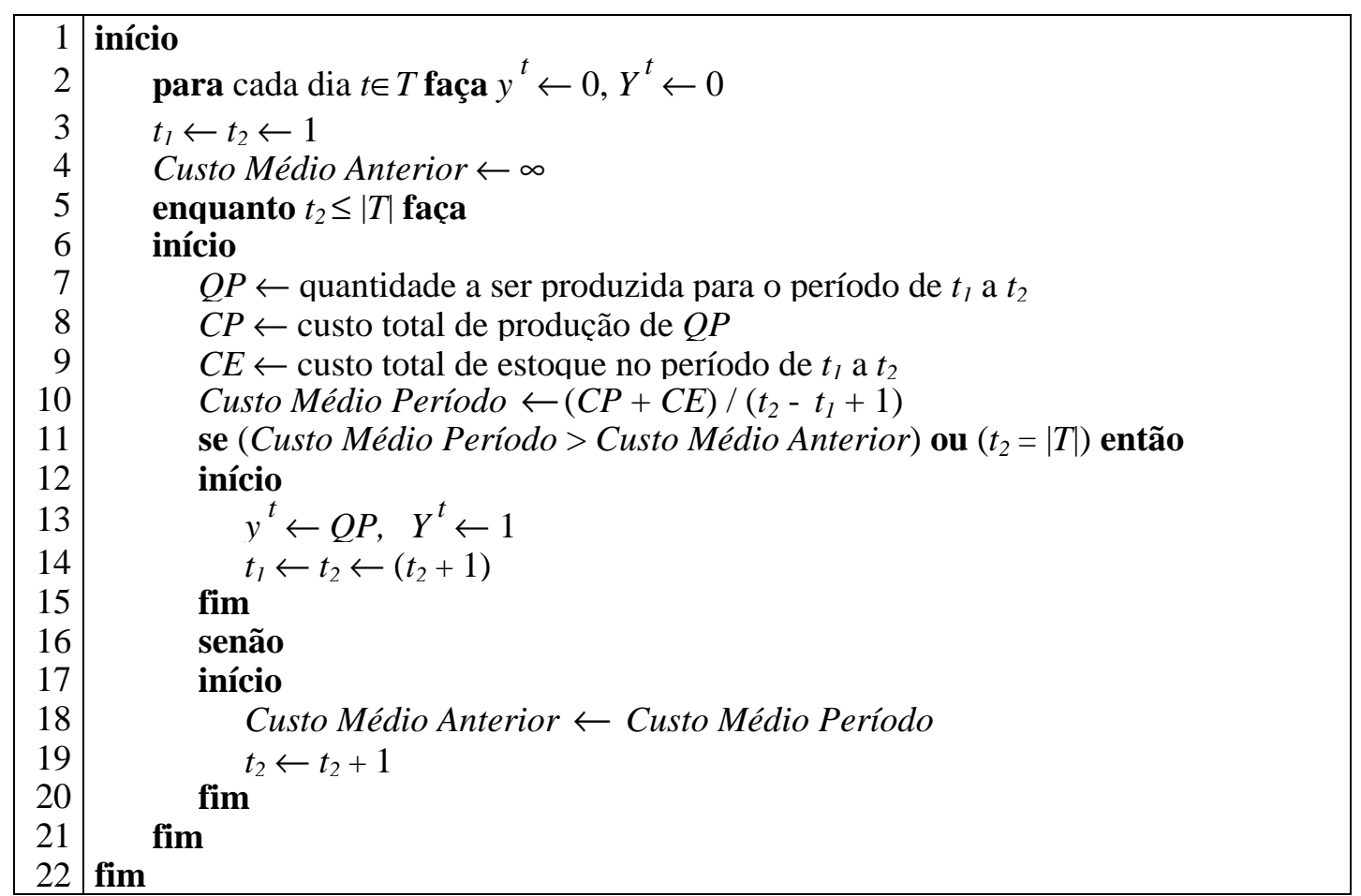

Figura 6.17 - Heurística proposta por SILVER; MEAL (1973) apud LEE; NAHMIAS (1993), utilizada para a resolução do SPP. 
Essa heurística baseia-se na propriedade já comentada na seção 5.4, que o estoque no depósito nos dias que imediatamente antecedem os dias de produção é sempre zero (excetuando-se o primeiro instante de produção, que pode ser influenciado pelo estoque inicial do depósito). Essa propriedade é explorada pela heurística que, fixado um dia $t_{1}$, busca definir o dia de produção subsequente $t_{2}$, de forma a atender a demanda e minimizar os custos médios associados à produção e estoque no período. Partindo do menor valor possível de $t_{2}$, a heurística aumenta progressivamente o período considerado, recalculando, para cada valor de $t_{2}$, a razão entre a soma dos custos e a duração do período, até que essa relação se torne crescente, indicando assim o novo dia de produção. Esse novo dia de produção passa a ser o novo dia $t_{1}$ fixo, e o processo se repete até o término do horizonte de planejamento.

\subsubsection{Busca Local}

Complementando o mecanismo de seleção aleatória dos movimentos, a BVV utiliza um procedimento de busca local como forma de explorar a vizinhança da nova solução gerada. Na presente implementação foram utilizados para esse fim os movimentos do tipo TV1 e TV2, definidos anteriormente na seção 6.2.1. Recordando o apresentado naquela ocasião, esses tipos de movimentos apenas trocam um ou dois atendimentos de veículos, não alterando os dias de reabastecimento dos clientes nem a programação da produção. Em outras palavras, esses movimentos atuam apenas na dimensão de roteirização do problema, mais especificamente, na atribuição dos atendimentos aos veículos, não afetando as demais dimensões do problema.

O procedimento de busca local consiste em, partindo de uma solução $s$, aplicar os movimentos do tipo TV1 ou TV2 até que não seja possível obter melhoria da solução, e seu funcionamento é apresentado a seguir na Figura 6.18. 


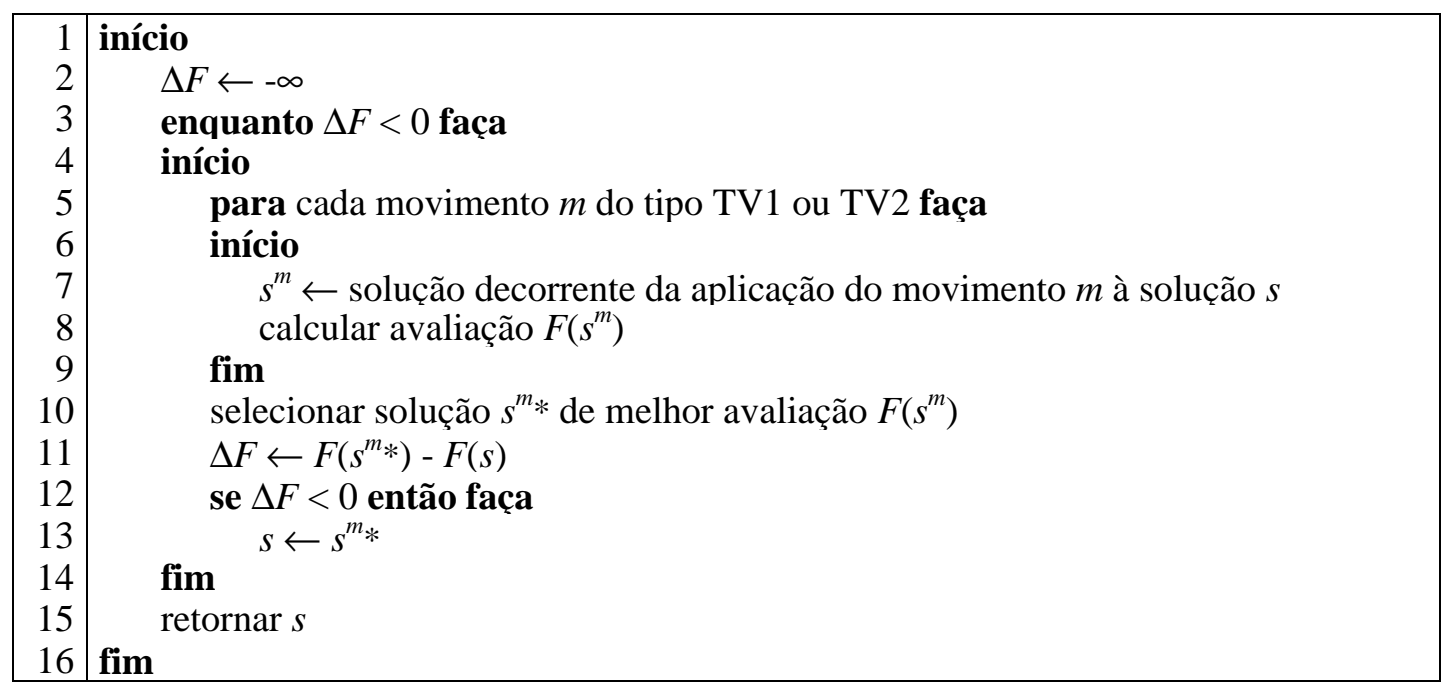

Figura 6.18 - Procedimento de busca local da BVV.

Observa-se que a busca local se dá pela exploração completa da vizinhança da solução $s$ definida pelos movimentos TV1 e TV2 (linhas 5 a 9). A solução de melhor avaliação é então selecionada (linha 10), e passa a ser a nova solução $s$ caso apresente melhor avaliação que a solução $s$ original (linhas 11 a 13). Esse processo se repete até que não seja mais possível obter redução da avaliação da solução $s$ (linha 3). Assim como ocorre na avaliação dos movimentos, o processo de busca local pode ser acelerado, uma vez que a exploração da vizinhança pode se restringir a apenas um subconjunto das rotas programadas. Isto é, apenas as rotas programadas para os dias correspondentes aos atendimentos envolvidos no último movimento selecionado necessitam ser examinadas, uma vez que não houve alteração nos atendimentos das demais.

É importante enfatizar que os movimentos TV1 e TV2 não alteram os dias da programação dos atendimentos, apenas trocam atendimentos de veículos. Ou seja, apenas as rotas de distribuição são melhoradas nessa etapa, embora aqui também sejam permitidos movimentos não viáveis, caso possuam uma melhor avaliação que os demais. Observe-se ainda que, nesse caso, apenas as restrições de capacidade dos veículos são violadas e o retorno à região viável não é tão problemático como no caso das restrições de estoque mínimo, uma vez que não se depende do sorteio de um determinado cliente para a eliminação da violação. 


\subsubsection{Critério de Parada}

Assim como na implementação da BT, o critério de parada adotado consiste em um limite de tempo predeterminado. Esse critério, comum a todas as heurísticas propostas, tem por objetivo permitir uma comparação mais justa e precisa entre as distintas heurísticas.

Conforme já comentado anteriormente, todas as heurísticas aqui apresentadas compartilham o mesmo procedimento de obtenção da solução inicial, e, por conseguinte, as diferenças de resultados devem-se exclusivamente às diferenças das respectivas etapas de melhoria.

\subsection{Considerações Finais}

Foram apresentadas nesse capítulo as heurísticas desenvolvidas como etapa de melhoria das estratégias de solução propostas para o PDEGF. Essas heurísticas baseiam-se em duas metaheurísticas: busca tabu (BT) e busca em vizinhança variável (BVV). Para a aplicação da BT, foram desenvolvidas ainda duas variantes, que consideram a utilização de uma estratégia de diversificação e de intensificação da busca.

Conforme apontado anteriormente no Capítulo 2, a utilização de metaheurísticas para a otimização de sistemas logísticos do tipo EGF ainda é relativamente incipiente, muito embora sua utilização em outros problemas de natureza combinatória, tais como planejamento da produção ou roteirização de veículos, seja crescente e bem sucedida. Nesse sentido, acredita-se que as estratégias de solução propostas para o PDEGF, em que se utiliza uma etapa de melhoria baseada em metaheurísticas, pode levar a resultados significativamente melhores que os resultados encontrados na literatura, o que vem a ser efetivamente a contribuição original do presente trabalho.

Adicionalmente, observa-se que as aplicações de metaheurísticas encontradas na revisão bibliográfica (LAU et al., 2000; COUSINEAU-OUIMET, 2002; LEE et al., 2003) não consideram custos relativos à produção, ou seja, não tratam de modelos 
em que a função de produção está integrada à distribuição e gerenciamento de estoques, como ocorre no modelo aqui apresentado.

A respeito das implementações da BT e da BVV realizadas no presente trabalho, é oportuno enfatizar algumas de suas características e tecer algumas considerações:

- A principal característica da BT consiste em utilizar estruturas de memória para alterar a vizinhança de uma solução em função das soluções previamente visitadas, permitindo o escape de mínimos locais e direcionando a busca a regiões mais promissoras. Nesse sentido, a estrutura de memória mais comum é a lista de movimentos (ou soluções) proibidos, definida pelo parâmetro de duração ou período tabu. No presente trabalho verificou-se que a determinação desse importante parâmetro deve levar em conta as características do problema e dimensões da instância a ser resolvida, e que a utilização de valores encontrados na literatura, mesmo que provenientes de problemas similares, deve ser judiciosa e acompanhada de testes de validação.

- Um dos pontos críticos para uma eficiente implementação de BT é o adequado gerenciamento da lista de movimentos candidatos. Freqüentemente essa lista é demasiado extensa para ser totalmente explorada a cada iteração, o que requer a utilização de algum tipo de simplificação no processo de seleção dos movimentos a serem avaliados. No presente trabalho, a simplificação adotada consiste em manter uma lista de movimentos candidatos com as respectivas avaliações, sendo essa lista seletivamente atualizada a cada iteração, em função do último movimento executado. Esse processo pode ser entendido como uma avaliação aproximada dos movimentos, uma vez que a não atualização de todos os movimentos pode dar margem à ocorrência de distorções na avaliação dos mesmos.

- Tanto a implementação da BT quanto da BVV permitem a exploração de soluções intermediárias inviáveis, ou seja, soluções em que ocorre a violação de alguma restrição do modelo original. Em ambas abordagens 
as violações das restrições são penalizadas por meio de multiplicadores auto-ajustáveis, que aumentam o peso das violações com a permanência da busca na região inviável, e, de forma inversa, reduzem os valores dos multiplicadores com o retorno à região viável. No caso da BT, essa característica induz a ocorrência de um desejável comportamento de oscilação estratégica, que pode ser entendido como uma alternância entre períodos de intensificação e diversificação. No caso da BVV, a exploração de soluções inviáveis apresenta o inconveniente de freqüentemente reter a busca na região inviável mais tempo que o necessário, em função do caráter aleatório de seleção dos movimentos. Muito embora esse efeito seja indesejado, e tenha ensejado o emprego de um método aproximado de resolução do SPP como forma de acelerar a busca e minimizar esse efeito negativo, observa-se que a restrição da vizinhança a soluções viáveis resulta em soluções de maior custo. Esse comportamento indica que, a despeito do efeito negativo comentado, a exploração de regiões inviáveis na BVV também promove, em certo grau, um comportamento de oscilação estratégica.

- A estratégia de diversificação proposta nas variações da BT explora deliberadamente o comportamento de oscilação estratégica para obter o efeito de diversificação da busca, e funciona em conjunto com o mecanismo de auto-ajuste dos pesos das penalidades. Essa estratégia pode ser resumida como um impulso em direção à região inviável, o que permite uma reorganização da estrutura da solução e induz o deslocamento da busca a uma região distinta, quando do retorno à região viável. Embora essa estratégia comparta o mesmo princípio da abordagem “shifting penalty approach", descrita por GLOVER et al. (1993), não há aqui a necessidade de um mecanismo de desligamento, uma vez que a estratégia proposta atua em conjunto com o mecanismo de auto-ajuste das penalidades, que se encarrega de dirigir a busca de volta à região viável.

- Uma interessante característica da metaheurística BVV é o número extremamente reduzido de parâmetros, especialmente quando comparada 
com metaheurísticas do tipo BT. Esse comportamento fica evidente ao se observar, na presente implementação, o esforço de calibração do parâmetro de duração tabu. Essa calibração exigiu extensos experimentos com distintos valores do parâmetro, o que, sem dúvida, contribuiu para que a implementação da BT fosse consideravelmente mais demorada que no caso da BVV.

No capítulo seguinte será apresentada uma avaliação das estratégias de solução propostas. Essa avaliação baseia-se em um conjunto de instâncias disponível na literatura, e permitirá, entre outros resultados, uma comparação entre as distintas heurísticas propostas para a etapa de melhoria. Uma vez mais, cabe recordar que as estratégias de solução utilizam a mesma solução inicial, e que a escolha do critério de parada busca justamente estabelecer as condições para uma comparação eqüitativa entre as heurísticas de melhoria apresentadas no presente capítulo, as quais constituem a contribuição original da presente pesquisa. 


\section{AVALIAÇÃO COMPUTACIONAL}

\subsection{Introdução}

Este capítulo tem por objetivo descrever a avaliação computacional das estratégias de solução para o PDEGF, descritas nos Capítulos 4, 5 e 6.

Segundo SILVER (2004), há dois aspectos a se considerar na avaliação do desempenho de uma heurística: qualidade da solução e esforço computacional envolvido. A primeira categoria envolve a comparação da solução obtida pela heurística em relação à solução ótima ou alguma outra referência. Por sua vez, a segunda categoria envolve a avaliação do tempo e memória requeridos pela heurística para a obtenção da solução para instâncias de porte real.

No que diz respeito à qualidade da solução, REEVES (1993) afirma que há três formas de se estimar o desempenho de uma heurística: métodos analíticos, testes empíricos, e inferência estatística. Métodos analíticos, como o próprio nome sugere, envolvem a obtenção de expressões analíticas de limitantes em relação à solução ótima do problema, seja para o caso do pior desempenho da heurística, ou para o seu desempenho médio. Por sua vez, os testes empíricos utilizam conjuntos de instâncias para comparar o desempenho de diferentes heurísticas. É usual, nesses casos, a geração de instâncias variando-se sistematicamente alguns parâmetros, de forma a construir um conjunto representativo do problema em estudo. Por fim, a última categoria considerada pelo autor trata do artifício de estimar, por meios estatísticos e a partir de uma amostra de soluções, o valor da solução ótima ou um intervalo que o contenha, utilizando-se essa informação para avaliar o desempenho da heurística.

Adicionalmente, RARDIN; UZSOY (2001) listam como métodos também utilizados para a avaliação da qualidade de uma heurística a extrapolação da avaliação obtida em instâncias de pequeno porte, para as quais é possível obter a solução ótima, e o emprego de instâncias construídas de forma que sua estrutura permita a resolução 
exata. Um exemplo desse segundo caso é a construção de instâncias do problema do caixeiro viajante em que os pontos estão distribuídos segundo um padrão geométrico predeterminado, permitindo a fácil obtenção da solução ótima (MOSCATO; NORMAN, 1998).

A existência de métodos alternativos para avaliação da qualidade de uma heurística levanta a questão: qual método escolher? A resposta a essa pergunta depende basicamente da natureza do problema em estudo e da dimensão das instâncias que se deseja resolver. Via de regra, instâncias de porte real de problemas de natureza combinatória são demasiado complexas para permitir a identificação da solução ótima, ou mesmo de um limitante suficientemente próximo, o que acaba por descartar a utilização de métodos analíticos. Nesses casos, a avaliação geralmente vale-se de conjuntos de instâncias de teste. É importante aqui relatar que uma relaxação linear do modelo matemático foi inicialmente testada como forma de se obter um limitante para a avaliação das estratégias de solução do presente trabalho. Esse limitante, entretanto, mostrou-se demasiado grosseiro para uma avaliação significativa das heurísticas propostas, razão pela qual essa abordagem foi abandonada.

Cabe observar ainda que alguns métodos são criticados nos trabalhos citados anteriormente, como é o caso da extrapolação do desempenho da heurística para instâncias de pequeno porte. A título de ilustração, pode-se afirmar que a fundamentação dessas críticas foi corroborada pelos experimentos realizados com instâncias de pequeno porte do PDEGF (5 clientes, 1 veículo e até 10 dias), para as quais foi possível obter a solução ótima com o software ILOG CPLEX 9.2. Nesses experimentos, a heurística EGF-BT também logrou encontrar a solução ótima de todas as instâncias testadas, entretanto, é evidente que a extrapolação desses resultados para instâncias de maior porte seria leviana.

No presente trabalho, a avaliação do desempenho das heurísticas propostas baseia-se em um conjunto de teste proposto por BERTAZZI et al. (2005), ou seja, é adotada uma abordagem baseada em testes empíricos. Muito embora essa escolha seja até certo ponto arbitrária, ela justifica-se pela virtual impraticabilidade de aplicação dos demais métodos. Vale notar ainda que a utilização de conjuntos de teste é prática 
comum na avaliação de diversos problemas de pesquisa operacional, como por exemplo os problemas de flow-shop, job-shop e open-shop (TAILLARD, 1993a), e o problema de roteirização de veículos com janelas de tempo (SOLOMON, 1987).

Por sua vez, o segundo aspecto da avaliação de uma heurística, referente ao tempo requerido para a obtenção da solução, está, no presente trabalho, diretamente relacionada ao critério de parada adotado. Cabe recordar que o critério adotado consiste em um período predefinido de processamento, compatível com um ambiente operacional de tomada de decisão. Assim sendo, pode-se afirmar que, nesse aspecto, as heurísticas desenvolvidas apresentam desempenho adequado.

A seguir, a seção 7.2 apresenta os conjuntos de teste que serão utilizados para a avaliação computacional das heurísticas propostas $\mathrm{Na}$ seção 7.3 são apresentados os resultados relativos às melhorias introduzidas no processo de obtenção da solução inicial, e a seção 7.4 apresenta os resultados da aplicação da etapa de melhoria nos cenários de teste considerados. Finalmente, na seção 7.5 são apresentados alguns comentários a respeito dos resultados obtidos.

A implementação das heurísticas foi realizada em linguagem $\mathrm{C}++$ e a avaliação computacional utilizou computador equipado com microprocessador Pentium $\mathrm{M}$ (Centrino) de $1.6 \mathrm{GHz}$ com 768 MB de memória RAM.

\subsection{Instâncias de Teste}

BERTAZZI et al. (2005) utilizaram em seu trabalho um conjunto de teste composto por 96 instâncias do PDEGF, geradas artificialmente por computador. Essas instâncias representam distintas situações de distribuição e relação entre os custos envolvidos, podendo ser reunidas em quatro grupos. O primeiro corresponde a um conjunto base de 24 instâncias, e os demais correspondem a três conjuntos de 24 instâncias cada, derivados do conjunto base.

A construção do conjunto base é realizada com a variação sistemática de alguns parâmetros, como é o caso do custo de manutenção de estoque no depósito, custo de manutenção de estoque nos clientes, e capacidade dos veículos da frota, sendo 
apresentada no Quadro 7.1 uma descrição completa dos parâmetros utilizados para a geração das instâncias do conjunto base.

As instâncias dos grupos restantes são derivadas do conjunto base, adotando-se valores particulares para alguns parâmetros, o que geralmente equivale a eliminar parcelas de custo da função objetivo original. Assim sendo, o segundo grupo (instâncias 25 a 48) corresponde ao conjunto base com o custo fixo de transporte igual a zero em todas as instâncias, o terceiro grupo (instâncias 49 a 72) corresponde ao caso em que o custo variável de produção é igual ao custo unitário diário de manutenção de estoque no depósito, e finalmente o quarto grupo (instâncias 73 a 96) corresponde ao caso em que o custo unitário diário de manutenção de estoque nos clientes é igual a zero.

A forma sistemática com que os conjuntos de teste foram gerados possibilita a comparação de instâncias que diferem apenas em um componente de custo (ou capacidade), permitindo assim isolar e avaliar seus efeitos no planejamento da distribuição. Como exemplo, pode-se citar o último conjunto de instâncias, em que o custo de manutenção de estoque nos clientes é desconsiderado, o que pode representar uma situação real em que o ônus da manutenção do estoque não é arcado pelo responsável pela distribuição. Ao ser comparado com o conjunto base, esse último conjunto permite a avaliação do impacto dos custos de estoque nos clientes, uma vez que os demais parâmetros são iguais.

Considerando-se ainda o último conjunto de instâncias, cabe informar que, ao se fixar o custo de manutenção de estoque dos clientes em zero, ocorre o caso de instâncias do conjunto base que diferenciavam-se apenas em relação a esse parâmetro de custo tornarem-se iguais. Com isso, das 24 instâncias do último conjunto, efetivamente apenas 12 são distintas, reduzindo assim o total de instâncias (distintas) de teste de 96 para 84, o que aparentemente passou despercebido pelos autores. O conjunto completo de instâncias, assim como os resultados obtidos por BERTAZZI et al. (2005) estão disponíveis na página web http://www-c.eco.unibs.it/ bertazzi/, mantida pelo primeiro autor. 


\section{QUADRO 7.1 - Parâmetros utilizados na geração das instâncias do conjunto base}

\begin{tabular}{|c|c|}
\hline Parâmetro & Valor \\
\hline $\begin{array}{l}\text { Número de } \\
\text { clientes }\end{array}$ & 50 \\
\hline $\begin{array}{l}\text { Número de dias do } \\
\text { horizonte de planejamento }\end{array}$ & 30 \\
\hline $\begin{array}{l}\text { Consumo diário } \\
\text { por cliente }\end{array}$ & $\begin{array}{l}\text { Inteiro aleatório no intervalo }[5,25] \text {, considerado constante } \\
\text { ao longo do horizonte de planejamento }\end{array}$ \\
\hline $\begin{array}{l}\text { Estoque máximo } \\
\text { por cliente }\end{array}$ & $\begin{array}{l}\text { Múltiplo do consumo diário, com multiplicador selecionado } \\
\text { aleatoriamente no conjunto }\{2,3,5,6\}\end{array}$ \\
\hline $\begin{array}{l}\text { Estoque inicial } \\
\text { por cliente }\end{array}$ & $\begin{array}{l}\text { Diferença entre o estoque máximo e } \\
\text { o consumo diário }\end{array}$ \\
\hline $\begin{array}{l}\text { Custo unitário diário dos } \\
\text { estoques nos clientes }\end{array}$ & Inteiro aleatório nos intervalos $[1,5]$ ou $[6,10]$ \\
\hline $\begin{array}{l}\text { Custo unitário diário do } \\
\text { estoque no depósito }\end{array}$ & 3 ou 8 \\
\hline $\begin{array}{l}\text { Custo unitário } \\
\text { de produção }\end{array}$ & 10 x Custo de manutenção de estoque \\
\hline $\begin{array}{l}\text { Custo fixo por dia em } \\
\text { que há produção no depósito }\end{array}$ & $100 \times$ Custo por unidade produzida \\
\hline $\begin{array}{l}\text { Coordenada X do } \\
\text { cliente ou depósito }\end{array}$ & Inteiro aleatório no intervalo $[0,500]$ \\
\hline $\begin{array}{l}\text { Coordenada Y do } \\
\text { cliente ou depósito }\end{array}$ & Inteiro aleatório no intervalo $[0,1000]$ \\
\hline $\begin{array}{l}\text { Capacidade } \\
\text { dos veículos }\end{array}$ & $\begin{array}{c}\text { Inteiro aleatoriamente selecionado no } \\
\text { conjunto }\{\bar{U}, 1.5 \bar{U}, 2 \bar{U}\} \text {, onde } \bar{U} \text { corresponde ao maior } \\
\text { estoque máximo dos clientes atendidos }\end{array}$ \\
\hline $\begin{array}{l}\text { Custo variável } \\
\text { de transporte entre } \\
\text { clientes e/ou depósito }\end{array}$ & $\begin{array}{c}{\left[\sqrt{\left.\left(x_{i}-x_{j}\right)^{2}+\left(y_{i}-y_{j}\right)^{2}\right]}\right.} \\
\text { onde }\left(x_{i}, y_{i}\right) \text { são as coordenadas do ponto } i \text { e }\left(x_{j}, y_{j}\right) \text { são } \\
\text { as coordenadas do ponto } j\end{array}$ \\
\hline $\begin{array}{l}\text { Custo fixo } \\
\text { de transporte }\end{array}$ & $\begin{array}{c}(|N|+1) \text { vezes o maior custo variável de transporte entre } \\
\text { pontos } i \text { e } j \text {, onde }|N| \begin{array}{c}\text { corresponde ao número de clientes } \\
\text { atendidos }\end{array}\end{array}$ \\
\hline
\end{tabular}

Fonte: Adaptado de BERTAZZI et al. (2005) 
É importante ressaltar que as instâncias de teste propostas por BERTAZZI et al. (2005) não correspondem ao caso mais geral do modelo abordado no presente trabalho, mas sim ao caso particular em que a frota de distribuição é homogênea e o consumo de cada cliente é constante ao longo do horizonte de planejamento. Os autores consideram ainda que a frota seja em número igual à quantidade de clientes, de forma a garantir a viabilidade da instância considerada. Isto é, na pior das hipóteses, os atendimentos podem ser realizados por meio de entregas diretas fornecedor-consumidor, em que cada veículo atende apenas um cliente.

Embora as instâncias de teste utilizadas pelos autores não correspondam ao caso mais geral do PDEGF em estudo, a sua utilização para a avaliação computacional das heurísticas propostas se justifica por representar um referencial de comparação da qualidade dos resultados obtidos. Esse conjunto de teste, correspondente ao caso particular com frota homogênea e demandas constantes, será doravante denominado cenário I.

O cenário I serviu de base para a construção de um segundo cenário, doravante denominado cenário II. Esse segundo cenário está dividido em dois grupos de 24 instâncias, derivados do conjunto base do cenário I, sendo que em ambos grupos é considerada disponível uma frota heterogênea de veículos. O primeiro grupo (instâncias 1 a 24) corresponde ao caso em que a demanda é constante ao longo do horizonte de planejamento, de forma idêntica ao cenário I; já o segundo grupo (instâncias 25 a 48) considera o caso em que a demanda dos clientes varia diariamente. Nesse segundo grupo, os valores de consumo diário de cada cliente foram determinados pelo sorteio de valores inteiros no intervalo [0.8 $r_{i}, 1.2 r_{i}$ ], onde $r_{i}$ é a demanda constante do cliente $i$ utilizada no cenário I. Ou seja, a demanda de cada cliente no segundo grupo obedece uma distribuição aleatória uniforme de média igual ao consumo constante do cliente no cenário anterior. Uma descrição das características da frota considerada no cenário II é apresentada seguir no Quadro 7.2. 
QUADRO 7.2 - Características da frota utilizada no cenário II.

\begin{tabular}{|c|c|c|c|c|}
\hline $\begin{array}{c}\text { Tipo do } \\
\text { veículo }\end{array}$ & $\begin{array}{c}\text { Número de } \\
\text { veículos }(*)\end{array}$ & Capacidade $(* *)$ & Custo fixo $(* *)$ & Custo variável $(* *)$ \\
\hline 1 & $\left\lceil 1 / 2 \times N V U^{\mathrm{T}}\right\rceil$ & 0,75 & 0,90 & 0,90 \\
2 & $\left\lceil 2 / 3 \times N V U^{\mathrm{T}}\right\rceil$ & 1,00 & 1,00 & 1,00 \\
3 & $\left\lceil 1 / 2 \times N V U^{\mathrm{I}}\right\rceil$ & 1,50 & 1,20 & 1,15 \\
\hline
\end{tabular}

(*) $\quad N V U^{1}=$ Número de veículos utilizados na instância correspondente do conjunto base (cenário I). (**) Valores relativos à capacidade e custos dos veículos da frota homogênea do cenário I.

Como pode-se observar, além da classe de veículos utilizados no cenário I (veículo tipo 2), o cenário II considera disponíveis veículos de menor capacidade (veículo tipo 1) e de maior capacidade (veículo tipo 3). Os custos correspondentes a cada categoria de veículo foram estipulados de forma que veículos maiores apresentem uma menor relação custo fixo/capacidade, embora acompanhada de custos variáveis maiores. Essa composição de custos procura refletir situações reais em que veículos maiores apresentam maior eficiência, verificando seu impacto na programação da distribuição. Um resumo das características das instâncias de teste utilizadas nos cenários I e II é apresentado no Quadro 7.3.

\section{QUADRO 7.3 - Resumo das características das instâncias de teste.}

\begin{tabular}{|c|c|c|}
\hline Grupo & Cenário I & Cenário II \\
\hline 1 & grupo base (GB) & GB + frota heterogênea \\
2 & $\begin{array}{c}\text { custo fixo dos veículos }=0 \\
\left(C_{f}^{v}=0, \quad \forall v \in V\right)\end{array}$ \\
3 & $\begin{array}{c}\text { custo variável da produção }= \\
\text { custo unitário de estoque no depósito } \\
\left(p=h_{0}\right)\end{array}$ \\
4 & $\begin{array}{c}\text { custo de estoque dos clientes }=0 \\
\left(h_{i}=0, \quad \forall i \in N\right)\end{array}$ \\
\hline
\end{tabular}




\subsection{Solução Inicial}

Esta seção tem por objetivo apresentar os resultados alcançados na etapa de obtenção da solução inicial pela aplicação do método de seleção aleatória de clientes em lista reduzida, descrito no Capítulo 5. Vale ressaltar que esse resultados são parciais, e não correspondem à aplicação completa das heurísticas propostas. Assim sendo, não será realizada nessa seção uma comparação entre os resultados de diferentes heurísticas, mas sim uma avaliação da melhoria proposta no processo de obtenção da solução inicial.

Conforme apresentado no Capítulo 5, a heurística de obtenção da solução inicial com seleção de clientes em lista reduzida é controlada pelos parâmetros correspondentes ao tamanho da lista dos clientes e ao número de iterações a ser realizado. Inicialmente, foi estudado o efeito da variação do parâmetro correspondente ao tamanho da lista. Fixando-se em 100 o número de iterações, foram testados valores de tamanho da lista variando de 1 a 15 , correspondendo o valor 1 à ordem de seleção de clientes originalmente proposta por BERTAZZI et al. (2005). Seguindo orientação de BARR et al. (1995) em relação à avaliação computacional de heurísticas, para cada valor de tamanho de lista foram realizados 20 experimentos, com diferentes sementes para a geração de números pseudo-aleatórios. Esse cuidado se justifica, pois diferentes sementes geram diferentes ordens de seleção dos clientes e, consequentemente, diferentes resultados. Assim, a realização de um único experimento pode enviesar a avaliação da heurística, sendo recomendada a realização de experimentos com distintas sementes para a avaliação da heurística.

Para efeito de comparação, os resultados obtidos são expressos em termos de variação percentual em relação ao custo total obtido com a seqüência original de seleção dos clientes. Ou seja, para cada valor de tamanho da lista, é calculado o custo total médio dos 20 experimentos realizados, e apresentada a variação percentual desse valor em relação ao custo obtido pela ordem original de seleção dos clientes. A Figura 7.1 ilustra os resultados obtidos em função do parâmetro tamanho da lista reduzida. 


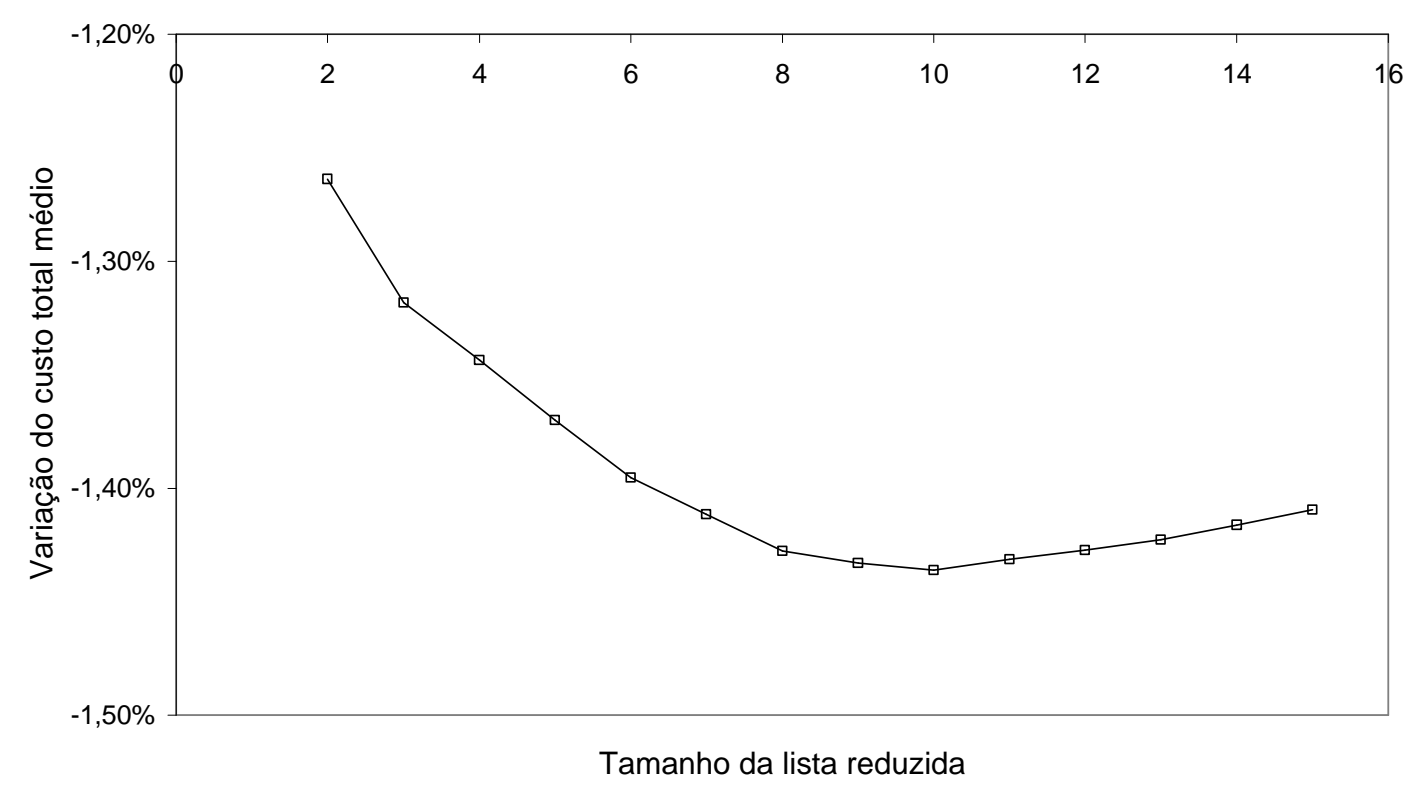

Figura 7.1 - Variação do custo total médio da solução inicial em função do tamanho da lista reduzida.

Observa-se, em linhas gerais, que o aumento do tamanho da lista no intervalo de 2 a 10 reflete-se em uma maior redução do custo total. Entretanto, esse comportamento se inverte para valores maiores que 10. A raiz desse fenômeno encontra-se na forma com que o conjunto de clientes é ordenado. Essa ordenação baseia-se na relação entre estoque inicial e o consumo, definida pelo índice $\alpha_{i}$, e indica o dia em que primeiro ocorre falta de estoque no cliente, caso este não seja atendido. Clientes com menor índice $\alpha_{i}$ apresentam menor número de combinações de dia e veículo para a realização do primeiro atendimento, e portanto devem ser programados primeiro. Entretanto, não é incomum que vários clientes apresentem o mesmo valor de $\alpha_{i}$. Nesse caso, a utilização de valores reduzidos de tamanho da lista geralmente é vantajosa, pois permite testar diferentes sequiências de ordem de programação dos clientes, respeitando-se, via de regra, uma ordem não decrescente de $\alpha_{i}$. Todavia, à medida em que o tamanho da lista é aumentado, esse efeito positivo se desvanece, pois a seleção dos clientes passa a ser mais aleatória, e clientes com maiores valores de $\alpha_{i}$ acabam sendo programados antes de clientes com menores valores de $\alpha_{i}$, o que diminui o número de combinações viáveis de inserção desses últimos. Com isso, 
as possibilidades de combinações vantajosas ficam reduzidas, refletindo-se em uma menor redução do custo total.

Estudado o comportamento da heurística em função da variação do tamanho da lista reduzida, o próximo passo consiste em examinar a influência do número de iterações no processo. Fixando-se em 10 o tamanho da lista, valor correspondente à maior redução de custo observada, foram testados valores do número de iterações variando de 1 a 100, sendo os resultado apresentados na Figura 7.2.

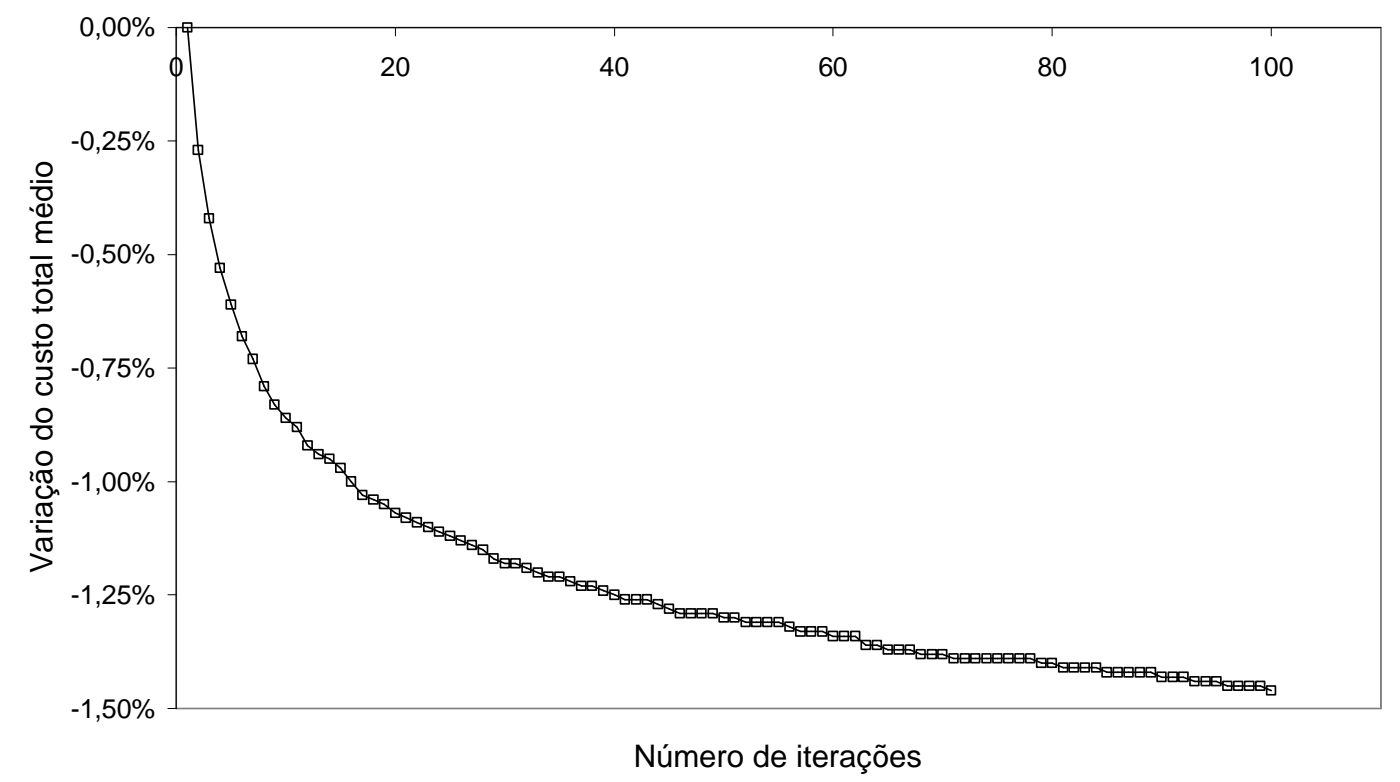

Figura 7.2 - Variação do custo total médio da solução inicial em função do número de iterações.

Embora um maior número de iterações proporcione uma maior redução do custo total médio, incorre-se também em maior tempo de processamento. Esse aumento do tempo de processamento, para ganhos cada vez menores, opõe-se à idéia central da etapa inicial da heurística proposta, que vem a ser justamente a obtenção de uma solução inicial de forma rápida e expedita. Por esse motivo, é necessário estipular um valor do número de iterações para sua aplicação prática. Na presente implementação, foi fixado em 100 o número de iterações. Esse valor, conquanto arbitrário, permite auferir grande parte da redução propiciada pela adoção da seleção de clientes em lista 
reduzida, sem que o tempo de processamento despendido nessa etapa seja demasiado, como pode-se verificar na Tabela 7.1.

Tabela 7.1 - Tempo de processamento da solução inicial.

\begin{tabular}{cccc}
\hline \multirow{2}{*}{$\begin{array}{c}\text { Grupo } \\
\text { do conjunto } \\
\text { de teste }\end{array}$} & \multicolumn{3}{c}{$\begin{array}{c}\text { Tempo de processamento por instância (s) } \\
(100 \text { iterações })\end{array}$} \\
\cline { 2 - 4 } 1 & Média & Melhor & Pior \\
\hline 2 & 13,6 & 11 & 25 \\
3 & 13,8 & 11 & 25 \\
$4(*)$ & 13,9 & 11 & 23 \\
\hline Total & 13,7 & 11 & 24 \\
\hline
\end{tabular}

(*) Foram excluídos desse grupo as instâncias duplicadas.

Os resultados obtidos permitem afirmar que o processo de seleção de clientes com lista reduzida é capaz de reduzir o custo da solução em relação à ordem de seleção de clientes originalmente proposta por BERTAZZI et al. (2005). Embora a redução percentual obtida não seja expressiva em termos absolutos, vale recordar que a ordem de grandeza da redução de custo obtida pelas etapas de melhoria propostas pelos autores é cerca de 4\%, o que torna a redução obtida com 100 iterações (cerca de $1,44 \%)$, não desprezível.

Conquanto válida em termos de ordem de grandeza, deve ficar claro que a comparação da solução obtida pela ordem de seleção original com a solução inicial obtida por BERTAZZI et al. (2005) não é rigorosa. Muito embora ambas soluções sejam construídas com base no mesmo critério de seleção de clientes, os procedimentos de inserção de um atendimento em uma rota são distintos, além do fato de que a ordenação dos clientes segundo uma ordem não decrescente de $\alpha_{i}$ geralmente não é única, o que também provoca diferenças nas soluções iniciais obtidas. 


\subsection{Etapa de Melhoria}

Esta seção tem por objetivo apresentar os resultados alcançados pela aplicação da etapa de melhoria, os quais constituem os resultados finais das heurísticas propostas para a resolução do PDEGF. Conforme comentado anteriormente, as distintas heurísticas testadas nessa etapa utilizam o mesmo processo de obtenção da solução inicial, podendo-se afirmar que as diferenças de resultados devem-se única e exclusivamente às diferenças das etapas de melhoria.

A seguir, as seções 7.4.1 e 7.4.2 apresentam os resultados obtidos para as instâncias dos cenários I e II.

\subsubsection{Cenário I}

As instâncias do cenário I tratam do caso particular do PDEGF em que o depósito dispõe de uma frota homogênea e a demanda dos clientes é considerada constante ao longo do horizonte de planejamento.

Antes de examinar os resultados obtidos pela aplicação da etapa de melhoria, é oportuno recordar alguns detalhes do trabalho de BERTAZZI et al. (2005), que será utilizado como referência para comparação. Conforme comentado quando da revisão bibliográfica, os autores propõem duas heurísticas baseadas na decomposição do PDEGF em subproblemas mais simples. É demonstrado que ambas heurísticas são equivalentes no caso da resolução exata de seus subproblemas, razão pela qual a primeira heurística é descartada.

Para essa segunda heurística são estudadas duas possíveis decomposições do problema original, respectivamente denominadas DP e DP'. A primeira decomposição (DP) separa o problema original em um subproblema de planejamento da distribuição e um subproblema de planejamento da produção, similares aos apresentados no Capítulo 4. A segunda decomposição (DP') diferencia-se da primeira pelo fato de os custos variáveis de produção estarem incorporados ao subproblema de planejamento da distribuição, e não ao subproblema de planejamento da produção. 
Em ambos os casos, a resolução do problema consiste em um processo de duas etapas: a construção de uma solução inicial e uma etapa de melhoria. A obtenção da solução inicial baseia-se num processo de inserção dos clientes na programação e a etapa de melhoria consiste em, sistematicamente, remover e reinserir dois clientes na programação, até que não seja possível obter redução de custo. Adicionalmente, um aprimoramento da etapa de melhoria considera ainda a alteração do estoque no depósito antes de cada iteração do processo de remoção e reprogramação de clientes. Como a execução de cada etapa vale-se da decomposição do problema original, a utilização de diferentes decomposições resulta em distintas soluções para o problema original.

A título de simplificação, a aplicação da heurística proposta por BERTAZZI et al. (2005) associada às decomposições DP e $\mathrm{DP}^{\prime}$ será denominada simplesmente heurística DP ou DP', conforme o caso. Em ambos casos, considera-se que à heurística de obtenção da solução inicial segue-se a aplicação da etapa de melhoria aprimorada, que apresenta resultados superiores à etapa de melhoria original. $\mathrm{Ou}$ seja, as heurísticas DP e DP' correspondem às heurísticas de melhores resultados propostas pelos autores, segundo as distintas decomposições do problema original.

Além das heurísticas DP e DP', são apresentados no trabalho de BERTAZZI et al. (2005) os resultados correspondentes à situação em que não há coordenação entre as entregas para os distintos clientes, denominada Estoque Gerido pelo Cliente - EGC. Nesse caso, os dias de reabastecimento são determinados pela iminência de se atingir o estoque mínimo de cada cliente, e não em decorrência de um planejamento integrado que visa a redução do custo total do sistema. A determinação das rotas de distribuição e do planejamento da produção seguem os mesmos procedimentos utilizados nas heurísticas DP e DP', podendo-se, portanto, afirmar que a diferença entre o EGC e as heurísticas DP e DP' decorre unicamente da escolha dos dias de atendimento. 
De forma similar à avaliação das melhorias propostas para a etapa de obtenção da solução inicial, a avaliação da etapa de melhoria também baseia-se em experimentos com 10 sementes distintas para a inicialização do gerador de números pseudoaleatórios, conforme orientação de BARR et al. (1995). Nesse sentido, vale recordar que, tanto a implementação da BT quanto da BVV utilizam esse recurso, seja na definição do período tabu (BT), seja na seleção dos clientes para construção das vizinhanças (BVV), justificando assim a realização de experimentos com distintas sementes.

Os parâmetros utilizados pelas heurísticas nos experimentos computacionais podem ser encontrados no Anexo A. Os resultados obtidos são apresentados de forma desagregada no Anexo B, e sintetizados na Tabela 7.2, que apresenta o custo médio por instância e por grupo do conjunto de teste, juntamente com os resultados publicados por BERTAZZI et al. (2005). Adicionalmente, uma comparação por grupo do conjunto de teste dos erros médios percentuais em relação aos melhores resultados obtidos é apresentada na Tabela 7.3.

O tempo médio de processamento por instância reportado por BERTAZZI et al. (2005) é apresentado no Quadro 7.4, sendo os valores obtidos em microcomputador equipado com processador Pentium III de $933 \mathrm{MHz}$ e $256 \mathrm{MB}$ RAM. Cabe recordar que o tempo de processamento é considerado como critério de parada na presente implementação, sendo adotado o valor de 900 segundos para esse parâmetro.

\section{QUADRO 7.4 - Tempo médio de processamento por instância reportado por BERTAZZI et al. (2005).}

\begin{tabular}{|c|c|c|c|}
\hline Etapa & $\begin{array}{c}\text { EGC } \\
\text { (segundos) }\end{array}$ & $\begin{array}{c}\text { heurística DP } \\
\text { (segundos) }\end{array}$ & $\begin{array}{c}\text { heurística DP' } \\
\text { (segundos) }\end{array}$ \\
\hline solução inicial & 0,2 & 0,1 & 0,2 \\
etapa de melhoria & 117,7 & 228,0 & 288,6 \\
\hline
\end{tabular}


Tabela 7.2 - Custo médio por instância e variação percentual em relação à heurística DP.

\begin{tabular}{|c|c|c|c|c|c|c|c|}
\hline \multirow{2}{*}{$\begin{array}{l}\text { Grupo } \\
\text { do } \\
\text { conjunto } \\
\text { de teste }\end{array}$} & \multirow[b]{2}{*}{$\begin{array}{l}\text { Heurística } \\
\text { EGF-BT }\end{array}$} & \multirow[b]{2}{*}{$\begin{array}{l}\text { Heurística } \\
\text { EGF-BT-D }\end{array}$} & \multirow[b]{2}{*}{$\begin{array}{l}\text { Heurística } \\
\text { EGF-BT-DI }\end{array}$} & \multirow[b]{2}{*}{$\begin{array}{l}\text { Heurística } \\
\text { EGF-BVV }\end{array}$} & \multicolumn{3}{|c|}{ BERTAZZI et al. (2005) } \\
\hline & & & & & $\begin{array}{l}\text { Heurística } \\
\text { DP }\end{array}$ & $\begin{array}{c}\text { Heurística } \\
\text { DP' }^{\prime}\end{array}$ & $\begin{array}{l}\text { Estoque Gerido } \\
\text { pelo Cliente } \\
\text { (EGC) }\end{array}$ \\
\hline 1 & $\begin{array}{l}1.864 .788,03 \\
(-2,43 \%)\end{array}$ & $\begin{array}{l}1.849 .232,68 \\
(-3,24 \%)\end{array}$ & $\begin{array}{l}1.853 .073,61 \\
(-3,04 \%)\end{array}$ & $\begin{array}{l}1.858 .414,66 \\
(-2,76 \%)\end{array}$ & $1.911 .188,38$ & $1.929 .263,50$ & $2.679 .264,83$ \\
\hline 2 & $\begin{array}{l}1.600 .903,75 \\
(-2,53 \%)\end{array}$ & $\begin{array}{l}1.591 .490,25 \\
(-3,11 \%)\end{array}$ & $\begin{array}{l}1.593 .758,49 \\
(-2,97 \%)\end{array}$ & $\begin{array}{l}1.597 .978,87 \\
(-2,71 \%)\end{array}$ & $1.642 .499,50$ & $1.665 .736,71$ & $1.792 .870,00$ \\
\hline 3 & $\begin{array}{l}726.873,08 \\
(-6,31 \%)\end{array}$ & $\begin{array}{l}716.236,35 \\
(-7,69 \%)\end{array}$ & $\begin{array}{l}719.079,73 \\
(-7,32 \%)\end{array}$ & $\begin{array}{l}724.414,86 \\
(-6,63 \%)\end{array}$ & $775.866,29$ & $802.480,88$ & $1.557 .791,67$ \\
\hline $4(*)$ & $\begin{array}{l}1.580 .837,10 \\
(-1,03 \%)\end{array}$ & $\begin{array}{l}1.575 .280,85 \\
(-1,37 \%)\end{array}$ & $\begin{array}{l}1.577 .183,50 \\
(-1,26 \%)\end{array}$ & $\begin{array}{l}1.577 .458,44 \\
(-1,24 \%)\end{array}$ & $1.597 .230,75$ & $1.614 .648,58$ & $2.376 .542,33$ \\
\hline Total & $\begin{array}{l}1.423 .709,55 \\
(-2,83 \%)\end{array}$ & $\begin{array}{l}1.412 .742,77 \\
(-3,58 \%)\end{array}$ & $\begin{array}{l}1.415 .572,45 \\
(-3,39 \%)\end{array}$ & $\begin{array}{l}1.419 .867,89 \\
(-3,09 \%)\end{array}$ & $1.465 .191,30$ & $1.487 .087,25$ & $2.062 .342,19$ \\
\hline
\end{tabular}

(*) Foram excluídos desse grupo as instâncias duplicadas. 
Tabela 7.3 - Erro médio percentual por grupo do conjunto de teste em relação aos melhores valores obtidos (cenário I).

\begin{tabular}{|c|c|c|c|c|c|c|c|}
\hline \multirow{2}{*}{\multicolumn{2}{|c|}{$\begin{array}{c}\text { Grupo } \\
\text { do conjunto } \\
\text { de teste }\end{array}$}} & \multirow{3}{*}{$\begin{array}{c}\text { Heurística } \\
\text { EGF-BT } \\
(* *)\end{array}$} & \multirow{3}{*}{$\begin{array}{c}\begin{array}{c}\text { Heurística } \\
\text { EGF-BT-D } \\
(* *)\end{array} \\
0,18\end{array}$} & \multirow{3}{*}{$\begin{array}{c}\begin{array}{c}\text { Heurística } \\
\text { EGF-BT-DI } \\
(* *)\end{array} \\
0,39\end{array}$} & \multirow{3}{*}{$\begin{array}{c}\text { Heurística } \\
\text { EGF-BVV } \\
(* *)\end{array}$} & \multicolumn{2}{|c|}{ BERTAZZI et al. (2005) } \\
\hline & & & & & & \multirow{2}{*}{$\begin{array}{c}\begin{array}{c}\text { Heurística } \\
\text { DP }\end{array} \\
3,79\end{array}$} & \multirow{2}{*}{$\begin{array}{c}\begin{array}{c}\text { Heurística } \\
\mathrm{DP}^{\prime}\end{array} \\
4,61\end{array}$} \\
\hline 1 & média & & & & & & \\
\hline & menor & 0,19 & 0,00 & 0,04 & 0,04 & 1,58 & 2,75 \\
\hline & maior & 2,96 & 0,91 & 1,23 & 3,13 & 6,75 & 7,93 \\
\hline \multirow[t]{3}{*}{2} & média & 1,23 & 0,60 & 0,76 & 1,02 & 4,17 & 5,48 \\
\hline & menor & 0,01 & 0,00 & 0,00 & 0,03 & 1,38 & 3,35 \\
\hline & maior & 3,73 & 1,83 & 2,14 & 3,98 & 7,75 & 7,90 \\
\hline \multirow[t]{3}{*}{3} & média & 1,82 & 0,38 & 0,78 & 0,95 & 8,73 & 13,08 \\
\hline & menor & 0,55 & 0,00 & 0,00 & 0,00 & 4,64 & 5,83 \\
\hline & maior & 7,02 & 1,35 & 2,20 & 3,36 & 13,33 & 30,62 \\
\hline \multirow[t]{3}{*}{$4(*)$} & média & 0,53 & 0,12 & 0,27 & 0,87 & 1,65 & 2,67 \\
\hline & menor & 0,08 & 0,00 & 0,00 & 0,00 & 0,77 & 2,14 \\
\hline & maior & 1,77 & 0,44 & 0,79 & 2,91 & 2,69 & 3,54 \\
\hline \multirow[t]{3}{*}{ Total } & média & 1,25 & 0,35 & 0,59 & 0,96 & 5,01 & 7,00 \\
\hline & menor & 0,01 & 0,00 & 0,00 & 0,00 & 0,77 & 2,14 \\
\hline & maior & 7,02 & 1,83 & 2,20 & 3,98 & 13,33 & 30,62 \\
\hline
\end{tabular}

(*) Foram excluídos desse grupo as instâncias duplicadas.

(**) Valores obtidos a partir de 10 experimentos com distintas sementes.

Uma avaliação mais formal do desempenho relativo das heurísticas propostas pode ser obtido por meio do teste estatístico de Friedman (vide Apêndice II), que indica que as heurísticas apresentam resultados estatisticamente distintos, conforme pode-se observar no Quadro 7.5. 
QUADRO 7.5 -Teste de Friedman.

\begin{tabular}{|c|c|}
\hline Parâmetro & Valor \\
\hline $\begin{array}{c}\text { Número de instâncias } \\
\text { Número de heurísticas }\end{array}$ & $n=84$ \\
\hline$A_{F}=\sum_{i=1}^{k} \sum_{j=1}^{n} R_{i j}^{2}$ & 2520 \\
$B_{F}=\frac{1}{n} \sum_{i=1}^{k} R_{i}^{2}$ & 2491,12 \\
\hline$T_{F}=\frac{}{(n-1) \cdot\left(B_{F}-\frac{n k(k+1)^{2}}{4}\right.}$ & 1124,02 \\
\hline$A_{F}-B_{F}$ & \\
\hline$F$ crítico $(\alpha=5 \%)$ & 2,64 \\
\hline Conclusão & $\begin{array}{c}T_{F}>F \text { crítico } \\
\end{array}$ \\
\hline
\end{tabular}

QUADRO 7.6 - Diferença absoluta entre as estatísticas de ordem $R_{i}$ e $R_{j}$ e sua comparação com valor crítico(*).

\begin{tabular}{|c|c|c|c|}
\hline \multirow{2}{*}{ Heurística $i$} & \multicolumn{3}{|c|}{ Heurística $j$} \\
\hline & EGF-BT-D & EGF-BT-DI & EGF-BVV \\
\hline EGF-BT & $\begin{array}{c}1201 \\
(>\text { Valor crítico) }\end{array}$ & $\begin{array}{c}927 \\
(>\text { Valor crítico) }\end{array}$ & $\begin{array}{c}504 \\
\text { (> Valor crítico) }\end{array}$ \\
\hline EGF-BT-D & & $\begin{array}{c}274 \\
(>\text { Valor crítico) }\end{array}$ & $\begin{array}{c}697 \\
\text { (> Valor crítico) }\end{array}$ \\
\hline EGF-BT-DI & & & $\begin{array}{c}423 \\
\text { (> Valor crítico) }\end{array}$ \\
\hline
\end{tabular}

(*) Valor crítico $=t_{\left(\frac{\alpha}{2},(n-1)(k-1)\right)} \sqrt{\frac{2 n\left(A_{F}-B_{F}\right)}{(n-1)(k-1)}}=9,95$ 
Rejeitada a hipótese nula de igualdade entre as médias, a comparação das heurísticas duas a duas indica quais heurísticas são distintas, estando os resultados resumidos no Quadro 7.6. Como pode-se observar, em todas as comparações o valor da diferença absoluta entre as estatísticas de ordem ("rank") $R_{i}$ e $R_{j}$ é maior que o valor crítico calculado para um nível de significância de 5\%, o que indica que as heurísticas produzem resultados estatisticamente distintos.

Dos resultados apresentados, pode-se afirmar que a coordenação das decisões de produção, gerenciamento de estoques e distribuição realmente propicia consideráveis ganhos em relação à abordagem tradicional, em que as decisões são tomadas de forma independente. Esse comportamento, já apontado por BERTAZZI et al. (2005), pode ser observado na Tabela 7.2, ao se comparar o custo médio por instância da situação em que os pedidos de reabastecimento são gerados pelos clientes na iminência de falta de estoque (Estoque Gerido pelo Cliente - ECG) com os valores obtidos pelas heurísticas, confirmando as expectativas de redução de custo decorrentes da integração das decisões logísticas.

Os resultados obtidos indicam que as heurísticas propostas no presente trabalho são nitidamente superiores às heurísticas DP e DP'. Esse comportamento é particularmente evidente ao se analisar os resultados desagregados (Anexo A), nos quais se observa que o custo médio obtido pelas heurísticas propostas é inferior ao obtido pelas heurísticas DP e DP' em todas as instâncias testadas. Observa-se ainda que, salvo uma única instância, o pior custo obtido pelas heurísticas propostas é sempre menor que o obtido pelas heurísticas DP e DP'.

Adicionalmente, pode-se afirmar que a heurística EGF-BT-D é superior às demais, uma vez que os valores esperados com a aplicação dessa heurística são menores que os das heurísticas restantes, e os resultados das heurísticas são estatisticamente distintos. Essa conclusão pode ser verificada na Figura 7.3, que apresenta o erro médio por instância em relação aos melhores resultados obtidos. 


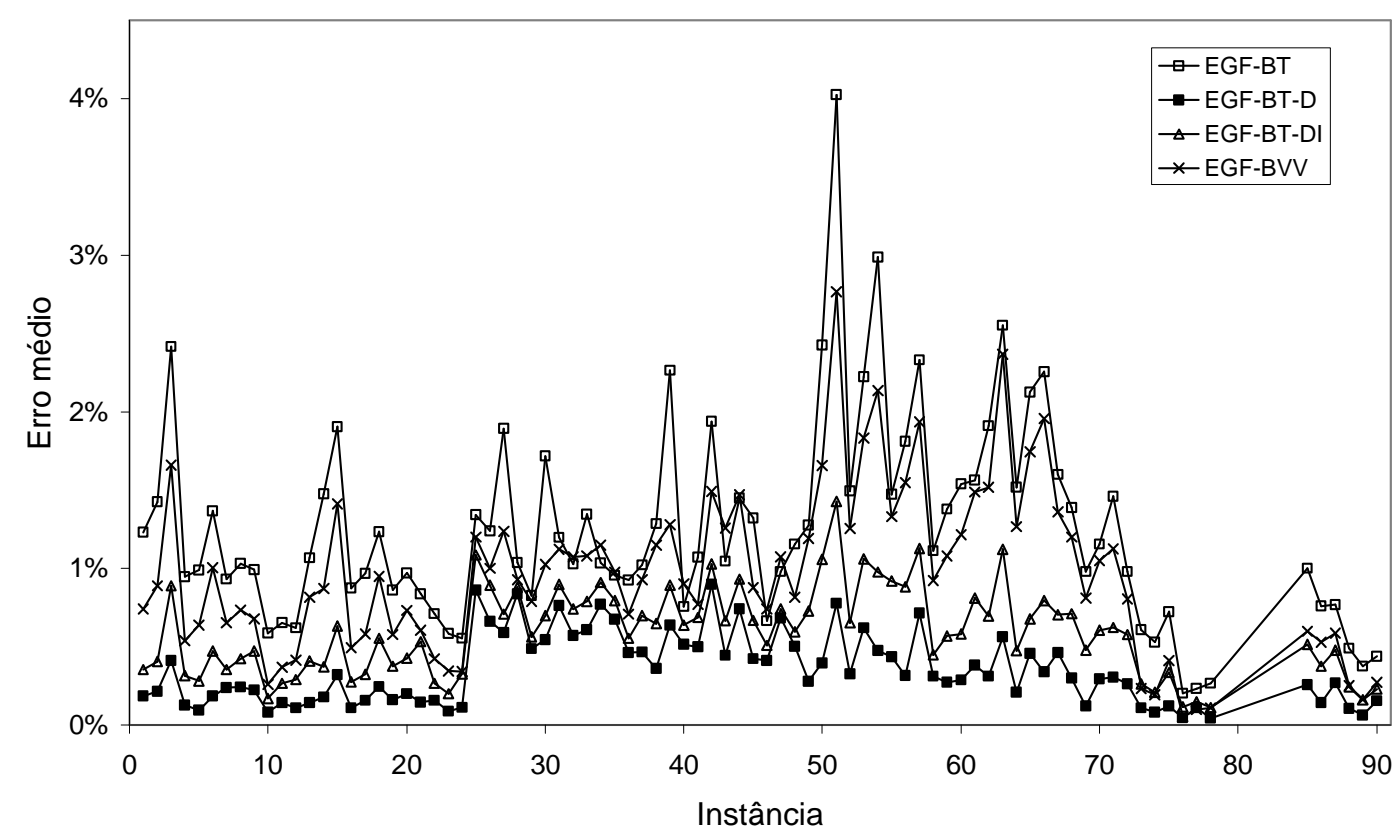

Figura 7.3 - Erro médio percentual por instância em relação aos melhores valores obtidos.

Uma comparação entre os resultados obtidos pelas heurísticas propostas permite ainda algumas interessantes observações. Nota-se que a heurística EGF-BT apresenta sistematicamente os piores resultados dentre as heurísticas propostas, o que indica que a utilização de estratégias de diversificação e intensificação é proveitosa e capaz de melhorar os resultados obtidos pela BT. No entanto, uma comparação entre as heurísticas EGF-BT-D e EGF-BT-DI indica que a utilização de uma fase de intensificação baseada em reinícios com os parâmetros adotados não foi tão efetiva quanto a prorrogação da BT com diversificação. Esse comportamento provavelmente decorre do fato de que, como regra geral, o número de iterações necessárias para se obter uma nova solução de menor custo cresce no decorrer da busca. Em outras palavras, encontrar uma solução de menor custo é cada vez mais difícil, e implica trajetórias de busca cada vez mais extensas, o que não condiz com a idéia central da fase de intensificação, que vem a ser justamente a exploração de trajetórias de busca distintas.

É interessante notar que as heurísticas de melhor e pior desempenho são respectivamente EGF-BT-D e EGF-BT, e diferenciam-se apenas pela utilização da estratégia de diversificação, o que é um indício positivo de sua eficiência. 
Observa-se ainda que a heurística EGF-BVV apresenta resultados nitidamente inferiores às variações mais sofisticadas da BT, superando apenas a heurística EGF-BT. Esse resultado provavelmente está relacionado ao indesejável comportamento de permanência na região inviável mais tempo que o necessário, já comentado no Capítulo 6. Muito embora os efeitos desse comportamento tenham sido reduzidos com a utilização de um método aproximado para a avaliação dos movimentos candidatos, a raiz do comportamento permanece e se reflete na qualidade dos resultados obtidos.

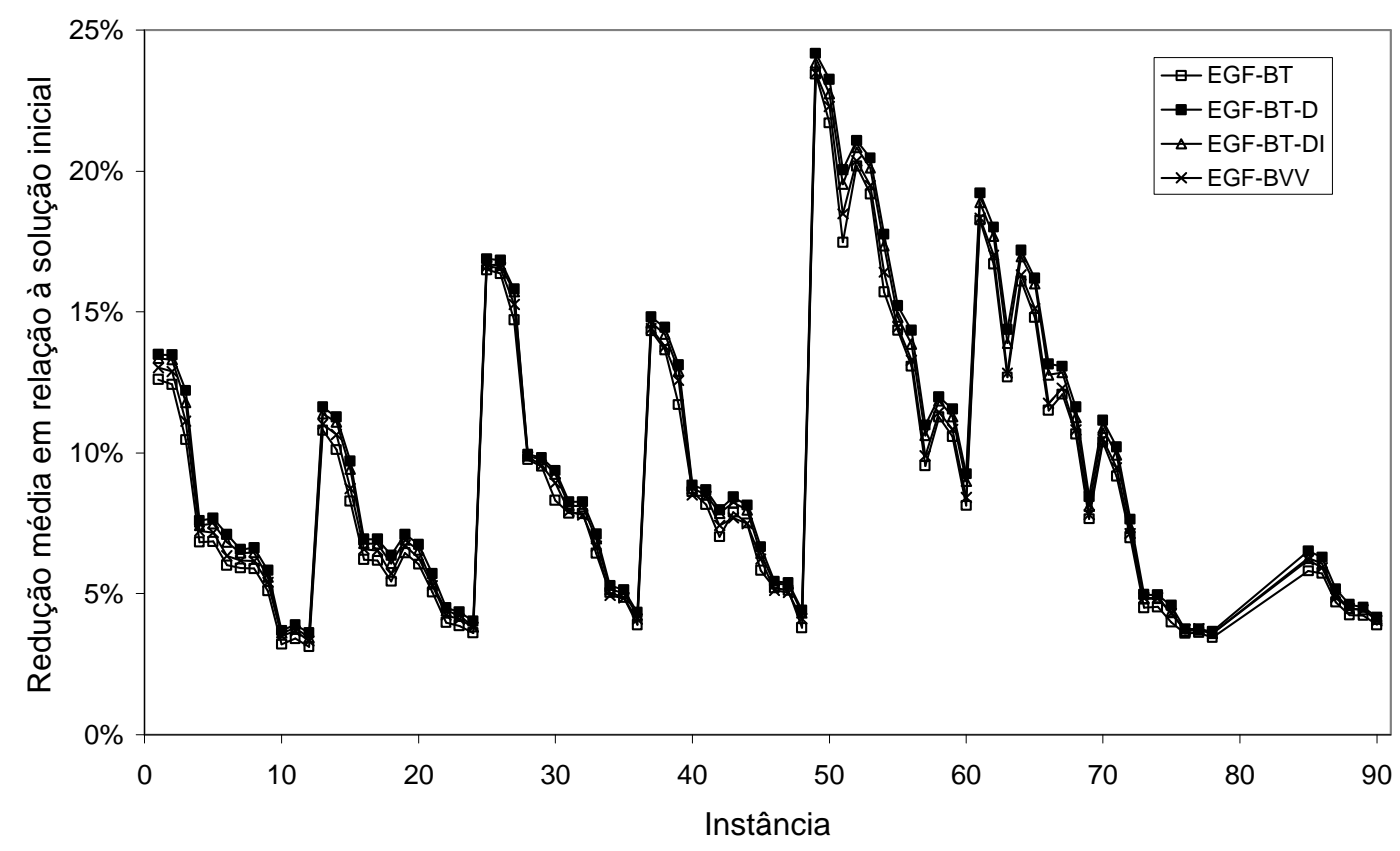

Figura 7.4 - Redução média de custo em relação à solução inicial.

Um interessante resultado obtido é a redução de custo em relação à solução inicial, apresentado na Figura 7.4. Como pode-se observar, a redução de custo apresenta diferenças marcantes entre as instâncias testadas, e um padrão bem definido de variação. Esse padrão deve-se à forma com que as instâncias de teste foram criadas, segundo uma variação sistemática dos parâmetros apresentados anteriormente no Quadro 7.1. Por exemplo, nota-se que as maiores reduções correspondem às instâncias em que a relação entre os custos unitários de manutenção de estoque nos clientes e no depósito é maior; ocorrendo o inverso nas instâncias em que a relação entre os custos unitários de manutenção de estoques nos clientes e no depósito é 
menor. Esses resultados sugerem que a qualidade da solução inicial depende de forma considerável da configuração dos custos e demais parâmetros das instâncias.

Os indícios de que a qualidade das solução inicial é afetada por características das instâncias suscitam a questão de como essas mesmas características afetam a qualidade da solução final obtida. Segundo RARDIN; UZSOY (2001), a ferramenta adequada para uma análise desse tipo é o conhecido teste estatístico de análise de variância (ANOVA). Esse teste assume que a variabilidade não aleatória dos resultados deve-se à diferença entre os efeitos médios dos distintos níveis (ou valores) que um determinado fator pode apresentar. Em outras palavras, considera-se que o resultado obtido para uma determinada instância pode ser decomposto segundo os efeitos médios de cada um dos fatores que a caracterizam, ademais de uma parcela correspondente ao erro residual. Esse modelo pode ainda ser estendido para a inclusão das heurísticas em avaliação como fatores determinantes dos resultados.

O exemplo a seguir, extraído de RARDIN; UZSOY (2001), ilustra o modelo estatístico no qual a análise se baseia. Note-se que, embora o exemplo considere um único fator, ele pode ser facilmente estendido para o caso em que diversos fatores estão presentes. Sejam $f=1, \ldots, F$ os possíveis níveis de um fator, e $h=1, \ldots, H$ as distintas heurísticas aplicadas ao problema. Seja ainda $y_{f h k}$ o resultado obtido na instância correspondente ao nível $f$ do fator, pela heurística $h$, e na replicação $k$. O modelo estatístico pode ser escrito como:

$$
y_{f h k}=\mu+\tau_{f}+\beta_{h}+\gamma_{f h}+\varepsilon_{f h k}
$$

onde

$$
\begin{aligned}
& \mu=\text { média global; } \\
& \tau_{f}=\text { efeito incremental do fator no nível } f, \text { sendo adotado } \sum_{f} \tau_{f}=0 ; \\
& \beta_{h}=\text { efeito incremental da heurística } h, \text { sendo adotado } \sum_{h} \beta_{h}=0 ;
\end{aligned}
$$


$\gamma_{f h}=$ efeito incremental da iteração entre o nível $f$ do fator e a heurística $h$, sendo adotado $\sum_{f} \gamma_{f h}=0$ para cada $h$, e $\sum_{h} \gamma_{f h}=0$ para cada $f$;

$\varepsilon_{f h k}=$ erro aleatório na observação definida por $f h k$.

Como pode-se observar, o modelo considera que o resultado de cada observação pode ser representado como uma soma de parcelas, correspondentes à média global, nível do fator, heurística aplicada e sua iteração com o nível do fator, além da parcela correspondente ao erro aleatório. Modelos mais sofisticados podem incluir ainda uma parcela correspondente à iteração entre o nível do fator e a replicação; no entanto, o modelo apresentado na expressão (58) é suficientemente completo para o entendimento da análise subsequente. Com base no modelo apresentado, o teste estatístico de análise de variância pode ser resumido como um conjunto de testes de hipótese em que se verifica a hipótese de igualdade entre os efeitos definidos anteriormente no modelo. No caso do efeito do fator em análise, esse teste de hipótese pode ser formalizado como:

$$
\begin{aligned}
& H_{0}: \tau_{1}=\tau_{2}=\ldots=\tau_{f}=0 \\
& H_{1}: \tau_{f} \neq 0 \text { para pelo menos um valor de } f
\end{aligned}
$$

Para os demais fatores (ou iterações entre fatores) o teste de hipótese é análogo, sendo que a rejeição da hipótese nula indica que há um efeito significativamente distinto entre diferentes níveis do fator analisado.

Ainda segundo RARDIN; UZSOY (2001), é recomendável a aplicação de algum tipo de transformação nas observações experimentais como forma de corrigir uma provável violação da hipótese de igualdade de variâncias entre os resultados obtidos. A transformação sugerida pelos autores consiste em, para uma mesma combinação de nível dos fatores e heurística, reordenar as observações na ordem crescente dos resultados obtidos, atribuindo o número de ordem ("rank") a cada observação. Esse número de ordem é então utilizado no lugar do resultado correspondente $\left(y_{f h k}\right)$, o que, afirma-se, produz uma indicação mais confiável da significância dos fatores. 
No presente trabalho, foi aplicada a transformação descrita no parágrafo anterior, ao que se seguiu a aplicação da análise de variância. Foram omitidos do modelo os fatores referentes ao custo fixo de produção e custo unitário de produção, pois os mesmos foram definidos como múltiplos do custo diário unitário de manutenção de estoque do depósito, e, portanto, seu efeito não pode ser capturado pelo modelo. Os resultados obtidos são apresentados na Tabela 7.4, que lista, para cada fator ou interação entre fatores os valores computados de soma dos quadrados, graus de liberdade (GL), média dos quadrados, estatística $F$ e respectiva significância, que pode ser entendida como uma medida da aleatoriedade da influência da causa de variação correspondente. Isto é, quanto menor a significância $(\operatorname{Pr}>\mathrm{F})$, maior a influência de um fator ou da interação entre fatores.

Tabela 7.4 - Análise de variância aplicada aos resultados do cenário I.

\begin{tabular}{|c|c|c|c|c|c|}
\hline Causa da Variação & Soma Quadrados & GL & Média Quadrados & $\mathrm{F}$ & $\operatorname{Pr}>\mathrm{F}$ \\
\hline$\overline{\text { HEUR }}$ & 166166,741 & 3 & 55388,914 & 1063,311 & ,000 \\
\hline CAP_VEIC & 4,522 & 2 & 2,261 &, 043 & ,958 \\
\hline CF_V̄EIC & 5,028 & 2 & 2,514 &, 048 & 953 \\
\hline GEOGR & 1,751 & 1 & 1,751 & ,034 &, 855 \\
\hline HDEP & 1,359 & 1 & 1,359 &, 026 &, 872 \\
\hline HCLIENTE &, 560 & 2 &, 280 &, 005 & ,995 \\
\hline HEUR *CAP_VEIC & 797,827 & 6 & 132,971 & 2,553 & 018 \\
\hline HEUR * CF_VEIC & 10552,316 & 6 & 1758,719 & 33,762 &, 000 \\
\hline HEUR $*$ GEOGR & 535,036 & 3 & 178,345 & 3,424 & 017 \\
\hline HEUR $*$ HDEP & 703,825 & 3 & 234,608 & 4,504 &, 004 \\
\hline HEUR * HCLIENTE & 6284,942 & 6 & 1047,490 & 20,109 &, 000 \\
\hline CAP_VEIC $*$ CF_VEIC & 6,014 & 4 & 1,504 &, 029 & ,998 \\
\hline CAP_VEIC $*$ GEOGR &, 877 & 2 & 439 &, 008 & ,992 \\
\hline CAP_VEIC $*$ HDEP & 1,232 & 2 &, 616 & 012 & ,988 \\
\hline CAP_VEIC * HCLIENTE & 1,549 & 4 &, 387 &, 007 & 1,000 \\
\hline CF_VEIC $*$ HDEP & 1,884 & 2 & ,942 &, 018 & ,982 \\
\hline CF_VEIC * HCLIENTE & 1,611 & 2 &, 806 &, 015 & ,985 \\
\hline GEOGR * HDEP & $1,042 \mathrm{E}-03$ & 1 & $1,042 \mathrm{E}-03$ &, 000 & ,996 \\
\hline GEOGR * HCLIENTE & $9,375 \mathrm{E}-03$ & 1 & $9,375 \mathrm{E}-03$ &, 000 & ,989 \\
\hline HDEP $*$ HCLIENTE & 659 & 2 & ,329 & ,006 & ,994 \\
\hline INSTÂNCIA(*) & 27,897 & 30 & ,930 &, 018 & 1,000 \\
\hline Erro & 170493,744 & 3273 & 52,091 & & \\
\hline
\end{tabular}

(*) INSTÂNCIA $=$ CAP_VEIC $*$ CF_VEIC $*$ GEOGR $*$ HDEP $*$ HCLIENTE

onde

HEUR = heurística utilizada;

CAP_VEIC $=$ capacidade dos veículos; 
CF_VEIC = custo fixo dos veículos;

GEOGR = distribuição geográfica dos clientes;

HDEP = custo unitário diário de manutenção de estoque no depósito;

HCLIENTE = custo unitário diário de manutenção de estoque nos clientes .

Os resultados da análise de variância indicam que, dos efeitos principais, apenas o fator HEUR apresenta significância menor que 5\%. Esse comportamento sugere que, quando considerados isoladamente, apenas a aplicação de distintas heurísticas afeta o resultado de forma estatisticamente significativa, o que confirma a conclusão já obtida anteriormente pela aplicação do teste de Friedman.

Adicionalmente, observa-se que as iterações do fator HEUR com os demais fatores também foi significativa, o que indica que as distintas heurísticas apresentam resultados estatisticamente diferenciáveis entre os níveis dos demais fatores. Essas iterações serão analisadas a seguir, à exceção da iteração entre as heurísticas e a distribuição geográfica dos clientes, uma vez que esta decorre da atribuição aleatória das coordenadas de cada cliente. Para cada um dos demais fatores, será apresentado graficamente o erro médio em relação aos melhores resultados obtidos por heurística, o que permite discriminar a influência dos distintos níveis dos fatores e sua iteração com as heurísticas propostas.

A Figura 7.5 apresenta o erro médio obtido por cada heurística em função da capacidade dos veículos. São considerados três níveis para esse fator, aqui denominados baixo, médio e alto. Como pode-se observar, a redução da capacidade dos veículos implica, via de regra, um aumento do erro médio em relação aos melhores resultados obtidos.

De forma similar, a Figura 7.6 apresenta o erro médio obtido por cada heurística em função do custo fixo dos veículos. São considerados três níveis para esse fator, aqui denominados nulo, baixo e alto. Pode-se observar que, assim como ocorre em relação à capacidade dos veículos, à redução do custo fixo dos veículos está associado um aumento do erro médio em relação aos melhores resultados obtidos. 
As Figuras 7.7 e 7.8 apresentam, respectivamente, o erro médio obtido por cada heurística em função do custo diário unitário de manutenção de estoque no depósito e nos clientes. No caso do custo de manutenção do estoque do depósito, dois níveis são considerados: baixo e alto. Já no caso do custo de manutenção de estoque dos clientes, inclui-se um terceiro nível nulo, que corresponde ao grupo 4 do conjunto de instâncias de teste.

Pode-se observar na Figura 7.7 que o aumento do custo de manutenção de estoque do depósito implica uma redução do erro médio para todas as heurísticas. Por sua vez, o efeito do aumento do custo de manutenção de estoque nos clientes é inverso, resultando em uma redução do erro médio, conforme apresentado na Figura 7.8.

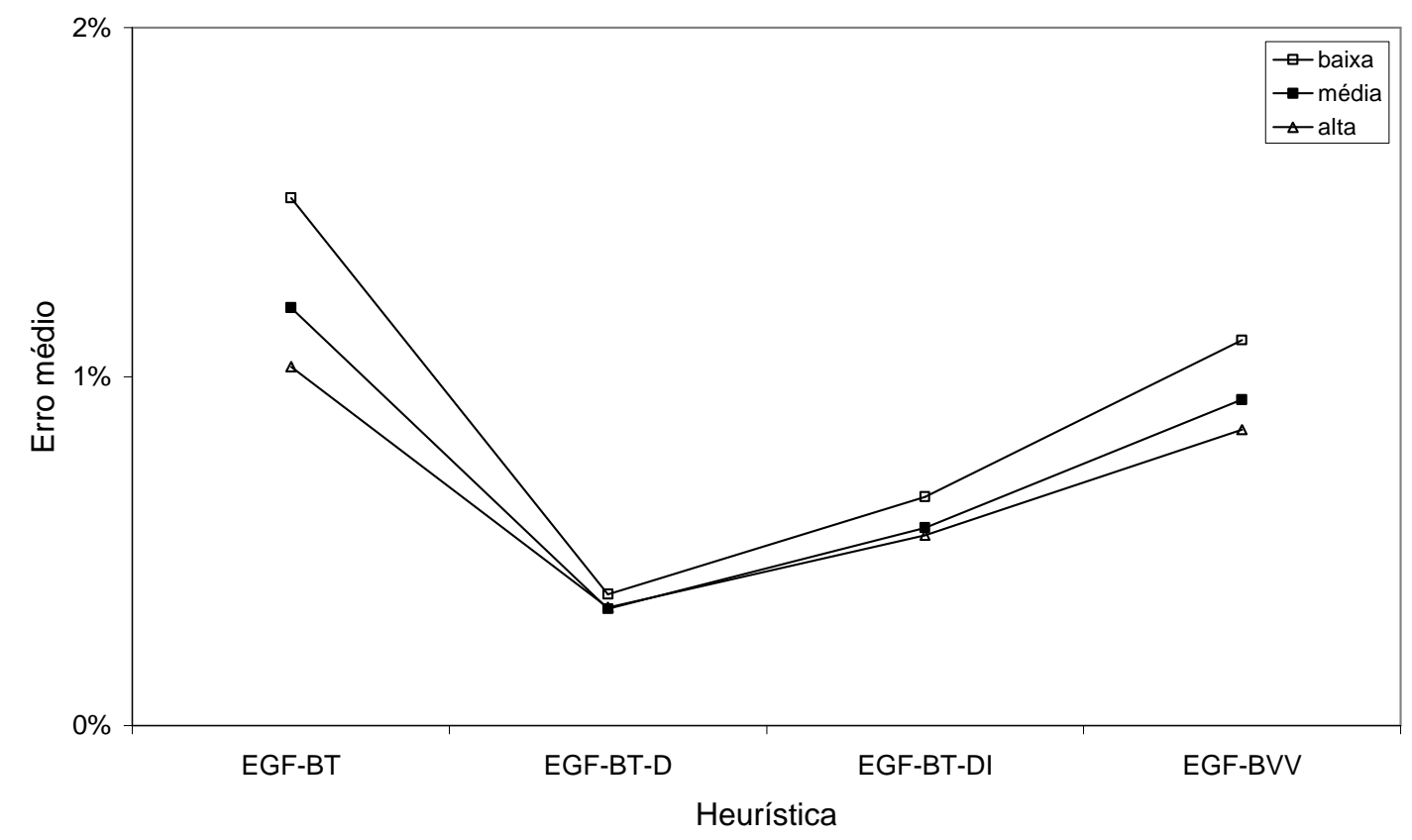

Figura 7.5 - Erro médio por heurística em função da capacidade dos veículos. 


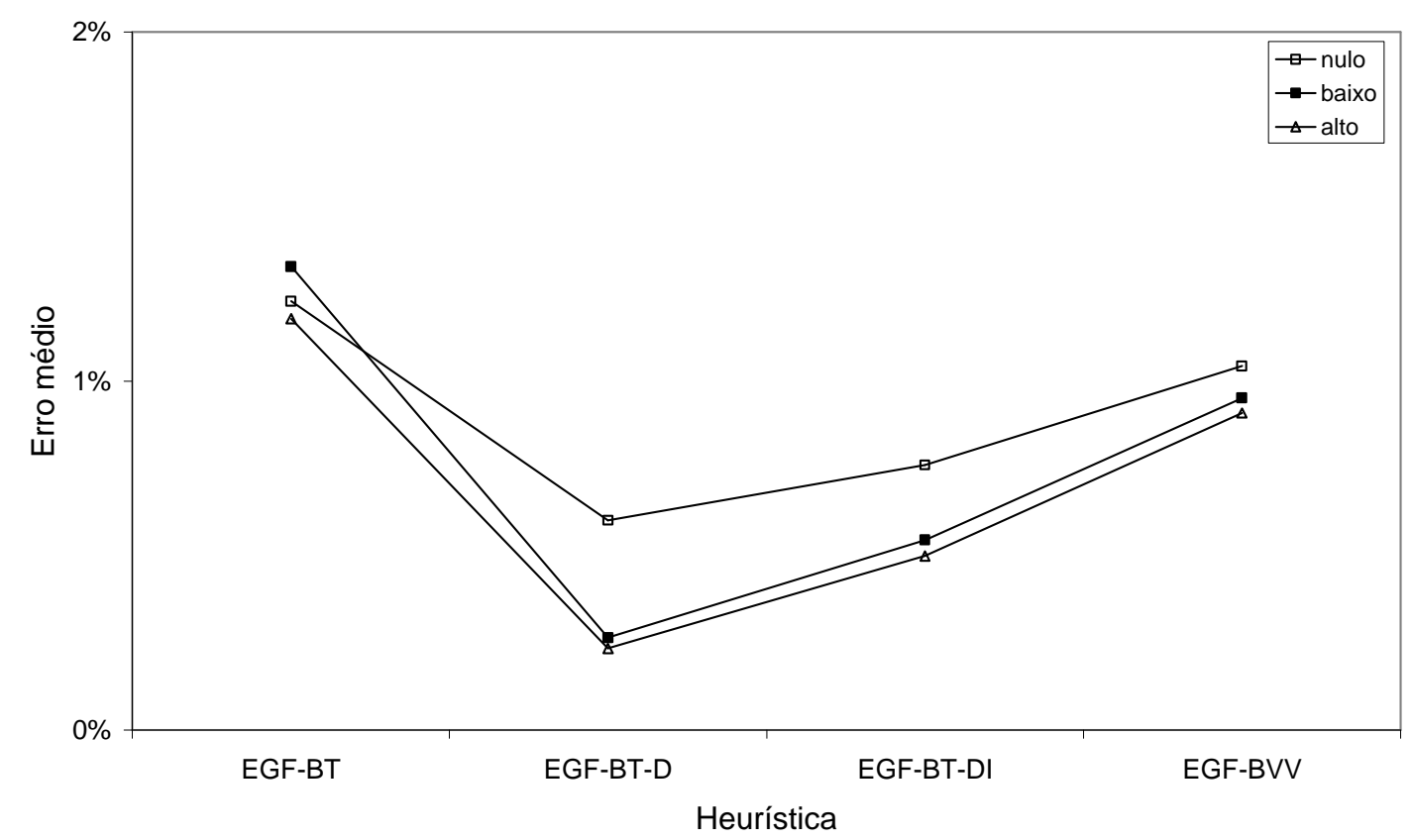

Figura 7.6 - Erro médio por heurística em função do custo fixo dos veículos.

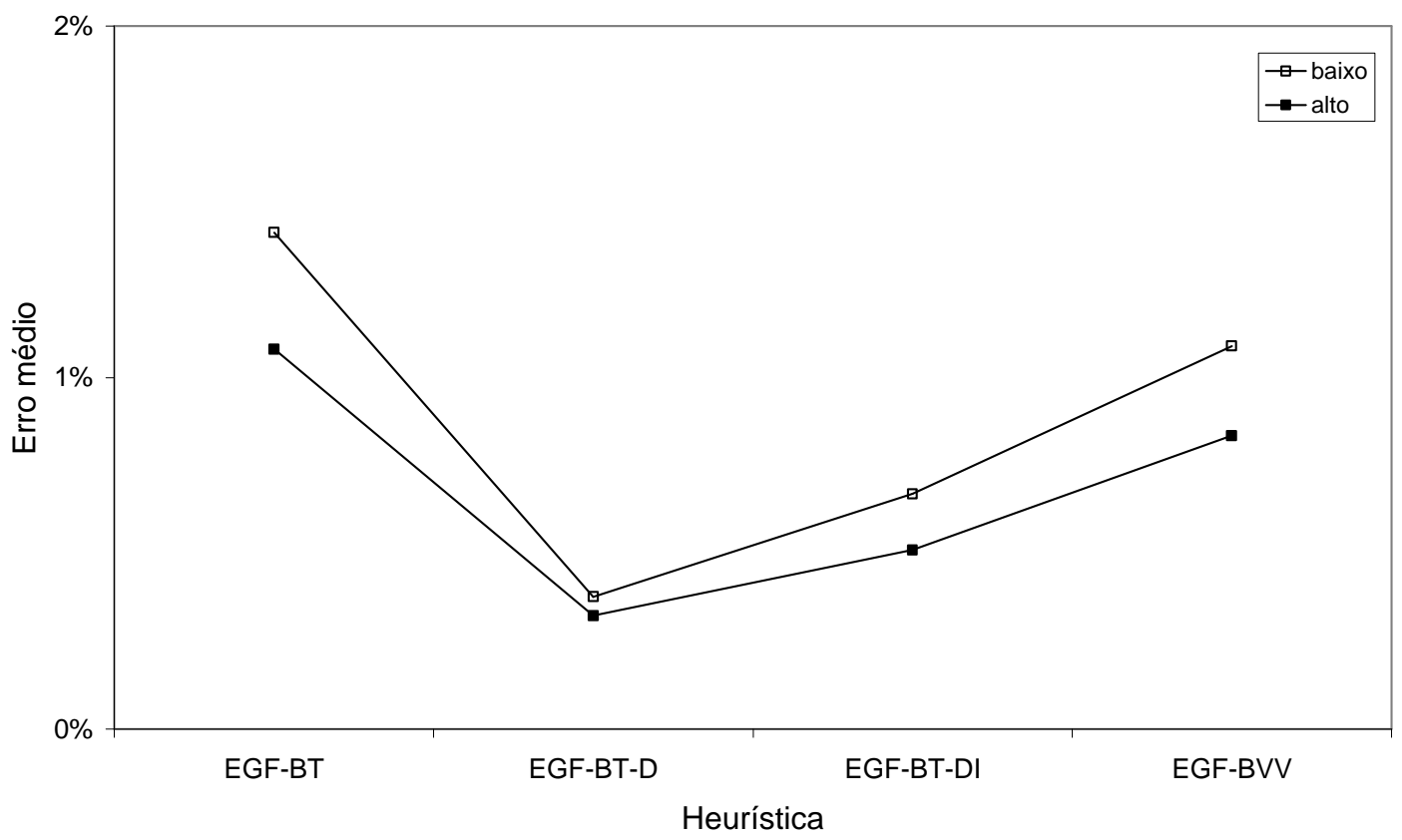

Figura 7.7 - Erro médio por heurística em função do custo unitário diário de manutenção de estoque no depósito. 


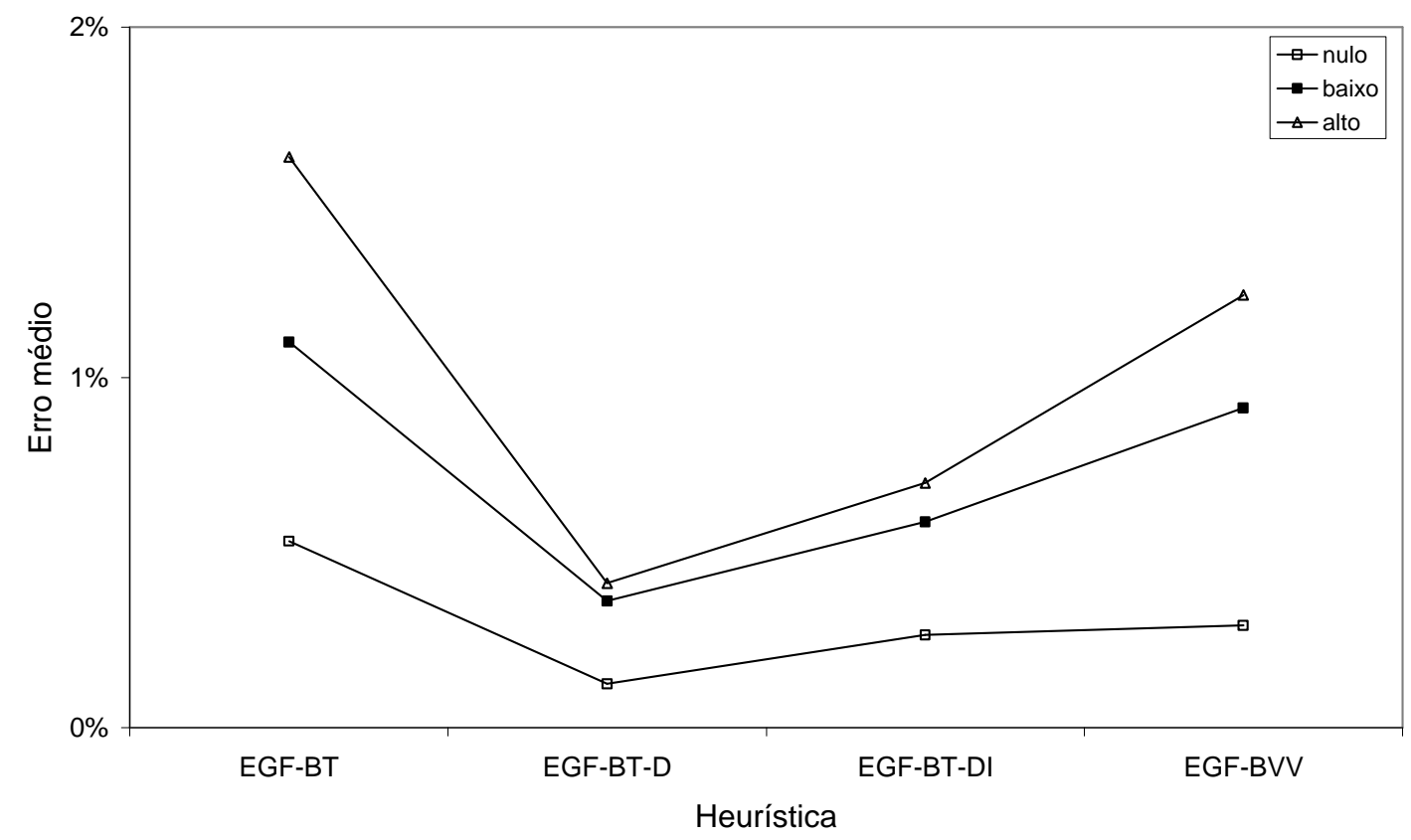

Figura 7.8 - Erro médio por heurística em função do custo unitário diário de manutenção de estoque nos clientes.

Embora a análise de variância seja uma poderosa ferramenta de análise dos resultados, e sua aplicação tenha permitido a identificação de fatores significativos e suas iterações, uma observação deve ser feita a respeito da sua utilização no presente trabalho. Segundo BARR et al. (1995), métodos estatísticos devem ser utilizados sempre que possível na identificação da relação entre diferentes fatores e na medida do desempenho de uma heurística, sendo enfatizada a importância de um adequado desenho do experimento estatístico na análise e avaliação subsequentes. Nesse sentido, as instâncias propostas por BERTAZZI et al. (2005), e utilizadas no presente trabalho, talvez apresentem algumas lacunas a serem preenchidas. Um exemplo dessa deficiência é a correlação entre os custos fixos de produção, os custos variáveis de produção e o custo unitário diário de manutenção de estoque no depósito. Tal correlação faz com que esses fatores sejam indistinguíveis no modelo estatístico, o que impede a avaliação isolada dos seus efeitos nos resultados obtidos. 


\subsubsection{Cenário II}

Neste cenário, será analisado o caso em que a frota disponível no depósito é heterogênea, sendo as instâncias de teste deste cenário divididas em dois grupos, segundo o consumo dos clientes: consumo constante e consumo variável.

Conforme comentado anteriormente no Capítulo 5, a resolução do SPD, quando da obtenção da solução inicial, acaba por definir a frota de veículos que será utilizada na etapa de melhoria subsequente. Cabe recordar que os veículos não utilizados na solução inicial são descartados na etapa de melhoria, como forma de redução do espaço de busca; assim sendo, a etapa de melhoria não possui meios de aumentar a frota utilizada em uma solução. Adicionalmente, verifica-se que, via de regra, a etapa de melhoria também não é capaz de reduzir a frota utilizada em uma solução, uma vez que os movimentos considerados nas heurísticas BT e BVV não abrangem a remoção simultânea de todos os atendimentos realizados por um determinado veículo. Como resultado, pode-se afirmar que a definição da frota utilizada ocorre na etapa de obtenção da solução inicial.

Esse comportamento evidencia a importância da etapa de obtenção da solução inicial e, em particular, do procedimento de resolução do SPD, que determina a frota utilizada. É oportuno recordar que a resolução do SPD pode ser entendida como uma agregação da programação de cada cliente, a qual é obtida pela resolução de um problema de caminho mínimo em um grafo orientado acíclico, construído de forma a representar as possíveis combinações de atendimento do cliente em questão e respectivos custos. Note-se que, originalmente, o custo de inserção de um atendimento no grafo inclui o custo fixo do veículo correspondente, caso esse veículo ainda não tenha sido utilizado na solução.

Embora esse critério de apropriação do custo fixo dos veículos seja adequado no caso em que a frota disponível é homogênea (cenário I), não se pode afirmar o mesmo no caso em que a frota disponível é heterogênea. Nesse caso, dada a diferença usual de ordem de grandeza entre os custos fixos e variáveis dos veículos, a inclusão de um veículo na solução é determinada, via de regra, pelo custo fixo. Isto é, no caso de frota heterogênea, o critério de cômputo do custo fixo total na resolução do SPD faz 
com que o veículo selecionado para inclusão na solução em construção seja sempre o veículo ainda não utilizado de menor custo fixo. Entretanto, veículos de menor custo fixo apresentam também menor capacidade, e possivelmente uma pior relação custo fixo/capacidade. Assim sendo, esse procedimento de programação dos atendimentos apresenta um viés indesejável, que favorece a utilização de veículos menos eficientes, o que pode se refletir negativamente na qualidade da solução.

Esse comportamento suscitou a introdução de uma variação na resolução do SPD, mais precisamente, na determinação da estimativa do custo da inserção de um atendimento em uma solução em construção, descrita na seção 5.3 do Capítulo 5 . Conforme apresentado naquela ocasião, a variação proposta consiste em alterar a forma com que o procedimento de programação de um cliente considera o custo fixo de um veículo. Essa variação é controlada pelo parâmetro UtilizaCustoProporcional, que determina, quando da construção do grafo utilizado na resolução do SPD, se o custo fixo do veículo é considerado em sua totalidade ou proporcional à capacidade utilizada pelo atendimento em programação.

Conforme apresentado na seção anterior, a heurística EGF-BT-D domina as demais heurísticas propostas no presente trabalho; assim sendo, apenas essa heurística será utilizada na resolução das instâncias do cenário II. Entretanto, a fim de diferenciar entre as possíveis variações na obtenção da solução inicial, serão denominadas EGF-BT-D(t) e EGF-BT-D(p) as heurísticas compostas, respectivamente, da etapa de obtenção da solução inicial com custo fixo total (t) ou proporcional (p), ao que se segue a aplicação da etapa de melhoria por BT com diversificação.

Os parâmetros utilizados no processamento das instâncias do cenário II estão relacionados no Anexo $\mathrm{C}$, sendo os resultados obtidos fornecidos de forma desagregada no Anexo D, e de forma resumida na Tabela 7.5, que apresenta um comparativo da variação do custo médio por instância em relação às instância correspondentes do cenário I. 
Tabela 7.5 - Variação percentual do custo médio por instância em relação às instâncias correspondentes (grupo 1) do cenário I. (*)

\begin{tabular}{cccc}
\hline $\begin{array}{c}\text { Grupo } \\
\text { do conjunto } \\
\text { de teste }\end{array}$ & Heurística & $\begin{array}{c}\text { Heurística } \\
\text { EGF-BT-D(p) }\end{array}$ \\
\hline $\begin{array}{c}\text { EGF-BT-D(t) } \\
\text { (demanda constante) }\end{array}$ & menor & $1,92 \%$ & $-2,63 \%$ \\
& maior & $0,11 \%$ & $-4,87 \%$ \\
\hline 2 & média & $4,53 \%$ & $-0,83 \%$ \\
\hline (demanda variável) & menor & $2,58 \%$ & $0,15 \%$ \\
& maior & $7,28 \%$ & $-2,13 \%$ \\
\hline
\end{tabular}

(*) Valores obtidos a partir de 10 experimentos com distintas sementes.

Dois efeitos podem ser notados nos resultados da tabela acima: a variação do custo médio em função da demanda e a comparação entre as variações na heurística de obtenção da solução inicial. No que diz respeito ao comportamento da demanda, pode-se observar que a variabilidade do consumo diário dos clientes acarreta um sensível aumento de custo em relação ao caso em que o consumo é constante. Esse comportamento indica que, mesmo em um sistema logístico em que as decisões de reabastecimento são coordenadas pelo fornecedor e a demanda conhecida de antemão, a variabilidade do consumo pode acarretar um significativo aumento do custo total de distribuição.

Por sua vez, no que tange à heurística de solução inicial, nota-se que a resolução do SPD com o custo fixo dos veículos computado de maneira proporcional à capacidade utilizada no atendimento é claramente superior à regra original, em que o custo fixo total é considerado. Em realidade, no caso da heurística original de resolução do SPD, a disponibilidade de uma frota heterogênea pode resultar em um aumento de custo da solução obtida, mesmo que estejam disponíveis veículos mais eficientes. Esse comportamento evidencia a incapacidade da heurística original em selecionar os veículos mais adequados, o que é, de certa forma, corrigido na heurística EGF-BT-D(p).

A Tabela 7.6 apresenta um comparativo do número médio de veículos utilizados por instância, onde pode-se observar que a heurística EGF-BT-D(p) realmente favorece a 
utilização dos veículos do tipo 3, de menor relação custo fixo/capacidade; de forma similar, observa-se que a heurística EGF-BT-D(t) favorece a utilização dos veículos dos tipos 1 e 2, de menor custo fixo. Verifica-se ainda que, em relação à situação com frota homogênea (cenário I), a heurística EGF-BT-D(t) provoca um aumento do número total de veículos utilizados, e o efeito inverso no caso da heurística EGF-BT-D(p).

Tabela 7.6 - Número médio de veículos utilizados por instância. (*)

\begin{tabular}{ccccc}
\hline $\begin{array}{c}\text { Grupo } \\
\text { do conjunto } \\
\text { de teste }\end{array}$ & $\begin{array}{c}\text { Tipo de } \\
\text { Veículo }\end{array}$ & $\begin{array}{c}\text { Heurística } \\
\text { EGF-BT-D(t) }\end{array}$ & $\begin{array}{c}\text { Heurística } \\
\text { EGF-BT-D(p) }\end{array}$ & $\begin{array}{c}\text { Heurística } \\
\text { EGF-BT-D } \\
\text { (cenário I) }\end{array}$ \\
\hline $\begin{array}{c}\text { EG } \\
\text { (demanda constante) }\end{array}$ & 1 & 2,33 & 0,00 & 4,33 \\
\hline 2 & 3 & 2,95 & 1,00 & \\
\hline & 1 & 0,03 & 2,33 & \\
\hline
\end{tabular}

(*) Valores obtidos a partir de 10 experimentos com distintas sementes.

Uma comparação adicional pode ser realizada em termos do custo associado à frota utilizada, e suas componentes, conforme apresentado na Tabela 7.7. Observa-se que, em comparação com a situação com frota homogênea (cenário I), a heurística EGF-BT-D(p) logra obter uma redução do custo associado à frota de aproximadamente $11,6 \%$, ao passo que a heurística EGF-BT-D(t) obtém um aumento de quase $12 \%$. Note-se que com a aplicação da heurística EGF-BT-D(p) há uma redução não apenas do custo fixo, mas também do custo variável. Esse comportamento indica que, apesar da utilização de veículos de maior custo variável unitário, a maior capacidade dos veículos selecionados permite que as rotas de distribuição sejam mais eficientes e que a distância total percorrida seja reduzida, o que se reflete em menor custo variável total. 
Tabela 7.7 - Custo médio por instância associado à frota utilizada. (*)

\begin{tabular}{ccccc}
\hline $\begin{array}{c}\text { Grupo } \\
\text { do conjunto } \\
\text { de teste }\end{array}$ & Custo & $\begin{array}{c}\text { Heurística } \\
\text { EGF-BT-D(t) }\end{array}$ & $\begin{array}{c}\text { Heurística } \\
\text { EGF-BT-D(p) }\end{array}$ & $\begin{array}{c}\text { Heurística } \\
\text { EGF-BT-D } \\
\text { (cenário I) }\end{array}$ \\
\hline $\begin{array}{c}1 \\
\text { (demanda constante) }\end{array}$ & variável & $121.740,53$ & $106.307,11$ & $118.884,38$ \\
& subtotal & $367.778,12$ & $290.029,44$ & $328.392,38$ \\
\hline 2 & fixo & $246.736,00$ & $183.722,33$ & \\
(demanda variável) & variável & $127.764,87$ & $113.301,67$ & \\
& subtotal & $374.500,87$ & $297.024,00$ & \\
\hline
\end{tabular}

(*) Valores obtidos a partir de 10 experimentos com distintas sementes.

Pode-se observar ainda que a heurística EGF-BT-D(p) obtém uma considerável redução do custo fixo da frota em relação à situação com frota homogênea, muito embora sejam utilizados nesse caso veículos de maior custo fixo. Isso se deve à utilização de um menor número de veículos, o que faz com que haja uma redução do custo fixo total. De modo inverso, a heurística EGF-BT-D(t) utiliza veículos de menor custo fixo, porém a utilização de um maior número de veículos faz com que o custo fixo total seja maior que o custo correspondente obtido no cenário I.

\subsection{Comentários}

Nesse capítulo foi apresentada uma avaliação computacional das estratégias de solução propostas para o PDEGF. Essa avaliação baseou-se em testes empíricos, por meio da comparação dos resultados de distintas heurísticas em um conjunto de instâncias publicado na literatura.

Os resultados obtidos indicam que as estratégias de solução propostas no presente trabalho logram superar heurísticas encontradas na literatura em todas as instâncias testadas. Adicionalmente, pode-se afirmar que a heurística EGF-BT-D, baseada na metaheurística busca tabu com uma estratégia de diversificação apresenta resultados claramente superiores às demais heurísticas avaliadas.

Um significativo resultado apresentado nesse capítulo é a comparação entre os casos com frota homogênea (cenário I) e frota heterogênea (cenário II). A avaliação 
realizada evidencia a importância do procedimento de obtenção da solução inicial no caso de frota heterogênea, uma vez que a determinação da frota utilizada se dá nessa etapa, e a qualidade da solução final depende em grande parte da correta escolha dos veículos. Nesse sentido, a variação proposta na resolução do SPD é capaz de favorecer a escolha de veículos mais eficientes, o que se reflete positivamente nos resultados obtidos.

Um último resultado obtido é a constatação de que a variação da demanda dos clientes acarreta um sensível aumento do custo total da distribuição, apesar da coordenação dos atendimentos dos clientes inerente ao sistema logístico do tipo EGF.

No capítulo seguinte serão apresentadas as conclusões e recomendações do presente trabalho. 


\section{CONCLUSÕES E RECOMENDAÇÕES}

\subsection{Introdução}

Segundo CHRISTOFER (1998) apud BARRATT (2003), desde a década de 90 há uma crescente percepção por parte das empresas da necessidade de integração, tanto interna quanto externa, eliminando barreiras funcionais em favor de processos administrativos horizontais e estreitando as relações com vendedores, fornecedores e clientes. Nesse sentido, BARRATT (2003) lista algumas iniciativas de colaboração empresarial, predominantemente desenvolvidas no âmbito do comércio varejista. Segundo o autor, a primeira iniciativa influente de integração de cadeias de abastecimento ocorreu em 1992, com a criação do "Efficient Consumer Response Movement" ou simplesmente ECR, que definiu diretrizes para uma maior eficiência do reabastecimento de pontos de venda, fomento à demanda via promoções e introdução de novos produtos, entre outras. Como forma de concretizar as diretrizes preconizadas pelo ECR, diversas iniciativas de integração sugiram desde então, sendo citadas pelo autor:

- "Vendor Managed Inventory" - VMI;

- "Continuous Replenishment Program" - CRP;

- "Collaborative Forecasting" - CF;

- "Collaborative Planning"- CP.

A partir de 1995, várias dessas iniciativas convergiram para a criação do "Collaborative Planning, Forecasting and Replenishment" - CPFR, que foi inicialmente utilizado com sucesso pelas empresas Wal-Mart e Warner Lambert. Atualmente, o desenvolvimento de diretrizes e orientações para a implementação do CPFR é realizada pelo "Voluntary Inter-Industry Commerce Standards" - VICS, que desde 1997 possui uma subcomissão exclusivamente destinada a isso. 
Observa-se que os esforços de integração envolvem, acima de tudo, o intercâmbio de informações e o desenvolvimento de relações de confiança entre os participantes da cadeia de suprimentos. Nesse sentido, a aplicação de uma iniciativa de integração baseada exclusivamente na centralização de decisões, como vem a ser o caso do modelo preconizado pelo VMI, resultou de pouco sucesso. Autores como BARRATT (2003) e SHEFFI (2002) apontam que a aplicação do VMI em geral se restringe à relação entre um fornecedor e um conjunto de centros de distribuição, não abrangendo os pontos de venda geridos pelos distribuidores. Essa configuração não considera os estoques e dados de demanda desses pontos de venda e resulta ser especialmente vulnerável em canais de distribuição que utilizam promoções como mecanismo de fomento da demanda.

Note-se, entretanto, que esses resultados pouco satisfatórios decorrem basicamente de deficiências do fluxo de informação, e ensejaram o desenvolvimento de modelos mais abrangentes de colaboração, com a inclusão dos responsáveis pelos pontos de venda no planejamento da distribuição e, principalmente, na previsão da demanda.

Conquanto a definição de diretrizes e orientações para uma maior integração da cadeia de distribuição já esteja bem estabelecida, e as principais dificuldades identificadas, o desenvolvimento de modelos quantitativos ainda apresenta algumas dificuldades, como bem observam CAMPBELL et al. (1998). Esses autores apontam a dificuldade de resolução dos problemas matemáticos envolvidos no desenvolvimento de estratégias de distribuição do tipo EGF como um dos motivos que impedem sua utilização de modo mais amplo. Essa lacuna pode ser observada especialmente em problemas que envolvem roteirização de entregas, que, por sua natureza combinatória, são de difícil resolução ("NP-Hard"). Além das dificuldades apontadas, há que se lembrar que as particularidades de cada situação real requerem, em geral, o desenvolvimento de implementações sob medida ou a adaptação de implementações já realizadas. 


\subsection{Conclusões}

Buscou-se, no presente trabalho, contribuir para o preenchimento dessa lacuna, com a apresentação de um modelo flexível, que permita representar distintas configurações de custo, e o desenvolvimento de heurísticas capazes gerar, de forma automatizada, soluções econômicas para o PDEGF.

O modelo matemático proposto, conquanto baseado em trabalhos publicados na literatura, apresenta algumas características relevantes, que vale a pena mencionar. Em primeiro lugar, trata-se de um modelo linear, isto é, tanto a função objetivo quanto as restrições são lineares, o que permitiu a utilização de softwares comerciais de programação matemática para a resolução de instâncias de pequeno porte. Aqui uma primeira conclusão pode ser obtida dos experimentos realizados com o software ILOG CPLEX: a resolução do PDEGF por meio de softwares de programação matemática só é viável para instâncias de dimensões reduzidas, havendo a necessidade de se utilizar alguma heurística para a resolução de instâncias de porte real.

Uma segunda característica relevante do modelo proposto é a possibilidade de se utilizar uma frota heterogênea, ou seja, veículos com custos e capacidades distintas. Essa característica aumenta de forma considerável a flexibilidade e generalidade do modelo, permitindo representar uma gama maior de situações práticas de distribuição.

As estratégias de solução propostas para a resolução do PDEGF podem ser resumidas como heurísticas de duas etapas, em que uma solução viável é obtida na etapa inicial, e melhorada iterativamente na etapa subsequente até a obtenção da solução final. O procedimento de obtenção da solução inicial, comum a todas as heurísticas propostas, baseia-se no trabalho de BERTAZZI et al. (2005), sendo a aplicação de uma etapa de melhoria baseada na metaheurística busca tabu ou busca em vizinhança variável a contribuição original da presente pesquisa.

Conforme comentado quando da revisão bibliográfica, a utilização de metaheurísticas na otimização de sistemas logísticos do tipo EGF não é tão disseminada como poderia se esperar, dado o recente sucesso de tais métodos na 
resolução de problemas de natureza combinatória. Nesse sentido, o presente trabalho vem ser uma contribuição, ao demonstrar não apenas a viabilidade da utilização de metaheurísticas em problemas desse tipo, mas também sua capacidade de fornecer soluções de boa qualidade.

A avaliação da qualidade das estratégias de solução foi realizada de forma empírica, por meio da comparação entre os resultados obtidos pelas heurísticas propostas e resultados publicados na literatura para um conjunto de instâncias de teste. Os resultados obtidos pelas heurísticas superam os resultados de referência em todas as instâncias testadas, o que permite concluir que as estratégias de solução propostas efetivamente logram fornecer soluções econômicas para o PDEGF, cumprindo assim com o objetivo principal do presente trabalho.

Uma análise dos resultados obtidos aponta que, dentre os a fatores determinantes da qualidade da solução, a heurística adotada é o único fator estatisticamente relevante, sendo ainda relevantes as iterações desse fator com os demais. Esses resultados indicam que as heurísticas propostas apresentam resultados estatisticamente distintos e permitem concluir que a heurística EGF-BT-D é superior às demais, o que indica a efetividade da estratégia de diversificação empregada nessa variação da BT original.

Em todas as estratégias de solução propostas, a determinação da frota utilizada ocorre na etapa de obtenção da solução inicial, o que é de especial importância no caso de frota heterogênea. Nesse caso, os resultados obtidos indicam que a estimativa de custo de transporte utilizada na resolução do SPD apresenta um viés no sentido de favorecer a utilização de veículos de menor custo fixo, o que pode refletir-se negativamente nos resultados. Nesse sentido, a variação proposta na resolução do SPD, em que o custo fixo dos veículos é considerado de forma proporcional à capacidade utilizada do veículo, evita esse viés negativo e favorece a escolha de veículos mais eficientes, de menor relação custo fixo/capacidade.

\subsection{Recomendações}

Considerando-se o estágio alcançado pela pesquisa desenvolvida na presente tese, algumas são as recomendações possíveis no tocante à sua continuidade: 
a) Conjunto de teste: Muito embora o conjunto de instâncias utilizado na avaliação computacional seja extenso e razoavelmente completo, a configuração dos parâmetros utilizados na sua elaboração evidencia que tais instâncias não foram geradas tendo em mente um experimento estatístico, desenhado de forma a avaliar a influência dos possíveis fatores no resultado final. Um exemplo disso, já comentado no Capítulo 7, é a correlação entre os custos de produção e manutenção de estoques no depósito, o que não permite isolar o efeito de cada um desses fatores por meio de ferramentas usuais de análise estatística, tais como a análise de variância. Nesse sentido, a avaliação de novas instâncias de teste, desenhadas de forma a permitir uma análise mais completa da influência de cada fator na qualidade da solução final, seria desejável.

b) Extensões do modelo: São diversas as possíveis extensões do modelo apresentado no presente trabalho, podendo-se citar aqui a incorporação de múltiplos produtos, a consideração de restrições de capacidade de produção e estocagem no depósito, e a utilização de uma política de reabastecimento distinta, como por exemplo a política do tipo "fill-fill-dump". Evidentemente, as mudanças citadas acarretam diferentes efeitos no modelo e, principalmente, nas estratégias de solução propostas. Em particular, a etapa de melhoria deve ser cuidadosamente reavaliada no caso em que a alteração da política de reabastecimento torna contínuas as variáveis que definem a quantidade de produto correspondente a cada atendimento. Nesse caso, a utilização da BT ou BVV se faz mais difícil, uma vez que tais metaheurísticas usualmente tratam da otimização de variáveis discretas, e não contínuas.

c) Calibração dos parâmetros: O comportamento das estratégias de solução propostas depende em grande parte da configuração dos parâmetros utilizados. Embora alguns parâmetros tenham sido cuidadosamente calibrados, como é o caso da duração tabu, os valores adotados para os demais parâmetros foram determinados de forma menos rigorosa, geralmente baseada em experimentos simplificados ou mesmo definidos ad hoc. Nesse sentido, uma extensão do presente trabalho seria a calibração dos parâmetros de forma sistemática, se possível com o auxílio de testes estatísticos, como sugerido por XU; CHIU; 
GLOVER (1998). Recomendação similar pode ser aplicada a outras características da implementação realizada, tais como a seleção dos movimentos no caso da BT, e a escolha dos movimentos constituintes de cada vizinhança no caso da BVV.

d) Frota Heterogênea: Muito embora a variação proposta na etapa de obtenção da solução inicial tenha apresentado resultados positivos no que diz respeito à seleção dos veículos no caso de a frota disponível ser heterogênea, essa questão pode ser abordada também na etapa de melhoria. Nesse sentido, uma possível extensão seria a subdivisão da etapa de melhoria em duas fases. A primeira fase incluiria movimentos mais complexos, associados à substituição de veículos na solução; já a segunda fase corresponderia à aplicação da etapa de melhoria nos moldes do apresentado nesse trabalho. Evidentemente, na primeira fase seriam considerados todos os veículos da frota, e não apenas os utilizados na etapa de obtenção da solução inicial.

e) Configurações do Sistema Logístico: No presente trabalho foi dada ênfase na elaboração de um conjunto de estratégias de solução inéditas, baseadas na aplicação de metaheurísticas como uma etapa de melhoria posterior à obtenção de uma solução inicial segundo uma heurística disponível na literatura, e capazes de gerar soluções de qualidade. Assim sendo, não foram exploradas questões relativas à configuração do sistema logístico modelado e sua comparação em relação a configurações alternativas, para as quais o modelo proposto no presente trabalho pode servir como valioso instrumento de simulação e análise.

f) Estudo de caso: A presente pesquisa iniciou-se tendo em vista um problema concreto de distribuição regional de gás combustível. Entretanto, deficiências encontradas nos dados disponíveis da empresa selecionada, sobrepostas a dificuldades decorrentes da mudança de controle acionário e conseqüente reestruturação, fizeram com que não fosse possível a aplicação e a avaliação das heurísticas propostas em uma situação real de distribuição. Nesse sentido, a aplicação das estratégias de solução propostas a um caso real seria de grande interesse, complementando o presente trabalho e contribuindo para o desenvolvimento da logística no âmbito da realidade brasileira. 
ANEXO A

\section{PARÂMETROS UTILIZADOS NO CENÁRIO I}

QUADRO A.1 - Parâmetros utilizados na Heurística EGF-BT.

\begin{tabular}{|c|c|c|}
\hline Etapa & Parâmetro & Valor \\
\hline $\begin{array}{c}\text { Solução } \\
\text { Inicial }\end{array}$ & $\begin{array}{c}\text { TamanhoLista } \\
\text { NumIterações } \\
\text { UtilizaCustoProporcional }\end{array}$ & $\begin{array}{c}10 \\
100 \\
0\end{array}$ \\
\hline $\begin{array}{l}\text { Etapa } \\
\text { de } \\
\text { Melhoria }\end{array}$ & $\begin{array}{c}\alpha_{\text {inicial }}, \quad \beta_{\text {inicial }} \\
\alpha_{\text {mínimo }}, \quad \beta_{\text {mínimo }} \\
\alpha_{\text {máximo }}, \quad \beta_{\text {máximo }} \\
\varphi \\
\begin{array}{c}\text { intervalo de sorteio da } \\
\text { duração tabu }\end{array} \\
\text { critério de parada }\end{array}$ & $\begin{array}{c}100 \\
1 \\
9999999 \\
0.05 \\
\theta=33,016 \ln (|\mathrm{N}||\mathrm{T}||\mathrm{VU}|)-218,56 \\
900 \mathrm{~s}\end{array}$ \\
\hline
\end{tabular}


QUADRO A.2 - Parâmetros utilizados na Heurística EGF-BT-D.

\begin{tabular}{|c|c|c|}
\hline Etapa & Parâmetro & Valor \\
\hline \multirow{3}{*}{$\begin{array}{c}\text { Solução } \\
\text { Inicial }\end{array}$} & TamanhoLista & 10 \\
\hline & NumIterações & 100 \\
\hline & UtilizaCustoProporcional & 0 \\
\hline \multirow{7}{*}{$\begin{array}{l}\text { Etapa } \\
\text { de } \\
\text { Melhoria }\end{array}$} & $\alpha_{\text {inicial }}, \quad \beta_{\text {inicial }}$ & 100 \\
\hline & $\alpha_{\text {mínimo }}, \beta_{\text {mínimo }}$ & 1 \\
\hline & $\alpha_{\text {máximo }}, \beta_{\text {máximo }}$ & 9999999 \\
\hline & $\varphi$ & 0.05 \\
\hline & $\begin{array}{l}\text { intervalo de sorteio da } \\
\text { duração tabu }\end{array}$ & $\begin{array}{c}{[0.95 \theta, 1.05 \theta], \text { onde }} \\
\theta=33,016 \ln (|\mathrm{N}||\mathrm{T}||\mathrm{VU}|)-218,56\end{array}$ \\
\hline & $\begin{array}{c}\text { ativação da } \\
\text { diversificação }\end{array}$ & $\begin{array}{l}500 \text { iterações sem redução do } \\
\text { custo da melhor solução }\end{array}$ \\
\hline & critério de parada & $900 \mathrm{~s}$ \\
\hline
\end{tabular}


QUADRO A.3 - Parâmetros utilizados na Heurística EGF-BT-DI.

\begin{tabular}{|c|c|c|}
\hline Etapa & Parâmetro & Valor \\
\hline $\begin{array}{l}\text { Solução } \\
\text { Inicial }\end{array}$ & $\begin{array}{c}\text { TamanhoLista } \\
\text { NumIterações } \\
\text { UtilizaCustoProporcional }\end{array}$ & $\begin{array}{c}10 \\
100 \\
0\end{array}$ \\
\hline $\begin{array}{l}\text { Etapa } \\
\text { de } \\
\text { Melhoria }\end{array}$ & $\begin{array}{c}\alpha_{\text {inicial }}, \quad \beta_{\text {inicial }} \\
\alpha_{\text {mínimo }}, \quad \beta_{\text {mínimo }} \\
\alpha_{\text {máximo }}, \quad \beta_{\text {máximo }} \\
\varphi \\
\text { intervalo de sorteio da } \\
\text { duração tabu } \\
\text { ativação da } \\
\text { diversificação } \\
\text { critério de parada } \\
\text { da fase com diversificação } \\
\text { (sem intensificação) }\end{array}$ & $\begin{array}{c}100 \\
1 \\
9999999 \\
0.05 \\
\theta=33,016 \ln (|\mathrm{N}||\mathrm{T}||\mathrm{VU}|)-218,56 \\
500 \text { iterações sem redução do } \\
\text { custo da melhor solução } \\
{[0.95 \theta, 1.05 \theta], \text { onde }} \\
450 \mathrm{~s}\end{array}$ \\
\hline $\begin{array}{c}\text { Intensificação } \\
(*)\end{array}$ & $\begin{array}{l}\text { tamanho da lista de } \\
\text { soluções de elite } \\
\text { diversidade mínima } \\
\text { entre soluções de elite } \\
\text { critério de reinício } \\
\text { critério de parada } \\
\text { da etapa de intensificação }\end{array}$ & $\begin{array}{c}3 \text { soluções } \\
5 \text { atendimentos } \\
1500 \text { iterações sem redução do } \\
\text { custo da melhor solução } \\
450 \mathrm{~s}\end{array}$ \\
\hline
\end{tabular}

(*) Os demais parâmetros da BT são mantidos na fase de intensificação. 
QUADRO A.4 - Parâmetros utilizados na Heurística EGF-BVV.

\begin{tabular}{|c|c|c|}
\hline Etapa & Parâmetro & Valor \\
\hline $\begin{array}{c}\text { Solução } \\
\text { Inicial }\end{array}$ & TamanhoLista & 10 \\
NumIterações & 100 \\
\hline $\begin{array}{c}\text { Etapa } \\
\text { de } \\
\text { Melhoria }\end{array}$ & $\alpha_{\text {inicial }}, \beta_{\text {inicial }}$ & 0 \\
\hline$\alpha_{\text {mínimo }}, \beta_{\text {mínimo }}$ & 100 \\
& $\alpha_{\text {máximo }}, \beta_{\text {máximo }}$ & 1 \\
$\varphi$ & critério de parada & 9999999 \\
\end{tabular}




\section{ANEXO B}

\section{CUSTO TOTAL MÉDIO POR INSTÂNCIA CENÁRIO I}

QUADRO B.1 - Custo total médio por instância para a Heurística EGF-BT.

\begin{tabular}{|c|c|c|c|c|c|}
\hline \multirow{2}{*}{ Instância } & \multicolumn{3}{|c|}{ Heurística EGF-BT } & \multicolumn{2}{|c|}{ BERTAZZi et al. (2005) } \\
\hline & Média (*) & $\operatorname{Melhor}(*)$ & Pior $(*)$ & Heurística DP & Heurística DP \\
\hline 1 & 1.242 .697 & 1.237 .998 & 1.248 .000 & 1.310 .473 & 1.307 .146 \\
\hline 2 & 1.293 .626 & 1.290 .225 & 1.298 .868 & 1.361 .021 & 1.356 .162 \\
\hline 3 & 1.409 .408 & 1.403 .183 & 1.416 .854 & 1.451 .055 & 1.448 .963 \\
\hline 4 & 2.392 .634 & 2.387 .717 & 2.402 .611 & 2.457 .237 & 2.485 .809 \\
\hline 5 & 2.443 .307 & 2.439 .908 & 2.447 .753 & 2.510 .718 & 2.520 .028 \\
\hline 6 & 2.559 .029 & 2.548 .749 & 2.577 .203 & 2.603 .863 & 2.628 .482 \\
\hline 7 & 982.967 & 979.454 & 984.939 & 1.011 .645 & 1.017 .350 \\
\hline 8 & 1.031 .557 & 1.029 .213 & 1.033 .418 & 1.056 .714 & 1.061 .470 \\
\hline 9 & 1.127 .042 & 1.124 .187 & 1.131 .216 & 1.148 .105 & 1.152 .899 \\
\hline 10 & 2.127 .348 & 2.123 .105 & 2.130 .801 & 2.158 .515 & 2.197 .917 \\
\hline 11 & 2.175 .666 & 2.173 .590 & 2.177 .384 & 2.209 .978 & 2.247 .441 \\
\hline 12 & 2.272 .122 & 2.266 .831 & 2.277 .756 & 2.293 .702 & 2.353.238 \\
\hline 13 & 1.401 .655 & 1.396 .742 & 1.408 .900 & 1.473 .124 & 1.496 .904 \\
\hline 14 & 1.503 .595 & 1.501 .120 & 1.506 .883 & 1.571 .989 & 1.572 .628 \\
\hline 15 & 1.706 .654 & 1.694 .304 & 1.721 .168 & 1.759 .682 & 1.753 .094 \\
\hline 16 & 2.552 .937 & 2.548 .161 & 2.561 .485 & 2.630 .846 & 2.655 .245 \\
\hline 17 & 2.652 .738 & 2.644 .200 & 2.661 .923 & 2.717 .344 & 2.740 .833 \\
\hline 18 & 2.852 .211 & 2.839 .030 & 2.864 .302 & 2.902 .029 & 2.963 .679 \\
\hline 19 & 1.141 .540 & 1.136 .264 & 1.145 .860 & 1.181 .789 & 1.185 .481 \\
\hline 20 & 1.234 .604 & 1.231 .285 & 1.238 .781 & 1.267 .135 & 1.273 .359 \\
\hline
\end{tabular}

(*) Valores obtidos a partir de 10 experimentos com distintas sementes.

(continua) 
QUADRO B.1 - Custo total médio por instância para a Heurística EGF-BT. (continuação)

\begin{tabular}{|c|c|c|c|c|c|}
\hline \multirow{2}{*}{ Instância } & \multicolumn{3}{|c|}{ Heurística EGF-BT } & \multicolumn{2}{|c|}{ BERTAZZi et al. (2005) } \\
\hline & Média (*) & Melhor (*) & Pior $(*)$ & Heurística DP & Heurística DP' \\
\hline 21 & 1.419 .783 & 1.416 .328 & 1.422 .370 & 1.454 .603 & 1.451 .870 \\
\hline 22 & 2.287 .470 & 2.283 .335 & 2.292 .735 & 2.322 .847 & 2.362 .208 \\
\hline 23 & 2.379 .824 & 2.374 .229 & 2.386 .543 & 2.415 .315 & 2.449 .453 \\
\hline 24 & 2.564 .502 & 2.555 .304 & 2.573 .540 & 2.598 .792 & 2.620 .665 \\
\hline 25 & 1.109 .154 & 1.096 .452 & 1.121 .635 & 1.174 .940 & 1.172 .479 \\
\hline 26 & 1.125 .499 & 1.120 .684 & 1.130 .194 & 1.188 .426 & 1.188 .413 \\
\hline 27 & 1.175 .998 & 1.168 .879 & 1.185 .493 & 1.207 .722 & 1.207 .461 \\
\hline 28 & 2.216 .153 & 2.196 .231 & 2.224 .413 & 2.281 .078 & 2.307 .320 \\
\hline 29 & 2.240 .787 & 2.228 .994 & 2.256 .230 & 2.292 .596 & 2.328 .687 \\
\hline 30 & 2.302 .580 & 2.286 .059 & 2.318 .032 & 2.321 .027 & 2.339 .639 \\
\hline 31 & 856.108 & 849.865 & 861.563 & 885.256 & 896.174 \\
\hline 32 & 870.696 & 866.606 & 877.669 & 895.356 & 907.063 \\
\hline 33 & 907.453 & 905.305 & 909.548 & 921.316 & 930.977 \\
\hline 34 & 1.951 .625 & 1.933 .759 & 1.972 .718 & 1.988 .610 & 2.071 .902 \\
\hline 35 & 1.973 .340 & 1.959 .879 & 1.997 .089 & 2.004 .072 & 2.055 .008 \\
\hline 36 & 2.019 .928 & 2.011 .389 & 2.031 .198 & 2.028 .979 & 2.085 .049 \\
\hline 37 & 1.166 .743 & 1.161 .987 & 1.171 .317 & 1.244 .489 & 1.246 .167 \\
\hline 38 & 1.202 .716 & 1.195 .926 & 1.210 .743 & 1.269 .301 & 1.270 .926 \\
\hline 39 & 1.277 .613 & 1.267 .916 & 1.295 .961 & 1.311 .903 & 1.314 .989 \\
\hline 40 & 2.274 .766 & 2.257 .914 & 2.284 .574 & 2.354 .421 & 2.382 .116 \\
\hline 41 & 2.317 .272 & 2.303 .337 & 2.334 .325 & 2.382 .779 & 2.393 .539 \\
\hline 42 & 2.399 .545 & 2.381 .574 & 2.414 .285 & 2.420 .912 & 2.456 .316 \\
\hline 43 & 915.014 & 908.259 & 919.597 & 953.549 & 965.532 \\
\hline 44 & 944.941 & 939.529 & 950.369 & 979.471 & 994.506 \\
\hline
\end{tabular}

(*) Valores obtidos a partir de 10 experimentos com distintas sementes.

(continua) 
QUADRO B.1 - Custo total médio por instância para a Heurística EGF-BT. (continuação)

\begin{tabular}{|c|c|c|c|c|c|}
\hline \multirow{2}{*}{ Instância } & \multicolumn{3}{|c|}{ Heurística EGF-BT } & \multicolumn{2}{|c|}{ BERTAZZi et al. (2005) } \\
\hline & Média $(*)$ & Melhor (*) & Pior $(*)$ & Heurística DP & Heurística DP' \\
\hline 45 & 1.005 .010 & 999.460 & 1.011 .382 & 1.025 .662 & 1.034 .407 \\
\hline 46 & 2.009 .585 & 2.000 .205 & 2.024 .069 & 2.063 .541 & 2.126 .739 \\
\hline 47 & 2.042 .501 & 2.031 .685 & 2.056 .231 & 2.090 .056 & 2.124 .213 \\
\hline 48 & 2.116 .665 & 2.109 .156 & 2.130 .248 & 2.134 .526 & 2.178 .059 \\
\hline 49 & 614.468 & 612.666 & 616.080 & 687.602 & 693.899 \\
\hline 50 & 670.613 & 663.870 & 682.917 & 738.924 & 742.314 \\
\hline 51 & 787.156 & 777.306 & 809.780 & 835.006 & 832.040 \\
\hline 52 & 734.332 & 729.184 & 737.411 & 808.713 & 840.515 \\
\hline 53 & 787.169 & 782.889 & 792.504 & 854.288 & 880.240 \\
\hline 54 & 903.134 & 893.405 & 912.139 & 952.190 & 971.709 \\
\hline 55 & 361.655 & 358.361 & 363.877 & 392.316 & 404.586 \\
\hline 56 & 410.114 & 408.262 & 411.987 & 436.723 & 448.208 \\
\hline 57 & 508.643 & 505.669 & 512.729 & 528.230 & 536.148 \\
\hline 58 & 479.401 & 477.498 & 481.653 & 509.870 & 619.281 \\
\hline 59 & 527.654 & 525.905 & 530.274 & 554.939 & 623.387 \\
\hline 60 & 625.556 & 622.371 & 630.426 & 646.309 & 748.424 \\
\hline 61 & 775.863 & 772.740 & 781.856 & 857.660 & 860.660 \\
\hline 62 & 874.055 & 869.748 & 880.364 & 951.667 & 951.952 \\
\hline 63 & 1.079 .237 & 1.070 .540 & 1.090 .207 & 1.139 .599 & 1.137 .259 \\
\hline 64 & 895.493 & 891.066 & 898.246 & 974.565 & 995.578 \\
\hline 65 & 994.546 & 986.727 & 1.000 .189 & 1.069 .598 & 1.084 .452 \\
\hline 66 & 1.198 .613 & 1.188 .799 & 1.205 .923 & 1.256 .841 & 1.270 .840 \\
\hline 67 & 519.923 & 516.691 & 523.601 & 553.404 & 562.653 \\
\hline 68 & 612.734 & 610.085 & 616.819 & 650.505 & 662.197 \\
\hline
\end{tabular}

(*) Valores obtidos a partir de 10 experimentos com distintas sementes.

(continua) 
QUADRO B.1 - Custo total médio por instância para a Heurística EGF-BT. (continuação)

\begin{tabular}{|c|c|c|c|c|c|}
\hline \multirow{2}{*}{ Instância } & \multicolumn{3}{|c|}{ Heurística EGF-BT } & \multicolumn{2}{|c|}{ BERTAZZi et al. (2005) } \\
\hline & Média (*) & Melhor (*) & Pior $(*)$ & Heurística DP & Heurística DP' \\
\hline 69 & 800.059 & 797.360 & 802.838 & 831.313 & 838.447 \\
\hline 70 & 636.706 & 635.230 & 639.358 & 674.953 & 738.801 \\
\hline 71 & 731.076 & 728.325 & 736.918 & 765.546 & 814.972 \\
\hline 72 & 916.753 & 914.000 & 919.676 & 950.030 & 1.000 .979 \\
\hline $73=79$ & 842.443 & 840.192 & 844.358 & 852.772 & 861.993 \\
\hline $74=80$ & 887.707 & 885.377 & 889.624 & 897.721 & 906.964 \\
\hline $75=81$ & 978.798 & 974.932 & 983.955 & 987.170 & 994.214 \\
\hline $76=82$ & 1.979 .481 & 1.977 .788 & 1.985 .377 & 1.990 .747 & 2.025 .517 \\
\hline $77=83$ & 2.024 .443 & 2.022 .989 & 2.025 .868 & 2.040 .249 & 2.071 .672 \\
\hline $78=84$ & 2.116 .324 & 2.112 .423 & 2.122 .089 & 2.130 .343 & 2.167 .499 \\
\hline $85=91$ & 999.968 & 996.755 & 1.007 .610 & 1.015 .879 & 1.025 .103 \\
\hline $86=92$ & 1.089 .682 & 1.085 .687 & 1.092 .439 & 1.110 .579 & 1.113 .878 \\
\hline $87=93$ & 1.270 .194 & 1.265 .921 & 1.276 .795 & 1.287 .443 & 1.287 .475 \\
\hline $88=94$ & 2.140 .621 & 2.135 .371 & 2.145 .421 & 2.154 .822 & 2.189 .997 \\
\hline $89=95$ & 2.229 .889 & 2.226 .019 & 2.236 .482 & 2.258 .448 & 2.279 .892 \\
\hline $90=96$ & 2.410 .495 & 2.405 .590 & 2.421 .987 & 2.440 .596 & 2.451 .579 \\
\hline
\end{tabular}

(*) Valores obtidos a partir de 10 experimentos com distintas sementes. 
QUADRO B.2 - Custo total médio por instância para a Heurística EGF-BT-D.

\begin{tabular}{|c|c|c|c|c|c|}
\hline \multirow{2}{*}{ Instância } & \multicolumn{3}{|c|}{ Heurística EGF-BT-D } & \multicolumn{2}{|c|}{ BERTAZZi et al. (2005) } \\
\hline & Média $(*)$ & Melhor $(*)$ & Pior $(*)$ & Heurística DP & Heurística DP' \\
\hline 1 & 1.229 .850 & 1.227 .600 & 1.232 .111 & 1.310 .473 & 1.307 .146 \\
\hline 2 & 1.278 .199 & 1.275 .476 & 1.281 .427 & 1.361 .021 & 1.356 .162 \\
\hline 3 & 1.381 .794 & 1.376 .144 & 1.388 .685 & 1.451 .055 & 1.448 .963 \\
\hline 4 & 2.373 .200 & 2.370 .217 & 2.377 .337 & 2.457 .237 & 2.485 .809 \\
\hline 5 & 2.421 .675 & 2.419 .388 & 2.423 .967 & 2.510 .718 & 2.520 .028 \\
\hline 6 & 2.529 .177 & 2.524 .532 & 2.540 .436 & 2.603 .863 & 2.628 .482 \\
\hline 7 & 976.226 & 973.902 & 977.869 & 1.011 .645 & 1.017 .350 \\
\hline 8 & 1.023 .501 & 1.021 .016 & 1.024 .844 & 1.056 .714 & 1.061 .470 \\
\hline 9 & 1.118 .461 & 1.115 .973 & 1.121 .288 & 1.148 .105 & 1.152 .899 \\
\hline 10 & 2.116 .626 & 2.114 .915 & 2.118 .473 & 2.158 .515 & 2.197 .917 \\
\hline 11 & 2.164 .617 & 2.161 .563 & 2.166 .499 & 2.209 .978 & 2.247 .441 \\
\hline 12 & 2.260 .556 & 2.258 .118 & 2.265 .638 & 2.293 .702 & 2.353 .238 \\
\hline 13 & 1.388 .845 & 1.386 .866 & 1.391 .820 & 1.473 .124 & 1.496 .904 \\
\hline 14 & 1.484 .379 & 1.481 .734 & 1.486 .691 & 1.571 .989 & 1.572 .628 \\
\hline 15 & 1.680 .119 & 1.674 .731 & 1.685 .019 & 1.759 .682 & 1.753 .094 \\
\hline 16 & 2.533 .566 & 2.530 .796 & 2.541 .333 & 2.630 .846 & 2.655 .245 \\
\hline 17 & 2.631 .442 & 2.627 .336 & 2.633 .784 & 2.717 .344 & 2.740 .833 \\
\hline 18 & 2.824 .322 & 2.817 .419 & 2.833 .202 & 2.902 .029 & 2.963 .679 \\
\hline 19 & 1.133 .575 & 1.131 .777 & 1.135 .309 & 1.181 .789 & 1.185 .481 \\
\hline 20 & 1.225 .187 & 1.222 .748 & 1.227 .357 & 1.267 .135 & 1.273 .359 \\
\hline 21 & 1.410 .022 & 1.407 .969 & 1.413 .044 & 1.454 .603 & 1.451 .870 \\
\hline 22 & 2.274 .891 & 2.271 .299 & 2.277 .503 & 2.322 .847 & 2.362 .208 \\
\hline 23 & 2.368 .077 & 2.366 .030 & 2.371 .573 & 2.415 .315 & 2.449 .453 \\
\hline 24 & 2.553 .280 & 2.550 .423 & 2.557 .546 & 2.598 .792 & 2.620 .665 \\
\hline 25 & 1.103 .903 & 1.094 .459 & 1.111 .721 & 1.174 .940 & 1.172 .479 \\
\hline
\end{tabular}

(*) Valores obtidos a partir de 10 experimentos com distintas sementes.

(continua) 


\section{QUADRO B.2 - Custo total médio por instância para a Heurística EGF-BT-D.}

\section{(continuação)}

\begin{tabular}{|c|c|c|c|c|c|}
\hline \multirow{2}{*}{ Instância } & \multicolumn{3}{|c|}{ Heurística EGF-BT-D } & \multicolumn{2}{|c|}{ BERTAZZi et al. (2005) } \\
\hline & Média $(*)$ & Melhor (*) & Pior (*) & Heurística DP & Heurística DP' \\
\hline 26 & 1.119 .068 & 1.111 .719 & 1.126 .619 & 1.188 .426 & 1.188 .413 \\
\hline 27 & 1.160 .944 & 1.154 .141 & 1.168 .387 & 1.207 .722 & 1.207 .461 \\
\hline 28 & 2.211 .743 & 2.193 .390 & 2.217 .962 & 2.281 .078 & 2.307.320 \\
\hline 29 & 2.233 .257 & 2.222 .431 & 2.249 .064 & 2.292 .596 & 2.328 .687 \\
\hline 30 & 2.276 .013 & 2.263 .696 & 2.292 .335 & 2.321 .027 & 2.339 .639 \\
\hline 31 & 852.416 & 845.975 & 855.903 & 885.256 & 896.174 \\
\hline 32 & 866.738 & 861.822 & 872.929 & 895.356 & 907.063 \\
\hline 33 & 900.840 & 895.403 & 903.786 & 921.316 & 930.977 \\
\hline 34 & 1.946 .553 & 1.932 .004 & 1.964 .465 & 1.988 .610 & 2.071 .902 \\
\hline 35 & 1.967 .876 & 1.954 .689 & 1.990 .392 & 2.004 .072 & 2.055 .008 \\
\hline 36 & 2.010 .669 & 2.001 .408 & 2.020 .573 & 2.028 .979 & 2.085 .049 \\
\hline 37 & 1.160 .324 & 1.154 .943 & 1.166 .999 & 1.244 .489 & 1.246 .167 \\
\hline 38 & 1.191 .723 & 1.187 .442 & 1.200 .079 & 1.269 .301 & 1.270 .926 \\
\hline 39 & 1.257 .302 & 1.252 .119 & 1.262 .225 & 1.311 .903 & 1.314 .989 \\
\hline 40 & 2.269 .283 & 2.257 .709 & 2.280 .988 & 2.354 .421 & 2.382 .116 \\
\hline 41 & 2.304 .135 & 2.294 .208 & 2.320 .776 & 2.382 .779 & 2.393 .539 \\
\hline 42 & 2.375 .066 & 2.353 .938 & 2.387 .566 & 2.420 .912 & 2.456 .316 \\
\hline 43 & 909.572 & 905.550 & 913.513 & 953.549 & 965.532 \\
\hline 44 & 938.352 & 931.458 & 944.836 & 979.471 & 994.506 \\
\hline 45 & 996.088 & 991.896 & 999.689 & 1.025 .662 & 1.034 .407 \\
\hline 46 & 2.004 .490 & 1.996 .278 & 2.019 .084 & 2.063 .541 & 2.126 .739 \\
\hline 47 & 2.036 .474 & 2.022 .659 & 2.046 .700 & 2.090 .056 & 2.124 .213 \\
\hline 48 & 2.102 .940 & 2.092 .466 & 2.111 .182 & 2.134 .526 & 2.178 .059 \\
\hline 49 & 608.408 & 606.725 & 610.081 & 687.602 & 693.899 \\
\hline
\end{tabular}

(*) Valores obtidos a partir de 10 experimentos com distintas sementes.

(continua) 
QUADRO B.2 - Custo total médio por instância para a Heurística EGF-BT-D. (continuação)

\begin{tabular}{|c|c|c|c|c|c|}
\hline \multirow{2}{*}{ Instância } & \multicolumn{3}{|c|}{ Heurística EGF-BT-D } & \multicolumn{2}{|c|}{ BERTAZZi et al. (2005) } \\
\hline & Média (*) & Melhor (*) & Pior $(*)$ & Heurística DP & Heurística DP' \\
\hline 50 & 657.322 & 654.738 & 661.835 & 738.924 & 742.314 \\
\hline 51 & 762.574 & 756.687 & 765.935 & 835.006 & 832.040 \\
\hline 52 & 725.875 & 723.523 & 728.411 & 808.713 & 840.515 \\
\hline 53 & 774.818 & 770.047 & 779.234 & 854.288 & 880.240 \\
\hline 54 & 881.097 & 876.925 & 888.732 & 952.190 & 971.709 \\
\hline 55 & 357.952 & 356.403 & 359.728 & 392.316 & 404.586 \\
\hline 56 & 404.079 & 402.812 & 405.055 & 436.723 & 448.208 \\
\hline 57 & 500.594 & 497.049 & 503.361 & 528.230 & 536.148 \\
\hline 58 & 475.598 & 474.121 & 477.863 & 509.870 & 619.281 \\
\hline 59 & 521.885 & 520.471 & 523.341 & 554.939 & 623.387 \\
\hline 60 & 617.853 & 616.078 & 620.651 & 646.309 & 748.424 \\
\hline 61 & 766.821 & 763.914 & 769.161 & 857.660 & 860.660 \\
\hline 62 & 860.347 & 857.668 & 863.494 & 951.667 & 951.952 \\
\hline 63 & 1.058 .294 & 1.052 .377 & 1.061 .686 & 1.139 .599 & 1.137 .259 \\
\hline 64 & 883.941 & 882.092 & 885.357 & 974.565 & 995.578 \\
\hline 65 & 978.279 & 976.594 & 982.202 & 1.069 .598 & 1.084 .452 \\
\hline 66 & 1.176 .140 & 1.172 .153 & 1.182 .848 & 1.256 .841 & 1.270 .840 \\
\hline 67 & 514.101 & 511.740 & 516.472 & 553.404 & 562.653 \\
\hline 68 & 606.144 & 604.342 & 608.751 & 650.505 & 662.197 \\
\hline 69 & 793.254 & 792.293 & 794.501 & 831.313 & 838.447 \\
\hline 70 & 631.291 & 629.440 & 632.726 & 674.953 & 738.801 \\
\hline 71 & 722.746 & 720.553 & 723.748 & 765.546 & 814.972 \\
\hline 72 & 910.259 & 907.865 & 912.315 & 950.030 & 1.000 .979 \\
\hline $73=79$ & 838.286 & 837.362 & 839.462 & 852.772 & 861.993 \\
\hline
\end{tabular}

(*) Valores obtidos a partir de 10 experimentos com distintas sementes. (continua) 
QUADRO B.2 - Custo total médio por instância para a Heurística EGF-BT-D. (continuação)

\begin{tabular}{|c|c|c|c|c|c|}
\hline \multirow{2}{*}{ Instância } & \multicolumn{3}{|c|}{ Heurística EGF-BT-D } & \multicolumn{2}{c|}{ BERTAZZi et al. (2005) } \\
\cline { 2 - 6 } & Média (*) & Melhor (*) & Pior (*) & Heurística DP & Heurística DP' \\
\hline $74=80$ & 883.756 & 883.041 & 884.404 & 897.721 & 906.964 \\
$75=81$ & 972.924 & 971.763 & 974.505 & 987.170 & 994.214 \\
$76=82$ & 1.976 .356 & 1.975 .475 & 1.978 .374 & 1.990 .747 & 2.025 .517 \\
$77=83$ & 2.021 .951 & 2.019 .740 & 2.024 .331 & 2.040 .249 & 2.071 .672 \\
$78=84$ & 2.111 .567 & 2.110 .696 & 2.112 .684 & 2.130 .343 & 2.167 .499 \\
$85=91$ & 992.621 & 990.071 & 994.310 & 1.015 .879 & 1.025 .103 \\
$86=92$ & 1.083 .007 & 1.081 .470 & 1.084 .780 & 1.110 .579 & 1.113 .878 \\
$87=93$ & 1.263 .892 & 1.260 .512 & 1.266 .089 & 1.287 .443 & 1.287 .475 \\
$88=94$ & 2.132 .427 & 2.130 .188 & 2.134 .478 & 2.154 .822 & 2.189 .997 \\
$89=96$ & 2.222 .953 & 2.221 .541 & 2.225 .192 & 2.258 .448 & 2.279 .892 \\
\hline
\end{tabular}

(*) Valores obtidos a partir de 10 experimentos com distintas sementes. 


\section{QUADRO B.3 - Custo total médio por instância para a Heurística EGF-BT-DI.}

\begin{tabular}{|c|c|c|c|c|c|}
\hline \multirow{2}{*}{ Instância } & \multicolumn{3}{|c|}{ Heurística EGF-BT-DI } & \multicolumn{2}{|c|}{ BERTAZZi et al. (2005) } \\
\hline & Média $(*)$ & Melhor $(*)$ & Pior $(*)$ & Heurística DP & Heurística DP' \\
\hline 1 & 1.231 .939 & 1.229 .608 & 1.234 .928 & 1.310 .473 & 1.307 .146 \\
\hline 2 & 1.280 .634 & 1.278 .411 & 1.282 .403 & 1.361 .021 & 1.356 .162 \\
\hline 3 & 1.388 .385 & 1.380 .965 & 1.393 .058 & 1.451 .055 & 1.448 .963 \\
\hline 4 & 2.377 .670 & 2.372 .951 & 2.381 .932 & 2.457 .237 & 2.485 .809 \\
\hline 5 & 2.426 .217 & 2.420 .854 & 2.432 .243 & 2.510 .718 & 2.520 .028 \\
\hline 6 & 2.536 .474 & 2.529 .886 & 2.548 .661 & 2.603 .863 & 2.628 .482 \\
\hline 7 & 977.340 & 975.014 & 980.722 & 1.011 .645 & 1.017 .350 \\
\hline 8 & 1.025 .342 & 1.024 .311 & 1.026 .832 & 1.056 .714 & 1.061 .470 \\
\hline 9 & 1.121 .251 & 1.118 .644 & 1.124 .928 & 1.148 .105 & 1.152 .899 \\
\hline 10 & 2.118 .466 & 2.117 .382 & 2.120 .781 & 2.158 .515 & 2.197 .917 \\
\hline 11 & 2.167 .335 & 2.165 .010 & 2.169 .491 & 2.209 .978 & 2.247 .441 \\
\hline 12 & 2.264 .673 & 2.261 .163 & 2.269 .224 & 2.293 .702 & 2.353 .238 \\
\hline 13 & 1.392 .525 & 1.389 .634 & 1.393 .698 & 1.473 .124 & 1.496 .904 \\
\hline 14 & 1.487 .228 & 1.483 .510 & 1.490 .991 & 1.571 .989 & 1.572 .628 \\
\hline 15 & 1.685 .337 & 1.680 .950 & 1.693 .411 & 1.759 .682 & 1.753 .094 \\
\hline 16 & 2.537 .729 & 2.533 .821 & 2.544 .034 & 2.630 .846 & 2.655 .245 \\
\hline 17 & 2.635 .839 & 2.632 .791 & 2.640 .330 & 2.717 .344 & 2.740 .833 \\
\hline 18 & 2.832 .999 & 2.824 .751 & 2.845 .678 & 2.902 .029 & 2.963 .679 \\
\hline 19 & 1.136 .007 & 1.133 .385 & 1.137 .956 & 1.181 .789 & 1.185 .481 \\
\hline 20 & 1.227 .964 & 1.225 .155 & 1.231 .886 & 1.267 .135 & 1.273 .359 \\
\hline 21 & 1.415 .481 & 1.411 .095 & 1.417 .337 & 1.454 .603 & 1.451 .870 \\
\hline 22 & 2.277 .360 & 2.273 .866 & 2.279 .461 & 2.322 .847 & 2.362 .208 \\
\hline 23 & 2.370 .788 & 2.366 .967 & 2.374 .195 & 2.415 .315 & 2.449 .453 \\
\hline 24 & 2.558 .785 & 2.554 .382 & 2.562 .411 & 2.598 .792 & 2.620 .665 \\
\hline 25 & 1.106 .342 & 1.095 .200 & 1.117 .871 & 1.174 .940 & 1.172 .479 \\
\hline
\end{tabular}

(*) Valores obtidos a partir de 10 experimentos com distintas sementes.

(continua) 


\section{QUADRO B.3 - Custo total médio por instância para a Heurística EGF-BT-DI.}

\section{(continuação)}

\begin{tabular}{|c|c|c|c|c|c|}
\hline \multirow{2}{*}{ Instância } & \multicolumn{3}{|c|}{ Heurística EGF-BT-DI } & \multicolumn{2}{|c|}{ BERTAZZi et al. (2005) } \\
\hline & Média (*) & Melhor (*) & Pior $(*)$ & Heurística DP & Heurística DP' \\
\hline 26 & 1.121 .650 & 1.113 .829 & 1.129 .701 & 1.188 .426 & 1.188 .413 \\
\hline 27 & 1.162 .303 & 1.155 .678 & 1.167 .749 & 1.207 .722 & 1.207 .461 \\
\hline 28 & 2.212 .696 & 2.194 .256 & 2.220 .190 & 2.281 .078 & 2.307.320 \\
\hline 29 & 2.234 .931 & 2.224 .346 & 2.249 .683 & 2.292 .596 & 2.328 .687 \\
\hline 30 & 2.279 .478 & 2.268 .670 & 2.296 .230 & 2.321 .027 & 2.339 .639 \\
\hline 31 & 853.584 & 847.726 & 856.995 & 885.256 & 896.174 \\
\hline 32 & 868.207 & 862.799 & 874.784 & 895.356 & 907.063 \\
\hline 33 & 902.459 & 899.517 & 906.524 & 921.316 & 930.977 \\
\hline 34 & 1.949 .238 & 1.931 .660 & 1.966 .109 & 1.988 .610 & 2.071 .902 \\
\hline 35 & 1.970 .239 & 1.955 .449 & 1.994 .840 & 2.004 .072 & 2.055 .008 \\
\hline 36 & 2.012 .503 & 2.004 .035 & 2.024 .252 & 2.028 .979 & 2.085 .049 \\
\hline 37 & 1.163 .000 & 1.156 .655 & 1.170 .174 & 1.244 .489 & 1.246 .167 \\
\hline 38 & 1.195 .142 & 1.188 .510 & 1.202 .809 & 1.269 .301 & 1.270 .926 \\
\hline 39 & 1.260 .484 & 1.249 .322 & 1.268 .785 & 1.311 .903 & 1.314 .989 \\
\hline 40 & 2.272 .139 & 2.260 .324 & 2.285 .673 & 2.354 .421 & 2.382 .116 \\
\hline 41 & 2.308 .446 & 2.296 .452 & 2.325 .660 & 2.382 .779 & 2.393 .539 \\
\hline 42 & 2.378 .138 & 2.358 .164 & 2.386 .731 & 2.420 .912 & 2.456 .316 \\
\hline 43 & 911.577 & 907.237 & 915.926 & 953.549 & 965.532 \\
\hline 44 & 940.135 & 932.792 & 946.204 & 979.471 & 994.506 \\
\hline 45 & 998.528 & 995.403 & 1.000 .933 & 1.025 .662 & 1.034 .407 \\
\hline 46 & 2.006 .396 & 1.998 .008 & 2.021 .289 & 2.063 .541 & 2.126 .739 \\
\hline 47 & 2.037 .644 & 2.026 .763 & 2.046 .656 & 2.090 .056 & 2.124 .213 \\
\hline 48 & 2.104 .947 & 2.096.207 & 2.111 .593 & 2.134 .526 & 2.178 .059 \\
\hline 49 & 611.141 & 608.543 & 612.262 & 687.602 & 693.899 \\
\hline
\end{tabular}

(*) Valores obtidos a partir de 10 experimentos com distintas sementes.

(continua) 


\section{QUADRO B.3 - Custo total médio por instância para a Heurística EGF-BT-DI.}

(continuação)

\begin{tabular}{|c|c|c|c|c|c|}
\hline \multirow{2}{*}{ Instância } & \multicolumn{3}{|c|}{ Heurística EGF-BT-DI } & \multicolumn{2}{|c|}{ BERTAZZi et al. (2005) } \\
\hline & Média $(*)$ & Melhor $(*)$ & Pior $(*)$ & Heurística DP & Heurística DP' \\
\hline 50 & 661.670 & 657.094 & 668.200 & 738.924 & 742.314 \\
\hline 51 & 767.487 & 763.630 & 771.719 & 835.006 & 832.040 \\
\hline 52 & 728.256 & 725.686 & 730.578 & 808.713 & 840.515 \\
\hline 53 & 778.231 & 773.871 & 784.424 & 854.288 & 880.240 \\
\hline 54 & 885.485 & 878.888 & 896.230 & 952.190 & 971.709 \\
\hline 55 & 359.682 & 357.894 & 361.142 & 392.316 & 404.586 \\
\hline 56 & 406.370 & 404.632 & 408.008 & 436.723 & 448.208 \\
\hline 57 & 502.656 & 499.054 & 506.092 & 528.230 & 536.148 \\
\hline 58 & 476.250 & 474.997 & 478.354 & 509.870 & 619.281 \\
\hline 59 & 523.422 & 522.126 & 524.683 & 554.939 & 623.387 \\
\hline 60 & 619.663 & 618.256 & 622.298 & 646.309 & 748.424 \\
\hline 61 & 770.098 & 766.970 & 774.816 & 857.660 & 860.660 \\
\hline 62 & 863.630 & 861.696 & 867.373 & 951.667 & 951.952 \\
\hline 63 & 1.064 .182 & 1.059 .755 & 1.068 .352 & 1.139 .599 & 1.137 .259 \\
\hline 64 & 886.281 & 883.984 & 889.180 & 974.565 & 995.578 \\
\hline 65 & 980.449 & 973.846 & 985.584 & 1.069 .598 & 1.084 .452 \\
\hline 66 & 1.181 .476 & 1.175 .349 & 1.190 .823 & 1.256 .841 & 1.270 .840 \\
\hline 67 & 515.353 & 513.176 & 518.303 & 553.404 & 562.653 \\
\hline 68 & 608.638 & 606.038 & 610.937 & 650.505 & 662.197 \\
\hline 69 & 796.067 & 792.341 & 799.444 & 831.313 & 838.447 \\
\hline 70 & 633.250 & 630.025 & 635.405 & 674.953 & 738.801 \\
\hline 71 & 725.052 & 723.360 & 726.512 & 765.546 & 814.972 \\
\hline 72 & 913.123 & 910.110 & 914.962 & 950.030 & 1.000 .979 \\
\hline $73=79$ & 839.565 & 838.422 & 840.928 & 852.772 & 861.993 \\
\hline
\end{tabular}

(*) Valores obtidos a partir de 10 experimentos com distintas sementes. 


\section{QUADRO B.3 - Custo total médio por instância para a Heurística EGF-BT-DI.}

(continuação)

\begin{tabular}{|c|c|c|c|c|c|}
\hline \multirow{2}{*}{ Instância } & \multicolumn{3}{|c|}{ Heurística EGF-BT-DI } & \multicolumn{2}{c|}{ BERTAZZi et al. (2005) } \\
\cline { 2 - 6 } & Média $(*)$ & Melhor $\left(^{*}\right)$ & Pior $\left(^{*}\right)$ & Heurística DP & Heurística DP' \\
\hline $74=80$ & 884.880 & 884.207 & 885.819 & 897.721 & 906.964 \\
$75=81$ & 975.025 & 972.725 & 977.581 & 987.170 & 994.214 \\
$76=82$ & 1.977 .764 & 1.975 .915 & 1.979 .793 & 1.990 .747 & 2.025 .517 \\
$77=83$ & 2.022 .754 & 2.020 .437 & 2.025 .763 & 2.040 .249 & 2.071 .672 \\
$78=84$ & 2.113 .069 & 2.111 .065 & 2.114 .610 & 2.130 .343 & 2.167 .499 \\
$85=91$ & 995.159 & 992.578 & 997.922 & 1.015 .879 & 1.025 .103 \\
$86=92$ & 1.085 .525 & 1.082 .960 & 1.088 .732 & 1.110 .579 & 1.113 .878 \\
$87=93$ & 1.266 .546 & 1.264 .038 & 1.268 .765 & 1.287 .443 & 1.287 .475 \\
$88=94$ & 2.135 .353 & 2.131 .470 & 2.139 .397 & 2.154 .822 & 2.189 .997 \\
$89=95$ & 2.225 .126 & 2.221 .641 & 2.227 .820 & 2.258 .448 & 2.279 .892 \\
$90=96$ & 2.405 .437 & 2.402 .952 & 2.407 .627 & 2.440 .596 & 2.451 .579 \\
\hline
\end{tabular}

(*) Valores obtidos a partir de 10 experimentos com distintas sementes. 
QUADRO B.4 - Custo total médio por instância para a Heurística EGF-BVV.

\begin{tabular}{|c|c|c|c|c|c|}
\hline \multirow{2}{*}{ Instância } & \multicolumn{3}{|c|}{ Heurística EGF-BVV } & \multicolumn{2}{|c|}{ BERTAZZi et al. (2005) } \\
\hline & Média $(*)$ & Melhor (*) & Pior $(*)$ & Heurística DP & Heurística DP' \\
\hline 1 & 1.236 .685 & 1.235 .212 & 1.237 .778 & 1.310 .473 & 1.307 .146 \\
\hline 2 & 1.286 .832 & 1.282 .663 & 1.291 .829 & 1.361 .021 & 1.356 .162 \\
\hline 3 & 1.398 .994 & 1.392 .256 & 1.406 .266 & 1.451 .055 & 1.448 .963 \\
\hline 4 & 2.383 .008 & 2.380 .376 & 2.386 .925 & 2.457 .237 & 2.485 .809 \\
\hline 5 & 2.434 .829 & 2.430 .572 & 2.439 .427 & 2.510 .718 & 2.520 .028 \\
\hline 6 & 2.549 .851 & 2.541 .847 & 2.561 .394 & 2.603 .863 & 2.628 .482 \\
\hline 7 & 980.258 & 976.880 & 981.959 & 1.011 .645 & 1.017 .350 \\
\hline 8 & 1.028 .533 & 1.026 .840 & 1.031 .421 & 1.056 .714 & 1.061 .470 \\
\hline 9 & 1.123 .521 & 1.120 .657 & 1.126 .981 & 1.148 .105 & 1.152 .899 \\
\hline 10 & 2.120 .424 & 2.118 .026 & 2.122 .857 & 2.158 .515 & 2.197 .917 \\
\hline 11 & 2.169 .542 & 2.167 .896 & 2.170 .897 & 2.209 .978 & 2.247 .441 \\
\hline 12 & 2.267 .454 & 2.264 .367 & 2.269 .031 & 2.293 .702 & 2.353 .238 \\
\hline 13 & 1.398 .189 & 1.394 .591 & 1.401 .903 & 1.473 .124 & 1.496 .904 \\
\hline 14 & 1.494 .655 & 1.490 .810 & 1.500 .693 & 1.571 .989 & 1.572 .628 \\
\hline 15 & 1.698 .373 & 1.690 .195 & 1.705 .587 & 1.759 .682 & 1.753 .094 \\
\hline 16 & 2.543 .289 & 2.539 .208 & 2.547 .767 & 2.630 .846 & 2.655 .245 \\
\hline 17 & 2.642 .602 & 2.638 .324 & 2.652 .818 & 2.717 .344 & 2.740 .833 \\
\hline 18 & 2.844 .194 & 2.833 .038 & 2.852 .318 & 2.902 .029 & 2.963 .679 \\
\hline 19 & 1.138 .324 & 1.135 .815 & 1.141 .484 & 1.181 .789 & 1.185 .481 \\
\hline 20 & 1.231 .701 & 1.228 .260 & 1.234 .171 & 1.267 .135 & 1.273 .359 \\
\hline 21 & 1.416 .466 & 1.411 .937 & 1.420 .894 & 1.454 .603 & 1.451 .870 \\
\hline 22 & 2.280 .921 & 2.276 .600 & 2.284 .066 & 2.322 .847 & 2.362 .208 \\
\hline 23 & 2.374 .202 & 2.371 .339 & 2.377 .847 & 2.415 .315 & 2.449 .453 \\
\hline 24 & 2.559 .103 & 2.556 .738 & 2.564 .616 & 2.598 .792 & 2.620 .665 \\
\hline 25 & 1.107 .591 & 1.094 .714 & 1.119 .285 & 1.174 .940 & 1.172 .479 \\
\hline
\end{tabular}

(*) Valores obtidos a partir de 10 experimentos com distintas sementes.

(continua) 
QUADRO B.4 - Custo total médio por instância para a Heurística EGF-BVV. (continuação)

\begin{tabular}{|c|c|c|c|c|c|}
\hline \multirow{2}{*}{ Instância } & \multicolumn{3}{|c|}{ Heurística EGF-BVV } & \multicolumn{2}{|c|}{ BERTAZZi et al. (2005) } \\
\hline & Média $(*)$ & Melhor (*) & Pior $(*)$ & Heurística DP & Heurística DP' \\
\hline 26 & 1.122 .851 & 1.115 .554 & 1.128 .714 & 1.188 .426 & 1.188 .413 \\
\hline 27 & 1.168 .402 & 1.160 .967 & 1.173 .622 & 1.207 .722 & 1.207 .461 \\
\hline 28 & 2.213 .742 & 2.200 .290 & 2.224 .941 & 2.281 .078 & 2.307.320 \\
\hline 29 & 2.240 .004 & 2.229 .506 & 2.254 .109 & 2.292 .596 & 2.328 .687 \\
\hline 30 & 2.286 .903 & 2.271 .351 & 2.305 .622 & 2.321 .027 & 2.339 .639 \\
\hline 31 & 855.467 & 847.999 & 858.472 & 885.256 & 896.174 \\
\hline 32 & 871.068 & 868.638 & 875.920 & 895.356 & 907.063 \\
\hline 33 & 905.061 & 901.427 & 908.510 & 921.316 & 930.977 \\
\hline 34 & 1.953 .851 & 1.943 .513 & 1.970 .821 & 1.988 .610 & 2.071 .902 \\
\hline 35 & 1.973 .781 & 1.962 .828 & 1.993 .599 & 2.004 .072 & 2.055 .008 \\
\hline 36 & 2.015 .599 & 2.005 .736 & 2.023 .213 & 2.028 .979 & 2.085 .049 \\
\hline 37 & 1.165 .652 & 1.160 .908 & 1.169 .816 & 1.244 .489 & 1.246 .167 \\
\hline 38 & 1.201 .105 & 1.195 .313 & 1.209 .157 & 1.269 .301 & 1.270 .926 \\
\hline 39 & 1.265 .311 & 1.258 .533 & 1.278 .632 & 1.311 .903 & 1.314 .989 \\
\hline 40 & 2.278 .078 & 2.263 .058 & 2.291 .462 & 2.354 .421 & 2.382 .116 \\
\hline 41 & 2.310 .386 & 2.292 .720 & 2.327 .998 & 2.382 .779 & 2.393 .539 \\
\hline 42 & 2.388 .999 & 2.365 .558 & 2.398 .771 & 2.420 .912 & 2.456 .316 \\
\hline 43 & 916.947 & 911.137 & 921.140 & 953.549 & 965.532 \\
\hline 44 & 945.135 & 939.949 & 951.736 & 979.471 & 994.506 \\
\hline 45 & 1.000 .596 & 996.828 & 1.005 .240 & 1.025 .662 & 1.034 .407 \\
\hline 46 & 2.011 .088 & 2.003 .926 & 2.021 .577 & 2.063 .541 & 2.126 .739 \\
\hline 47 & 2.044 .353 & 2.031 .918 & 2.055 .254 & 2.090 .056 & 2.124 .213 \\
\hline 48 & 2.109 .526 & 2.104 .334 & 2.114 .880 & 2.134 .526 & 2.178 .059 \\
\hline 49 & 613.954 & 611.508 & 616.706 & 687.602 & 693.899 \\
\hline
\end{tabular}

(*) Valores obtidos a partir de 10 experimentos com distintas sementes.

(continua) 


\section{QUADRO B.4 - Custo total médio por instância para a Heurística EGF-BVV.}

(continuação)

\begin{tabular}{|c|c|c|c|c|c|}
\hline \multirow{2}{*}{ Instância } & \multicolumn{3}{|c|}{ Heurística EGF-BVV } & \multicolumn{2}{|c|}{ BERTAZZi et al. (2005) } \\
\hline & Média (*) & $\operatorname{Melhor}(*)$ & Pior $(*)$ & Heurística DP & Heurística DP' \\
\hline 50 & 665.592 & 662.275 & 672.256 & 738.924 & 742.314 \\
\hline 51 & 777.621 & 770.573 & 786.807 & 835.006 & 832.040 \\
\hline 52 & 732.605 & 730.362 & 734.989 & 808.713 & 840.515 \\
\hline 53 & 784.159 & 779.133 & 789.139 & 854.288 & 880.240 \\
\hline 54 & 895.640 & 891.125 & 902.318 & 952.190 & 971.709 \\
\hline 55 & 361.150 & 358.724 & 363.911 & 392.316 & 404.586 \\
\hline 56 & 409.052 & 407.294 & 410.795 & 436.723 & 448.208 \\
\hline 57 & 506.668 & 503.550 & 510.638 & 528.230 & 536.148 \\
\hline 58 & 478.491 & 476.003 & 479.945 & 509.870 & 619.281 \\
\hline 59 & 526.097 & 523.634 & 528.402 & 554.939 & 623.387 \\
\hline 60 & 623.572 & 620.905 & 627.138 & 646.309 & 748.424 \\
\hline 61 & 775.290 & 771.415 & 779.543 & 857.660 & 860.660 \\
\hline 62 & 870.686 & 866.497 & 875.560 & 951.667 & 951.952 \\
\hline 63 & 1.077 .305 & 1.069 .567 & 1.087 .785 & 1.139 .599 & 1.137 .259 \\
\hline 64 & 893.260 & 889.571 & 898.780 & 974.565 & 995.578 \\
\hline 65 & 990.830 & 986.328 & 997.873 & 1.069 .598 & 1.084 .452 \\
\hline 66 & 1.195 .094 & 1.186 .344 & 1.209 .816 & 1.256 .841 & 1.270 .840 \\
\hline 67 & 518.704 & 516.342 & 521.039 & 553.404 & 562.653 \\
\hline 68 & 611.607 & 608.155 & 614.495 & 650.505 & 662.197 \\
\hline 69 & 798.715 & 795.105 & 802.614 & 831.313 & 838.447 \\
\hline 70 & 636.042 & 633.735 & 638.875 & 674.953 & 738.801 \\
\hline 71 & 728.658 & 726.160 & 730.357 & 765.546 & 814.972 \\
\hline 72 & 915.167 & 911.479 & 918.235 & 950.030 & 1.000 .979 \\
\hline $73=79$ & 839.316 & 837.679 & 840.154 & 852.772 & 861.993 \\
\hline
\end{tabular}

(*) Valores obtidos a partir de 10 experimentos com distintas sementes. 
QUADRO B.4 - Custo total médio por instância para a Heurística EGF-BVV. (continuação)

\begin{tabular}{|c|c|c|c|c|c|}
\hline \multirow{2}{*}{ Instância } & \multicolumn{3}{|c|}{ Heurística EGF-BVV } & \multicolumn{2}{c|}{ BERTAZZi et al. (2005) } \\
\cline { 2 - 6 } & Média (*) & Melhor (*) & Pior (*) & Heurística DP & Heurística DP' \\
\hline $74=80$ & 884.763 & 883.693 & 885.802 & 897.721 & 906.964 \\
$75=81$ & 975.756 & 974.788 & 976.850 & 987.170 & 994.214 \\
$76=82$ & 1.976 .560 & 1.975 .481 & 1.977 .293 & 1.990 .747 & 2.025 .517 \\
$77=83$ & 2.021 .781 & 2.020 .571 & 2.022 .453 & 2.040 .249 & 2.071 .672 \\
$78=84$ & 2.112 .983 & 2.111 .141 & 2.115 .231 & 2.130 .343 & 2.167 .499 \\
$85=91$ & 995.989 & 992.995 & 998.410 & 1.015 .879 & 1.025 .103 \\
$86=92$ & 1.087 .199 & 1.085 .110 & 1.089 .194 & 1.110 .579 & 1.113 .878 \\
$87=93$ & 1.267 .921 & 1.266 .248 & 1.270 .110 & 1.287 .443 & 1.287 .475 \\
$89=94$ & 2.135 .553 & 2.132 .030 & 2.140 .311 & 2.154 .822 & 2.189 .997 \\
$90=96$ & 2.225 .183 & 2.222 .265 & 2.227 .346 & 2.258 .448 & 2.279 .892 \\
\hline
\end{tabular}

(*) Valores obtidos a partir de 10 experimentos com distintas sementes. 


\section{ANEXO C}

\section{PARÂMETROS UTILIZADOS NO CENÁRIO II}

QUADRO C.1 - Parâmetros utilizados na Heurística EGF-BT-D(t).

\begin{tabular}{|c|c|c|}
\hline Etapa & Parâmetro & Valor \\
\hline $\begin{array}{c}\text { Solução } \\
\text { Inicial }\end{array}$ & $\begin{array}{c}\text { TamanhoLista } \\
\text { NumIterações } \\
\text { UtilizaCustoProporcional }\end{array}$ & $\begin{array}{c}10 \\
100 \\
0\end{array}$ \\
\hline $\begin{array}{l}\text { Etapa } \\
\text { de } \\
\text { Melhoria }\end{array}$ & $\begin{array}{c}\alpha_{\text {inicial }}, \quad \beta_{\text {inicial }} \\
\alpha_{\text {mínimo }}, \quad \beta_{\text {mínimo }} \\
\alpha_{\text {máximo }}, \quad \beta_{\text {máximo }} \\
\varphi \\
\text { intervalo de sorteio da } \\
\text { duração tabu } \\
\text { ativação da } \\
\text { diversificação } \\
\text { critério de parada }\end{array}$ & 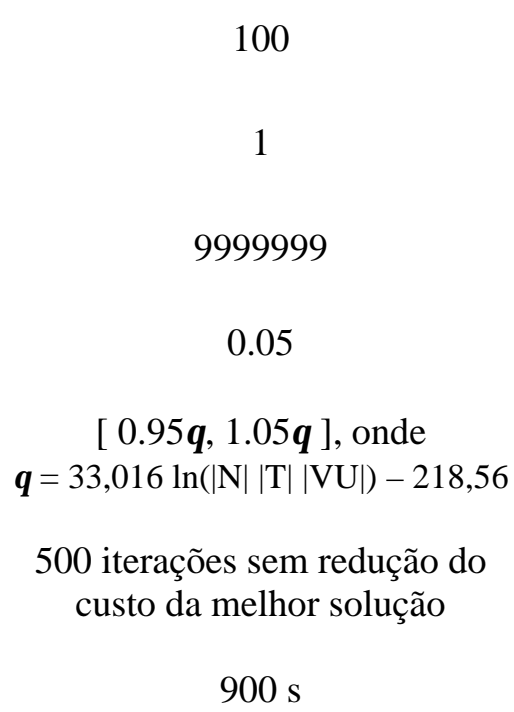 \\
\hline
\end{tabular}


QUADRO C.2 - Parâmetros utilizados na Heurística EGF-BT-D(p).

\begin{tabular}{|c|c|c|}
\hline Etapa & Parâmetro & Valor \\
\hline \multirow{3}{*}{$\begin{array}{c}\text { Solução } \\
\text { Inicial }\end{array}$} & TamanhoLista & 10 \\
\hline & NumIterações & 100 \\
\hline & UtilizaCustoProporcional & 1 \\
\hline \multirow{7}{*}{$\begin{array}{l}\text { Etapa } \\
\text { de } \\
\text { Melhoria }\end{array}$} & $\alpha_{\text {inicial }}, \quad \beta_{\text {inicial }}$ & 100 \\
\hline & $\alpha_{\text {mínimo }}, \beta_{\text {mínimo }}$ & 1 \\
\hline & $\alpha_{\text {máximo }}, \beta_{\text {máximo }}$ & 9999999 \\
\hline & $\varphi$ & 0.05 \\
\hline & $\begin{array}{l}\text { intervalo de sorteio da } \\
\text { duração tabu }\end{array}$ & $\begin{array}{c}{[0.95 \theta, 1.05 \theta], \text { onde }} \\
\theta=33,016 \ln (|\mathrm{N}||\mathrm{T}||\mathrm{VU}|)-218,56\end{array}$ \\
\hline & $\begin{array}{c}\text { ativação da } \\
\text { diversificação }\end{array}$ & $\begin{array}{l}500 \text { iterações sem redução do } \\
\text { custo da melhor solução }\end{array}$ \\
\hline & critério de parada & $900 \mathrm{~s}$ \\
\hline
\end{tabular}




\section{ANEXO D}

\section{CUSTO TOTAL MÉDIO POR INSTÂNCIA CENÁRIO II}

\section{QUADRO D.1 - Custo total médio por instância para as Heurísticas EGF-BT-D(t) e EGF-BT-D(p).}

\begin{tabular}{|c|c|c|c|c|c|c|}
\hline \multirow{2}{*}{ Instância } & \multicolumn{3}{|c|}{ Heurística EGF-BT(t) } & \multicolumn{3}{|c|}{ Heurística EGF-BT(p) } \\
\hline & Média $(*)$ & Melhor (*) & Pior $(*)$ & Média $(*)$ & Melhor (*) & Pior $(*)$ \\
\hline 1 & 1.358 .793 & 1.243 .883 & 1.485 .236 & 1.308 .280 & 1.200 .566 & 1.437 .788 \\
\hline 2 & 1.407 .732 & 1.292 .685 & 1.530 .588 & 1.352 .040 & 1.247 .008 & 1.472 .079 \\
\hline 3 & 1.512 .528 & 1.393 .153 & 1.628 .297 & 1.445 .103 & 1.334 .364 & 1.563 .930 \\
\hline 4 & 2.499 .776 & 2.375 .124 & 2.633 .996 & 2.453 .663 & 2.345 .412 & 2.585 .728 \\
\hline 5 & 2.551 .813 & 2.431 .732 & 2.679 .928 & 2.498 .345 & 2.391 .838 & 2.617 .294 \\
\hline 6 & 2.659 .128 & 2.534 .231 & 2.780 .062 & 2.591 .469 & 2.473 .934 & 2.717 .645 \\
\hline 7 & 1.038 .539 & 994.867 & 1.085 .453 & 988.277 & 950.369 & 1.034 .255 \\
\hline 8 & 1.086 .912 & 1.041 .702 & 1.135 .939 & 1.034 .189 & 993.058 & 1.078 .687 \\
\hline 9 & 1.178 .607 & 1.123 .483 & 1.218 .653 & 1.127 .960 & 1.082 .297 & 1.177 .976 \\
\hline 10 & 2.183 .516 & 2.126 .151 & 2.250 .503 & 2.138 .333 & 2.088 .275 & 2.204 .450 \\
\hline 11 & 2.233 .938 & 2.178 .735 & 2.296 .519 & 2.185 .876 & 2.134 .847 & 2.248 .097 \\
\hline 12 & 2.328 .485 & 2.268 .774 & 2.378 .488 & 2.278 .929 & 2.218 .061 & 2.347 .991 \\
\hline 13 & 1.535 .928 & 1.429 .000 & 1.647 .855 & 1.429 .941 & 1.334 .479 & 1.533 .290 \\
\hline 14 & 1.638 .217 & 1.523 .754 & 1.766 .069 & 1.526 .163 & 1.422 .926 & 1.641 .521 \\
\hline 15 & 1.826 .991 & 1.728 .515 & 1.927 .719 & 1.716 .696 & 1.603 .576 & 1.841 .036 \\
\hline 16 & 2.681 .420 & 2.566 .148 & 2.804 .125 & 2.580 .464 & 2.477 .850 & 2.695 .435 \\
\hline 17 & 2.786 .527 & 2.658 .901 & 2.928 .244 & 2.679 .933 & 2.568 .567 & 2.811 .631 \\
\hline 18 & 2.975 .235 & 2.870 .167 & 3.084 .624 & 2.868 .153 & 2.743 .051 & 3.003 .681 \\
\hline 19 & 1.232 .247 & 1.179 .248 & 1.289 .711 & 1.126 .690 & 1.080 .802 & 1.175 .766 \\
\hline
\end{tabular}


QUADRO D.1 - Custo total médio por instância para as Heurísticas EGF-BT-D(t) e EGF-BT-D(p).

\begin{tabular}{|c|c|c|c|c|c|c|}
\hline \multirow{2}{*}{ Instância } & \multicolumn{3}{|c|}{ Heurística EGF-BT(t) } & \multicolumn{3}{|c|}{ Heurística EGF-BT(p) } \\
\hline & Média $(*)$ & Melhor $(*)$ & Pior $(*)$ & Média $(*)$ & Melhor $(*)$ & Pior $(*)$ \\
\hline 20 & 1.328 .511 & 1.271 .298 & 1.393 .708 & 1.214 .692 & 1.166 .445 & 1.259 .515 \\
\hline 21 & 1.502 .029 & 1.414 .000 & 1.551 .842 & 1.404 .358 & 1.348 .744 & 1.464 .244 \\
\hline 22 & 2.379 .851 & 2.311 .916 & 2.459 .951 & 2.281 .090 & 2.219 .888 & 2.349 .911 \\
\hline 23 & 2.480 .063 & 2.407 .515 & 2.566 .208 & 2.365 .965 & 2.307 .452 & 2.420 .910 \\
\hline 24 & 2.654 .184 & 2.562 .070 & 2.716 .852 & 2.556 .495 & 2.487 .188 & 2.632 .909 \\
\hline 25 & 1.428 .900 & 1.322 .609 & 1.540 .836 & 1.387 .219 & 1.284 .007 & 1.503 .234 \\
\hline 26 & 1.479 .486 & 1.372 .553 & 1.592 .907 & 1.445 .058 & 1.332 .520 & 1.565 .988 \\
\hline 27 & 1.593 .889 & 1.490 .250 & 1.718 .728 & 1.519 .922 & 1.414 .979 & 1.629 .984 \\
\hline 28 & 2.624 .256 & 2.515 .870 & 2.734 .636 & 2.588 .705 & 2.482 .382 & 2.705 .610 \\
\hline 29 & 2.679 .363 & 2.569 .418 & 2.793 .447 & 2.645 .662 & 2.535 .770 & 2.771 .073 \\
\hline 30 & 2.794 .642 & 2.674 .324 & 2.917 .653 & 2.722 .332 & 2.619 .919 & 2.830 .799 \\
\hline 31 & 1.090 .577 & 1.050 .052 & 1.136 .642 & 1.040 .613 & 1.007 .283 & 1.075 .177 \\
\hline 32 & 1.138 .628 & 1.098 .412 & 1.184 .127 & 1.088 .234 & 1.051 .689 & 1.127 .680 \\
\hline 33 & 1.234 .562 & 1.199 .736 & 1.272 .737 & 1.180 .120 & 1.140 .852 & 1.221 .192 \\
\hline 34 & 2.289 .887 & 2.240 .104 & 2.350 .338 & 2.246 .793 & 2.205 .143 & 2.293 .627 \\
\hline 35 & 2.340 .944 & 2.292 .799 & 2.398 .697 & 2.295 .279 & 2.250 .403 & 2.348 .010 \\
\hline 36 & 2.438 .662 & 2.400 .440 & 2.481 .867 & 2.383 .715 & 2.336 .605 & 2.436 .722 \\
\hline 37 & 1.615 .585 & 1.515 .105 & 1.716 .292 & 1.513 .377 & 1.424 .357 & 1.601 .441 \\
\hline 38 & 1.717 .888 & 1.610 .918 & 1.836 .026 & 1.611 .821 & 1.516 .446 & 1.714 .115 \\
\hline 39 & 1.913 .850 & 1.817 .160 & 2.019.294 & 1.800 .827 & 1.692 .299 & 1.922 .500 \\
\hline 40 & 2.813 .094 & 2.712 .367 & 2.915 .337 & 2.717 .943 & 2.628 .981 & 2.807 .036 \\
\hline 41 & 2.920 .345 & 2.809 .647 & 3.047 .211 & 2.820 .347 & 2.722 .776 & 2.931 .330 \\
\hline 42 & 3.118 .674 & 3.023 .430 & 3.224 .434 & 3.007 .716 & 2.890 .984 & 3.141 .485 \\
\hline 43 & 1.290 .966 & 1.241 .352 & 1.347 .932 & 1.206 .120 & 1.145 .838 & 1.302 .168 \\
\hline
\end{tabular}

(*)Valores obtidos a partir de 10 experimentos com distintas sementes. 
QUADRO D.1 - Custo total médio por instância para as Heurísticas EGF-BT-D(t) e EGF-BT-D(p).

\begin{tabular}{|c|c|c|c|c|c|c|}
\hline \multirow{2}{*}{ Instância } & \multicolumn{3}{|c|}{ Heurística EGF-BT(t) } & \multicolumn{3}{c|}{ Heurística EGF-BT(p) } \\
\cline { 2 - 7 } & Média (*) & Melhor (*) & Pior (*) & Média (*) & Melhor (*) & Pior (*) \\
\hline 44 & 1.386 .348 & 1.334 .628 & 1.442 .120 & 1.298 .709 & 1.234 .145 & 1.400 .949 \\
45 & 1.574 .521 & 1.523 .815 & 1.628 .826 & 1.466 .788 & 1.410 .737 & 1.528 .335 \\
46 & 2.492 .178 & 2.430 .276 & 2.561 .767 & 2.416 .528 & 2.343 .374 & 2.528 .024 \\
47 & 2.590 .749 & 2.530 .340 & 2.656 .980 & 2.507 .812 & 2.428 .882 & 2.625 .069 \\
48 & 2.780 .477 & 2.724 .440 & 2.841 .641 & 2.672 .894 & 2.608 .981 & 2.744 .830 \\
\hline
\end{tabular}

(*)Valores obtidos a partir de 10 experimentos com distintas sementes. 


\section{BIBLIOGRAFIA}

AGGARWAL, A.; PARK, J.K. Improved algorithms for economic lot size problems. Operations Research, v.41, p.549-571, 1993.

AHUJA, R.K.; HOCHBAUM, D.S. Solving linear cost dynamic lot sizing problems in $\mathrm{O}(\mathrm{n} \log \mathrm{n})$ time. Operations Research. 2004. No prelo. Disponível em: <http://www.ise.ufl.edu/ahuja/>. Acesso em 27 fev. 2006.

AHUJA, R.K.; MAGNANTI, T.L.; ORLIN, J.B. Network flows. New Jersey: Prentice-Hall, 1993. 846p.

ANILY, S.; FEDERGRUEN, A. One warehouse multiple retailer systems with vehicle routing costs. Management Science, v.36, n.1, p.92-114, 1990.

Rejoinder to "Comments on one-warehouse multiple retailer systems with vehicle routing costs”. Management Science, v.37, n.11, p.1497-1499, 1991.

Two-echelon distribution systems with vehicle routing costs and central inventories. Operations Research, v.41, n.1, p.37-47, 1993.

ANILY, S. The general multi-retailer EOQ problem with vehicle routing costs. European Journal of Operational Research, v.79, p.451-473, 1994.

ARCHETTI, C.; BERTAZZI, L.; LAPORTE, G.; SPERANZA, M.G. A branchand-cut algorithm for a vendor managed inventory routing problem. Brescia: Università di Brescia - Dipartimento di Metodi Quantitativi, 2004. (Relatório Técnico n.240).

BAITA, F.; UKOVICH, W.; PESENTI, R.; FAVARETTO, D. Dynamic routingand-inventory problems: a review. Transportaion Research A, v.32, n.8, p.585-598, 1998.

BALL, M.O. Allocation/Routing: Models and algorithms. In: GOLDEN, B.L.; ASSAD, A.A. (Eds.). Vehicle Routing: Methods and Studies. Amsterdam: North Holland, 1988. p.199-221.

BALLOU. R.H. Business logistics management: planning, organizing, and controlling the supply chain. 4.ed. New Jersey: Prentice Hall, 1998. 681p.

BARD, J.F.; HUANG, L.; JAILLET, P.; DROR, M. A decomposition approach to the inventory routing problem with satellite facilities. Transportation Science, v.32, n.2, p.189-203, 1998. 
BARR, R.S.; GOLDEN, B.L.; KELLY, J.P.; RESENDE, M.G.C.; STWEART JR., W.R. Designing and reporting on computational experiments with heuristic methods. Journal of Heuristics, v.1, p.9-32, 1995.

BARRATT, M. Positioning the role of collaborative planning in grocery supply chains. The International Journal of Logistics Management, v.14, p.53-66, 2003.

BELL, W.J.; DALBERTO, L.M.; FISHER, M.L.; GREENFIELD, A.J.; JAIKUMAR, R.; KEDIA, P.; MACK, R.G.; PRUTZMAN, P.J. Improving the distribution of industrial gases with an on-line computerized routing and scheduling optimizer. Interfaces, v.13:6, p.4-23, 1983.

BENJAMIN, J. An analysis of inventory and transportation costs in a constrained network. Transportation Science, v.23, n.3, p.177-183, 1989.

BERTAZZI, L.; PALETTA, G.; SPERANZA, M.G. Deterministic order-up-to level policies in an inventory routing problem. Transportation Science, v.36, n.1, p.119-132, 2002.

Minimizing the total cost in an integrated vendor-managed inventory system. Journal of Heuristics, v.11, p.393-419, 2005.

BERTAZZI, L.; SPERANZA, M.G. Continuous and discrete shipping strategies for the single link problem. Transportation Science, v.36, n.3, p.314-325, 2002.

BERTAZZI, L.; SPERANZA, M.G.; UKOVICH, W. Minimization of logistic costs with given frequencies. Transportation Research B, v.31, n.4, p.327-340, 1997.

. Exact and heuristic solutions for a shipment problem with given

frequencies. Management Science, v.46, n.7, p.973-988, 2000.

BODIN, L.; GOLDEN, B.; ASSAD, A.; BALL, M. Routing and scheduling of vehicles and crews. Computers \& Operations Research, v.10, n.2, p.63-211, 1983.

BLANCHINI, F.; QUEYRANNE, M.; RINALDI, F.; UKOVICH, W. A feedback strategy for periodic network flows. Networks, v.27, p.25-34, 1996 a.

BLANCHINI, F.; RINALDI, F.; UKOVICH, W. A dynamic game for distribution problems with non-stochastic uncertainty. International Journal of Production Economics, v.45, p.479-487, 1996 b.

BLUMENFELD, D.E.; BURNS, L.D.; DILTZ, J.D.; DAGANZO, C.F. Analyzing trade-offs between transportation, inventory and production costs on freight networks. Transportation Research B, v.19B, n.5, p.361-380, 1985.

BLUMENFELD, D.E.; BURNS, L.D.; DAGANZO, C.F.; FRICK, M.C.; HALL, R.W. Reducing logistics costs at General Motors. Interfaces, v.17, n.1, p.26-47, 1987. 
BRAMEL, J.; SIMCHI-LEVI, D. A location based heuristic for general routing problems. Operations Research, v.43, p.649-660, 1995.

The logic of logistics: theory, algorithms and applications for logistics management. New York: Springer-Verlag, 1997. 281p.

BURNS, L.D.; HALL, R.W.; BLUMENFELD, D.E.; DAGANZO, C.F. Distribution strategies that minimize transportation and inventory costs. Operations Research, v.33, p.469-490, 1985.

CAMPBELL, A.; CLARKE, L.; KLEYWEGT, A.; SAVELSBERGH, M.W.P. The inventory routing problem. In: CRAINIC, T.G.; LAPORTE, G. (Eds.). Fleet Management and Logistics. Norwell: Kluwer Academic Publishers, 1998. p.95-112.

CAMPBELL, A.; CLARKE, L.; SAVELSBERGH, M.W.P. Inventory routing in practice. In: TOTH, P.; VIGO, D. (Eds.). The Vehicle Routing Problem.

Philadelphia: SIAM, 2002. (SIAM Monographs on Discrete Mathematics and Applications, v.9). p.309-330.

CAMPBELL, A.; SAVELSBERGH, M.W.P. Delivery volume optimization. Transportation Science, v.38, n.2, p.210-223, 2004.

CHAN, L.M.A.; FEDERGRUEN, A.; SIMCHI-LEVI, D. Probabilistic analyses and practical algorithms for inventory-routing models. Operations Research, v.46, n.1, p.96-106, 1998.

CHANDRA, P. A dynamic distribution model with warehouse and customer replenishment requirements. Journal of the Operational Research Society, v.44, n.7, p.681-692, 1993.

CHANDRA, P.; FISHER, M.L. Coordination of production and distribution planning. European Journal of Operational Research, v.72, p.503-517, 1994.

CHAO, I-M.; GOLDEN, B.L.; WASIL, E. An improved heuristic for the period vehicle routing problem. Networks, v.26, p.25-44, 1995.

CHEN, Z.-L. Integrated Production and distribution operations: taxonomy, models, and review. In: SIMCHI-LEVI, D.; WU, S.D.; SHEN, Z.-J. (Eds.). Handbook of Quantitative Supply Chain Analysis: Modeling in the E-Business Era. Norwell: Kluwer Academic Publishers, 2004. p.711-735.

CHIEN, T.W.; BALAKRISHNAN, A.; WONG, R.T. An integrated inventory allocation and vehicle routing problem. Transportation Science, v.23, n.2, p.67-76, 1989.

CHRISTOFIDES, N. Vehicle routing. In: LAWLER, E.L.; LENSTRA, J.K.; RINNOOY KAN, A.H.G.; SHMOYS, D.B. (Eds.). The Traveling Salesman Problem. Chichester: John Wiley \& Sons, 1985. p.431-448. 
CLARKE, G.; WRIGHT, J.W. Scheduling of vehicles from a central depot to a number of delivery points. Operations Research, v.12, p.568-581, 1964.

CORDEAU, J.-F.; GENDREAU, M.; LAPORTE, G. A tabu search heuristic for periodic and multi-depot vehicle routing problems. Networks, v.30, p.105-119, 1997.

COSTA, D. A tabu search algorithm for computing an operational timetable. European journal of Operational Research, v.76, p.98-110, 1994.

COUSINEAU-OUIMET, K. A tabu search heuristic for the inventory routing problem. In: ANNUAL ORSNZ CONFERENCE, Auckland, 2002. Disponível em: <http://www.esc.auckland.ac.nz/Organisations/ORSNZ/conf37/Program.htm>. Acesso em 02 out. 2004.

CRAINIC, T.G.; LAPORTE, G. Planning models for freight transportation. European Journal of Operational Research, v.97, p.409-438, 1997.

CROES, G.A. A method for solving traveling-salesman problems. Operations Research, v.6, p.791-812, 1958.

DROR, M.; BALL, M. Inventory/Routing: Reduction from an annual to a shortperiod problem. Naval Research Logistics, v.34, p.891-905, 1987.

DROR, M.; LEVY, L. A vehicle routing improvement comparison of a "greedy" and a matching implementation for inventory routing. Computers \& Operations Research, v.13, n.1, p.33-45, 1986.

EVANS, J.R. An efficient implementation of the Wagner-Whitin algorithm for dynamic lot-sizing. Journal of Operations Management, v.5, n.2, p.229-235, 1985.

FEDERGRUEN, A.; PRASTACOS, G.; ZIPKIN, P. An allocations and distribution model for perishable products. Operations Research, v.34, n.1, p.75-82, 1986.

FEDERGRUEN, A.; TZUR, M. A simple forward algorithm to solve general dynamic lot sizing models with $n$ periods in $\mathrm{O}(\mathrm{n} \log \mathrm{n})$ or $\mathrm{O}(\mathrm{n})$ time. Management Science, v.37, n.8, p.909-925, 1991.

FEDERGRUEN, A.; ZIPKIN, P. Solution techniques for some allocation problems. Mathematical Programming, v.25, p.13-24, 1983.

A combined vehicle routing and inventory allocation problem. Operations Research, v.32, n.5, p.1019-1037, 1984.

FISHER, M.L.; JAIKUMAR, R. A generalized assignment heuristic for vehicle routing. Networks, v.11, p.109-124, 1981. 
FLORIAN, M.; LENSTRA, J.K.; RINNOOY KAN, H.G. Deterministic production planning: algorithms and complexity. Management Science, v.26, n.7, p.669-679, 1980.

FUMERO, F.; VERCELLIS, C. Synchronized development of production, inventory, and distribution schedules. Transportation Science, v.33, n.3, p.330-340, 1999.

GALLEGO, G.; SIMCHI-LEVI, D. On the effectiveness of direct shipping strategy for the one-warehouse multi-retailer R-systems. Management Science, v.36, n.2, p.240-243, 1990.

GENDREAU, M.; HERTZ, A.; LAPORTE, G. A tabu search for the vehicle routing problem. Management Science, v.40, n.10, p.1276-1290, 1994.

GILLETT, B.E.; MILLER, L.R. A heuristic algorithm for the vehicle-dispatch problem. Operations Research, v.22, p.340-349, 1974.

GLOVER, F. Future paths for integer programming and links to artificial intelligence. Computers \& Operations Research, v.13, n.5, p.533-549, 1986.

GLOVER, F.; LAGUNA, M. Tabu search. In: REEVES, C. (Ed.). Modern Heuristic Techniques for Combinatorial Problems. Oxford: Blackwell Scientific Publishing, 1993. p.70-150.

Tabu search. Norwell: Kluwer Academic Publishers, 1997. 382p.

GLOVER, F.; TAILLARD, E.; DE WERRA, D. A user's guide to tabu search. Annals of Operations Research, v.41, p.3-28, 1993.

GOLDEN, B.L.; STEWART, W.R. Empirical analysis of heuristics. In: LAWLER, E.L.; LENSTRA, J.K.; RINNOOY KAN, A.H.G.; SHMOYS, D.B. (Eds.). The Traveling Salesman Problem. Chichester: John Wiley \& Sons, 1985. p.207-249.

HALL, R.W. Determining vehicle dispatch frequency when shipping frequency differs among suppliers. Transportation Research B, v.19B, p.421-431, 1985.

Comments on "One-warehouse multiple retailer systems with vehicle routing costs”. Management Science, v.37, n.11, p.1496-1497, 1991.

HANSEN, P.; MLADENOVIC, N. A tutorial on variable neighborhood search. Montréal: Groupe d'études et de recherche en analyse des décisions - GERAD, 2003. (Les Cahiers du GERAD G-2003-46).

HERER, Y.T.; LEVY, R. The metered inventory routing problem, an integrative heuristic algorithm. International Journal of Production Economics, v.51, p.69-81, 1997. 
HERTZ, A.; TAILLARD, É.; DE WERRA, D. Tabu search. In: AARTS, E.; LENSTRA, J.K. (Eds.). Local Search in Combinatorial Optimization. Chichester: John Wiley \& Sons, 1997. p.121-136.

KONTORAVDIS, G.; BARD, J.F. A greedy random adaptive search procedure for the vehicle routing with time windows. ORSA Journal of Computing, v.7, p.10-23, 1995.

LAO, Y.; LEONG, H.W. A multi-agent based approach to the inventory routing problem. In: PACIFIC RIM INTERNATIONAL CONFERENCE ON ARTIFICIAL INTELLIGENCE, 7th, Tokyo, 2002. PRICAI 2002: Trends in Artificial Intelligence. Proceedings. p.345-354.

LAPORTE, G. The vehicle routing problem: An overview of exact and approximate algorithms. European Journal of Operational Research, v.59, p.345-358, 1992.

LAPORTE, G.; GENDREAU, M.; POTVIN, J.-Y.; SEMET, F. Classical and modern heuristics for the vehicle routing problem. International Transactions in Operational Research, v.7, p.285-300, 2000.

LARSON, R.C. Transporting sludge to the 106-mile site: An inventory/routing model for fleet sizing and logistics system design. Transportation Science, v.22, n.3, p.105-119, 1988.

LAU, H.C.; LIM, A.; LIU, Q.Z. Solving a supply chain optimization problem collaboratively. In: NATIONAL CONFERENCE ON ARTIFICIAL

INTELLIGENCE, Austin, 2000. Disponível em:

<http://www.comp.nus.edu.sg/ lauhc/>. Acesso em 02 out. 2004.

LEE, C.-G.; BOZER, Y.A.; WHITE III, C.C. A heuristic approach and properties of optimal solutions to the dynamic inventory routing problem. Toronto:

University of Toronto - Department of Mechanical and Industrial Engineering, 2003. (Relatório Técnico). Disponível em:

<http://www.mie.utoronto.ca/labs/ilr/research.htm>. Acesso em 12 out. 2004.

LEE, H.L.; NAHMIAS, S. Single-product, single-location models. In: GRAVES, S.C.; RINNOOY KAN, A.H.G.; ZIPKIN, P.H. (Eds.). Handbooks in Operations Research and Management Science v.4. Amsterdam: North Holland, 1993. p.3-55.

LEE, H.L.; PADMANABHAN, V.; WHANG, S. Information distortion in a supply chain: the bullwhip effect. Management Science, v.43, n.4, p.546-558, 1997.

LENSTRA, J.; RINNOY KAN, A. Complexity of vehicle routing and scheduling problems. Networks, v.11, p.221-228, 1981.

LIN, S.; KERNIGHAN, B.W. An effective heuristic algorithm for the travelingsalesman problem. Operations Research, v.21, p.498-516, 1973. 
MIN, H.; JAYARAMAN, V.; SRIVASTAVA, R. Combined location-routing problems: A synthesis and future research directions. European Journal of Operational Research, v.108, p.1-15, 1998.

MLADENOVIC, N.; HANSEN, P. Variable neighborhood search. Computers \& Operations Research, v.24, p.1097-1100, 1997.

MOSCATO, P.; NORMAN, M.G. On the performance of heuristics on finite and infinite fractal instances of the euclidian traveling salesman problem. INFORMS Journal on Computing, v.10, p.121-132, 1998.

RARDIN, R.L.; UZSOY, R. Experimental evaluation of heuristic optimization algorithms: a tutorial. Journal of Heuristics, v.7, p.261-304, 2001.

REEVES, C.R. Evaluation of heuristic performance. In: REEVES, C. (Ed.). Modern Heuristic Techniques for Combinatorial Problems. Nova York: John Willey \& Sons, 1993. p.304-315.

ROSENKRANTZ, D.J.; STEARNS, R.E.; LEWIS II, P.M. An analysis of several heuristics for the traveling salesman problem. SIAM Journal of Computing, v.6, n.3, p.563-581, 1977.

SARMIENTO, A.M.; NAGI, R. A review of integrated analysis of productiondistribution systems. IIE Transactions, v.31, n.11, p.1061-1074, 1999.

SAVELSBERGH, M.; SONG, J.-H. Inventory routing with continuous moves. Computers \& Operations Research, 2005. No prelo. Disponível em: $<$ http://www.isye.gatech.edu/faculty/Martin_Savelsbergh/publications/>. Acesso em 10 ago. 2006.

SHEFFI, Y. The value of CPFR. In: RIRL CONFERENCE PROCEEDINGS, Lisboa, 2002. Disponível em: <http://ctl.mit.edu/index.pl?id=2213>. Acesso em 06 ago. 2006.

SILVER, E.A. An overview of heuristic solution methods. Journal of the Operational Research Society, v.55, p.936-956, 2004.

SINDHUCHAO, S.; ROMEIJN, H.E.; AKÇALI, E.; BOONDISKULCHOK, R. An integrated inventory-routing system for multi-item joint replenishment with limited vehicle capacity. Journal of Global Optimization, v.32, n.1, p.93-118, 2005.

SOLOMON, M.M. Algorithms for the vehicle routing and scheduling problems with time window constraints. Operations Research, v.35, p.254-265, 1987.

SPERANZA, M.G.; UKOVICH, W. Minimizing transportation and inventory costs for several products on a single link. Operations Research, v.42, n.5, p.879-894, 1994.

An algorithm for optimal shipments with given frequencies. Naval

Research Logistics, v.43, p.655-671, 1996. 
STALK, G.; EVANS, P.; SHULMAN, L.E. Competing on capabilities: the new rules of corporate strategy. Harvard Business Review, v.70, n.2, p.57-69, 1992.

TAILLARD, É. Benchmarks for basic scheduling problems. European Journal of Operational Research, v.64, p.278-285, 1993a.

Parallel iterative search methods for vehicle routing problems. Networks, v.23, p.661-673, 1993 b.

TOTH, P.; VIGO, D. The granular tabu search and its application to the vehiclerouting problem. INFORMS Journal on Computing, v.15, n.4, p.333-346, 2003.

VISWANATHAN, S.; MATHUR, K. Integrating routing and inventory decisions in one-warehouse multiretailer multiproduct distribution systems. Management Science, v.43, n.3, p.294-312, 1997.

WAGELMANS, A.; VAN HOESEL, S.; KÖLEN, A. Economic lot sizing: an O(n $\log n)$ algorithm that runs in linear time in the Wagner-Whitin case. Operations Research, v.40, p.142-150, 1992.

WAGNER, H.M.; WHITIN, T.M. Dynamic version of the economic lot size model. Management Science, v.5, p.89-96, 1958.

WEBB, I.R.; LARSON, R.C. Period and phase customer replenishment: A new approach to the Strategic Inventory/Routing Problem. European Journal of Operational Research, v.85, p.132-148, 1995.

XU, J.; CHIU, S.Y.; GLOVER, F. Fine-tuning a tabu search algorithm with statistical tests. International Transactions in Operational Research, v.5, p.233-244, 1998. 


\section{APÊNDICE I}

\section{TESTE DE WILCOXON}

O teste estatístico de Wilcoxon ("Wilcoxon signed rank test") é um teste não paramétrico que pode ser utilizado para a avaliação dos resultados de duas heurísticas no caso de observações emparelhadas.

Sejam $H_{1}$ e $H_{2}$ as duas heurísticas a ser avaliadas. Inicialmente, os valores das observações são normalizados, definindo-se as razões $x_{i}=\frac{H_{1}(i)}{L_{i}}$ e $y_{i}=\frac{H_{2}(i)}{L_{i}}$, onde $L_{i}$ corresponde ao melhor resultado conhecido para a instância $i$, e $H_{j}(i)$ corresponde ao resultado obtido pela aplicação da heurística $H_{j}$ à instância $i$ do problema. Em seguida são calculadas as diferenças entre as observações normalizadas, $d_{i}=x_{i}-y_{i}$, e as observações são ordenadas segundo a ordem crescente de $\left|d_{i}\right|$, descartando-se as observações em que $d_{i}=0$. Por fim, agrega-se ao número de ordem de cada observação o sinal da diferença $x_{i}-y_{i}$, denominando-se esse valor $R_{i}$.

A estatística de teste é definida como:

$$
W=\sum_{i=1}^{n} R_{i}
$$

A hipótese nula a ser testada corresponde à igualdade das expectativas dos valores de $x$ e $y$, podendo ser formalizada como:

$\mathrm{H} 0: E[x]=E[y]$ 
A hipótese nula deve ser rejeitada ao nível de significância $\alpha$, se:

$$
\begin{array}{ll}
W>W_{1-\frac{\alpha}{2}} \text { ou } W<W_{\frac{\alpha}{2}}, & \text { caso H1: } E[x] \neq E[y] \\
W>W_{1-\alpha}, & \text { caso H1: } E[x]>E[y] \\
W<W_{\alpha}, & \text { caso H1: } E[x]<E[y]
\end{array}
$$

Tabulações de valores críticos de $W_{\alpha}$ podem ser encontrados na bibliografia referente a testes não paramétricos. Entretanto, para os casos em que o número de observações $n \geq 10$, o valor crítico de $W_{\alpha}$ pode ser aproximado pela seguinte expressão:

$$
W_{\alpha}=Z(\alpha) \sqrt{\frac{n(n+1)(2 n+1)}{6}}
$$

onde $Z(\alpha)$ corresponde ao inverso da distribuição normal padronizada.

Uma descrição da utilização do teste de Wilcoxon na avaliação de heurísticas pode ser encontrada em GOLDEN; STEWART (1985). 


\section{APÊNDICE II}

\section{TESTE DE FRIEDMAN}

O teste estatístico de Friedman é um teste não paramétrico de homogeneidade, similar ao clássico método de análise de variância (ANOVA), e pode ser entendido como uma extensão do teste de Wilcoxon apresentado no Apêndice I.

Sejam $k$ heurísticas a ser avaliadas, denominadas $H_{1}, H_{2}, \ldots, H_{\mathrm{k}}$, e $n$ instâncias de teste. Seja ainda $x_{i j}$ o resultado obtido pela aplicação da heurística $i$ à instância $j$ do problema. A fim de eliminar a dependência em relação aos parâmetros do problema,

define-se a razão $r_{i j}=\frac{x_{i j}}{L_{j}}$, onde $L_{j}$ corresponde ao melhor resultado conhecido para a instância $j$. Inicialmente, ordena-se, para cada instância $j$, as razões $r_{i j}$ em ordem crescente, atribuindo-se a cada razão o respectivo número de ordem. Isto é, a menor razão recebe o número 1 , a seguinte menor o número 2 , e assim sucessivamente até a maior razão, que recebe o número $k$. Para razões de igual valor, atribui-se a cada razão o valor da média dos números de ordem correspondentes. Seja $R_{i j}$ o valor do número de ordem atribuído à heurística $i$ para a instância $j$ do problema. Atribui-se, para cada heurística $i$, a totalização dos números de ordem obtidos pela heurística, isto é:

$$
R_{i}=\sum_{j=1}^{n} R_{i j}
$$

A hipótese nula a ser testada corresponde à igualdade das expectativas dos valores de $R_{i}$ para todas as heurísticas em avaliação, podendo ser formalizado como:

$\mathrm{H} 0: E\left[R_{1}\right]=E\left[R_{2}\right]=\ldots=E\left[R_{k}\right]$ 
A estatística de teste é definida por:

$$
T_{F}=\frac{(n-1) \cdot\left(B_{F}-\frac{n k(k+1)^{2}}{4}\right)}{A_{F}-B_{F}}
$$

onde

$$
\begin{gathered}
A_{F}=\sum_{i=1}^{k} \sum_{j=1}^{n} R_{i j}^{2} \\
B_{F}=\frac{1}{n} \sum_{i=1}^{k} R_{i}^{2}
\end{gathered}
$$

A estatística de teste obedece à distribuição $F$, sendo a hipótese nula rejeitada ao nível de significância $\alpha$ se $T_{F}>F((k-1),(n-1)(k-1))$, ou seja, se a estatística de teste exceder o quantil $(1-\alpha)$ da distribuição $F \operatorname{com}(k-1)$ e $(n-1)(k-1)$ graus de liberdade.

Adicionalmente, caso seja rejeitada a hipótese nula, é desejável determinar quais heurísticas são estatisticamente distintas. Duas heurísticas $j$ e $l$ são consideradas distintas se:

$$
\left|R_{j}-R_{l}\right|>t_{\left(\frac{\alpha}{2},(n-1)(k-1)\right)} \sqrt{\frac{2 n\left(A_{F}-B_{F}\right)}{(n-1)(k-1)}}
$$

Uma descrição da utilização do teste de Friedman na avaliação de heurísticas pode ser encontrada em GOLDEN; STEWART (1985). 